Helmut KöNig,

Manfred Sicking (HG.)

G e $h \ddot{o r} \mathbf{t}$

die Türkei

zu Europa?

Wegweisungen für ein Europa am Scheideweg

[transcript $]$ G $\mid \circ$ b a $\mid \mathbf{S ~ t ~ u ~ d ~ i ~ e ~ s ~}$ 
Gehört die Türkei zu Europa? 

Helmut König, Manfred Sicking (Hg.)

Gehört die Türkei zu Europa?

Wegweisungen für ein Europa am Scheideweg 


\section{(9) $(1) \Theta$}

Dieses Werk ist lizenziert unter der Creative Commons AttributionNonCommercial-NoDerivs 4.0 Lizenz (BY-NC-ND). Diese Lizenz erlaubt die private Nutzung, gestattet aber keine Bearbeitung und keine kommerzielle Nutzung. Weitere Informationen finden Sie unter https://creativecommons.org/licenses/by-nc-nd/4.o/deed.de/. Um Genehmigungen für Adaptionen, Übersetzungen, Derivate oder Wiederverwendung zu kommerziellen Zwecken einzuholen, wenden Sie sich bitte an rights@transcript-verlag.de

\section{(C) 2005 transcript Verlag, Bielefeld}

Die Verwertung der Texte und Bilder ist ohne Zustimmung des Verlages urheberrechtswidrig und strafbar. Das gilt auch für Vervielfältigungen, Übersetzungen, Mikroverfilmungen und für die Verarbeitung mit elektronischen Systemen.

\section{Bibliografische Information der Deutschen Nationalbibliothek}

Die Deutsche Nationalbibliothek verzeichnet diese Publikation in der Deutschen Nationalbibliografie; detaillierte bibliografische Daten sind im Internet über http://dnb.d-nb.de abrufbar.

Umschlaggestaltung: Kordula Röckenhaus, Bielefeld Lektorat \& Satz: Sabine Schielke, Aachen

Druck: Majuskel Medienproduktion $\mathrm{GmbH}$, Wetzlar

Print-ISBN 978-3-89942-328-0

PDF-ISBN 978-3-8394-0328-0

Gedruckt auf alterungsbeständigem Papier mit chlorfrei gebleichtem Zellstoff.

Besuchen Sie uns im Internet: http://www.transcript-verlag.de Bitte fordern Sie unser Gesamtverzeichnis und andere Broschüren an unter:info@transcript-verlag.de 


\section{Inhalt}

Statt einer Einleitung: Gehört die Türkei zu Europa? -

Konturen einer Diskussion

HELMUT KÖNIG/MANFRED SICKING

Der EU-Beitritt der Türkei als Vollendung eines Europa der kulturellen Vielfalt

FARUK ŞEN

Der Türkei-Beitritt zerstört die Europäische Union

HANS-ULRICH WEHLER

Warum die Türkei die Gemeinschaft bereichern würde

HAKKI KESKIN

Die Türkei und Europa. Eine geopolitische Herausforderung 81 HERFRIED MÜNKLER

Der türkisch-armenische Konflikt und die Europafähigkeit der Türkei 101

OTTO LUCHTERHANDT

Im Irrgarten der Argumente 129 MARTIN WINTER 


\section{Zwei Kommentare zum Kommissionsbericht}

Konditionierte Demokratisierung

CLAUS LEGGEWIE/SABRINA GIESENDORF

Die Botschaft der Diskurse zum EU-Beitritt der Türkei

EMANUEL RICHTER

\section{Anhang}

Empfehlung der Europäischen Kommission

zu den Fortschritten der Türkei auf dem Weg zum Beitritt 


\section{Vorwort}

Den Beiträgen dieses Buches liegen Vorträge zugrunde, die in Aachen im Rahmen der Vortragsreihe "Gehört die Türkei zu Europa?« im Oktober/November 2004 gehalten wurden. Hinzugekommen sind die Einleitung der Herausgeber und die Kommentare von Emanuel Richter und Claus Leggewie/Sabrina Giesendorf zur »Empfehlung der Europäischen Kommission zu den Fortschritten der Türkei auf dem Weg zum Beitritt«. Der Bericht der Kommission wurde in den Anhang des Buches aufgenommen.

Veranstalter der genannten Vortragsreihe waren die »Europäischen Horizonte«. Europäische Horizonte ist ein Zusammenschluss des Fachbereichs Wirtschaftsförderung/Europäische Angelegenheiten der Stadt Aachen, des Kulturwissenschaftlichen Instituts, Essen, der Vertretung der Europäischen Kommission in Bonn und des Instituts für Politische Wissenschaft der RWTH Aachen.

Die Herausgeber danken der Philosophischen Fakultät der RWTH Aachen für die Unterstützung der Publikation des Buches. Und sie danken Sabine Schielke, die als Geschäftsführerin und Koordinatorin der Europäischen Horizonte bereits die Hauptlast bei der Organisation der Vortragsreihe zu tragen hatte, für die redaktionelle Betreuung und Bearbeitung der Texte.

Aachen, im Februar 2005 



\section{Statt einer Einleitung: Gehört die Türkei zu Europa? - Konturen einer Diskussion}

HELMUT KÖNIG/MANFRED SICKING

Die Frage, ob die Türkei zu Europa gehört und der EU beitreten soll, hat zu heftigen Kontroversen geführt." Die 25 Staats- und Regierungschefs der Mitgliedsstaaten haben auf ihrem Gipfeltreffen in Brüssel am 17. Dezember 2004 einstimmig beschlossen, dass vom 3. Oktober 2005 an Beitrittsverhandlungen mit der Türkei begonnen werden sollen. Die Befürworter des Türkei-Beitritts sprechen von einer historischen Entscheidung, die Gegner sehen Europa am Abgrund. Alle rechnen mit sehr langwierigen Verhandlungen. Die Rede ist von einem Beitrittstermin um das Jahr 2015 herum. Wenn die Türkei vom europäischen Weg abkommt, bei Verstößen gegen die Menschenrechte z.B., können die Gespräche ausgesetzt werden. Und immer wieder wird betont, dass die Verhandlungen auch scheitern können und der Beitritt der Türkei nicht zustande kommt.

Die Brüsseler Entscheidung der Staats- und Regierungschefs fiel einstimmig. Diese Einstimmigkeit verdeckt die Tatsache, dass es zwischen und in den beteiligten Ländern heftige Mei-

\footnotetext{
* Der besseren Lesbarkeit wegen verzichten wir auf Einzelnachweise. Die Literatur, auf die wir uns neben den im vorliegenden Buch abgedruckten Texten beziehen, ist am Ende des Beitrags zusammengestellt.
} 
nungsverschiedenheiten gibt. Frankreich und Österreich haben Volksabstimmungen über die Türkei-Frage angekündigt. Das ist ein Novum in der EU-Erweiterungsgeschichte. Bislang haben nicht die Bevölkerungen über die Aufnahme neuer Mitglieder entschieden, sondern die Volksvertreter. Die Ankündigung der Referenden ist keineswegs das Resultat einer plötzlich entdeckten Liebe zur Basisdemokratie, sondern Ausdruck von Unsicherheit und Zweifeln.

Die Meinungen und Haltungen zum Türkei-Beitritt gehen quer durch die politischen Parteien und Lager. Der französische Staatspräsident Chirac plädiert für den Türkeibeitritt, während der Vorsitzende seiner eigenen Partei, Nicolas Sarkozy, und mit ihm die Mehrheit der Parteimitglieder vehement dagegen sind. Auch die Opposition in Frankreich ist gespalten. Und nach jüngsten Umfragen lehnt eine Mehrheit von 64 Prozent der französischen Bevölkerung den Beitritt der Türkei ab.

Im Vergleich zu Frankreich sind in der Bundesrepublik die politischen Parteien fast geschlossen. Die CDU favorisiert das Konzept einer privilegierten Partnerschaft. Die SPD und die Grünen sind für die volle Mitgliedschaft. Allerdings plädieren die CDU-Außenpolitiker Rühe und Polenz im Gegensatz zur Mehrheit ihrer Partei für den Beitritt, und Helmut Schmidt, der elder statesman der SPD, hält die von seiner eigenen Partei favorisierte Idee des Türkei-Beitritts schlicht für den Ausdruck von Größenwahn. Der britische Premierminister Blair ist zwar für den EU-Beitritt der Türkei. Aber viele Beobachter werden den Eindruck nicht los, dass er damit vor allem die Interessen der britischen Europa-Skeptiker vertritt, für die nur eine verwässerte EU eine gute EU ist. Außerdem erweisen sich die Briten an dieser Stelle wieder einmal als treue Gefolgsleute der USA, die seit Jahren offensiv für den EU-Beitritt der Türkei eintreten.

Auch in den übrigen EU-Mitgliedsstaaten gehen die Meinungen weit auseinander. Die italienische Regierung Berlusconi ist für den Beitritt und argumentiert vor allem mit ökonomischen Gesichtspunkten. Die italienische Bevölkerung interessiert das Thema bislang kaum. In den Mittelmeerländern Spanien, Portugal und Malta überwiegen deutlich die Stimmen, die für den EU-Beitritt der Türkei sind. In Belgien ist die sozialliberale Regierung dafür, die oppositionellen Christdemokraten 
sind dagegen, während der rechtsradikale Vlaams Blok die Gelegenheit ergreift und sich in antitürkischen Parolen ergeht. Jean-Claude Juncker, der christlich-demokratische Ministerpräsident des Großherzogtums Luxemburg, äußert sich vorsichtig und widersprüchlich. In Österreich wie in Schweden sind die Sozialdemokraten gegen einen Beitritt, in Dänemark sind die Sozialdemokraten dafür und stimmen in diesem Punkt mit der konservativen Regierung ihres Landes überein. In Griechen land sprechen sich die beiden großen Volksparteien des Landes übereinstimmend für den Betritt des ehemaligen Erzrivalen aus. Und in Osteuropa schließlich folgt man durchgängig der Sichtweise der USA: Die Türkei gehöre zu Europa und sei eine unverzichtbare Brücke in den neuen Nahen Osten.

Alles in allem: Die Frage des EU-Beitritts der Türkei polarisiert Europa. Man kann das auch positiv ausdrücken und sich darüber freuen, dass endlich einmal vehement über ein europäisches Thema gestritten und diskutiert wird und dass schon dieses pure Faktum für Europa auf jeden Fall klärend und gut ist. Bereits jetzt steht fest, dass die Entscheidungsbefugnis nicht auf die Parlamente und politischen Eliten reduziert wird, sondern die Bevölkerungen zumindest in einigen Mitgliedsstaaten selber über die Frage entscheiden. Und die Hürden liegen hoch: Die Entscheidung für den Beitritt der Türkei erfordert Einstimmigkeit. Wenn also am Ende auch nur ein Referendum gegen den Beitritt ausfällt oder ein Mitgliedsstaat nicht zustimmt, ist das Beitrittsprojekt gescheitert.

\section{II}

Wo liegen die Gründe für die Heftigkeit der Diskussionen und die Gespaltenheit Europas in der Türkeifrage? Zuvörderst und erstens sicherlich darin, dass die Türkei den Kernländern der EU fremder gegenübersteht als alle bisherigen Kandidaten in den zurückliegenden Erweiterungsrunden. Diese Fremdheit hat zu tun mit der türkischen Religion und Kultur, mit der türkischen Geschichte und Geographie. Die Türkei liegt mit dem größten Teil ihres Territoriums nicht in Europa, sondern in Asien. Also, sagen die Kritiker des Vorhabens, würde aus der 
Europäischen Union mit dem Türkei-Beitritt eine Eurasische Union. Und schon das zeige die Absurdität des Vorhabens.

Ferner ist die Türkei deswegen so fremd, weil sie ein islamisches Land ist, und offenbar ist es auch in den aufgeklärten und säkularisierten Gesellschaften, die seit mehr als hundert Jahren wissen, dass Gott tot ist, immer noch so, dass die wirkliche Fremde dort beginnt, wo die Menschen an einen anderen Gott glauben, und dazu auch noch an einen, von dem Samuel Huntington in seinem Buch Der Kampf der Kulturen in kühner Diagnose behauptet, dass er die Demokratie ablehnte. Und schließlich wird das Gefühl der Fremdheit auch dadurch gespeist, dass sich in das kollektive Gedächtnis der Europäer tief das Bild eingeprägt hat, nach dem die Türkei bzw. das Osmanische Reich über Jahrhunderte hinweg der Erzfeind Europas und des Abendlands waren und europäischer Kultur und Gesittung vollkommen entgegenstanden.

Ein zweiter Grund für die Schärfe der Debatten liegt darin, dass zur Frage nach dem Verhältnis zwischen der EU und der Türkei die Frage nach dem Verhältnis der europäischen Gesellschaften zu den türkischen bzw. muslimischen Migranten hinzutritt und mit der Frage des EU-Beitritts der Türkei vermengt wird. Von der Diagnose, dass die gesellschaftliche Integration der Muslime gescheitert ist, wird auf die Unmöglichkeit des EU-Beitritts geschlossen. Die Diskussion über den Beitritt eines Landes zum Staatenverbund der EU gerät ins Fahrwasser der häufig emotionalisiert geführten Diskussionen über Multikulturalismus, Parallelgesellschaften und Leitkultur.

Und drittens schließlich erhält die Diskussion - zumindest in der Bundesrepublik - dadurch eine weitere Schärfe, dass ein Generationenthema mit hineinspielt. Die europäische Integration war das zentrale Projekt der politischen Generation, die nach 1945 auf den Trümmern des großdeutschen Wahns die institutionelle Neugründung der Bundesrepublik unternahm. Und es war eben diese europäische Integration, die die sog. Flakhelfer-Generation bei ihrem Projekt einer nachholenden intellektuellen Gründung und Demokratisierung der Bundesrepublik mit ihrer Vorgängergeneration verband. Die Idee einer europäischen politischen Union, die hier verfochten wurde, ging mit der Relativierung der nationalstaatlichen Souveränität und der Überwindung aller weltmachtpolitischen Ambitionen 
einher. Aus dieser Sicht erscheint der EU-Beitritt der Türkei, den die Jüngeren gegenwärtig betreiben, als vollkommene $\mathrm{Ab}$ wendung vom bisherigen Pfad der europäischen Integration, als Größenwahn (Helmut Schmidt) und als wilhelminisches Säbelgerassel (Hans-Ulrich Wehler).

\section{III}

Die Voraussetzungen für eine rationale Debatte sind also nicht allzu gut. Es wird schweres Geschütz aufgefahren, und kaum kontrollier- und entscheidbare Elemente spielen eine große Rolle. Vielleicht ist es einfacher und produktiver, sich die Detailfragen der Kontroverse anzusehen. Worüber genau geht der Streit? Wie lauten die Argumente? - Im Wesentlichen geht es um Geographie, Wirtschaft, Politik und Geostrategie. Hinzu kommt ein Argument, das sich auf die Bindungskraft und Wirkung von Versprechungen und die Folgen ihrer Nichteinhaltung bezieht, und ein Argument, das sich auf die Frage der inneren Modernität und Rechtsstaatlichkeit der Türkei bezieht.

Versprechungen: Beim Beitritt der Türkei, so sagen die Befürworter, geht es um die Einlösung früherer Zusagen. Was man vor langer Zeit, nämlich bereits in den 60er Jahren, der Türkei in Aussicht stellte und nie widerrufen hat, müsse eingehalten werden. Alles andere wäre ein Affront mit unabsehbaren politischen Folgen, zumal im Dezember 1999 beim EUGipfel in Helsinki die damals 15 Staats- und Regierungschefs die Türkei ohne viel Aufhebens offiziell zum Beitrittskandidaten ernannten.

Natürlich kann niemand aus diesen Versprechungen und Zusagen einen juristischen Anspruch herleiten. Das Argument entstammt eher dem weiten und vagen Feld der politischen Diplomatie und Psychologie. Unwichtig ist es deswegen nicht. Auch die Kritiker des EU-Beitritts nehmen es ernst. Sie weisen aber darauf hin, dass die Zusagen unter ganz anderen historischen Umständen gegeben wurden und sich im Grunde nur auf ökonomische Belange bezogen. Dieses Versprechen sei aber durch die Zollunion, die die EU mit der Türkei im Jahre 1995 eingegangen ist, und durch eine Reihe weiterer Kooperationen und gemeinsamer Projekte längst eingelöst. 
Geographie: Fünf Sechstel des Territoriums der Türkei liegen außerhalb des europäischen Kontinents. Dieser geographische bzw. geomorphologische Hinweis scheint elegant und stark. Aber obwohl das Argument so naturwissenschaftlich unwiderlegbar aussieht, taugt es wenig. Es ist aussichtslos, die Feststellung der Grenzen Europas an die Geographen zu delegieren. Sie haben, seitdem sie in den 60er Jahren vom Europarat den Auftrag bekamen, die Grenzverläufe für die Ausarbeitung verbindlicher Schuldbuchdefinitionen zu klären, den Schwarzen Peter auch längst wieder abgegeben. Im Osten und Südosten jedenfalls ist der Verlauf der Grenzen Europas unscharf. Das vergleichsweise niedrige Gebirge des Ural als Grenze zu nehmen, ist wenig überzeugend und eher Ausdruck einer Verlegenheit. In der Antike galt meistens der Don als Grenzfluss, im 18. Jahrhundert wurde es die Wolga, und erst seitdem ist die Ukraine geographisch ein Teil Europas. Ob die Kaukasusregion als europäisch oder asiatisch anzusehen sei, ist bis heute umstritten. Und warum sollte dem Bosporus, der es nicht einmal schafft, die Bevölkerung Istanbuls zu trennen, die Bedeutung zugesprochen werden, Kontinente und politische Einheiten gegeneinander abzugrenzen?

Reichtum und Armut: Die Türkei ist reich und arm zugleich. Ihr Lebensstandard und ihre Wirtschaftskraft liegen weit unter dem europäischen Durchschnitt. Von der Bevölkerungszahl her ist die Türkei aber sehr reich. Etwa 73 Millionen Menschen leben in der Türkei, das sind, abgesehen von der Bundesrepublik, mehr als in jedem anderen europäischen Staat. Durch einen Beitritt der Türkei würde die Einwohnerzahl der EU stärker wachsen als im Jahre 2004 durch den gleichzeitigen Beitritt von zehn Staaten. Hinzukommt, dass die Geburtenrate in der Türkei für europäische Verhältnisse ungewöhnlich hoch ist.

Beides, ökonomische Armut und Bevölkerungsreichtum, hätte im Falle eines Türkei-Beitritts für die EU bedeutsame Konsequenzen. Wegen der Armut der Türkei könnte ihr Beitritt für die EU sehr teuer werden. Die entsprechenden Strukturfonds würden über die Maßen belastet, hohe Transferleistungen müssten getätigt werden. Bevölkerungsreichtum und hohe Geburtenrate wiederum lösen in vielen europäischen Gesellschaften heftige Ängste vor ungesteuerter Zuwanderung und kultureller Überfremdung aus. Der Arbeitsmarkt, so lautet die 
damit verbundene Befürchtung, gerate aus den Fugen, und Demagogen könnten das bei Wahlen und Volksabstimmungen ausnutzen und politisches Kapital daraus schlagen.

Der Bevölkerungsreichtum hätte beim EU-Beitritt noch weitere, unmittelbar politische Folgen für die Mehrheitsverhältnisse in den Institutionen der EU. Die Zahl der Abgeordneten im Europäischen Parlament ist begrenzt auf 750, die auf die Mitgliedsländer verteilt werden. Eine Mitgliedschaft der Türkei würde mithin dazu führen, dass die zugeteilten Abgeordnetenzahlen der anderen Länder kleiner würden. Die Türkei wäre nach den gegenwärtigen Regeln mit 96 Abgeordneten so stark im Europäischen Parlament vertreten wie die Bundesrepublik. Auch im Ministerrat würde die Türkei sofort zu einem zentralen Akteur der Beschlussfassung und zu einem der wichtigsten Entscheidungsträger aufrücken. Alles in allem: Die Türkei würde den europäischen Bau aus dem Gleichgewicht und am Ende zum Einsturz bringen. Die EU, sagen die Gegner des Beitritts, sei vollkommen außerstande, ein Land von der Größe der Türkei zu integrieren.

Aber auch dieser Punkt ist umstritten. Die türkische Wirtschaft zeigt gegenwärtig Wachstumsraten, von denen die Staaten der EU träumen. Und es wäre nicht schwer, die Kosten des Beitritts zu senken. Die Agrar-, Kohäsions- und Strukturpolitik der EU könnte grundlegend revidiert und damit vor der Überlastung bewahrt, die Freizügigkeit könnte vorerst ausgesetzt werden.

Geopolitik: Die Türkei hat eine kurze Grenze zu ihren beiden europäischen Nachbarn, Griechenland und Bulgarien, und eine sehr viel längere Grenze zu den Ländern des Mittleren Ostens, die früher zum Osmanischen Reich gehörten, d.h. zu Syrien und zum Irak. Und sie hat eine gemeinsame Grenze mit Iran und Armenien. Mit dem Türkei-Beitritt würde die EU also direkt an gefährliche Krisenregionen der Welt heranrücken. Das sei überaus riskant, meinen die Kritiker, und bringe zusätzliche außenpolitische und strategische Komplikationen mit sich.

Was die Kritiker des EU-Beitritts als Gefahr sehen, ist für seine Befürworter umgekehrt eine große Chance und kann ihnen zufolge zu einem großen Zugewinn an Sicherheit und Stabilität für Europa führen. Die Türkei als Mitglied der EU würde eine hervorragende Brücke in den Nahen und Mittleren Osten 
darstellen. Als muslimisches und zugleich europäisches Land könnte sie das Ansehen und den Einfluss der EU in dieser Region erheblich erhöhen.

Demokratische Defizite: Die Türkei sei, so sagen die Gegner des Beitritts, von Beitrittsreife weit entfernt. Manche Reformen stünden nur auf dem Papier, manche nicht einmal das. Die Liste der demokratischen, zivilisatorischen und rechtsstaatlichen Defizite in der Türkei ist lang: keine Religionsfreiheit für die nicht-muslimischen Religionsgemeinschaften, staatliche Duldung frauenfeindlicher Traditionen, keine Gewährleistung der Menschen- und Minderheitenrechte, keine energische und flächendeckende Abschaffung der Folter. Und obwohl nirgendwo in Europa die Trennung zwischen Staat und Religion so stark festgeschrieben ist wie in der Türkei, beobachten viele einen starken religiösen Einfluss und eine massive Reislamisierung der türkischen Gesellschaft.

Zudem treffen die Demoskopen und Sozialforscher auf eine Mentalität, für die Toleranz bislang ein Fremdwort geblieben ist. Die Vorstellung, Homosexuelle oder Juden als Nachbarn zu haben, ist ihnen zu einem erheblich höheren Prozentsatz unheimlich als den Bürgern der gegenwärtigen Mitgliedsstaaten der EU. In den Mitgliedsländern der salten< EU, vor der MaiErweiterung des Jahres 2004, sagten 18,6 Prozent der Befragten, sie hätten Homosexuelle nicht gern als Nachbarn, in den zehn Ländern, die 2004 hinzukamen, sind es 45,3 Prozent, in Bulgarien und Rumänien, deren Aufnahme bevorsteht, sind es 59,3 Prozent und in der Türkei 90 Prozent. Auf die Frage, ob bei knappen Arbeitsplätzen Männer eher ein Recht auf Arbeit haben als Frauen, halten 19,7 Prozent der Bürger der salten< EU, 25,3 Prozent der Befragten der zehn neuen Länder, 37,3 Prozent in Bulgarien und Rumänien, und 62 Prozent der Befragten in der Türkei die Bevorzugung von Männern für richtig.

Freilich: Werthaltungen können sich ändern, und sie ändern sich mit den Lebensumständen und der politischen Umwelt. Die Geschichte der Bundesrepublik ist dafür ein gutes Beispiel. Und auch am Beispiel Irlands lässt sich zeigen, dass sich intolerante Werthaltungen, die über Jahrhunderte hinweg tradiert wurden, unter dem Einfluss der bestimmenden und zugleich sanften Nachhilfe der EU nach und nach liberalisierten. 
Ein eigenes und für den offenbar noch vollkommen ungebrochenen Nationalismus der Türkei typisches Kapitel ist ihre Geschichts- bzw. Gedächtnispolitik. Bis heute darf man in der Türkei nicht offen über den Völkermord an den Armeniern sprechen, dem vor 90 Jahren 1,5 Millionen Menschen zum Opfer fielen. Und die Türkei versucht sogar dafür zu sorgen, dass auch in anderen Ländern, z.B. in der Bundesrepublik, das Thema nicht behandelt wird. So führte die Intervention eines türkischen Generalkonsuls bei der Regierung des Bundeslandes Brandenburg dazu, dass der kleine Hinweis auf den Genozid der Jungtürken, den das zuständige Ministerium im Jahre 2002 voller Kühnheit in den Geschichtslehrplan für die Jahrgangsstufen neun und zehn aufgenommen hatte, zu Beginn des Jahres 2005 wieder daraus verschwand.

Es könnte allerdings sein, dass - wie so oft in der Gedächtnisgeschichte - der Versuch der damnatio memoriae das Gegenteil bewirkt. Das allgemeine Interesse in der deutschen Öffentlichkeit für dieses Thema und die Empörung über die Türkei und über das Land Brandenburg, das dem Druck der Türkei ohne großes Zögern nachgab, sind einhellig. In der Türkei selber gibt es erste zaghafte Ansätze einer Thematisierung ihrer dunklen Vergangenheit. Der Genozid an den Armeniern, da kann man sicher sein, wird aus den Diskussionen über den EUBeitritt der Türkei nicht mehr verschwinden. Der Satz: »Wer erinnert sich heute noch an die Vernichtung der Armenier?", mit dem Hitler sich mit seinen Verbrechen vor der Geschichte und dem Gedächtnis der Nachwelt in Sicherheit wähnte, wird nicht das letzte Wort sein.

\section{IV}

Die Debatte über den EU-Beitritt der Türkei ist mehr als die Summe ihrer Einzelaspekte. Schon der flüchtige Durchgang durch die einzelnen Streitpunkte, den wir hier unternommen haben, zeigt, dass über die Einzelfragen und die Bedeutung, die ihnen beigemessen wird, sinnvoll nur dann entschieden werden kann, wenn zentrale übergreifende und vorgeordnete Fragen geklärt sind. So spiegelt sich in der Türkei-Diskussion das große Versäumnis, dass Europa keine Klarheit darüber hat, was 
es ist, wie groß es sein, wie es sich definieren und welchen Ort es in der Welt einnehmen will. Kurz: Die Türkei-Diskussion zeigt, dass die europäische Frage immer noch offen ist.

Europa war nie ein Gebilde mit endgültiger Gestalt, sondern stets ein offener Prozess. Jede Erweiterung bedeutete Veränderung und erforderte eine neue Definition des eigenen Selbstverständnisses. Vielleicht ist aber mit der Entscheidung über den EU-Beitritt der Türkei nun ein Wendepunkt erreicht, an dem eine Richtungsentscheidung großen Ausmaßes getroffen werden muss. Zugespitzt gesagt, ist die Alternative, um die es dabei geht, die folgende: Entweder wird der Weg zu einer politischen Union, der in den letzten 15 Jahren eingeschlagen wurde und mit dem Verfassungsvertrag ein wichtiges Etappenziel erreicht hat, fortgesetzt. Mit dieser Präferenz ist der Beitritt der Türkei unvereinbar (1). Oder aber die EU definiert sich im Kern als Sicherheitsunion und weltpolitischer Akteur, dessen zentrale Aufgabe darin besteht, an seiner Peripherie, an der gegenwärtig die gefährlichsten Krisenregionen der Welt liegen, Sicherheit und Stabilität herbeizuführen. Für diese Strategie ist der Beitritt der Türkei ein zentraler Baustein (2). Die Entscheidung zwischen politischer Union und weltpolitischem Akteur hängt am Ende davon ab, ob der Gefahr des internationalen Terrorismus die absolute weltpolitische Priorität eingeräumt wird oder nicht.

Es könnte freilich sein, dass das Drama um die genannten Alternativen nur auf der Vorderbühne gegeben wird, während auf der Hinterbühne ein ganz anderes Stück unverdrossen weiter auf dem Spielplan steht. In ihm haben die Pragmatiker ihren Auftritt und bedienen die Manuale des sog. europäischen Mehrebenensystems, das sich in der Welt der punktuellen Kooperationen und Koalitionen auf den unterschiedlichen Politikfeldern mit großer Rationalität und Effektivität bewährt hat und, unbeeindruckt von dem, was auf der Vorderbühne geschieht, voranschreitet. Das Problem ist, dass das große Publikum dieses Stück gar nicht sieht und dass es der hochgradig geschulten Augen der politikwissenschaftlichen Europaforscher bedarf, um es überhaupt zu Gesicht zu bekommen. Und selbst wenn dieses unspektakuläre Geschehen auf der europäischen Hinterbühne die Entwicklung Europas weiterhin bestimmen wird, sind die Dialoge der Akteure auf der Vorderbühne nicht 
unwichtig. Sie leisten die Arbeit der Zuspitzung, sie geben die Wege des Selbstverständnisses und der Selbstverständigung vor, und sie sind damit gerade für die Wendepunkte, an denen die Weichen der europäischen Integrationspolitik neu gestellt werden, von großer Bedeutung.

(1) Das Ziel einer politischen Union mit den dazu gehörenden Institutionen, Kompetenzen und Handlungsfähigkeiten im Bereich der Rechts- und Innenpolitik, der Steuer-, Sozial-, Agrar-, Umwelt-, Verbraucher- und Medienpolitik kann auf die Dauer nur erreicht werden, wenn es zu einer deutlich über den bisherigen Rahmen hinausgehenden inneren gesellschaftlichen Einheit Europas kommt. Unter den Bedingungen sehr großer sozialer, geschichtlicher, kultureller, religiöser und lebensweltlicher Heterogenität wird eine solche politische Union nicht funktionieren. Die Konstitution einer handlungsfähigen politischen Ordnung bedarf der Basierung in gemeinsamen Lebenswelten und zuverlässiger Formen von Zusammengehörigkeit und Solidarität. Ohne einen Bereich von Übereinstimmung und Loyalität, der für das Austragen der unvermeidlich auftretenden Interessenskonflikte einen tragfähigen Rahmen bietet, ist sie auf Sand gebaut. Die EU greift regulierend und gestaltend tief in das gesellschaftliche Leben ihrer Mitgliedsländer ein. Die europäischen Gesellschaften werden ein Fortschreiten auf diesem Weg nur dann akzeptieren, wenn sie das Bewusstsein und das Empfinden ausbilden, dass sie Angehörige eines gemeinsamen politischen Projekts bzw. einer gemeinsamen politischen Einheit sind und angesichts dieser Einheit die bestehenden Unterschiede und Divergenzen in den Hintergrund treten. Wie immer es genannt wird: europäischer Patriotismus, Wir-Gefühl, Solidaritätsempfinden, - eine politische Union in Europa braucht eine Art von Gemeinsamkeitsglauben, der die Bedeutung der nationalen Zugehörigkeiten relativiert und im Blick auf die europäische Einheit übersteigt.

Warum ist das so? Weil andernfalls z.B. die Praxis von Mehrheitsentscheidungen, die für das Regieren in einer politischen Union unverzichtbar ist, kaum akzeptiert würde. Jedenfalls gilt das dann, wenn die Mehrheitsentscheidungen auch jene Bereiche betreffen, die unmittelbar und massiv das Leben der europäischen Bürger regulieren und gestalten. Die Entscheidungen müssen auch von den Überstimmten, von den je- 
weiligen Minderheiten mitgetragen werden. Minderheiten finden sich mit Mehrheitsentscheidungen, in denen sie überstimmt wurden, nur dann ab, wenn sie das Vertrauen haben, dass die Mehrheit ihre Machtposition nicht missbraucht, und wenn sie prinzipiell die Chance haben, ihrerseits zur Mehrheit zu werden.

Das ist solange kein Problem, wie wir es mit politischen Entscheidungen $\mathrm{zu}$ tun haben, von denen alle profitieren, und der Unterschied nur darin besteht, dass der Gewinn für einige etwas höher und für die anderen etwas geringer ausfällt. Viel schwieriger wird es aber, wenn wir es nicht mehr mit Positiv-, sondern mit Nullsummenspielen zu tun bekommen, d.h. wenn Entscheidungen mit gravierenden Umverteilungen verbunden sind, bei denen die einen die Kosten und die anderen den Nutzen haben. Zur Legitimierung solcher Entscheidungen bedarf es der Ressource Solidarität, die nur aktiviert werden kann, wenn es belastbare und fest verankerte Gemeinsamkeiten, $\mathrm{Zu}$ gehörigkeiten und Loyalitäten gibt. Deren Erzeugung aber steht nicht in der Macht der politischen Steuerungszentralen. Ein Gemeinsamkeitsglaube kann nicht mit Hilfe von Gesetzen, Geld, Geboten und Verboten angeordnet oder hergestellt werden wie eine Ware in der Welt der Produktion. Er ist das Resultat von komplizierten langfristigen Prozessen und Entwicklungen, an denen eine unübersehbare Fülle von Einflüssen und Akteuren mitwirkt.

Ein Gemeinsamkeitsglaube kann auf europäischer Ebene nicht, wie im Falle der Nation, der Herstellung ethnischer und sprachlicher Homogenität verpflichtet sein. Das ist nicht nur deswegen so, weil der Nationalismus untrennbar mit den groBen Katastrophen des 20. Jahrhunderts verbunden ist, sondern weil ein derartiges Konzept natürlich sofort das Ende Europas bedeuten wurde. Die Idee der europäischen Integration hat ihre entscheidenden Antriebskräfte nach dem Ende des Zweiten Weltkriegs umgekehrt gerade aus der Überwindung des nationalstaatlichen Modells politischer Ordnung bezogen. Wenn man aber die finalité Europas als politische Union bestimmt, kehrt das aus der Geschichte der Nationen bekannte systematische Problem der politischen Legitimation unvermeidlich wieder. Die Idee der Nation war weltgeschichtlich seit dem Ende des 18. Jahrhunderts deswegen so attraktiv, weil sie die Prinzi- 
pien dynastischer Legitimation abzulösen und die politische Herrschaft aus dem Willen der national bestimmten Bevölkerungen herzuleiten versprach. Der Name Nation diente dabei zur Bezeichnung und Abgrenzung der kollektiven Bezugsgruppe, auf die sich die jeweilige staatliche Herrschaft bezog. Weil sich die politische Herrschaft aus dem Willen der Nation ableitete, konnten Nation, Staat und Demokratie eine enge Verbindung miteinander eingehen. Zugleich sicherte die Berufung auf die übergreifende Einheit der Nation den inneren Zusammenhalt und die innere Loyalität der jeweiligen Bevölkerungen.

Auf dem Weg Europas zu einer politischen Union kommt der Lösung des Legitimationsproblems eine Schlüsselstellung zu. Benötigt werden dann Substitute für das, was die Funktion der Nation in den Prozessen demokratischer nationalstaatlicher Legitimation gewesen ist. Niemand träumt heute glücklicherweise mehr von der Herstellung ethnisch homogener Bevölkerungen. Im Blick auf Europa wird stattdessen immer wieder und sehr zu recht darauf hingewiesen, dass seine Qualität gerade in der Vielheit von Kulturen, Sprachen und Eigenheiten auf engstem Raum besteht. Damit ist aber nicht die grundsätzliche Frage gelöst, was diese Vielheit zu einer Einheit macht, die sie sein muss, wenn sie als Basis der Legitimation politischer Herrschaft in Anspruch genommen werden soll. Die Auskunft, es gehe gerade um die Erhaltung der Vielfalt, ist so schön wie unergiebig, weil sie unterstellt, dass die Einheit niemals in Interessenskonflikte mit den Vielheiten kommen könnte. Eben das aber ist der Fall, wenn z.B. hohe Transferleistungen zum Zweck der Angleichung der Lebensverhältnisse von einem europäischen Land auf dem Umweg über Brüssel in ein anderes europäisches Land vorgenommen werden. Offenkundig darf das Insistieren auf Verschiedenheit nicht so weit führen, dass derartige Umverteilungen nicht mehr auf Zustimmung stoßen.

Europa als politische Union ist angewiesen darauf, dass es in seinen Bevölkerungen einen Vorrat an Gemeinsamkeiten und das Bewusstsein der Zugehörigkeit zu einem gemeinsamen Projekt gibt. Eine politische Union muss ihre Politik und Existenz im Willen, in den Haltungen, im Bewusstsein und in den Empfindungen europäischer Staatsbürger fundieren und legitimieren. Sicherlich folgt das europäische Regieren jenseits des Nationalstaats einem anderen Selbstverständnis als es für das 
Zeitalter der Nationalstaaten typisch ist, aber auf tragfähige Formen von Legitimation und Loyalität kann es keineswegs verzichten. Griechen und Italiener, Portugiesen und Dänen, Polen und Franzosen müssen sich gegenseitig als Bürger desselben politischen Gemeinwesens anerkennen und verstehen. Europa im Kern als einheitlichen Rechtsraum und Solidarität als die rein rechtlich vermittelte Solidarität von Staatsbürgern zu definieren, reicht dazu nicht hin. Die wichtigste Voraussetzung für die Entstehung eines europäischen Zusammengehörigkeitsgefühls ist die Entstehung einer europaweiten politischen Öffentlichkeit, von der gegenwärtig nur in Ansätzen die Rede sein kann.

Der europäische Gemeinsamkeitsglaube hat unmittelbar mit der Frage zu tun, in welchen Abläufen und Zuständigkeiten die demokratische Legitimation der EU realisiert wird. Nach wie vor haben wir den Zustand einer Mischung zwischen einem Staatenbund, der seine Legitimation aus den jeweiligen Parlamenten der Einzelstaaten bezieht, und einem föderal konzipierten Staatswesen, das direkt seinen europäischen Wählern verantwortlich ist. Dem Maastricht-Urteil des Bundesverfassungsgerichts zufolge sind es die Staatsvölker der Mitgliedsstaaten, die über ihre Parlamente dem europäischen Staatenverbund zu demokratischer Legitimität verhelfen. Für die Zwecke einer politischen Union ist die Entstehung von Verhältnissen unabdingbar, in denen die Europäer unmittelbar und nicht auf dem Weg über ihre nationale politische Repräsentation als Staatsbürger in Erscheinung treten. Ihre Befürworter wie z.B. Wolfgang Schäuble fordern deswegen, dass etwa bei den Wahlen zum Europäischen Parlament die nationalen Grenzen wirklich überwunden werden müssen. Grenzüberschreitende Wahlbezirke und Kandidatenlisten sollten zur Regel werden. Ferner sollte die Direktwahl des Präsidenten der Kommission ins Auge gefasst werden. Sie zwinge die Kandidaten und Parteien zu europäischer Dimension und Kommunikation und fördere damit die europäische Öffentlichkeit und die Entstehung eines europäischen Bewusstseins.

Die Verbindung dieser Überlegungen zur Frage des EU-Beitritts der Türkei liegt auf der Hand. Je größer, umfassender und heterogener der Raum der Zugehörigkeit zu einer gemeinsamen politischen Ordnung wird, desto aufwendiger und riskan- 
ter gestaltet sich die Herstellung des inneren Gemeinsamkeitsglaubens. Und da die Türkei aus den bereits angesprochenen Gründen als fremd, belastend und bedrohlich erscheint, halten die Fürsprecher der politischen Union die Herstellung eines fundierten und belastbaren Gemeinsamkeitsglaubens mit ihr für vollkommen ausgeschlossen.

Auch ohne die Aufnahme der Türkei gehört zur Herstellung einer europäischen Form von Staatsbürgersolidarität ein im Vergleich zur nationalstaatlichen Integration viel größeres Ausmaß an Toleranz für Vielfalt, Verschiedenheit und Andersheit, für Fremdheit und Divergenz. Generell gilt, dass die Diskussion über Parallelgesellschaften, Multikulturalismus und Leitkultur nur in Gesellschaften aufkommen kann, die im Bannkreis der nationalen Legitimation stehen. Mit ihr ist regelmäßig das Problem der Minderheiten verbunden. Minderheiten gleich welcher Art waren durch die Geschichte des nationalen Zeitalters hindurch immer wieder dem Verdacht ausgesetzt, dass sie einen Staat im Staate bilden und damit die Einheit der Nation untergraben. So lautete z.B. der Standardvorwurf an die Adresse der jüdischen Minderheiten in den europäischen Nationalstaaten.

Im alten Europa vor der französischen Revolution gab es die Einheit von Nation und Staat nicht. Die Grundlage für das Leben der Minderheiten mit unterschiedlicher Herkunft, Religion, Sprache, Kultur und Geschichte sah deswegen ganz anders aus. Es beruhte zumeist auf der Verleihung eines eigenen Rechtsstatus durch den zuständigen Herrscher. Die fremden Bevölkerungsgruppen sollten durchaus nicht integriert oder assimiliert werden, sondern ihre Wurzeln, d.h. ihre Sprache, Sitten und Kultur behalten dürfen. Eine heterogen zusammengesetzte Bevölkerung verträgt sich im Prinzip problemlos mit der dynastischen Legitimation. Dass die Minderheiten die jeweilige Herrschaft nicht in Frage stellten, versteht sich beinahe von selbst. Schließlich waren sie darauf angewiesen, dass ihnen die jeweiligen Herrscher das Lebensrecht garantierten, und sie honorierten ihrerseits diesen Schutz mit Unterwerfung und Gehorsam. Die Kehrseite war, dass sie der Willkür der Fürsten und Herrscher ausgeliefert waren. Diese konnten nach eigenem Belieben die Minderheiten unter ihren besonderen Schutz stellen, ihnen diesen Status aber auch wieder entziehen. Auch dafür ist die Geschichte des Judentums voller Beispiele. 
(2) Das zweite Konzept sieht die Zukunft Europas nicht in der Annäherung an das Ziel einer politischen Union, sondern favorisiert ein Europa, das sich im Wesentlichen als sicherheitspolitische Macht mit weltweitem Einfluss versteht. Die zentrale Aufgabe der EU in den kommenden Jahrzehnten besteht danach nicht im Ausbau und der Intensivierung der Integration nach innen, sondern darin, ein tragfähiger und belastbarer Akteur bei der Bewältigung der Bedrohungen zu werden, die in großem Maßstab die Sicherheit Europas und der Welt gefährden. Hinter diesem Konzept steckt eine Analyse, die die äußeren Bedrohungen für die zentrale politische Herausforderung Europas im 21. Jahrhundert hält: der international operierende Terrorismus, die Konflikte im Nahen und Mittleren Osten, die Gefahr eines allgemeinen clash of civilisation zwischen dem Islam und dem Westen, Entwicklung und Besitz von Massenvernichtungswaffen, zerfallende Staaten, Ressourcenknappheiten, Seuchen, Umweltprobleme, weltweite demographische Verschiebungen.

Bei den Befürwortern des EU-Beitritts der Türkei stehen diese weltpolitischen Gefahren im Zentrum der Aufmerksamkeit, und die Perspektiven, die sie für die EU entwerfen, sind das Resultat dieser Bedrohungswahrnehmung. Sie dürfte z.B. dazu geführt haben, dass Bundesaußenminister Fischer innerhalb kurzer Zeit aus einem Befürworter der EU als politischer Union $\mathrm{zu}$ einem Protagonisten des neuen strategisch ausgerichteten Europa geworden ist. Sein Votum für den Türkei-Beitritt wird jedenfalls von geostrategischen Motiven getragen. Nach der Veränderung der Welt durch den islamistischen Terrorismus sei es blind, so sagte Fischer in der Bundestagsdebatte am Vorabend (16.12.2004) der Brüsseler Türkei-Entscheidung der Staats- und Regierungschefs, der Türkei den Weg nach Europa $\mathrm{zu}$ verwehren. Ähnliche Verlautbarungen gibt es von anderen hochrangigen Amts- und Entscheidungsträgern. Der frühere Erweiterungs- und jetzige Industriekommisar Verheugen plädiert für den EU-Beitritt der Türkei, weil die EU damit zu einem weltpolitisch zentralen Akteur aufsteigen könnte. Der spanische Ministerpräsident Zapatero meint, Europa müsse daran glauben, in zwanzig Jahren die bedeutendste Weltmacht sein zu können. Der türkische Regierungschef Erdoğan sieht das nicht anders. Die Türkei, so argumentiert er, befinde sich im 
Zentrum von Eurasien, sie habe Einfluss auf den Balkan, den Kaukasus, auf Zentralasien und den Nahen Osten. Wenn die EU in der Welt eine wichtige Rolle spielen wolle, dann führe an der Türkei kein Weg vorbei.

In diesen Vorstellungen ist die EU kein Staatenverbund auf dem Weg in eine politische Union, sondern eine Macht mit globalem Einfluss, die die inneren Loyalitätsforderungen an die Bürger deutlich ermäßigen und dennoch als weltpolitischer Akteur auftreten kann. Die Sicherheitspolitik rückt ins Zentrum, alles weitere wird ihr untergeordnet. Der Blick auf die Landkarte der Bedrohungen lehrt, dass die Türkei bei der Bewältigung der großen Gefahren des 21. Jahrhunderts eine Schlüsselrolle spielt. Nur mit ihrer Hilfe, so argumentiert etwa Münkler, könne Europa seine Südostflanke sichern und verhindern, dass die Krisengebiete des Balkans sowie des Nahen und Mittleren Ostens mit denen des südlichen Randes der ehemaligen Sowjetunion zu einem explosiven und unkontrollierbaren Pulverfass zusammenfließen. Hinzu komme, dass die USA ihren Schwerpunkt stärker in den pazifischen Raum hineinverlagerten und die EU die dadurch entstehende Lücke auszufüllen habe.

Man sieht: Hier wird tatsächlich ein weit reichender Richtungswechsel der EU ins Auge gefasst. Wenn Europa als weltpolitischer Akteur verstanden wird, ist die Entwicklung eines innereuropäischen und weit reichenden Staatsbürgerbewusstseins überflüssig. Die Verständigung auf eine gemeinsame Bedrohungsanalyse und auf die Einhaltung von rechtsstaatlichen und menschenrechtlichen Minimalforderungen würde ausreichen. Zusammengehalten würde diese Einheit nicht durch die Gemeinsamkeit von positiven Gestaltungsoptionen im Innern, sondern durch die äußeren Bedrohungen, deren Bewältigung Europa nicht anderen überlassen kann. Das hat Tradition: Europa war in der bisherigen Geschichte immer dann einig und eigentlich immer nur dann einig, wenn es galt, sich gegen äußere Gefahren zu wappnen. Das schließt keineswegs aus, dass einzelne Politikbereiche stärker europäisch vernetzt werden. Aber das wären jeweils pragmatisch entscheidbare Angelegenheiten auf der intergouvernementalen Ebene. Die Perspektive auf eine politische Union müsste mit ihnen keineswegs verbunden werden. 
Nahtlos fügt sich in dieses Konzept das Argument ein, dass die EU im Blick auf die Türkei die Aufgabe hat, die demokratischen Transformations- und Verwestlichungsprozesse dort nach Kräften zu stützen und durch den Einsatz von soft power weit in den arabischen Raum hinein positive Zeichen zu setzen. Die Stabilisierung der türkischen Demokratie ist dann das Experimentierfeld und bei positivem Ausgang des Experiments ein weiterer Beleg für die Überzeugungskraft und Richtigkeit des europäischen Modells der Weltsicherheitspolitik. Wo die USA mit ihrer Strategie des gewaltsam betriebenen regime change immer wieder scheitern, da bewirkt die EU allein durch ihre Vorbildhaftigkeit bei ihren Nachbarn Veränderungen von revolutionären Ausmaßen, - vorgestern in Griechenland, Spanien und Portugal, gestern in Mittel- und Osteuropa, heute in der Türkei und in der Ukraine, morgen in Georgien und Armenien und in den nordafrikanischen Staaten. Unter diesen Vorzeichen ist die Diskussion über den EU-Beitritt der Türkei dann auch keine Religions- und Kulturdebatte mehr, - oder nur noch insofern, als mit dem erfolgreichen Ausgang der Demokratisierung und Verwestlichung der islamischen Türkei unter Beweis gestellt würde, dass die Behauptung der konstitutionellen Unverträglichkeit von Islam und Demokratie auf einer einseitigen und falschen Sicht der Dinge basiert.

Das also ist die Frage, vor der Europa steht: Soll die EU das Ziel einer politischen Union weiter im Blick behalten oder soll sie sich zu einem sicherheitspolitischen Akteur mit globalem Einfluss entwickeln? An der Türkei-Frage wird sich diese Alternative entscheiden. Darin liegt ihre überragende Bedeutung.

\section{Literatur}

Alber, Jens (2004): Gehört die Türkei zu Europa? - Ein Sozialporträt der Türkei im Licht vergleichender Daten der Umfrageforschung, in: Leviathan 4/2004, S. 464-494.

Beck, Ulrich (2004): So macht Gleichheit Ungleiche aus uns allen. Und kann es so etwas wie eine europäische Gesellschaft überhaupt geben? in: Frankfurter Allgemeine Zeitung vom 8. Oktober 2004.

Böckenförde, Ernst-Wolfgang (2004): Nein zum Beitritt der Türkei, in: Frankfurter Allgemeine Zeitung vom 10. Dezember 2004. 
Bacia, Horst et al. (2004): Fast noch ergebnisoffen, in: Frankfurter Allgemeine Zeitung vom 16. November 2004.

Giscard d'Estaing, Valéry (2004): Zurück zur Vernunft, in: Frankfurter Allgemeine Zeitung vom 26. November 2004.

Glotz, Peter (2004): Heiße Mischung. Welchen Consensus braucht die EU? in: Frankfurter Allgemeine Zeitung vom 24. Dezember 2004.

Grimm, Dieter (2004): Integration durch Verfassung. Absichten und Aussichten im europäischen Konstitutionalisierungsprozess, in: Leviathan 4/2004.

Habermas, Jürgen (2004): Ist die Herausbildung einer europäischen Identität nötig, und ist sie möglich? in: ders., Der gespaltene Westen, Frankfurt a.M.

Leggewie, Claus (Hg.) (2004): Die Türkei und Europa. Die Positionen, Frankfurt a.M.

Münkler, Herfried (2004): Das imperiale Europa, in: Die Welt vom 29. Oktober 2004.

Münkler, Herfried (2004): Die Zeit der Kuscheleuropäer ist zu Ende, in: Aachener Nachrichten vom 30. Oktober 2004.

Prantl, Heribert (2004): Ein 780.576 Quadratkilometer großes Kopftuch, in: Süddeutsche Zeitung vom 15./16. Mai 2004 .

Schäuble, Wolfgang (2005): Die europäische Integration voranbringen, in: Frankfurter Allgemeine Zeitung vom 28. Januar 2005.

Schmidt, Helmut (2004): Bitte keinen Größenwahn. Ein Beitritt der Türkei würde die Europäische Union überfordern, in: DIE ZEIT vom 25. November 2004.

Schulze, Hagen (1990): Die Wiederkehr Europas, Berlin.

Thumann, Michael (2004): Europa leuchtet, in: DIE ZEIT vom 9. Dezember 2004.

Thumann, Michael (2004): Pack den Tiger in die EU, in: DIE ZEIT vom 16. Dezember 2004.

Verheugen, Günter (2004): Das Kuschel-Europa ist von gestern. Ein Beitritt der Türkei würde die Europäische Union stärken und sie zum weltpolitischen Akteur machen, in: DIE ZEIT vom 7. Oktober 2004.

Wernicke, Christian (2004): Das große Aber, in: Süddeutsche Zeitung vom 18./19. Dezember 2004.

Winkler, Heinrich August (2004): Im Lauf der Zeit, in: Der Tagesspiegel vom 7. November 2004. 
Yerushalmi, Yosef Hayim (1995): »Diener von Königen und nicht Diener von Dienern«. Einige Aspekte der politischen Geschichte der Juden, München. 


\title{
EU-Beitritt der Türkei als Vollendung eines Europa der kulturellen Vielfalt
}

\author{
FARUK ŞEN
}

\section{Einführung}

Für die Türkei in ihrer heutigen Form als säkularer und demokratischer Staat in einem unsicheren geopolitischen Umfeld ist der Weg nach Europa auf lange Sicht alternativlos. Die Beziehungen zwischen der Türkei und der EU befinden sich momentan in einer ausgesprochen wichtigen Phase ihrer rund vierzigjährigen Geschichte, die 1963 mit dem Assoziierungsabkommen begann. Eine Reihe von Fort- und Rückschritten in den gegenseitigen Beziehungen markiert den Weg: das bisher erfolglose Beitrittsgesuch der Türkei 1987, die Umbrüche im Internationalen System 1989/90, die die politischen Koordinaten nachhaltig und die Präferenzen der EU bei der Erweiterung verschoben haben, die Zollunion der EU mit der Türkei 1996 und schließlich die Gewährung des Status eines offiziellen EU-Beitrittskandidaten in Helsinki 1999. Ende 2004 stand die Entscheidung über die Aufnahme von Beitrittsverhandlungen mit der Türkei an.

Der vorliegende Beitrag gibt einen kurzen Überblick über die Historie der Türkei-EU-Beziehungen sowie die wichtigsten Folgen eines möglichen Beitritts der Türkei zur Union. In diesem Zusammenhang werden einzelne Bereiche diskutiert, in denen 
der türkische Beitritt in besonderem Maße Veränderungen zeitigen könnte.

\section{Geschichte der EU-Türkei-Beziehungen}

Die Beziehungen zwischen Europa und der Türkei sowie der gegenseitige kulturelle Austausch sind seit Jahrhunderten in starkem Maße vorhanden. Das Osmanische Reich war für Europa immer die Brücke zum Orient, und die Republik Türkei spielt diese Schlüsselrolle noch heute. Während das europäische Geistesleben insbesondere nach der Eroberung Konstantinopels im Jahre 1453 unzählige Impulse aus der osmanischen Kultur empfing, bewegt sich seit dem 19. Jahrhundert die Türkei kontinuierlich auf Europa zu, indem sie westliche Gesellschaftsentwürfe zum Leitbild der Modernisierung von Staat und Wirtschaft machte. So wie in der allgemeinen Wahrnehmung der vergangenen Jahrhunderte die konfrontativen Elemente dieser intensiven Beziehungen zwischen der Türkei und Europa oftmals im Vordergrund standen und zum Teil noch immer stehen - mit der Belagerung Wiens als Sinnbild eines türkisch-europäischen Gegensatzes - wird der Einfluss europäischen Denkens auf die Türkei seitens der Europäer vielfach unterschätzt. Tatsächlich befindet sich die Türkei auf dem kontinuierlichen Weg nach Europa. Die staatlichen Strukturen in der Türkei - parlamentarisch-repräsentative Demokratie, Rechtssystem, Verwaltung - sind im Gegensatz zu allen anderen muslimisch geprägten Staaten weitgehend von europäischen Vorbildern durchdrungen. Der feste Wille des Landes, zu Europa zu gehören, ist die Grundkonstante der türkischen Politik seit der Staatsgründung durch Atatürk. Die Orientierung am Westen ist im Selbstverständnis der Türkei nicht eine Option unter mehreren, sondern integraler Bestandteil der säkularen Republik und der wirtschaftlichen Modernisierung.

Den Antrag auf die Assoziierung mit der damaligen EWG stellte die Türkei am 31. Juli 1959, kurz nachdem Griechenland den gleichen Schritt unternommen hatte. So stand $\mathrm{zu}$ diesem Zeitpunkt keine wirtschaftliche Überlegung oder der Wunsch der Intensivierung der Beziehungen zu Europa im Vordergrund, 
sondern das Kalkül, bei der Westintegration nicht hinter dem Rivalen Griechenland zurückzubleiben.

Am 12. September 1963 wurde das Assoziierungsabkommen schließlich in Ankara unterzeichnet (vgl. Ankara Agreement 1963). Es definierte die Schritte bis zur Vollmitgliedschaft, die die Errichtung einer Zollunion nach einer Vorbereitungs-, Übergangs- und Endphase bis zum 1. Januar 1995 sowie die Schaffung der Freizügigkeit für Arbeitnehmer bis zum 1. Dezember 1986 einschlossen. Die Türkei sollte zudem für die Angleichung ihrer Wirtschaft an die Strukturen der EWG/EG sowie für den Ausgleich der Nachteile, die aufgrund des Abbaus der Zölle entstehen würden, finanzielle Mittel von der EWG/EG erhalten, die durch Finanzprotokolle geregelt wurden.

In den auf das Assoziierungsabkommen folgenden Jahren belasteten drei Militärinterventionen in der Türkei die europäisch-türkischen Beziehungen. Aufgrund der Wirtschaftskrise wurden 1978 die Verpflichtungen der Türkei hinsichtlich des Zollabbaus für fünf Jahre eingefroren. Der Militärputsch vom 12. September 1980 verlängerte den Stillstand in den Beziehungen. Erst am 16. September 1986 fand die Sitzung des Assoziationsrates wieder statt. Etwa ein halbes Jahr später, am 14. April 1987, stellte die Türkei einen Antrag auf Vollmitgliedschaft in der EG. Die Antwort war, die EG könne bis zur Realisierung des bevorstehenden Binnenmarktes mit keinem Land Beitrittsverhandlungen aufnehmen (vgl. EG-Kommission 1987). Zudem stünden trotz positiver Entwicklungen in den letzten Jahren das wirtschaftliche Gefälle zwischen der Türkei und dem EG-Durchschnitt sowie Mängel in der Demokratie- und Menschenrechtspraxis einer Mitgliedschaft entgegen. Der Weg zur türkischen Mitgliedschaft wurde aber nicht völlig blockiert. Mit dem Bericht der Kommission vom 5. Juli 1990 für den Ministerrat wurden Modalitäten einer Annäherung der Türkei festgelegt. Zunächst wurde die Vollendung der Zollunion bis 1995 beschlossen. Ein weiterer Beschluss war, dass die 600 Millionen Euro aus dem IV. Finanzprotokoll, dessen Freigabe seit 1981 stets am griechischen Veto scheiterte, der Türkei so schnell als möglich gewährt werden sollten.

Die Türkei erklärte sich bereit, alle erforderlichen Maßnahmen zur Realisierung der Zollunion innerhalb des von der EU angegebenen Zeitrahmens zu ergreifen. Dazu musste die Türkei 
das innerstaatliche Recht, vor allem was die Wirtschaftsordnung betraf, dem der EU angleichen. Hierzu mussten von der Türkei etwa 100 Gesetze verändert bzw. erlassen werden. Obwohl die EU von der Zollunion mit der Türkei profitieren und sie für die Türkei kurz- bis mittelfristig wirtschaftliche Nachteile bringen würde, war die türkische Regierung an einer raschen Realisierung stark interessiert. Der Grund lag darin, dass die Zollunion möglicherweise der letzte Trumpf der Türkei zur Erreichung einer langfristigen Anbindung an die EU war, die bereits über die Osterweiterung nachdachte. In den veränderten internationalen Koordinaten dürfte auch die Ursache dafür gelegen haben, dass die Türkei bereits eine große Überzeugungsarbeit für die Realisierung der Zollunion leisten musste, da die EU und das Europäische Parlament (EP) wegen Vorbehalten aufgrund der Menschenrechtspraxis die Vollendung der Zollunion zunächst ablehnten. Die Zollunion trat nach einer spannenden Abstimmung im EP (im Dezember 1995) am 1. Januar 1996 in Kraft. Somit ist die Türkei das erste (und das einzige) Land, das der Zollunion beigetreten ist, ohne Vollmitglied in der EU zu sein.

Doch weder die errichtete Zollunion noch das lang währende Assoziationsverhältnis waren für die EU vorerst ein ausreichendes Argument, um die Türkei in die Erweiterungspläne mit einzubeziehen. Auf dem Luxemburger Gipfeltreffen 1997, bei dem die von der Kommission vorgeschlagene Agenda 2000 angenommen wurde, verschob man die Möglichkeit einer Vollmitgliedschaft der Türkei auf unbestimmte Zeit. Die Türkei wurde nicht in die Liste der Beitrittskandidaten aufgenommen. Als Ergebnis des luxemburgischen Gipfeltreffens wurden der Türkei lediglich regelmäßige Konsultationen angeboten (vgl. Europäischer Rat 1997). Die Ablehnung durch die EU löste starke Enttäuschung in der Türkei aus, die sich auch in der Ankündigung von Ministerpräsident Mesut Yılmaz äußerte, die Beziehungen der Türkei zur EU auf politischer Ebene abzubrechen.

\section{Rolle Deutschlands}

Bei der Zuerkennung des Kandidatenstatus durch die EU 1999 war die deutsche Regierung eine treibende Kraft. 1999 hatte sie nicht nur die historische Chance eines EU-Beitritts der Türkei 
erkannt, sondern auch den besonderen Beziehungen zwischen Deutschland und der Türkei Rechnung getragen. Diese besonderen Beziehungen basieren auf einer humanen Dimension. Nirgendwo auf der Welt außerhalb der Türkei sind Türken zahlenmäßig so stark vertreten wie in Deutschland. Mit rund 2,6 Millionen (incl. Eingebürgerte) leben die meisten von insgesamt 3,6 Millionen Türken außerhalb der Türkei heute in Deutschland. Unter den 7,3 Millionen Ausländern in Deutschland bilden Türken mit einer Bevölkerungsanteil von rund 27 Prozent mit weitem Abstand die größte Gruppe. Nach Schätzungen des Zentrums für Türkeistudien sind derzeit über 700.000 bereits eingebürgert.

2001 jährte sich der Beginn der Migration der größten in Deutschland lebenden Zuwanderergruppe zum vierzigsten Mal. Ein beträchtlicher Teil der türkischstämmigen Menschen, nämlich rund 37 Prozent (714.000) ist inzwischen in Deutschland geboren und kennt die Türkei nur aus Erzählungen und von Reisen. Mehr als die Hälfte der Erwachsenen ist bereits länger als 20 Jahre hier. Die anfänglich homogene Gruppe, die mehrheitlich aus Männern und Arbeitern bestand, befindet sich in einer Phase der soziodemographischen Ausdifferenzierung. Aufgrund der Erhöhung des Bildungsniveaus und der Verbesserung des beruflichen Standes steigt die zweite Generation in die Mittel- und Oberschicht auf. Heute studieren an deutschen Hochschulen mehr als 30.000 junge Türkinnen und Türken. Diese gerade heranreifende akademische Generation wird in Zukunft in anspruchsvolleren Positionen repräsentiert sein. Die Veränderung im gesellschaftlichen Status wurde auch mit Hilfe von ausländischen Existenzgründern eingeleitet. Das Zentrum für Türkeistudien schätzt die Zahl der türkischen Selbständigen auf rund 60.000. Die türkischen Unternehmer, die sich in verschiedenen Branchen etabliert haben, bieten nicht mehr nur klassische Dienstleistungen für ihre eigene Subgesellschaft, sondern nehmen sich auch den Markt des Zuwanderungslandes als Zielgruppe und etablieren dort ihre erfolgreichen Firmen. In ihren Betrieben werden 327.000 Menschen beschäftigt. Die türkischen Unternehmen sind zugleich eine wichtige Stütze der intensiven deutsch-türkischen Handelsbeziehungen. Beide Länder haben ein Außenhandelsvolumen von jährlich über zehn Milliarden Euro. 


\begin{tabular}{|l|l|l|l|}
\hline \multicolumn{5}{|l|}{ Entwicklung des deutschen Außenhandels mit der Türkei (Millionen EUR) } \\
\hline & Importe in die Türkei & Exporte aus der Türkei & Saldo \\
\hline $\mathbf{1 9 9 7}$ & $7.039,7$ & $5.074,4$ & $1.965,2$ \\
\hline $\mathbf{1 9 9 8}$ & $6.968,1$ & $5.489,2$ & $1.478,9$ \\
\hline $\mathbf{1 9 9 9}$ & $5.877,4$ & $5.663,9$ & 213,5 \\
\hline $\mathbf{2 0 0 0}$ & $8.340,6$ & $6.201,8$ & $2.138,8$ \\
\hline $\mathbf{2 0 0 1}$ & $6.005,8$ & $6.547,1$ & $-541,3$ \\
\hline $\mathbf{2 0 0 2}$ & $5.313,1$ & $5.028,3$ & 284,8 \\
\hline $\begin{array}{l}\text { Quelle: Statistisches Bundesamt, Landesamt für Datenverarbeitung und Statistik NRW, } \\
\text { Zentrum für Türkeistudien }\end{array}$
\end{tabular}

\begin{tabular}{|c|c|c|c|c|c|c|}
\hline \multicolumn{7}{|c|}{ Wirtschaftskraft der türkischen Selbstständigen in Deutschland } \\
\hline \multirow{2}{*}{ Indikator } & \multicolumn{6}{|l|}{ Jahr } \\
\hline & 1985 & 1990 & 1995 & 2000 & 2001 & 2002 \\
\hline Anzahl & 22.000 & 33.000 & 40.500 & 59.500 & 58.000 & 56.800 \\
\hline $\begin{array}{l}\text { Durchschnittliche Investition } \\
\text { pro Betrieb (in Euro) }\end{array}$ & 88.400 & 88.400 & 104.800 & 116.600 & 118.000 & 115.300 \\
\hline $\begin{array}{l}\text { Gesamtinvestitionsvolumen } \\
\text { (Mrd. Euro) }\end{array}$ & 1,9 & 2,9 & 4,2 & 6,9 & 6,8 & 6,5 \\
\hline $\begin{array}{l}\text { Durchschnittlicher Umsatz } \\
\text { pro Betrieb (in Euro) }\end{array}$ & 400.000 & 387.600 & 429.500 & 478.600 & 467.000 & 458.200 \\
\hline $\begin{array}{l}\text { Jährlicher Gesamtumsatz } \\
\text { (Mrd. Euro) }\end{array}$ & 8,8 & 12,8 & 17,4 & 28,5 & 27,1 & 26,0 \\
\hline Beschäftigte pro Betrieb & 3,5 & 3,3 & 4,1 & 5,5 & 5,3 & 5,1 \\
\hline Beschäftigung insgesamt & 77.000 & 100.000 & 168.000 & 327.000 & 307.000 & 290.000 \\
\hline
\end{tabular}

Ein anderer Bereich, in dem die türkischen Migranten immer mehr in den Vordergrund treten, ist die Politik. Eine Reihe von Personen türkischer Herkunft sind mittlerweile in vielen Kommunal- und Länderparlamenten sowie auch im Europaparlament und in den Vorständen von politischen Parteien aktiv. Migranten in entscheidenden Positionen haben die Möglichkeit, bestehende Vorurteile abzubauen und einen Beitrag dazu zu leisten, dass ein realistisches Bild über Türken und die Türkei gezeichnet wird. Diese Personen haben gleichzeitig eine Vorbildfunktion für die kommenden Generationen und spielen demzufolge eine motivierende Rolle bei Integration und aktiver Teilnahme an der Gesellschaft.

Türkische Migranten in Deutschland versprechen sich von einem Beitritt ihres Herkunftslandes zur EU mehr soziale Anerkennung und eine Stärkung ihrer europäischen Identität. Die 
EU-Integration der Türkei kann mithin auch als innerstaatlicher Integrationsprozess in Deutschland verstanden werden.

Die Gastarbeitermigration ist indessen nicht das einzige denkwürdige Ereignis in der jüngeren deutsch-türkischen Geschichte. Auch die wissenschaftlichen Beziehungen haben das deutsch-türkische Verhältnis maßgeblich geprägt. Die Türkei war während der Nazizeit 1933-1945 selbst Migrationsziel hunderter Wissenschaftler und Künstler aus dem Deutschen Reich, die, in ihrer Heimat verfolgt, auf Einladung der türkischen Regierung an der Modernisierung der Gesellschaft mitwirkten. Einige von ihnen blieben auch danach in der Türkei, weil sie dort eine neue Heimat gefunden hatten. Diese leisteten durch ihre Beratungs- und Lehrtätigkeiten beispielsweise bei der Gründung der Universitäten, innerhalb des Staatsapparates und bei der Städteplanung einen wichtigen Beitrag zum Aufbau der modernen Türkei. Zeitweise waren bis zu 70 Deutsche in Istanbul und Ankara im Hochschulbetrieb beschäftigt und haben vor allem die Bereiche Medizin (Erich Frank, Rudolf Nissen, Phillip Schwartz), Rechts- und Wirtschaftswissenschaften (Ernst E. Hirsch, Fritz Neumark, Ernst Reuter), Architektur (Gustav Oelsner, Clemens Holzmeister) und Musik (Paul Hindemith, Eduard Zuckmayer, Ernst Prätorius) dauerhaft geprägt. Nach der Befreiung Deutschlands pflegten sie auch nach ihrer Rückkehr intensiven Kontakt zu ihrem ehemaligen Exil. Kurzum: Deutsche Technologie, deutsche Wissenschaftler, Architekten, Ingenieure und Fachleute haben überall in der Türkei ihre Spuren hinterlassen. Das beste Beispiel hierfür liefert die Bagdad-Bahn, die von Istanbul bis Bagdad, quer durch die Türkei mit deutscher Technologie und durch deutsche Fachleute errichtet wurde.

\section{Die Türkei als Beitrittskandidat}

Erst vierzig Jahre nach der Antragstellung auf Assoziierung erhielt die Türkei beim Gipfeltreffen der EU-Staats- und Regierungschefs am 10./11. Dezember 1999 in Helsinki den offiziellen Status eines Beitrittskandidaten zur Europäischen Union (vgl. Europäischer Rat 1999). Durch die Entscheidung auf dem Gipfel von Helsinki, die Türkei als Kandidaten anzuerkennen, 
konnte die politische Eiszeit, die seit dem Gipfel von Luxemburg 1997 angebrochen war, überwunden werden.

Der Kandidatenstatus hat die Türkei selbst spürbar und nachhaltig verändert. Im März 2001 verabschiedete das türkische Kabinett sein nationales Programm, welches einen Zeitplan beinhaltete, in dem sich die Türkei zur Erfüllung der im Rahmen des Beitrittspartnerschaftsdokuments der EU erwarteten Reformen verpflichtete. Von diesem Zeitpunkt an machte die Türkei bei der Erfüllung der EU-Beitrittskriterien von Kopenhagen beachtliche Fortschritte. ${ }^{1}$

Hierzu gehören umfangreiche Gesetzesnovellen, insbesondere die Verfassungsreform, die im Oktober 2001 vom Parlament verabschiedet wurde. Ihr folgte im November 2001 eine umfangreiche Zivilrechtsnovelle, die insbesondere die Rechte der Frauen nachhaltig gestärkt hat. Den Anforderungen an die neue Verfassung genügen insbesondere das Anfang August 2002 vom Parlament verabschiedete Gesetzespaket, das zugleich einen wichtigen Durchbruch zur Erfüllung der politischen Beitrittskriterien von Kopenhagen darstellt: die Abschaffung der Todesstrafe, die Gewährung muttersprachlichen Unterrichts in anderen als der offiziellen Amtssprache sowie die Zulassung kurdisch- oder anderssprachiger Rundfunk- und Fernsehprogramme. Hinter diesem für die Türkei rasanten Reformtempo stand der Zeitdruck, vor der bevorstehenden Erweiterung der EU um zehn Staaten, ihre Beitrittsperspektiven durch den Beginn von Betrittsverhandlungen sichern zu wollen.

Die historische Einigung Europas auf dem Gipfel von Kopenhagen 2002, mit der bislang größten Erweiterung um zehn Staaten ab Mai 2004, hat die Verhältnisse innerhalb Europas, aber auch die Beziehungen zu Drittstaaten, stark geändert. Auch hieraus erklärte sich das Bemühen der Türkei, so schnell als möglich mit den Beitrittsverhandlungen zu beginnen. Jede Erweiterung der EG/EU, zuerst der Beitritt Griechenlands, aber auch Spaniens und Portugals, verschlechterte die Mitgliedschaftsperspektiven der Türkei. Dies dürfte für die Türkei nach der vollzogenen Erweiterung noch stärker gelten. Entsprechend war die Türkei mit dem Beschluss des EU-Rates in Kopenhagen nicht zufrieden. Darin rief die Union 
»die Türkei auf, ihren Reformprozess energisch voranzutreiben. Entscheidet der Europäische Rat im Dezember 2004 auf der Grundlage eines Berichts und einer Empfehlung der Kommission, dass die Türkei die politischen Kriterien von Kopenhagen erfüllt, so wird die Europäische Union die Beitrittsverhandlungen mit der Türkei ohne Verzug eröffnen« (Europäischer Rat 2002: Ziff. 19).

Die Hinauszögerung des Beschlusses in den Dezember 2004 bedeutete, dass die Beitrittsverhandlungen erst nach Aufnahme der anderen Kandidaten beginnen würden, wodurch sich die Rahmenbedingungen für die Türkei verschlechterten. Mit der ersten Runde der Erweiterung treten zehn neue Mitgliedsstaaten in den internen Ressourcenkampf ein, wodurch der Platz für einen weiteren großen Netto-Empfänger noch enger wird.

Aber der Kopenhagener Beschluss zeigte eine - wenn auch nicht sehr klare - Perspektive. Darüber hinaus wird in Ziffer 18 des Beschlusses unterstrichen, dass die Türkei laut »1999 in Helsinki gefasstem Beschluss ein beitrittswilliges Land ist, das auf der Grundlage derselben Kriterien, die auch für die übrigen beitrittswilligen Länder gelten, Mitglied der Union werden soll« (Ebd.: Ziff. 18).

Somit erübrigte sich immerhin die Debatte über die Grenzen Europas bzw. die kulturelle und geographische Zugehörigkeit der Türkei zu Europa. Nach weiteren Reformen, insbesondere der Strafrechtsnovelle, empfahl die Europäische Kommission im Oktober 2004 den Beginn von Beitrittsverhandlungen, der im Dezember von den Regierungschefs beschlossen wurde.

Mit dem politischen Machtwechsel und der Erosion in der Parteienlandschaft der Türkei im November 2002 waren sowohl Chancen als auch Risiken für die weitere EU-Annäherung des Landes verbunden. Die Tatsache, dass nur noch zwei Parteien im Parlament vertreten sind, hat für politische Stabilität gesorgt. Auch die Fähigkeit der AKP, die notwendige Mehrheit zur weiteren Reformierung der Verfassung zustande zu bringen, hat zu Fortschritten im Lande geführt. Bisher wurde der Reformprozess fortgesetzt, so durch die Beschneidung der Kompetenzen des Nationalen Sicherheitsrats - ein wichtiger Schritt zur Behebung des Demokratiedefizits im Land. Wenn es der AKP gelingen sollte, sich vom Außenrand der konservativreligiösen Linie zu lösen und sich erfolgreich im Spektrum Mit- 
te-Rechts zu positionieren, könnte der jetzige Wechsel auch eine allgemeine Stabilisierung des Parteiensystems mit sich bringen. Mit der neuen Konstellation ist auch die Chance auf die Relativierung der gesellschaftlichen Polarität zwischen laizistischen und religiös orientierten Schichten verbunden. Günstigstenfalls kann sich eine Interessenidentität zwischen der Erfüllung der EU-Beitrittskriterien und dem eigenen Streben der AKP nach einem Mehr an religiöser Freiheit ergeben. Die mit dem Machtwechsel verbundenen Risiken ergeben sich aus der Gefahr, dass die AKP ihren Bekundungen nicht folgt und einen Kurs nicht des Pluralismus, sondern der Islamisierung einschlägt. Gleiches gilt, wenn sie den Fehler wiederholt, den nahezu alle Vorgänger machten: Die Durchsetzung der staatlichen Administration mit eigenen Parteimitgliedern. Gerade die Durchsetzung der Bürokratie mit stark religiös orientieren Personen würde die ohnehin bestehenden europäischen Vorbehalte gegen die Aufnahme der Türkei in die EU in beträchtlichem Umfang aktivieren und auch den sozialen Frieden in der Türkei gefährden.

\section{Gegenseitige Perzeptionen}

Es ist berechtigt, auch weiterhin darauf hinzuweisen, dass Reformgesetze in der Türkei nicht allein auf dem Papier stehen dürfen, sondern auch umgesetzt werden sollten. So wurde etwa der Einfluss des Nationalen Sicherheitsrates auf die Exekutive stark beschnitten - es bestehen indessen Zweifel, ob das Gremium nicht weiter arbeitet wie bisher. Zahlreiche andere Beispiele, insbesondere aus Justiz- und Polizeiapparat, streuen Zweifel an der konsequenten Umsetzung der rechtsstaatlichen Reformen der letzten Jahre. Nur scheint angesichts des Reformeifers der Erdoğan-Regierung absehbar, dass auch diese Probleme bewältigt werden. Dann würde nur noch die ungelöste Zypernfrage der türkischen Forderung nach der Aufnahme von Beitrittsverhandlungen im Wege stehen. Mittelfristig drohen den Gegnern eines EU-Beitritts der Türkei also die Argumente auszugehen.

Indessen muss sich die türkische Regierung mit einer neuen Argumentationslinie gegen den Beitritt auseinandersetzen: Immer weniger ist bei den Beitrittsgegnern von der fehlenden 
EU-Reife des Landes die Rede und umso mehr von der fehlenden Integrationsfähigkeit der EU.

Vielleicht ist die EU der 25 bereits ein überdehntes, handlungsunfähiges Gebilde, das seine geographische Ausdehnung auf Kosten der Vertiefung der Integration betrieben hat?

Nur: Eine Partnerschaft zwischen EU und Türkei besteht bereits aufgrund des Assoziierungsabkommens von 1963 und der Zollunion von 1996. Sie kann aber nur ein Übergangsstadium sein, da sie immer als Vorstufe zu einer späteren Vollmitgliedschaft verstanden wurde. Die Vorstellung, es könnte eine dauerhafte Alternative zu einer Vollmitgliedschaft geben, ignoriert die Realitäten im Europäischen Einigungsprozess. Stehen einem Land nicht theoretisch alle Integrationsschritte offen, so machen die Beziehungen nicht viel Sinn. Auch die Zollunion wurde nur verwirklicht, weil die Türkei auf die langfristige Kompensation der ihr aus dem Abkommen erwachsenen Nachteile nach einem Beitritt hofft. Die Idee der "privilegierten Partnerschaft« stellt also aus türkischer Sicht die Grundlage der Zusammenarbeit in Frage.

Die öffentliche Meinung in Deutschland sieht einen Beitritt der Türkei inzwischen aber durchaus differenziert: Der mittelfristige Beitritt der Türkei zur EU wird von zwei Dritteln der Deutschen unterstützt. Nach einer repräsentativen Befragung des Zentrums für Türkeistudien vom Herbst 2003 unter 1000 Deutschen machen 58 Prozent die Aufnahme der Türkei aber von der Erfüllung von Voraussetzungen abhängig. Für eine kurzfristige Aufnahme sprechen sich nur acht Prozent aus. Ein Drittel der Deutschen (30 Prozent) ist auch dann gegen die Aufnahme der Türkei, wenn sie die Voraussetzungen für einen Beitritt erfüllt. Die überwiegende Mehrheit der Deutschen von 85 Prozent möchte die Diskussion über den EU-Beitritt der Türkei nicht zum Wahlkampfthema gemacht sehen. 

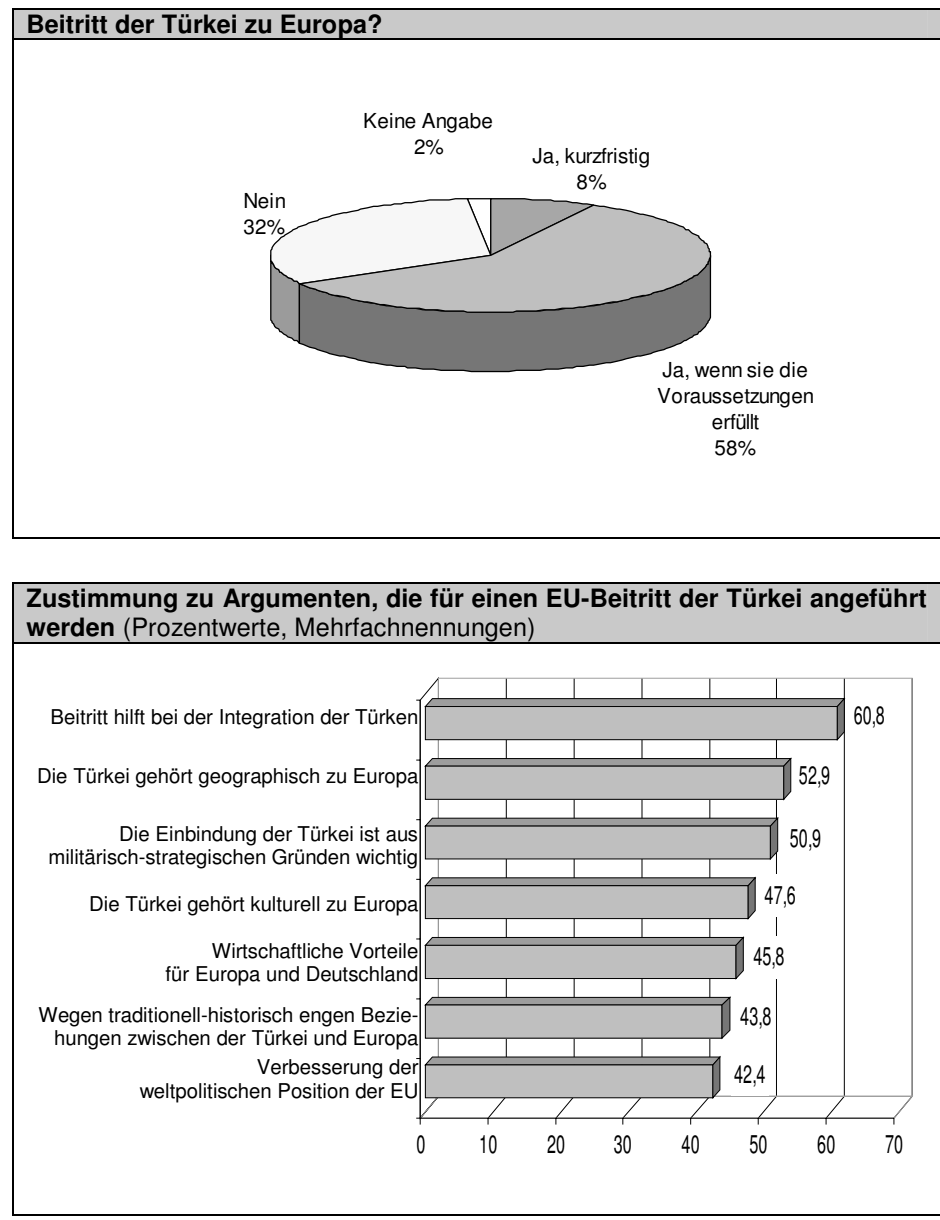

Allerdings relativiert sich diese positive Haltung der Deutschen zum EU-Beitritt der Türkei, stellt man das Modell der Partnerschaft mit besonderen Privilegien, wie es seit kurzem von der CDU vertreten wird, als Alternative daneben. Immerhin 57 Prozent bevorzugen auf Nachfrage zu beiden Optionen die Partnerschaft als den besseren Weg.

Argumente, die aus der Sicht der Deutschen für einen Beitritt sprechen, sind an erster Stelle mit 61 Prozent eine verbesserte Integration der Türken in Europa - eine bemerkenswerte Angabe; für 53 Prozent ist die geographische Zugehörigkeit der 
Türkei ein Argument für die Aufnahme und 51 Prozent halten die Aufnahme der Türkei aus militärisch-strategischen Gründen für wichtig. Eine kulturelle Zugehörigkeit der Türkei zu Europa sehen allerdings nur 48 Prozent, wirtschaftliche Vorteile für Europa erwarten 46 Prozent. Bezüglich des so wichtigen Pro-Arguments der Integration der in Deutschland lebenden Türken erwarten auf spezielle Nachfrage immerhin 51 Prozent positive Impulse durch den EU-Beitritt der Türkei, 39 Prozent erwarten keine Auswirkungen, acht Prozent sogar negative Folgen. Insbesondere die Befürworter des Beitritts erhoffen sich hier wesentliche Fortschritte.

Das Argument, das nach Ansicht der Deutschen am stärksten gegen den Beitritt spricht, ist die von zwei Dritteln als mangelhaft eingestufte Menschenrechtslage und Demokratisierung. 60 Prozent sind der Meinung, die innenpolitische Lage der Türkei sei aufgrund der Gefahr von Extremismus und Fundamentalismus zu unsicher, fast ebenso viele sind der Ansicht, der Einfluss des Militärs sei zu hoch. Somit beziehen sich die Contra-Argumente in erster Linie auf die innenpolitische Situation der Türkei. Allerdings sehen auch 52 Prozent die Region als zu unsicher an. Darüber hinaus befürchtet die Hälfte der Befragten wirtschaftliche Nachteile, 50 Prozent haben Angst vor einem Zustrom türkischer Arbeitssuchender nach Deutschland und 45 Prozent erwarten wirtschaftliche Nachteile durch zu hohe Kosten, die der Beitritt der Türkei verursachen würde. Deutlich wird hier, dass wirtschaftliche Argumente eher eine Nebenrolle spielen.

Gegner und Befürworter des Beitritts der Türkei zur EU unterscheiden sich erwartungsgemäß generell darin, dass die Gegner den Pro-Argumenten in geringerem Maß und den Contra-Argumenten in höherem Maß zustimmen als die Befürworter. Allerdings unterscheidet sich die Rangfolge der Pround Contra-Argumente nur wenig bei Gegnern und Befürwortern. Lediglich die Angst vor zu vielen Arbeitssuchenden hat bei den Gegnern ein deutlich höheres Gewicht als bei den Befürwortern. Nicht unterschätzt werden darf das Ergebnis, dass auch eine Mehrheit der Befürworter des Beitritts die innenpolitische Situation der Türkei (Menschenrechte, Demokratie, Extremismus und Einfluss des Militärs) als bedenklich einstuft. 
70 Prozent der Deutschen sind der Ansicht, dass die Zugehörigkeit zu einer Religions- oder Kulturgemeinschaft keinen Einfluss auf die Aufnahme in die EU haben sollte, wobei dennoch gut ein Viertel der Meinung ist, die Türkei sollte nicht aufgenommen werden, weil sie eine islamische Bevölkerungsmehrheit hat. Somit vertritt nur eine kleine Minderheit der Deutschen das Bild eines durch die christlich-abendländische Kultur geprägten Europas. Selbst die Mehrheit derjenigen, die die Türkei kulturell nicht als zugehörig zu Europa definieren, sieht darin keinen Grund, sie nicht in die EU aufzunehmen.

Dennoch scheint bei einem Teil der Gegner des Beitritts die kulturell-religiöse Andersartigkeit der Türkei und der in Deutschland lebenden Türken sowie eine implizierte Integrationsunfähigkeit neben den innenpolitischen Argumenten eine nicht unbedeutende Rolle für die Ablehnung des EU-Beitritts der Türkei zu spielen: Gegner des Beitritts lehnen zu 56 Prozent den Beitritt aufgrund der islamischen Bevölkerungsmehrheit der Türkei ab. Mehr als drei Viertel der Gegner des Beitritts sind der Ansicht, die Türkei gehöre kulturell nicht zu Europa und sollte deshalb nicht aufgenommen werden. Ebenso viele formulieren als Ablehnungsgrund des Beitritts die Angst vor zu vielen Arbeitssuchenden. Darüber hinaus erhoffen sich nur ein Viertel der Gegner durch den Beitritt positive Auswirkungen auf die Integration der in Deutschland lebenden Türken.

Somit relativiert sich die Bedeutung der innenpolitischen Zustände in der Türkei, die von den Gegnern des Beitritts als Ablehnungsgründe angeführt werden. Immerhin die Hälfte von ihnen scheint das Leitbild der christlich-abendländischen Kulturgemeinschaft, die Europa ausmacht, zu vertreten. Auch die Angst vor weiterem Zuzug und die Einschätzung einer geringen Integrationsfähigkeit der Türken in Deutschland kommen bei den Gegnern durchaus zum Tragen. Wirtschaftliche Argumente spielen sowohl bei Gegnern als auch bei Befürwortern eine untergeordnete Rolle.

Generell stößt die Erweiterung der EU auf eine breite $\mathrm{Zu}$ stimmung unter den Deutschen, eine Beschränkung der EU auf die Kernstaaten befürwortet lediglich ein Drittel. Gut zwei Drittel der Befragten stimmen der Erweiterung $2004 \mathrm{zu}$; auch die Aufnahme von Bulgarien und Rumänien 2007 wird mehrheitlich unterstützt, wobei hier mehr Skepsis herrscht, insbesondere 
gegenüber Rumänien, dessen Aufnahme immerhin 42 Prozent ablehnen (vgl. Goldberg 2003).

\section{Wirkung eines türkischen Beitritts auf den EU-Haushalt}

Veränderungen beim Beitritt neuer Mitglieder zur Union sind insbesondere in fünf Bereichen von Belang: im Kräfteverhältnis in den EU-Organen, im zwischenstaatlichen Handel, in der gemeinsamen Außen- und Sicherheitspolitik, bei der Arbeitskräftemigration innerhalb der Union sowie bei der Struktur der Einnahmen und Ausgaben im EU-Haushalt. Welche Veränderungen würde der türkische Beitritt zum jetzigen Zeitpunkt bewirken? In das Europäische Parlament würde die Türkei, entsprechend dem auf dem »Reformgipfel « von Nizza festgelegten Schlüssel, 74 Abgeordnete entsenden und sie würde im Rat - analog zu den anderen großen EU-Staaten - 29 Stimmen besitzen. Zudem würde sie einen Kommissar, permanent oder nach Rotationsprinzip, stellen. Die Entscheidungsstrukturen würden mithin verändert, aber nicht umgeworfen. Beim zwischenstaatlichen Handel brächte der türkische Beitritt keinerlei Neuerung - eine Zollunion für Güter zwischen EU und Türkei besteht bereits seit 1996. In der heiklen Frage der Freizügigkeit der Arbeitskräfte können lange Übergangsfristen festgelegt werden, wie es auch bei den osteuropäischen Beitrittsstaaten der ersten Erweiterungsrunde der Fall ist. Für eine gemeinsame Sicherheits- und Verteidigungspolitik indessen wäre ein türkischer Beitritt durchweg positiv. Die Entwicklung einer gemeinsamen Europäischen Sicherheitspolitik würde deutlich erleichtert, wenn die Türkei nicht länger als NATO-Mitglied ohne Zugehörigkeit zur EU zwischen den transatlantischen Stühlen säße. Die EU-Integration der Türkei würde zuvorderst die Stärkung der europäischen Position im transatlantischen Bündnis bedeuten.

Zum Dreh- und Angelpunkt der Beitrittsfrage wird damit, was die pragmatischen Argumente anbetrifft, das Finanzierungsproblem. Vor dem Hintergrund der Tatsache, dass die Preisgarantie für Agrarprodukte den mit Abstand größten Posten im EU-Haushalt ausmacht, kann man mit Recht darüber 
nachdenken, ob die Türkei als ein in Teilen noch stark agrarisch geprägter Staat von beträchtlicher Größe die EU vor weitere Probleme stellen wird. Entsprechend hat die Debatte um den EU-Beitritt der Türkei zahlreiche Schätzungen und Modellrechnungen evoziert, die teils zu sehr unterschiedlichen Einschätzungen gekommen sind. Die Tageszeitung »Die Welt« bezifferte die Kosten 2002 auf jährlich 20 Milliarden Euro. Das Münchner Ost-Europa-Institut kam im Januar 2004 in einer Modellrechnung auf eine Zahl von 14 Milliarden Euro jährlich, die Brüsseler »Friends of Europe « auf 15 Milliarden Euro. Unterschiede zwischen den Ergebnissen sind insbesondere in den unterschiedlich angesetzten Strukturfondszahlungen begründet.

Alle Modellrechnungen stehen unter dem Vorbehalt einer Veränderung dieser Größen zum Zeitpunkt eines tatsächlichen Beitritts. Sie stehen ferner unter dem Vorbehalt des politischen Einigungsprozesses im Zuge von Beitrittsverhandlungen, die zu Umverteilungen im EU-Haushalt führen. Als Orientierungsgröße für die Beantwortung der Frage nach der prinzipiellen fiskalischen Machbarkeit eines türkischen Beitritts sind Modellrechnungen aber gleichwohl geeignet.

Um eine Integration der Türkei in die Union zu ermöglichen, werden einige europäische Politikfelder nicht ohne weitere Reformen auskommen. Diese würden besonders in der Agrarpolitik notwendig - schlicht weil sie den mit weitem Abstand größten Posten im Unionshaushalt beansprucht. Alle finanziellen Probleme des Beitritts neuer Mitglieder zur Union sind primär Probleme der gemeinsamen Agrarpolitik. Der Blick auf die jüngere Entwicklung weist die Befürchtung, dass die EU tatsächlich an die Grenzen ihrer Leistungsfähigkeit kommen könnte, aber eher als self-fulfilling prophecy denn als Argument gegen die Aufnahme neuer Mitglieder aus. Der Kompromiss im Agrarrat vom Juni 2003, der die Entkopplung von Produktionsmenge und Beihilfen in die gemeinsame Landwirtschaftspolitik eingeführt, am bestehenden Interventions- und Preisstützungssystem aber im Grundsatz nicht gerüttelt hat, war gerade eben ausreichend, um den Beitritt der zehn Kandidaten zum 1. Mai $2004 \mathrm{zu}$ finanzieren. Anders herum betrachtet: Eine grundlegende Reform des insbesondere für die europäischen Verbraucher ausgesprochen nachteiligen Systems der Interventi- 
onspreise für Agrarprodukte birgt ein beträchtliches Potential für die sogar kostenneutrale Aufnahme weiterer Mitglieder. Allerdings werden tief greifende Reformen im Europa der 25 nicht wahrscheinlicher - was bereits der gescheitere Verfassungsgipfel angedeutet hat. Die Türkei könnte mithin - will sie dem Finanzierungsargument der Beitrittsgegner aus dem Weg gehen - darauf angewiesen sein, dass das bestehende System der Preisstützung für landwirtschaftliche Produkte in den nächsten Jahren aus sich heraus kollabiert, im Rahmen des WTO-Prozesses gemildert oder aufgrund der nicht mehr tragbaren Fehlallokation von Ressourcen reformiert wird.

\section{Fazit}

Als problematisch erweisen sich diejenigen Fragen, die auch ohne einen Beitritt der Türkei zu den zentralen politschen Herausforderungen der Union in den nächsten Jahren gehören werden: die Fortentwicklung der internen Entscheidungsstrukturen sowie das den Großteil des Haushalts verschlingende Preisstützungssystem für Agrarprodukte. Insbesondere die Finanzierungsfrage könnte entscheidend für den Beitritt sein. Allerdings wird deutlich, dass bei der Frage nach dem EU-Beitritt der Türkei eben nicht nur die Reformfähigkeit des Beitrittskandidaten, sondern auch die Erneuerung der EU-Strukturen angesprochen ist.

Es geht beim EU-Beitritt der Türkei um eine nicht weniger historische Entscheidung als bei der Überwindung der OstWest-Teilung Europas. Die Konflikte des 21. Jahrhunderts, die viel beschworene Rivalität zwischen Kulturen und Religionen, finden ihr potentielles Schlachtfeld auch auf dem europäischen Kontinent. Die Kriege im ehemaligen Jugoslawien könnten erste Vorboten gewesen sein. Die Einbeziehung der muslimisch geprägten Türkei in den europäischen Einigungsprozess würde weitere solche Auseinandersetzungen im Keim ersticken, und dies bleibt das Hauptargument für den EU-Beitritt der Türkei. 


\section{Anmerkungen}

1 Die Kopenhagener Kriterien im Wortlaut: »Membership requires that the candidate country has achieved stability of institutions guarenteeing democracy, the rule of law, human rights and respect for and protection of minorities, the existence of a functioning market economy as well as the capacity to cope with competitive pressure and market forces within the union, and has the ability to take on the obligations of membership, including adherence of the aims of political, economic and monetary union« (Copenhagen criteria 2002).

\section{Literatur}

Ankara Agreement (1963): »Agreement establishing an Association between the European Economic Community and Turkey; signed at Ankara, 12 September 1963«, in: Official Journal of the European Communities, No L 361/8.

Copenhagen Criteria (2002): The Copenhagen European Council and the Copenhagen criteria.

EG-Kommission (1987): 23. Gesamtbericht, Brüssel.

Europäischer Rat (1997): Schlussfolgerungen des Vorsitzes. Europäischer Rat (Luxemburg), 12. und 13. Dezember 1997, online unter http:/ /europa.eu.int/european_council/conclusions/index_de.htm.

Europäischer Rat (1999): Schlussfolgerungen des Vorsitzes. Europäischer Rat (Helsinki), 10. und 11. Dezember 1999; online unter http:/ /europa.eu.int/european_council/conclusions/index_de.htm.

Europäischer Rat (2002): Schlussfolgerungen des Vorsitzes, Europäischer Rat (Kopenhagen), 12. und 13. Dezember 2002, online unter http://europa.eu.int/european_council/conclusions/index_de.htm.

Goldberg, Andreas (2003): Repräsentativbefragung zur Einstellung der deutschen Bevölkerung zum EU-Beitritt der Türkei, Essen. 


\title{
Der Türkei-Beitritt zerstört die Europäische Union
}

\author{
HANS-ULRICH WEHLER
}

Die erste fatale Entscheidung ist im Herbst 2004 gefallen: Die Hohe Kommission zu Brüssel hat die Aufnahme von Beitrittsverhandlungen mit der Türkei empfohlen. Im Dezember haben die Regierungschefs der EU-Staaten, das schwächste Geschlecht von Europapolitikern im letzten halben Jahrhundert, dieselbe Entscheidung getroffen. Offen ist dann zwar noch, wann die Verhandlungen beginnen werden, da zumal der französische Staatspräsident Chirac wegen einer Belastung des anstehenden Referendums über die europäische Verfassung einen möglichst späten Termin wünscht. Doch bisher haben solche Verhandlungen stets zur Aufnahme der Kandidaten in die Europäische Union geführt. Die EU würde damit einen muslimischen Großstaat kooptieren, der das ärmste, wegen seiner Bevölkerungszahl zugleich aber auch das größte Mitgliedsland mit dem Anspruch auf eine Führungsrolle würde. Einen nichteuropäischen, kleinasiatischen, muslimischen Staat an die Spitze der EU zu katapultieren - das bedeutet einen fundamentalen Bruch mit der gesamten bisherigen Europapolitik.

Was aber gebietet eine nüchterne Bestandsaufnahme der Interessenlage der EU, auch und gerade der Bundesrepublik? Denn es steht großen Staaten nicht an, um Bismarcks berühmtes Diktum zu wiederholen, anders als nach Maßgabe ihrer Interessen zu handeln. Die These lautet: Kommt es zur Aufnahme 
der Türkei, würden damit vitale europäische und deutsche Interessen verraten. Das große Projekt der politischen Einigung Europas würde mutwillig zerstört.

Zunächst sollen aus Gründen der Fairness sechs Perspektiven erörtert werden, die eine protürkische Position begründen, deshalb aber auch erste Einwände hervorrufen.

1. Unstreitig liegt es im europäischen und deutschen (überhaupt im westlichen) Interesse, dass das Experiment der Demokratiegründung und -verankerung endlich einmal auch in einem islamischen Land und auf lange Sicht eine Immunisierung gegen den islamistischen Fundamentalismus gelingt. Deshalb verdient es wirksame Unterstützung. Im Vergleich kommt zurzeit am ehesten die türkische Republik für diese politische Modernisierung in Frage. Gelänge das Experiment, ginge davon eine ungleich attraktivere Vorbildwirkung im Nahen Osten, darüber hinaus vielleicht in der muslimischen Welt überhaupt aus als von den Demokratisierungsillusionen des amerikanischen Präventivkriegs im Irak. Die offene Frage ist jedoch, ob diese Entwicklung zu einer auf Dauer stabilen demokratischen Republik innerhalb der EU gefördert werden muss oder ob sie nicht ebenso gut von außen, zudem mit weitaus geringeren Kosten jeder Art, unterstützt werden kann.

2. Mit diesem Argument hängt die Behauptung eng zusammen, dass die westlich orientierten türkischen Funktions- und Machteliten ihre Annäherung an Europa nur dann auf lange Sicht erfolgreich fortsetzen könnten, wenn sie mit dem Anschluss an die EU belohnt würden. Diese Forderung hat einen leicht erpresserischen, ja ultimativen Charakter; sie ignoriert, dass solche Transformationsprozesse wie die Europäisierung der Türkei letztlich aus eigener Kraft gewollt und durchgesetzt werden müssen, und sie setzt sich stillschweigend über den gewaltigen Preis hinweg, der Europa dafür zugemutet wird.

3. Ein sehr grundsätzliches Argument besagt, dass die Globalisierung ohnehin alle nationalen Grenzen gewissermaßen verflüssigte. Die Dominanz inter- oder transnationaler Märkte und Kommunikationsnetze sei unaufhaltbar. Die überkommenen nationalstaatlichen Grenzen taugten zu einer plausiblen Unter- 
scheidung nicht mehr. Dieser oft euphorisch vertretenen Auffassung liegt jedoch ein gravierender Irrtum zu Grunde. Auch die Entstehung der globalisierten Welt als eines einheitlichen politischen und ökonomischen Aktionsfelds muss man sich, um realistisch zu bleiben, in Stufen vorstellen. Die EU verkörpert eine solche Stufe als historisch legitimierbarer Verband europäischer Staaten. Er beruht auf der Inklusion der europäischen und der Exklusion nichteuropäischer Staaten. Die nordamerikanische Freihandelszone, die ASEAN-Gruppe und ähnliche Verbindungen verkörpern ähnliche Stufen. Aus ihrer Kooperation könnte allmählich die Kantsche Weltgesellschaft und -politik entstehen, ohne dass sich die nationalstaatlichen Grenzen innerhalb der großen Machtaggregate gleich auflösten.

Das hiermit zusammenhängende Argument auch von Teilen der deutschen Wirtschaft, in der Türkei lasse sich ein riesiger Zukunftsmarkt gewinnen, erinnert an vergleichbare Illusionen in der Vergangenheit. Denn im ausgehenden 19. Jahrhundert sollte erst der vermeintlich riesige chinesische, dann der ebenso verlockende afrikanische Großmarkt die europäische und amerikanische Wirtschaft auf Dauer ankurbeln. Beides blieb eine Chimäre.

Die Statistik der Außenhandelsbeziehungen ist unwiderlegbar: Entwickelte Industrieländer sind füreinander die besten Kunden. Entwicklungsländer auf dem Weg in die Moderne absorbieren stets nur einen erstaunlich geringen Exportanteil.

4. Der viel beschworene geostrategische Wert der Türkei gebiete, heißt es insbesondere in Washington und in der NATO, der Türkei die Vollmitgliedschaft in der EU einzuräumen, um ihr beachtliches militärisches Potential - wie bis 1991 für die »Eindämmung" der Sowjetunion - einzubinden und bei künftigen Konflikten im Nahen Osten einsetzen zu können. Entsprechende Äußerungen aus Berlin erinnern freilich an die wilhelminische Großmannssucht der deutschen »Weltpolitik "von 1914. Diese Befürwortung entbehrt heutzutage nicht des Zynismus, da sie über das türkische Heer wie einen Landsknechthaufen verfügt.

Vor allem aber hat die Regierung Erdoğan mit ihrer Opposition gegen die Teilnahme am zweiten Irakkrieg unmissverständlich demonstriert, dass sie gegen muslimische Nachbarn 
nicht zum zweiten Mal Krieg führen will - und aus innerparteilicher Rücksichtnahme auf den Zusammenhalt und den islamistischen Charakter der "Gerechtigkeitspartei« (AKP) auch nicht führen kann. (Ohnehin wird oft vergessen, dass schon 1991 aus Protest gegen den ersten Irakkrieg der Außen- und der Verteidigungsminister sowie der Generalstabschef zurückgetreten sind.) Künftiger Streit im Nahen Osten involviert aber stets muslimische Staaten, ein simpler Tatbestand, der das vermeintlich durchschlagkräftige geostrategische Argument im Kern entwertet.

5. Bombastisch kommt das Argument daher, nur zusammen mit der Türkei könne die EU zur wahren Weltmacht werden - zum imponierenden Akteur, dessen Basis, wie sich Kommissar Verheugen ausdrückte, vom Nordkap bis zur irakischen Grenze reiche. Dabei handelt es sich um eine der Attacken jener Großmannssucht, unter denen die Berliner Politik in letzter Zeit öfters leidet. Da das schwierige Feld der Innenpolitik abschreckt, lässt sich, so die Erfahrung nicht nur mit der derzeitigen Regierung, auf dem Parcours der Außenpolitik unbeschwerter dem Pläneschmieden nachgehen. All dieses neumodische Weltmachtgerede hat man schon wortwörtlich vor 1914 gehört. Jetzt erlebt es eine irritierende Renaissance. Es passt aber zu dem enervierenden Kampf um einen deutschen Sitz im Sicherheitsrat der Vereinten Nationen - einen Schleudersitz und Feuerstuhl, von dem der gesunde Menschenverstand wegen der neuen Belastungen für die deutsche Politik strikt Abstand zu halten gebietet. Diese Prestigepolitik lenkt nur von den vorrangigen inneren Problemen ab. Und die aufgeblasene Weltmachtsemantik lenkt überdies davon ab, dass eine um die Türkei - demnächst ja noch um Rumänien, Bulgarien und Kroatien, vielleicht auch um die Ukraine und weitere Nachfolgestaaten des verblichenen Jugoslawiens - aufgeblähte EU zu gemeinsamer Außenund Sicherheitspolitik auf Grund überwältigender Heterogenität erst recht nicht im Stande sein wird.

6. Und schließlich wird immer wieder auf das seit 1962/63 wiederholte Versprechen verwiesen, das der Türkei den Anschluss an die damalige europäische Wirtschaftsgemeinschaft in Aussicht stellte. Ob damit auch die Einbeziehung in eine po- 
litische Staatenunion gemeint war, ist zumindest umstritten. Da es bereits eine Zollunion zwischen der EU und der Türkei gibt, wäre, wenn sie formell auch zur Freihandelszone erweitert würde, der Zusage des ökonomischen Anschlusses Genüge getan. Außerdem ist zum einen die Geschäftsgrundlage des Versprechens, der Kalte Krieg gegen die Sowjetunion, inzwischen entfallen, und zum anderen hat die Türkei fast vierzig Jahre lang buchstäblich nichts getan, um das Land allmählich europakompatibel zu machen.

Nach dem Blick auf die protürkischen Argumente ist hier noch eine Skizze der Motive der Europapolitik Ankaras am Platz, verbunden mit dem Hinweis auf überhaupt noch nicht in Angriff genommene Reformprobleme. Erdoğans AKP ist eine islamistische Partei, welche ihre Vorgänger unter Erbakans Leitung aufgesogen hat, zugleich aber den Protest der vernachlässigten anatolischen Peripherie gegen die urbanen Zentren der Türkei und ihre kemalistischen Eliten verkörpert. De facto kommt ihre Rolle einer Einparteienherrschaft gleich, die von europäischen Politikern auf einmal unverdient milde beurteilt wird. Was ergibt ein schlichtes Kosten-Nutzen-Kalkül für die Regierung Erdoğan?

Sie gewinnt mit dem Beitritt zur EU (ja schon mit den Beitrittsverhandlungen, die mit enormen Vor-Beitrittszahlungen aus Brüssel verbunden sind) den Zugang zu den attraktiven Finanzressourcen der EU. Sie gestatten u.a. die Bedienung der eigenen Klientel mit einem gewaltigen, Steuern vermeidenden Einkommen aus Brüssel. Allein die Gewährung der bisher üblichen Agrarsubventionen kommt nach Kommissionsberechnungen auf jährlich elf Milliarden Euro; die Gesamtzahlungen an die Türkei können nach dem Beitritt mindestens dreißig, wahrscheinlicher sogar vierzig Milliarden Euro erreichen, wovon ein Viertel auf den exponierten Nettozahler Deutschland entfiele. Noch ist die mancherorts geäußerte Hoffnung, mit der Keule des Türkeibeitritts eine generelle Kürzung der Subventionszahlungen erreichen zu können, nichts als eine realitätsferne Utopie. Weder wird sich ein großer Staat wie die Türkei auf eine fünfzehnjährige Verhandlungsdauer einstellen, noch drastische Kürzungen, die als gezielte Diskriminierung jetzt schon stigmatisiert werden, hinnehmen. 
1. Mit dem EU-Beitritt würde das europäische Prinzip der Religionsfreiheit auch in der Türkei gültig. Davon könnten die unverändert scharf diskriminierten christlichen Minderheiten nur profitieren. Das Prinzip schützt aber auch die ohnehin voranschreitende Reislamisierung und die Tendenzen eines fundamentalistischen Islamismus, den der umstrittene türkische Staatsislam auch bisher nicht hat verhindern können.

2. Das Militär würde weiterhin Schritt für Schritt entmachtet. Das kann man als Schritt hin zu einer türkischen Zivilgesellschaft unstreitig begrüßen. Bisher war aber gerade das Militär als Hüter eines kemalistischen Laizismus der effektivste Hüter der säkularisierten Republik. Wer wird sie weiter so energisch verteidigen?

3. Der Anschluss an die EU garantiert eine lange Serie von Wahlsiegen für die AKP, mithin eine hohe parteipolitische Belohnung für den erreichten Beitritt. Eine überlegene Alternative $\mathrm{zu}$ ihrer Europapolitik ist daher für die Regierung Erdoğan schwerlich zu erkennen.

Freilich gibt es eine Fülle von Problemen, die für die Brüsseler Entscheidung offenbar keine Rolle gespielt haben. So hat etwa die neue AKP-Regierung sogleich 60.000 Imame eingesetzt, welche die orthodoxe Klientel zufrieden stellen, aber staatlich alimentiert werden. Der oft zitierte Staatsislam der Türkei ist auch auf diesem Gebiet von einer europäischen Trennung von Staat und Kirche weit entfernt.

Die Absolventen der Vorbeter-Schulen können jetzt, im Gegensatz zu allen anderen Schülern und Schülerinnen Höherer Schulen, ohne Prüfung auf die Universität ziehen. Der Universitätsrat, vergleichbar mit einer Mischung aus KMK und DFG, ist mit einer Mehrheit von AKP-Vertrauten besetzt worden.

Überdies gibt es eine Reihe von archaischen Sitten, die europäische Rechtsvorstellungen krass verletzen: Weithin ist noch immer die Kinderehe üblich. Auch ein Sohn Erdoğans hat unlängst eine Minderjährige zur Frau genommen. Zwei von drei Männern in Anatolien zahlen Brautgeld für ihre Frau, die sie folgerichtig als ihr Eigentum betrachten. Ohnehin wird noch immer jede zweite Frau ohne ihre Einwilligung meist an Män- 
ner verheiratet, die sie vorher nie kennen gelernt hat. Jeder zehnte Mann hat mindestens zwei oder mehr Frauen, die in der Moschee angetraut werden, wo die Ehe nicht die zivilrechtliche Verbindlichkeit gewinnt und vom Mann gelöst werden kann.

Ebenso irritierend sind einige Umstände, welche der schlampige Prüfungsbericht der Brüsseler Kommission nicht angemessen berücksichtigt hat. So hatte etwa »Amnesty International« für die beiden letzten Jahre jeweils mehr als 2000 Folterfälle, für das erste Halbjahr 2004 auch schon wieder 700 registriert. Die verbale Versicherung der Regierung, Folter werde nicht mehr von Staats wegen ausgeübt, hat die scharfsichtigen Kontrolleure aus Brüssel offenbar beruhigt.

Jahrelang war die Lösung des Zypern-Problems als Conditio sine qua non von Beitrittsverhandlungen genannt worden. Auch dieser Streitpunkt ist jetzt auf die lange Bank geschoben worden.

Gravierender ist die Tatsache, dass die christlichen Minderheiten des Landes weiterhin krass diskriminiert werden. Nicht zufällig ist der christliche Anteil an der Einwohnerschaft Istanbuls von immerhin noch acht Prozent im Jahre 1939 auf 0,08 Prozent sechzig Jahre später abgesunken. Noch immer wird den christlichen Kirchen der Status einer öffentlich-rechtlichen Körperschaft verweigert: Eine neue Bitte des Vatikans im Jahre 2002 wurde wiederum abgelehnt. Vielmehr werden die christlichen Kirchen als Minderheiten definiert, die unter der straffen Aufsicht eines staatlichen Stiftungsrats stehen, auf den das Religionsministerium angeblich den entscheidenden Einfluss ausübt. Unverändert bleibt den Kirchen Immobilienbesitz versagt, nachdem ihr früherer Besitz konfisziert worden ist. Die Geistlichen können nicht in ihrer Funktion tätig sein, sondern gelten als Konsulatsbeamte. Hätte die Brüsseler Kommission nicht dezidiert auf Remedur bestehen müssen, ehe sie grünes Licht für Beitrittsverhandlungen gab?

Es war offenbar ein gelungener Coup der PR-Agentur, die Ankara in der Bundesrepublik vertritt, die AKP Erdoğans als »türkische $\mathrm{CDU}$ « zu verkaufen. Die CDU ist jedoch eine bikonfessionelle Volkspartei, während von christlichen Mitgliedern der islamistischen AKP bisher nichts bekannt ist. Kein europäischer Politiker hat sich überdies Erdoğans hämische Kritik am »christlichen Klub« verbeten, zu dem manche Europäer die EU 
machen wollten. Immerhin zählen seit dem Mai 2004438 Millionen von den 450 Millionen Europäern zu den Christen, und Kritiker des künftigen Türkei-Beitritts sprechen ja auch nicht vom unerwünschten »islamistischen Klüngel«.

Ein letztes heikles Beispiel für offene Probleme: Die Türkei sieht die erleichterte Einbürgerung von Angehörigen der Turkvölker als so genannten »erweiterten Familienmitgliedern « vor. Die Staaten der Turkvölker erstrecken sich von der Türkei über Turkmenistan, Usbekistan, Tadschikistan, Kasachstan bis hin zur chinesischen Grenze. Wird dieses Privileg bei der Einwanderung großzügig gehandhabt, steht ein weiterer Zustrom aus den Staaten der Turkvölker zu erwarten. Wer kontrolliert ihn auf eine effektive Weise? Und wie wäre die EU an dieser Kontrolle beteiligt? Vermutlich wird es auch deshalb mehr als 90 Millionen Türken im Jahre 2004 geben.

Von all diesen Problemen, denen eine Türkei, die nach Europa will, entgegensieht, ist in den bisher eingeleiteten Reformen nicht die Rede, geschweige denn, dass archaische Bräuche schon aufgelöst würden und europäischen Verhältnissen wichen.

Das derzeit vorherrschende neurotische Drängen, als europäischer Staat anerkannt zu werden, hat zwar neuerdings zu einigen in hektischer Eile verabschiedeten Reformgesetzen geführt, die aber nicht nur noch immer sehr unvollständig sind, sondern in den nächsten Jahrzehnten auch der glaubwürdigen Realisierung im Alltag, in der Verwaltung und Justiz bedürfen. Da die EU-Prüfungskommission dazu gekommen ist, die Aufnahmekriterien bereits zwei Jahre nach dem Reformbeginn für erfüllt zu erklären, heißt das sinngemäß, dass die Türkei die Belastungen eines langlebigen Traditionsüberhangs in fabulös kurzer Zeit angeblich abgeschüttelt hätte.

Unvergleichlich stichhaltiger als die angreifbaren protürkischen Argumente ist die Vielzahl der grundsätzlichen Einwände gegen einen Türkei-Beitritt.

1. Die Türkei ist ein kleinasiatischer, nichteuropäischer Staat, dessen Aufnahme das großartige Projekt der politischen Einheit Europas torpedieren würde. Sie gehört einem anderen Kultur- 
kreis an und würde mit 90 Millionen Muslimen, die sie in den Beitrittsjahren nach 2012/14 zählen wird, eine nichteuropäische Bevölkerung mitbringen, die weder das unverzichtbare, historisch gewachsene europäische Identitätsbewusstsein teilt, noch zur künftigen Identitätskontinuität beitragen könnte. Überdies entfiele jedes plausible Argument gegen die Beitrittswünsche der Ukraine (Beitritt: bis 2011!) und anderer östlicher Länder, aber auch Marokkos (Beitrittsantrag liegt vor) und anderer maghrebinischer Staaten. Statt der politischen Einheit des historischen Europas käme es allenfalls zu einer Freihandelszone vom Atlantik bis eventuell nach Wladiwostok. Sie käme zwar englischen Vorstellungen, auch geheimen Wünschen der USA entgegen, die ein politisch geeintes Europa zusehends als ernsthaften Konkurrenten betrachten. Mit der Zielutopie eines politisch geeinten Europas, das aus zwei totalen Kriegen in einem mühseligen Lernprozess endlich die richtige Konsequenz gezogen hat, hätte der pure Ökonomismus einer riesigen Freihandelszone nichts mehr gemein. (Auch diese Problematik unterstreicht die Aufgabe, dass Europa endlich seine Grenzen nach Ostern und Südosten definieren muss.)

2. Nach der Aufnahme der acht osteuropäischen Länder und der beiden Inselstaaten zeichnet sich eine extreme Belastung aller europäischen Ressourcen ab; der ohnehin strittige Agrarsubventionismus ist nur ein besonders eklatantes Beispiel dafür. Da die EU seit der Konferenz in Nizza ihre Hausaufgaben nicht gemacht hat, überschneidet sich diese Belastung mit den ungelösten Fragen einer Reform der komplizierten politischen Entscheidungsprozesse. Im Grunde zeichnet sich bereits das klassische Problem des "Imperial Overstretch « deutlich ab. Ein Türkei-Beitritt wenige Jahre nach der »Osterweiterung « würde diese Gefahr bis zu einer lebensgefährlichen Überdehnung aller Sehnen und Gelenke, bis zu einer fatalen Belastungsprobe dramatisch zuspitzen. Überdies wäre die Türkei sogleich der größte EU-Staat, stellte die größte Fraktion im Straßburger Parlament (da sich deren Umfang nach der Bevölkerungszahl der Heimatländer bemisst), wäre ständig in Versuchung, eine politische Sonderrolle und finanzielle Sonderzuweisungen zu beanspruchen. 
3. Ökonomisch ist die Türkei wegen ihrer Probleme dringend auf die europäische Wirtschafts- und Finanzkraft angewiesen, nachdem die Milliarden des Internationalen Währungsfonds immer wieder spurlos versickert sind. Die türkische Wirtschaft erreicht gerade einmal 20 Prozent des durchschnittlichen europäischen Sozialprodukts, und jahrelang hat sie mit einer Inflationsrate von mehr als 40 Prozent zu kämpfen gehabt. Mehr als ein Drittel aller Erwerbstätigen lebt von einer zwergbäuerlichen Subsistenzwirtschaft. Die Grundlagen für ein »Wirtschaftswunder « sind nicht von Ferne zu erkennen. Ökonomisch bleibt die Türkei auf absehbare Zeit ein Fass ohne Boden. Künftige EU-Zuschüsse werden auf jährlich bis zu 40 Milliarden geschätzt. Der Nettozahler Bundesrepublik müsste davon wohl 10 Milliarden übernehmen.

4. Die Armut Anatoliens verschärft das Migrationsproblem. Einschließlich der Auslandstürken gibt es zurzeit dank der jährlichen demographischen Zuwachsrate von 3,4 Prozent rund 75 Millionen Türken. Selbst wenn man diese Rate auf 2,5 Prozent absenkt, kommt man für die eventuelle Beitrittsphase auf 90 Millionen Türken oder sogar noch auf mehr. Deshalb hat unlängst der damalige türkische Präsident Demirel gegenüber Altbundeskanzler Schmidt von der Notwendigkeit des »Exports« von 15 Millionen Türken gesprochen. Türkische Experten gehen ebenfalls von der Abwanderungsbereitschaft von 15 bis 18 Millionen aus.

Deutschland hat zwischen 1950 und 2000 die weltweit relativ höchste Zuwanderungsrate erlebt und ist, aufs Ganze gesehen, mit der Einwanderung bisher bravourös fertig geworden. Hier lebt die größte türkische Minderheit in Europa, nahezu drei Millionen Menschen umfassend. Ihre Integration ist bisher, um es vorsichtig zu sagen, unvollständig verlaufen, da der Widerwille der Zuwanderer und das Versagen der deutschen Eingliederungspolitik zusammenwirken. Wenn unlängst 94 Prozent aller in Berlin eingeschulten Kinder türkischer Herkunft kein Wort Deutsch konnten und zwei Drittel aller vierzehn- bis vierundzwanzigjährigen Berliner Türken, also alle aus der dritten Generation, wegen des fehlenden Schulabschlusses und der mangelhaften Sprachkompetenz arbeitslos waren, unterstreichen solche Gefahrensignale das Integrationsdefizit. 
Ein Gutteil des Türkenproblems in der Bundesrepublik hängt damit zusammen, dass es sich um eine geradezu klassische Unterschichtenemigration aus Anatolien gehandelt hat und weiterhin handelt. Aus den urbanen Zentren des Landes sind denkbar wenige »Gastarbeiter« nach Deutschland gegangen. Gerade in diesen anatolischen Unterschichten werden auch die archaischen Züge der heimatlichen Kultur verteidigt, und der Koran dient dann oft nur als religiöse Rechtfertigung von Bräuchen und Werten, die im Kern nichts mit ihm zu tun haben. Gerade die starren Formen des neuen Islamismus eignen sich aber, besonders in der dritten Generation, zur Verteidigung subkultureller Eigenarten, die in den städtischen Zentren der Türkei abschätzige Verwunderung auslösen wie andererseits anatolische Mädchen mit strenger Kleidung über die rasanten Bikinis von Türkinnen in den Badeorten an der Südküste nur staunen können.

Käme es $\mathrm{zu}$ einer weiteren nahe liegenden anatolischen Massenzuwanderung, würde die unabdingbare Integration der türkischen Minderheit noch einmal extrem erschwert, vielleicht sogar dauerhaft blockiert, zumal sich muslimische Zuwanderer bisher in allen europäischen Ländern gegen die Integration erfolgreich gesträubt haben.

5. Auffallend selten wird hierzulande diskutiert, dass in der Türkei zum zweiten Mal eine islamistische Protestpartei gegen den säkularisierenden Kemalismus und die laizistische Republik gewonnen hat.

Teilt aber die Erdoğan-Partei, die Türkei überhaupt, die westliche »Wertegemeinschaft «? Fraglos gelten seit der Republikgründung 1922 für die Machteliten westliche Zielwerte, da die Türkei, wie auch Russland seit Peter dem Großen, Europa ähnlich zu werden bestrebt ist. Doch eine soziologische Umfrage ergab neulich eklatante Unterschiede des Wertehimmels. In der EU wünschten nur mehr zehn Prozent einen Einfluss der Religion auf die Politik, in der Türkei aber mehr als zwei Drittel. Die Demokratie wurde in der EU von 85 Prozent als überlegenes politisches System betrachtet, in der Türkei votierten, der historischen Erfahrung folgend, mehr als zwei Drittel für ein Regime autoritärer Führungspersönlichkeiten. Und wie ist mit der beanspruchten Zugehörigkeit zur westlichen »Wertege- 
meinschaft « das hartnäckige Leugnen des türkischen Genozids an 1,5 Millionen Armeniern (1915) zu vereinbaren, dem wenige Jahre später die Ermordung und Vertreibung von 1,5 Millionen Griechen aus Kleinasien folgte? Läuft die Linie dieser gewaltsamen Homogenisierung nicht in der Kurdenverfolgung mit ihren 40.000 Toten, 4.000 zerstörten Dörfern und 4.000.000 Flüchtlingen weiter fort? Zugegeben, die Bundesrepublik trägt mit dem Holocaust eine schwerere Bürde. Doch hätte sie ein einziger westlicher Staat, wenn sie während der Entstehung der EG, der EWG, der EU Auschwitz geleugnet hätte, auch nur mit der Feuerzange angefasst?

6. Warum sollte sich die EU so charmante Nachbarn wie den chaotischen Irak, die syrische Diktatur, die iranische Theokratie und erodierende Staaten wie Georgien und Armenien freiwillig zulegen? Ganz zu schweigen von dem Kurdenproblem, das die zurzeit latente türkische Aggressivität, wie im letzten Irakkrieg wieder deutlich wurde, weiterhin zu mobilisieren vermag.

7. Allensbach hat im April 2004 erneut ermittelt, dass 66 Prozent der Deutschen gegen, nur zwölf Prozent für einen TürkeiBeitritt sind. Auch in Frankreich sind es 68 Prozent. Vier Fünftel der Befragten halten die Türkei nicht für ein europäisches Land. Beitrittsverhandlungen unterstreichen daher das Demokratiedefizit der bisherigen Vorentscheidungen. Das Ideal des mündigen, argumentativ überzeugten Bürgers spielt für sie keine Rolle mehr. Die Generationengerechtigkeit wird ebenfalls ignoriert, obwohl kommenden Generationen mit einem TürkeiBeitritt aberwitzige Kosten ohne erkennbare überzeugende Gegenleistungen aufgebürdet würden.

8. Die Auguren auf den Berliner »Korridoren der Macht« raunen, dass Berlin sich ungefährdet türkeifreundlich gebärden könne, da Einstimmigkeit bei der Aufnahmeprozedur von den 25 (vielleicht sogar 28) EU-Staaten schlechterdings nicht zu erwarten sei, insbesondere die osteuropäischen Mitglieder würden ihre konkreten Eigeninteressen gegen jede Schmälerung zugunsten der Türkei zu verteidigen wissen. Außerdem: Wenn von ca. 600.000 wahlberechtigten Staatsbürgern türkischer Herkunft tatsächlich - so die demoskopischen Umfragen - 80 Pro- 
zent für Rot-Grün stimmen sollten, lohne sich, zumal mit dem Blick auf den geringen Stimmenunterschied im Wahljahr 2002, die türkeifreundliche Rhetorik allemal. Im Kern sind das unredliche oder parteiegoistische Hoffnungen, die der Dimension der Problematik völlig unangemessen sind.

9. Falls die Verhandlungen zwischen 2010 und 2014 zu einem Beitritt der Türkei führen, vergrößerte sich das berüchtigte Demokratiedefizit der EU. Die Umfragewerte sind mit stabiler Eindeutigkeit gegen den Beitritt gerichtet. Nun soll Politik nicht primär demoskopischen Trendmeldungen folgen. Aber wann und wo hat es eine offene, ungeschminkte Debatte über die zahlreichen Probleme eines Türkei-Beitritts je gegeben? Erst viel zu spät, nach vollzogener Entscheidung, hat sich die rot-grüne Regierung zu einigen fadenscheinigen Erläuterungen und Begründungen bereit gefunden, die eigentlich am Anfang des Entscheidungsprozesses hätten stehen sollen. Dabei liegen doch bedrohliche Folgen eines Beitritts auf der Hand: Die Türkei würde sofort der größte EU-Staat, dem politischen Führungsansprüche nicht fremd wären. Sie stellte sofort die größte Fraktion im Straßburger Parlament, da dort die Fraktionsgröße nach der Kopfzahl der Bevölkerung eines Staates festgelegt wird und die Aufteilung auf das christlich-konservative oder das sozialdemokratische Lager für AKP-Abgeordnete schlechterdings nicht möglich ist. Nicht zuletzt würde die Türkei wohl das entscheidende Wort bei der Formulierung der europäischen Nahostpolitik beanspruchen.

10. Nicht zuletzt wüchse die Euroskepsis weiter, da das Ideal des mündigen Bürgers in krasser Form verraten und die Generationengerechtigkeit missachtet worden wäre. Denn auf künftige Generationen in Europa kämen endlose Belastungen ohne überzeugende Gegenleistung zu.

Im Hinblick auf die Zukunft Deutschlands wird allerdings noch ein irreführendes Argument ins Feld geführt. Da die Deutschen nicht mehr genug Kinder bekommen, heißt es, um die Bestandserhaltung der Bevölkerung und der Sozialsysteme, geschweige denn eine Expansion zu gewährleisten, müsse das Defizit durch den Import von Menschen, mithin durch eine ge- 
zielte und jährlich umfangreiche Einwanderung gewährleistet werden. Diese Aufgabe könne von türkischen Migranten übernommen werden. Tatsächlich steht dem aber die Lage der Türken auf dem deutschen Arbeitsmarkt entgegen. Sie ist gekennzeichnet durch eine hohe Arbeitslosigkeit, namentlich in der dritten Generation mit ihrer fehlenden Sprachkompetenz und den ausbleibenden Schulabschlüssen. Mit vierzig Prozent ist die Arbeitslosenquote doppelt so hoch wie unter deutschen Erwerbswilligen. Die Sozialhilfe fällt dreimal so hoch aus wie der türkische Anteil an der Bevölkerung. Im Durchschnitt gehen türkische Arbeitnehmer wegen Berufsunfähigkeit mit fünfzig Jahren in Rente, was ein krasses Missverhältnis zwischen Einzahlung in die Sozialversicherung und Leistung hervorruft. Überhaupt sind nur 44 Prozent der türkischen Erwerbsfähigen in den Arbeitsprozess eingegliedert, auf Seiten der Deutschen sind es sechzig Prozent. Wie die Recherchen des Berliner Instituts für Demographie, der ZEIT und des »Tagesspiegels« ergeben haben, trägt daher die türkische Einwanderung nach Deutschland nicht zur Entlastung der Sozialsysteme bei, vielmehr erweist sie sich unter dem Strich bereits seit langem als Zuschussunternehmen auf Kosten der anderen Beitragszahler. Da die künftige türkische Migration auf Grund der Freizügigkeit in der EU auch weiterhin vor allem aus den anatolischen Unterschichten gespeist würde, erweist sich die Auffassung, durch diese Migranten die Sozialsysteme zu stabilisieren, als Chimäre.

Längst hätte die europäische Politik an Stelle der dürren Alternative von Vollmitgliedschaft oder Außenseiterrolle vielfältige, flexible Stufen der Kooperation entwickeln sollen, wie sie jetzt endlich Artikel 57 des Verfassungsentwurfs vorsieht. Ein großes Nachbarland wie die Türkei, mit dem freundschaftliche Beziehungen geboten sind, verdient, so gesehen, durchaus eine "privilegierte Partnerschaft", als nichteuropäischer Staat aber keineswegs die EU-Mitgliedschaft. Auch das engstirnige Wählerstimmenkalkül setzt sich über alle überzeugenden Einwände gegen einen Türkei-Beitritt hinweg. Dabei könnte sich eine rationale Interessenabwägung schon über die beiden besonders triftigen Gegenargumente: die Bedrohung mit der letalen Überforderung aller Ressourcen, erst Recht die unvermeidbare Zerstörung des großen Projekts der europäischen Staatenunion 
durch die Aufnahme eines nichteuropäischen muslimischen Staates, nicht hinwegsetzen.

Kein Zweifel, das großartige Projekt einer Europäischen Union wird mit dem Beitritt der Türkei begraben. Zu der derzeitigen strategischen Überdehnung mit dem Zehnerbeitritt im Mai 2004 kommt ja binnen kurzem noch der Beitritt Rumäniens, Bulgariens und Kroatiens, in absehbarer Zukunft auch der anderen Nachfolgestaaten des ehemaligen Jugoslawiens und Albaniens hinzu; Marokkos Aufnahmeantrag liegt längst vor. Die Ukraine drängt ebenfalls, von Polen wegen des Schutzes der neuen europäischen Grenze im Osten bereits lebhaft unterstützt, in die EU. Aller Wahrscheinlichkeit nach bleibt dann eine riesige Freihandelszone übrig, die manche ökonomischen Interessen, auch das amerikanische und britische Anti-EU-Kalkül befriedigt, mit einem handlungsfähigen Akteur Großeuropa aber nichts mehr gemein hat.

Will man nicht vor diesem Ergebnis des Versagens kapitulieren, bleibt eine Möglichkeit weiter offen: Innerhalb der EU könnte ein neuer Verband europäischer Staaten gegründet werden, der dank strenger Aufnahmekriterien nur den Kern der EU-Gründerstaaten umfassen und das Konzept eines Europas der unterschiedlichen Geschwindigkeiten verwirklichen würde. Eine solche Föderation der wahrhaft europäischen Staaten zu schaffen, bedeutet, sich einer Herkulesaufgabe zu stellen. Auf die ersten Überlegungen hin, die in diese Richtung zielten, haben z.B. ungarische, tschechische und polnische bereits vorsorglich erklärt, dass sie sogleich zum Kerneuropa, keineswegs aber zur neuen Peripherie gehören wollten. Die Realisierung der Absicht, innerhalb der EU einen kleinen Verband der »Vereinigten Staaten von Europa « zu schaffen, träfe auf überaus harten Widerstand, und die handelnden Akteure wären um dieses politische Geschäft nicht zu beneiden. Wie anders aber könnte die Vision von einem vereinten Europa, das sich nicht mit dem Linsengericht einer Freihandelszone zufrieden geben will, doch noch verwirklicht werden? 



\section{Warum die Türkei die Gemeinschaft bereichern würde}

HAKKI KESKIN

\section{Vereinbarungen zwischen Türkei und EU}

Keines der heute 25 Mitglieder der EU hatte einen solch lang währenden Prozess vor der eigentlichen Mitgliedschaft zu durchlaufen wie die Türkei. Bereits am 31. Juli 1959 bewarb sich die Türkei um die Mitgliedschaft in der damaligen "Europäischen Wirtschaftsgemeinschaft« (EWG). Am 12. September 1963 wurde das »Abkommen zur Gründung einer Assoziation zwischen der Europäischen Wirtschaftsgemeinschaft und der Republik Türkei« in Ankara unterzeichnet. Das Assoziierungsabkommen zwischen der EWG und der Türkei mit dem Ziel des Beitritts zur Gemeinschaft erschien am 29. Dezember 1964 im Amtsblatt Nr. 217 und wurde dort als »Ankara-Abkommen« bezeichnet. Am 23. November 1970 wurde zwischen der EWG und der Türkei ein Zusatzprotokoll unterzeichnet, welches die Mitgliedschaft der Türkei in der EWG in drei Phasen vorsah und die Detailfragen regelte. Die Türkei wurde am 1. Januar 1996 in die Zollunion der EU aufgenommen. Für die türkische Bevölkerung stellte der Beitritt zur Zollunion einen weit reichenden Schritt hin zu einer Vollmitgliedschaft in der EU dar. Die Staats- und Regierungschefs der EU-Mitgliedsstaaten gaben der Türkei am 9. Dezember 1999 in Helsinki den Status des Beitrittskandidaten. Neben den zehn bereits im Mai 2004 als Voll- 
mitglieder aufgenommenen Staaten und neben Rumänien und Bulgarien, die 2007 der EU beitreten sollen, ist die Türkei offiziell gleichberechtigter Beitrittskandidat. Auf dem EU-Gipfeltreffen im Dezember 2002 in Kopenhagen wurde die Beitrittsperspektive dahingehend bekräftigt, dass die EU-Staats- und Regierungschefs am 17. Dezember 2004 über den »unverzüglichen " Beginn der Beitrittsverhandlungen zu entscheiden hätten, falls die EU-Kommission in ihrem vorangehenden Bericht die politischen Kriterien als erfüllt bewertet. Voraussetzung für ein positives Votum der EU-Kommission war die Erfüllung der so genannten »Kopenhagener Kriterien «, deren Umsetzung und Einhaltung in einem Fortschrittsbericht der Europäischen Kommission dokumentiert wird. Am 6. Oktober 2004 hat die Europäische Kommission den Staats- und Regierungschefs der EU die Aufnahme von Beitrittsverhandlungen unter strengen Auflagen empfohlen, auf die ich noch zurückkommen werde.

\section{Argumente der Gegner}

Die Gegner einer EU-Mitgliedschaft der Türkei führen hauptsächlich folgende Gründe für ihre ablehnende Haltung an: Erstens sei die Türkei weder geographisch noch historisch ein europäisches Land: »Die Türkei gehört nicht zu Europa«. Zweitens basiere die EU auf der christlichen Religion und Kultur. Die Türkei entspreche nicht dem westlichen Wertesystem und als ein islamisches Land gefährde sie sogar die auf der christlichen Kultur basierende Identität der EU: »Die Unionsidee wird zerstört. « Drittens sei sie eine zu große finanzielle Belastung für die EU: »Die EU ist keine karitative Anstalt.«Viertens ziehe der Beitritt der Türkei in die EU darüber hinaus eine starke $\mathrm{Zu}$ wanderung türkischer Arbeitskräfte in den Arbeitsmarkt der EU nach sich: »Es droht eine Völkerwanderung." Fünftens grenze die Türkei an zentrale Konfliktregionen: "Die EU kommt in üble Nachbarschaft." Sechstens sei der Einfluss des Kemalismus und des Militärs ein Hinderungsgrund für Demokratie und Rechtsstaatlichkeit. Außerdem sei die Gefahr des Islamismus in der Türkei nicht gebannt. Und siebtens versuche die Türkei mit der in den letzten Jahren verabschiedeten Verfassungsreform und den »EU-Anpassungsgesetzen« lediglich 
dem Anschein nach, die politischen Kriterien von Kopenhagen zu erfüllen, ohne diese tatsächlich auch inhaltlich umsetzen zu wollen. Die Kopenhagener Kriterien seien trotz beachtlicher Reformen noch nicht realisiert und vor allem nicht umgesetzt, es gebe weiterhin Menschenrechtsverletzungen: »Die Türkei missachtet die Menschenrechte" (vgl. Schuster/Köppel 2004).

Wie berechtigt, überzeugend und stichhaltig sind diese Behauptungen? Ich werde mich im Folgenden in sehr komprimierter Form mit den referierten Positionen der Gegner einer EU-Mitgliedschaft auseinandersetzen.

\section{Geographie}

Kein Zweifel: Geographisch liegt nur ein kleiner Teil der Türkei auf dem europäischen Kontinent. Diesen Aspekt jedoch nach 40 Jahren - so lange besteht das Assoziierungsabkommen zwischen Türkei und EU - mit dem darin festgelegten Ziel einer EU-Mitgliedschaft $\mathrm{zu}$ thematisieren, scheint sehr weit hergeholt. Diejenigen EU-Vertreter, die 1963 mit der Türkei das Abkommen paraphierten, wussten sicherlich auch damals bereits, wo die Türkei liegt. Die Rede des Präsidenten der damaligen EWG-Kommission, Walter Hallstein (CDU), bei diesem Festakt verdient gerade gegenwärtig Beachtung: »Wir sind heute Zeugen eines großen Ereignisses. Die Türkei gehört zu Europa « (Hallstein 1979: 439ff.). Diese Feststellung unterstreicht ganz deutlich, dass sich auch die damalige EWG nicht auf die geographische Lage beschränkte, sondern eine klare politische Entscheidung traf. Genau in diesem Sinne schreibt der ehemalige Außenminister der Türkei, Ismail Cem: »Unsere Welt durchläuft radikale Veränderungen. Geographie wandelt sich nun in eine Konzeption, die deutliche Visionen ins Leben ruft und ausführt. Sie dient nicht dazu, unsere Wahrnehmung zu begrenzen« (Cem 2001: 73).

Gerade die geographische Lage der Türkei - sowohl in Europa als auch in Asien - verleiht ihr als Brücke zwischen den Kontinenten eine besondere Bedeutung. Diese zukunftsträchtige Perspektive darf nicht durch eine nach Quadratkilometern rechnende Sichtweise relativiert oder gar eingeschränkt werden. 
Die Zielsetzung der Türkei, einerseits Mitglied der EU zu werden, sich andererseits aber als ökonomischer und politischer Machtfaktor konsequent im eurasischen Raum einzusetzen, wird letztlich beiden, der Türkei wie der EU, zugute kommen. Abgesehen davon, kann man die mehr als 300-jährige gemeinsame Geschichte der Türkei und Europas, wie immer man diese heute auch bewerten mag, nicht einfach ignorieren.

\section{Wertehorizont}

Die politische und wirtschaftliche Zielrichtung der Türken und der Türkei ist, was die Werteorientierung und Wertephilosophie anbelangt, eindeutig auf Europa gerichtet, und zwar nicht erst, wie man denken könnte, seit der Gründung der Republik Türkei im Jahre 1923. Diese Bestrebung begann bereits im Osmanischen Reich mit den so genannten "Tanzimat Fermani « (Tanzimat Reformen), mit denen 1839 die Gleichberechtigung aller Untertanen verkündet wurde. 1876 wurde eine Verfassung verabschiedet, die auch die Gründung eines Parlaments vorsah, allerdings mit sehr stark eingeschränkten Befugnissen. Diese Reformen, die bereits erste Demokratisierungstendenzen zeitigten, wurden 1889 mit radikalen Neuerungen von den »Jungtürken« fortgeführt.

Der junge Offizier Mustafa Kemal, der einen heroischen Abwehrsieg bei Gelibolu an den Dardanellen gegen die britisch-französische Invasionsarmee errang, hatte die Französische Revolution ausgiebig studiert. Sein Ziel und das seiner Gesinnungsfreunde war die Befreiung des von den Siegermächten besetzten und aufgeteilten Vaterlandes (im Türkischen sagt man Mutterland) und die Gründung einer modernen Republik Türkei.

Dem erfolgreichen Befreiungs- und Unabhängigkeitskampf folgte die Konstituierung der Republik Türkei am 29. Oktober 1923. Das erklärte Ziel ihres Gründers Mustafa Kemal Atatürk war es, »die Türkei auf das Entwicklungsniveau der zeitgenössischen Zivilisation « zu führen. Mit radikalen Reformen und einem grundlegenden Erneuerungsprozess sollte die Türkei den Anschluss an die entwickelten Nationen Westeuropas erreichen. 
Das säkulare, auf Wissenschaft, Technologie und Modernisierung basierende und gerade deshalb wirtschaftlich entwickelte Westeuropa stellte für die junge Republik Türkei die Orientierung auf dem Weg zu einer "zeitgenössisch entwickelten Zivilisation « dar. Bereits in der Verfassung von 1924 wurde der "Laizismus", die Trennung von Staat und Religion, zum wesentlichen Grundelement des Staates erklärt, um den Missbrauch und die Instrumentalisierung der Religion für politische Zwecke zu unterbinden. In der Folgezeit haben die Parteien und Regierungen der Türkei, von den Kemalisten über die Konservativen bis zu den Sozialdemokraten, an diesem Staatsziel »Westorientierung « stets festgehalten.

Die immer noch entschlossene Haltung des türkischen Volkes und der Regierungen der Türkei, die volle Mitgliedschaft in der EU zu erlangen, ist daher auch keine Neuausrichtung der türkischen Politik. Sie ist vielmehr eine konsequente politische Fortsetzung der seit der Gründung der Republik Türkei verfolgten Bestrebungen.

Aufgrund dieser eindeutigen Westorientierung trat die Türkei 1952 der NATO bei und wurde nicht nur militärisch in das westliche Verteidigungssystem integriert. Die NATO ist nämlich nicht nur ein Militärbündnis, sie dient vielmehr auch zur Verteidigung der westlichen Wertegemeinschaft.

Ebenfalls als Konsequenz dieser Westorientierung bewarb sich die Türkei bereits am 31. Juli 1959 um die Mitgliedschaft in der damaligen "Europäischen Wirtschaftsgemeinschaft" (EWG). Unabhängig von der politischer Orientierung haben alle im Parlament der Türkei vertretenen Parteien an dem Ziel der EU-Mitgliedschaft und Westorientierung festgehalten.

\section{Religion}

Die EU ist kein Christenclub, sondern eine Gemeinschaft der kulturellen, sprachlichen und religiösen Vielfalt. In der Präambel des Vertrags über eine europäische Verfassung heißt es:

»In der Gewissheit, dass die Völker Europas, wiewohl stolz auf ihre nationale Identität und Geschichte, entschlossen sind, die alten Trennungen zu überwinden und immer enger vereint ihr Schicksal zu gestalten. 
In der Gewissheit, dass Europa sin Vielfalt geeint ihnen die besten Möglichkeiten bietet, unter Wahrung der Rechte des Einzelnen und im Bewusstsein ihrer Verantwortung gegenüber den künftigen Generationen und der Erde dieses große Abenteuer fortzusetzen, das einen Raum eröffnet, in dem sich die Hoffnung der Menschen entfalten kann« (CIG/84/04).

In Deutschland sind es in der Regel die konservativen Politiker der Unionsparteien oder Historiker, die sich engagiert gegen eine EU-Mitgliedschaft der Türkei wenden. Einige Beispiele zeigen diese Tendenz:

»Wenn wir eine politische Union Europa wollen, dann brauchen wir ein hohes Maß an Integration. [...] Nimmt man die Türkei auf, dann ist dies das Ende der Vision von der politischen Union Europas. [...] Mit einem Staat wie der Türkei, der einen ganz anderen gesellschaftlichen Hintergrund hat, sprengt man die politische Union « (Edmund Stoiber im SZInterview vom 21./22.02.04). Und Stoiber in einem anderen Zusammenhang: »Wir sind ganz klar gegen ein Europa der verwischten kulturellen und geographischen Grenzen.«

»Für die Vollmitgliedschaft in der EU ist auch eine gemeinsame Identität und das Gefühl der Zugehörigkeit notwendig. Das fehlt der Türkei, die nur teilweise zu Europa gehört. [...] Natürlich können wir die Beitrittsperspektive, die es seit den sechziger Jahren gibt, jetzt nicht einseitig aufkündigen. Das ist eine Verpflichtung, zu der wir stehen« (Wolfgang Schäuble im Interview mit dem Tagesspiegel vom 16.02.04).

»Im Islam fehlen die für die europäische Kultur entscheidenden Entwicklungen der Renaissance, der Aufklärung und der Trennung zwischen geistlicher und politischer Autorität« (Schmidt 2004: 162).

»Das historische Europa und die Türkei gehören zwei unterschiedlichen Kulturkreisen an. [...] Integration meint auch die Stärkung des europäischen Identitätsgefühls. Das aber würde durch die auf grundverschiedenen historischen Traditionen beruhende Türkei dauerhaft in Frage gestellt« (Hans-Ulrich Wehler im Focus vom 16.02.04).

Wie zu sehen ist, wird den Türken und der Türkei eine europäische Identität wegen ihrer unterschiedlichen Geschichte, Religion und Kultur aberkannt. Als ob es in Europa nur die christliche Religion, eine einheitliche Kultur, die gleiche Geschichte 
und somit auch eine bestimmte Identität für alle $25 \mathrm{EU}$ Mitgliedsstaaten gäbe. Zudem wird in dieser Vorstellung die Identität als etwas historisch Eingefrorenes, also Statisches verstanden und bewertet. Dass dies nicht der Fall ist, beweist die Vielfalt der Sprachen, der Kulturen und der Geschichten eines jeden Volkes und Landes.

»Plötzlich entdecken Zeitgenossen die >christliche Identität $<$ des Abendlandes wieder, die bisher kaum als glühende Vertreter des Christlichen hervorgetreten waren. Jetzt aber brauchen sie das, was sie >christliche Identität $<$ nennen, weil es gegen den Islam geht. [...] Gegen diese politische Instrumentalisierung des Begriffs >christliche Identität‘, die gestern gegen Juden, heute gegen Muslime ins Spiel gebracht wird, streite ich aus theologischen Gründen. [...] Er taugt dafür nicht, vor allem aus zwei Gründen: aus Gründen der Geschichte und aus Gründen des Christlichen selber. Was die Geschichte betrifft, so ist gegen alles Vergessen und Verdrängen festzuhalten: In Europa hat es jahrhundertelang auch ein lebendiges Judentum und einen lebendigen Islam gegeben. Europa ist auch durch jüdische und muslimische Kultur mitgeformt und mitgeprägt worden« (Kuschel 2004: 91).

Die oben zitierte Feststellung von Altbundeskanzler Helmut Schmidt ist sehr allgemein gefasst und gerade für die Türkei nicht zutreffend. Der Islam in Südostasien, Afrika, im Nahen Osten und in Europa ist sowohl in seiner Auslegung als auch in der praktischen Anwendung sehr unterschiedlich und zeigt eine ähnliche Vielfalt wie das Christentum. Es ist falsch, die islamische Religionsgemeinschaft, der ca. 1,3 Milliarden Menschen in mehr als fünfzig Ländern angehören, in Fragen der Auslegung und Ausübung als homogen zu betrachten.

Die Türkei hat 1923, nach Ausrufung der Republik, durch revolutionäre Umwälzungen die Entwicklung der europäischen Aufklärung mit ihrer Trennung von Staat und Religion bereits in den 20er und 30er Jahren des vorigen Jahrhunderts erfolgreich nachvollzogen: Mit der Ausrufung der Republik Türkei wurde das Sultanat, 1924 das Kalifat als oberste Instanz der Scharia abgeschafft; Rechts-, Bildungs- und Schriftreform (anstelle der arabischen die Lateinschrift) wurden verwirklicht, Gleichstellung der Frau und Wahlrecht für Frauen eingerichtet. Mit einer Reihe weit reichender Reformen in den Folgejahren wurde die Westorientierung der Türkei gezielt eingeleitet. Die 
Trennung von Religion und Staat wurde 1931 mit Aufnahme des »Laizismus" in die Verfassung vollzogen. Seitdem gehört diese Staatsphilosophie zu den unveränderlichen Grundpfeilern des neuen Staates.

Ähnlich wie der Artikel 20 des deutschen Grundgesetzes, der die Staatsform der Bundesrepublik Deutschland definiert und unabänderlich gilt, sind auch Art. 1 »Die Türkei ist eine Republik« und Art. 2 »die Türkei ist ein demokratischer, laizistischer und sozialer Rechtsstaat « der Verfassung der Türkei unveränderbar. Eine sehr große Mehrheit der Bevölkerung der Türkei hat den Laizismus verinnerlicht. Selbst unter den für die Gegner des Laizismus günstigsten Bedingungen, also in Zeiten politischer, wirtschaftlicher und sozialer Krisen, haben laizismusfeindliche Parteien maximal 20 Prozent der Wählerstimmen auf sich ziehen können. Diese Tatsache belegt, dass die türkische Bevölkerung den »laizistischen, demokratischen und sozialen Rechtsstaat « längst angenommen und als Grundsatz der Verfassung akzeptiert hat.

Was ich aber an den konservativen Positionen nicht akzeptieren kann, ist Folgendes: Die EU betrachtet die Menschrechte einerseits als ein universelles Recht, das überall, also auch in »nicht westlich geprägten Kulturen « gelten soll. Wenn aber einzelne dieser Rechte nicht mit den Vorstellungen, die der Islam in mehr als Tausend Jahren entwickelt hat, zusammenpassen, dann muss man deren universelle Gültigkeit anzweifeln. In dieser Hinsicht wird eine Art Absonderung der islamischen Religion, aber auch anderer Kulturen und Identitäten vorgenommen, damit sozusagen die Reinheit der europäischen Kultur bewahrt werden kann. Gerade die Universalität dieser Errungenschaften setzt aber voraus, dass sie weltweite Akzeptanz, Anerkennung und Anwendung erfahren. Die Aufnahme in die EU darf aber nicht so ausgelegt werden, dass die eigene islamisch geprägte Identität und die eigene Kultur oder gar die eigene religiöse Überzeugung aufgegeben werden müssten.

Die EU, als ein Staatenbund aus bereits heute 25 und in naher Zukunft mehr als 28 Staaten, darf und kann in einer Epoche der Globalisierung der Welt nicht allein auf Werte christlicher Religion und der darauf basierenden Kultur reduziert werden. Die Staaten der EU sind faktisch multikulturell, multiethnisch und multireligiös geworden. In diesen Ländern leben mehr als 
15 Millionen Menschen islamischen Glaubens, von der Bevölkerungszahl entspricht dies der Größe einiger Staaten der EU. Allein mehr als 3,5 Millionen Menschen türkischer Abstammung leben heute in den EU-Staaten, allein in der Bundesrepublik Deutschland 2,5 Millionen.

Die EU ist ein globales, zukunftsgerichtetes Modell einer offenen und multikulturellen Gesellschaft. Ihr Verdienst sollte nicht nur darin bestehen, den Wohlstand und den sozialen Frieden ihrer Bevölkerung zu sichern und zu steigern, sondern auch zum Prozess eines engen Dialogs und Austausches mit anderen Religionen und Kulturen und somit zum Frieden weltweit aktiv beizutragen. In diesem Sinne ist die EU-Mitgliedschaft der Türkei für ein solches Projekt bestens geeignet.

\section{Wanderung}

Von einem Mitgliedsland Türkei wird keine starke Zuwanderung ausgehen. Mit völlig unbegründeten Fantasiezahlen über eine Zuwanderung von 10 bis 18 Millionen Menschen, die nach einem EU-Beitritt aus der Türkei in die EU abwandern würden, machte der Historiker Wehler den Menschen Angst. Diese Argumentation ist nicht selten auch von manchen Politikern $\mathrm{zu}$ hören, die damit Befürchtungen unter der von Arbeitslosigkeit ohnehin stark verunsicherten und verängstigten Bevölkerung verbreiten.

Prognosen wie diese sind jedoch durch die Erfahrungen nach dem Beitritt der Länder Spanien, Portugal und Griechenland widerlegt worden. In den Jahren 1991 bis Anfang 2003 kam es im Saldo aus $\mathrm{Zu}$ - und Abwanderung nach und aus Deutschland gegenüber Griechenland $\mathrm{zu}$ einem Zuwanderungs-Überschuss von lediglich 1.663 Personen, bei den Portugiesen waren es 37.094 Personen, bei den Spaniern hingegen kam es zu einem Abwanderungs-Überschuss aus Deutschland von 186.629 Personen (Beauftragte der Bundesregierung für Migration, Flüchtlinge und Integration 2003: 110, 112). Mit anderen Worten: Innerhalb von zwölf Jahren wanderten für diese drei Länder insgesamt 147.872 Personen mehr aus Deutschland ab als nach Deutschland zuwanderten. Dies ist dadurch zu erklären, dass die Zugehörigkeit zur EU für die neuen Mitgliedsstaaten die Möglichkeit eröffnet, durch neue Investitionen neue 
Arbeitsplätze im eigenen Land entstehen zu lassen. Dies wird im Falle der Türkei nicht anders verlaufen. Bereits mit Beginn der Beitrittsverhandlungen über die Mitgliedschaft der Türkei dürften die Investitionen dort ganz erheblich zunehmen, zumindest erwarten dies die Befürworter eines Beitritts. Dadurch würde der Migrationsdruck aus der Türkei in die EU und nach Deutschland ganz erheblich gemindert.

\section{Kosten}

Was nun die Kosten einer EU-Mitgliedschaft der Türkei anbelangt, so arbeitet Wehler in dem bereits oben zitierten Beitrag im Focus wiederum mit völlig frei erfundenen Summen. Er spricht von jährlich 20 bis 40 Milliarden Euro und sorgt damit ganz gezielt für eine Verunsicherung der EU-Bürger. Die Kosten, die der EU im Falle einer Mitgliedschaft der Türkei entstehen würden, können heute nur annähernd ermittelt werden. Dies hat vor allem damit zu tun, dass es für eine EU Mitgliedschaft der Türkei noch kein Datum gibt und es bis dahin höchst wahrscheinlich - insbesondere bei den Agrarsubventionen durchgreifende Veränderungen gegeben haben wird. Daher möchte ich hier mit aller gebotenen Vorsicht die Modellrechnungen von drei unterschiedlichen Institutionen wiedergeben.

»Ich rechne mit Nettozahlungen an die Türkei, die einer heutigen Finanzierungsanstrengung von höchstens 10 bis 15 Milliarden Euro entspräche«, so die EU-Haushaltskommissarin Michaele Schreyer (Handelsblatt vom 05.10.2004). Das »Osteuropa-Institut München" schätzt die Kosten für die EU bei einem Beitritt 2013 auf »maximal 14 Milliarden Euro« (Quaisser 2004). Die Deutsche Industrie- und Handelskammer zu Istanbul rechnet mit Kosten von »bestenfalls 8 Milliarden Euro" (Hermann 2004: 130f.). Woher der Historiker Wehler seine Zahlen nimmt, gibt er nicht an. Aber sämtliche Angaben sind nachweislich von ihm frei erfunden und falsch.

Für das Bevölkerungswachstum der Türkei geht Wehler für die Zukunft von 2,5 Prozent aus, mit der Behauptung, dies sei sogar zu gering geschätzt. Tatsächlich liegt das Wachstum seit einigen Jahren bei nur noch 1,6 Prozent - mit rückläufigem Trend. Die Türkei erlebt infolge der nach wie vor starken Landflucht eine rasche Zunahme der städtischen Bevölkerung, und 
dies hat zur Folge, dass sich das Bevölkerungswachstum erheblich verlangsamt. Auch die Angaben Wehlers über die Wirtschaft der Türkei sind falsch. Richtigerweise wird das ProKopf-Einkommen heute nach der Parität der Kaufkraft errechnet. Demgemäß beträgt das jährliche Pro-Kopf-Einkommen in der Türkei mehr als 8.000 Euro. Hinzu kommt, dass in der Türkei ein ganz beachtlicher Teil der Wirtschaftsleistungen nicht registriert wird. Dieser Teil der nicht registrierten und somit in der Statistik nicht berücksichtigten Wirtschaftskraft wird heute auf nahezu 45 Prozent geschätzt.

\section{Grenzen}

Die EU würde nach einem Beitritt der Türkei an die zentralen Konfliktregionen im Nahen Osten grenzen, also an den Iran, Irak und an Syrien. Die Türkei ist seit 52 Jahren Mitglied der NATO. Als Mitglied dieser Werte- und Verteidigungsgemeinschaft hat sie auch ein Recht darauf, bei einem Konfliktfall von den NATO-Mitgliedsstaaten unterstützt zu werden. Die meisten EU-Staaten sind ebenfalls Mitglied der NATO, z.B. auch die Bundesrepublik Deutschland. Also könnten sich Deutschland und die anderen EU- und NATO-Staaten in einem denkbaren Konfliktfall zwischen den genannten Ländern und der Türkei ohnehin nicht aus der Verantwortung stehlen. Oder sind etwa die Unionsparteien der Meinung, dass man die Türkei in einem solchen Ernstfall allein lassen müsse, obwohl dieses Land seit über einem halben Jahrhundert weit über seine finanziellen Möglichkeiten hinaus für die Südflanke der NATO größtmögliche Anstrengungen auf sich genommen hat?

Die EU ist heute sogar bemüht, in dieser Region im Falle des Irak-Krieges oder bei der friedlichen Lösung des Konfliktes zwischen Israel und Palästina ihren Beitrag zu leisten. Die Bundesrepublik Deutschland, und nicht nur sie, versucht bereits heute, zur Herstellung und Sicherung des Friedens und der politischen Stabilität mit eigenen Soldaten im Kosovo und in Afghanistan beizutragen. Es ist längst bekannt, dass Sicherheit, Frieden und Wohlstand nicht allein vom Frieden in Deutschland und Europa abhängen, sondern auch von anderen Regionen und Ländern der Welt. Wie Recht hatte Atatürk mit seinem Spruch: »Frieden im Heimatland, Frieden in der Welt.« 
Die EU hat gegenwärtig nicht das politische Gewicht, sich mit Nachdruck für dieses Ziel im Nahen Osten einzusetzen. Dies ist ein ganz gewichtiges Argument für die EU-Mitgliedschaft der Türkei. Mit der Türkei wäre die EU in der Lage, in dieser Region den gewollten Einfluss geltend zu machen. Darauf werde ich weiter unten eingehen.

\section{Kemalismus und Militär}

Die Kemalisten und das türkische Militär wollen, dass die Türkei gleichberechtigtes EU-Mitglied wird. Die Rolle und die Bedeutung des Militärs in der Geschichte der Türkei unterscheiden sich stark von denen der meisten westeuropäischen Staaten, insbesondere aber von der Deutschlands.

Der Befreiungskrieg des türkischen Volkes nach der Besetzung der Türkei infolge des verlorenen Ersten Weltkriegs wurde von Offizieren unter Führung von Mustafa Kemal und seinen engsten Gesinnungsfreunden durchgeführt. Sie waren es, die die Nationalversammlung der Türkei auf Volkskongressen in Sivas und Erzurum organisierten und 1921 einberiefen. Mit revolutionären Entscheidungen der »Nationalversammlung der Türkei« (das Parlament in der Türkei heißt immer noch »Große Nationalversammlung der Türkei«) in Ankara wurde die Republik der Türkei 1923 konstituiert, und das 624-jährige osmanische Sultanat und der "Şeyhulislam", eine Art Papst der ganzen islamischen Welt, wurden abgeschafft.

Das türkische Militär sieht sich dieser kemalistischen Tradition verpflichtet. Daher ist der Kemalismus für den politischen Islam, also in den Augen derer, die einen theokratischen Staat nach den Geboten der Scharia errichten möchten, ein Hindernis. Der »Nationale Sicherheitsrat", den es übrigens auch in den USA und in mach anderen Ländern gibt, wurde neu strukturiert. In diesem Gremium sitzen neben dem Staatspräsidenten der Ministerpräsident, seine beiden Stellvertreter und je nach Tagesordnung andere Minister sowie in gleicher Zahl die Offiziere der Militärspitze. Der Sicherheitsrat trifft aber keine Entscheidungen mehr, sondern kann in seiner Funktion als ein verfassungsmäßiges Beratungsorgan lediglich Ratschläge über wichtige Fragen, die die Sicherheit des Landes betreffen, als Empfehlung an die Regierung geben. 
Es ist gänzlich falsch zu glauben, die Kemalisten seien gegen eine EU-Mitgliedschaft der Türkei. Sie sind vielmehr aufgrund ihrer prinzipiellen politischen Orientierung für den Beitritt der Türkei zur EU, allerdings mit klarer Betonung darauf, dass um der bloßen Mitgliedschaft willen nicht alles akzeptiert werden darf. Und das bedeutet Gleichbehandlung der Türkei im Vergleich mit den übrigen EU-Staaten.

\section{Kopenhagener Kriterien}

Die Türkei hat die Kopenhagener Kriterien erfüllt. Mit der Änderung von 37 der 177 Verfassungsartikel wurden die Fundamente der weiteren Demokratisierung der Türkei gelegt. Sehr umstritten waren vor allem die Änderungen, mit denen die Todesstrafe abgeschafft sowie das Erlernen anderer Muttersprachen neben dem Türkischen - insbesondere des Kurdischen erlaubt wurde. Hervorzuheben ist auch die verfassungsrechtliche Garantie, muttersprachliche Sendungen in Rundfunk und Fernsehen ausstrahlen zu dürfen.

Es folgten eine Reihe grundlegender Gesetzesänderungen mit dem Ziel, die Stärkung der Demokratie und der zivilen Behörden zu erreichen. Meinungsfreiheit, der Schutz vor Folter, die Freiheit und Sicherheit des Individuums, das Recht auf Privatsphäre, die Unverletzlichkeit der Wohnung, die Kommunikationsfreiheit, Vereinigungsfreiheit und die Gleichberechtigung der Geschlechter wurden verfassungsrechtlich den EUStandards angepasst.

Das Zivilgesetzbuch wurde geändert und trat mit den Änderungen im Januar 2002 in Kraft. Dieses war erforderlich, um die Gleichberechtigung von Mann und Frau auf allen Ebenen der Gesellschaft umsetzen zu können. Die Regierung Erdoğan setzt auch das unter der Regierung Ecevit vorgesehene Konsolidierungsprogramm der Wirtschaft fort. Mit dem siebten EUHarmonisierungspaket vom August 2003 wurde das Gesetz über den Nationalen Sicherheitsrat und dessen Generalsekretariat mit dem Ziel geändert, die Aufgaben und Zuständigkeiten dieses Gremiums neu zu ordnen und diese auf ihre beratende Rolle festzulegen. Das Generalsekretariat des Sicherheitsrates hat keine exekutiven Befugnisse mehr, sondern lediglich die Funktion eines Sekretariats des Rates. 
Die Kopenhagener Kriterien, die zur Voraussetzung für den Beginn von Beitrittsverhandlungen mit der Türkei gemacht wurden, gehören seit Jahren zu den zentralen Anliegen großer Teile der türkischen Bevölkerung. Mit ihrer Umsetzung wird die Demokratisierung des Landes vervollständigt sowie die Behebung von Defiziten in Menschenrechts- und Minderheitenfragen gewährleistet.

Ich persönlich freue mich heute außerordentlich über diesen unschätzbaren Gewinn des Beginns einer Epoche »echter Demokratie« in der Türkei. Seit Jahrzehnten haben wir den Demokratisierungsprozess verlangt und dafür gekämpft, weshalb wir in der Vergangenheit politische Repressalien erleiden mussten.

\section{III »Privilegierte Partnerschaft «}

Der Vorschlag der CDU/CSU, mit der Türkei lediglich eine "privilegierte Partnerschaft" einzugehen, ist eine Provokation. Die Christlichen Parteien Deutschlands scheinen verhindern zu wollen, dass ein demokratischer und laizistischer Rechtsstaat wie die Türkei mit ihrer mehrheitlich islamischen Bevölkerung in Zukunft EU-Mitglied wird. Sie wollen, wie sie zum Ausdruck brachten, eine EU als christliche Gemeinschaft.

Es ist für die Türken, vor allem aber für Deutschlandtürken verärgernd und verletzend, wenn Frau Merkel, Herr Schäuble, Herr Stoiber, Herr Glos oder andere Unionspolitiker die Türkei stets anders und ungleich behandeln als andere EU-AnwärterStaaten. Ihre Vorwände hierfür sind unterschiedlich: Mal werden religiöse und kulturelle Unterschiede, mal geographische Gründe oder politisch-wirtschaftliche Diskrepanzen für die ablehnende Haltung der CDU/CSU vorgebracht. Damit sie aber ihre Ablehnung gegenüber den Türken verschleiern können, haben sie neuerdings eine Worthülse als Mogelpackung entdeckt: die "privilegierte Partnerschaft« anstelle einer EU- Mitgliedschaft.

Es ist durchaus das Recht der Parteiführung, gegen eine EUMitgliedschaft der Türkei und somit auch gegen den Beginn der Beitrittsverhandlungen, mit welcher Begründung auch immer, öffentlich Position beziehen. Dies tun sie auch auf vielfäl- 
tige und höchst engagierte Weise. Frau Merkel bemüht sich sogar um Unterstützung ihrer Position bei anderen konservativen Parteien der EU.

Verwunderlich und verärgernd ist jedoch ihre Selbsteinschätzung: Sie erwartet, dass die Türkei dieses ganz offen diskriminierende und erniedrigende Angebot akzeptieren könnte. Dabei ist die von den Unionsparteien vorgeschlagene "privilegierte Partnerschaft« für die Türkei nicht nur völlig indiskutabel, sondern sie wird vielmehr als eine außenpolitische Grobheit angesehen. Wenn intensiv danach gefragt wird, was mit der "privilegierte Partnerschaft" gemeint ist, wird mit Mühe nach einer Antwort gesucht. Sie besagt, es gehe um eine Freihandelszone zwischen EU und der Türkei, eine gemeinsame Außen- und Sicherheitspolitik und Zusammenarbeit beim Kampf gegen Terror.

Diese Partnerschaft, wenn man sie privilegiert nennen will, hat die Türkei längst: Die Türkei ist seit 1996 in der Zollunion der EU. Das heißt, ein Freihandel zwischen der EU und der Türkei existiert bereits, wovon allerdings bislang die EU profitiert hat. Eine gemeinsame Sicherheitspolitik und enge Abstimmung in außenpolitischen Fragen ist mit der Türkei als NATO-Mitglied seit über 50 Jahren vorhanden. Die Türkei gehört zu den entschiedenen Ländern beim Kampf gegen internationalen Terrorismus, und es besteht bereits eine gute Zusammenarbeit mit den EU-Staaten. Da diese Idee der "privilegierten Partnerschaft « als Alternative zur EU-Mitgliedschaft der Türkei gemeint ist, wird sie von der Bevölkerung der Türkei und von Deutschlandtürken als "privilegierte Diskriminierung « bewertet.

Hinter dieser Mogelpackung steht eine freche Art der Kolonialherren-Manieren, die bezeugt, wie weit die Unionsführung von verantwortungsvollem Handeln im Bereich der Außenund Internationalen Politik entfernt ist. Der Vorstoß von Frau Merkel ist nicht staatspolitisch gedacht, sondern eine innenund parteipolitische Handlung, mit dem Ziel, Wählerstimmen zu fangen. Dabei scheuen sich die Unionsparteien nicht, bei den Wählern Ängste zu schüren. Aber sie täuschen sich. Damit unterstützen sie viel eher die Rechtsaußenparteien und bewirken, dass diese mit ihrer Anti-Türkei- und Anti-Türkenpolitik mehr Gehör finden. 


\section{Die Türkei als Bereicherung}

Die Türkei ist Chance und Bereicherung für eine visionäre EU. Die EU braucht die Türkei. Bei der Diskussion um den EUBeitritt der Türkei geht es nur um Probleme und mögliche Risiken für die EU. Welche Vorteile die EU von einer solchen Mitgliedschaft der Türkei haben würde, wird kaum diskutiert. Die Frage ist, welche Visionen die EU hat und welche Rolle sie in der Welt zu spielen gedenkt.

Will die EU lediglich eine wichtige Wirtschaftsmacht in der Welt bleiben und politisch den Weltgeschehnissen nur als $\mathrm{Zu}-$ schauer beiwohnen? Oder will sie aktiv, gestalterisch, Frieden stiftend und als aktiver Vermittler bei Konfliktlösungen tätig sein? Will sie neben den USA und zukünftig neben China etwas $\mathrm{zu}$ sagen haben, so braucht sie eine neue Gestalt, eine neue weltpolitische Orientierung. Sie muss sich als ein Weltmachtzentrum verstehen, wenn ihre ökonomische Macht auch politische Bedeutung gewinnen soll!

Beim drohenden, in manchen Teilen gewollten Kampf der Kulturen und Zivilisationen müsste sie eine Vermittlerrolle übernehmen, sie müsste Brücken zwischen den Zivilisationen, zwischen Okzident und Orient bauen. Nur so kann weltweit mehr Sicherheit, mehr Frieden, mehr Verständigung und mehr Zusammenarbeit zwischen vermeintlich gegensätzlichen Positionen in den islamischen und christlichen Ländern gestiftet werden. Der Türkei kommt genau hierbei eine ganz wichtige und unverzichtbare Rolle und Bedeutung zu. Mit ihrer geographischen und geopolitischen Lage als Brücke zwischen den Kontinenten Europa und Asien ist sie als Stabilitäts- und Machtfaktor im Nahen Osten für diese Rolle in einer besonderen Weise geeignet.

Als demokratischer, laizistischer Rechtsstaat kann sie als Modell für viele islamische Länder gelten, weil sie zeigt, dass Islam und universale Werte nicht im Widerspruch stehen. Demokratie, Laizismus, Rechtsstaatlichkeit, Menschenrechte und Modernität können genauso gut in einem Land mit islamischer Bevölkerung voll verwirklicht werden. Genau diese Ausstrahlung der Türkei mit ihrer mehrheitlich islamischen Bevölkerung wäre ein Modell für viele der islamischen Länder. 
Der EU-Beitritt der Türkei wäre ein großer Schritt zur Versöhnung der historisch belasteten Beziehungen zwischen beiden Zivilisationen, Religionen und vielfältigen Kulturen, zwischen islamisch und christlich geprägten Ländern. Genau diesen ganz elementaren Ansatz unterstreicht Alt-Bundespräsident Richard von Weizsäcker, wenn er sagt: " $\mathrm{Zu}$ den großen globalen Aufgaben gehört es, eine Brücke von den westlichen Demokratien zur muslimischen Welt zu bauen. Dafür bietet eine demokratische Türkei einen unverzichtbaren Pfeiler« (Der Spiegel vom 23. Februar 2004).

Die Türkei würde die EU stärken, und als Mitglied kann die Türkei der EU im Nahen Osten zu großem Gewicht verhelfen. Zum einen im Demokratisierungsprozess der Region, zum anderen aber auch als Vermittler für eine friedliche Lösung des Konflikts beispielsweise zwischen Israel und Palästina. Heute kommt der EU in diesen Konflikten eher eine Zuschauerrolle zu. Hiermit kann und darf sich eine so bedeutende Wirtschaftsmacht nicht zufrieden geben. Mit der Mitgliedschaft der Türkei wird die EU bedeutend an Sicherheit und Einfluss, nicht nur im Nahen Osten, gewinnen. Die Türkei kann auch eine große Bereicherung für die Wirtschaft der EU darstellen - gerade wegen ihrer sehr jungen und dynamischen Bevölkerung und Wirtschaft.

\section{Literatur}

Beauftragte der Bundesregierung für Migration, Flüchtlinge und Integration (Hg.) (2003): Migrationsbericht, Berlin.

Cem, Ismail (2001): Türkei, Europa, Eurasien: die Türkei im neuen Jahrhundert, Köln.

CIG/84/04: Vertrag über eine Verfassung für Europa vom 06. August 2004, Brüssel.

Hallstein, Walter (1979): Europäische Reden, in: Thomas Oppermann (Hg.): Europäische Reden, Stuttgart.

Hermann, Rainer (2004): Die türkische Wirtschaft macht sich fit für die EU, in: Claus Leggewie (Hg.): Die Türkei und Europa, Frankfurt a.M. 
Kuschel, Karl-Josef (2004): Die »christliche Identität« Europas und die Zukunft der Türkei, in: Claus Leggewie (Hg.): Die Türkei und Europa, Frankfurt a.M.

Quaisser, Wolfgang (2004): Die Türkei in der Europäischen Union? in: Kurzanalysen und Informationen 11/2004 des Osteuropa-Instituts München. Online unter: http://www.cdu-csu-ep.de/tuerkei/ studie_osteuropainstitut_0304.pdf.

Schmidt, Helmut (2004): Sind die Türken Europäer? Nein, sie passen nicht dazu, in: Claus Leggewie (Hg.): Die Türkei und Europa, Frankfurt a.M.

Schuster, Jacques/Köppel, Roger (2004): Zehn Gründe gegen den EU-Beitritt der Türkei, in: Die Welt vom 24. September 2004. 


\section{Die Türkei und Europa. Eine geopolitische Herausforderung}

HERFRIED MÜNKLER

I

Das türkische EU-Beitrittsersuchen und das Erfordernis, über den Beginn von Verhandlungen mit der Türkei zu entscheiden, hat die Europäer gezwungen, sich nicht nur mit den politischen, wirtschaftlichen, sozialen und rechtlichen Verhältnissen in der Türkei zu beschäftigen, sondern sich auch über die Finalität des europäischen Integrationsprozesses Rechenschaft abzulegen und zugleich die weltpolitische Rolle Europas im Lichte der jüngsten Entwicklungen im Nahen und Mittleren Osten zu bedenken. Wie also wird die Rolle aussehen, die Europa in der Weltpolitik spielen will, spielen kann und spielen muss? Die Differenz zwischen Wollen und Müssen und die Frage nach dem Können ist wohl der Schlüssel, mit dem das Problem des Beitritts oder Nichtbeitritts der Türkei in die Europäische Union anzugehen ist. Dabei steht Wollen für die Debatte, wie sie in den zurückliegenden Monaten vor allem in Deutschland geführt worden ist, wobei die Einbindung der Türkei fast durchweg als ein Problem behandelt wurde, bei dem die Europäer nach Belieben darüber entscheiden können, ob der Türkei Beitrittsverhandlungen mit dem Ziel einer Vollmitgliedschaft angeboten werden sollen oder nicht. Dass die Türkei für die politische Positionierung Europas in der Welt von entscheidender Bedeu- 
tung sein könne, wurde dagegen selten erwähnt (vgl. Bahr 2004).

In dieser Debatte haben ökonomische Gesichtspunkte, in der Regel der Abstand der Türkei zu den europäischen Durchschnittswerten bei den sozioökonomischen Indikatoren, eine große Rolle gespielt, dazu kulturalistische Fragen, die sich zumeist um die islamische Grundierung der türkischen Gesellschaft drehten, und nicht zuletzt die demokratischen und menschenrechtlichen Standards der EU, bei denen gefragt wurde, ob sie für die Türken in absehbarer Zeit erreichbar seien. Bei allen drei Komplexen, dem sozioökonomischen, dem kulturellreligiösen und dem politisch-verfassungsrechtlichen, ist die Frage nach dem EU-Beitritt der Türkei ebenso bejaht wie verneint worden. Bei der Verneinung hat vor allem der sozioökonomische Abstand der Türkei zu Europa eine entscheidende Rolle gespielt. Die Europäische Union sei, so eines der häufiger zu hörenden Argumente, nach der jüngsten Beitrittsrunde und der in ihr vollzogenen Osterweiterung nicht in der Lage, ein so großes und so rückständiges Land wie die Türkei zu verkraften. Die Grenze der wirtschaftlichen Belastbarkeit der EU, insbesondere im Bereich der Agrarpolitik und der Strukturfonds, sei inzwischen erreicht. In der Regel wurde diesem Argument noch der Hinweis auf die für den Fall eines türkischen EUBeitritts erfolgende Migration Arbeitssuchender von Anatolien nach Westeuropa hinzugefügt, die zu einer Überlastung insbesondere des deutschen Arbeitsmarkts führen werde. Noch stärker haben kulturalistische Überlegungen, die den religiösen Unterschied zwischen Islam und Christentum ins Zentrum rückten, zu einer Ablehnung des EU-Beitritts der Türkei geführt. Gegen die Akzentuierung der grundlegenden Unterschiede zwischen Christentum und Islam hat der Hinweis auf die mögliche Brückenfunktion der Türkei zwischen Europa und der islamischen Welt einen nur schwachen Einspruch dargestellt.

Am ehesten noch dürfte das Verhältnis zwischen Befürwortern und Gegnern des EU-Beitritts der Türkei ausgewogen gewesen sein, wenn das türkische Beitrittsersuchen mit politischverfassungsrechtlichen Argumenten ausgemessen worden ist: Dem Hinweis auf Demokratiedefizite der Türkei und Verletzungen der Menschenrechte stand hier das Argument gegen- 
über, dass die Türkei mit Blick auf den EU-Beitritt in jüngster Zeit in beiden Bereichen gewaltige Fortschritte gemacht habe und durch eine Entscheidung für die Aufnahme von Beitrittsverhandlungen diese Entwicklungen stabilisiert und weiter vorangetrieben werden könnten. Alle Argumente, die in den 70er Jahren für den EU-Beitritt Spaniens, Portugals und Griechenlands geltend gemacht worden waren, konnten in dieser Debatte nunmehr zugunsten der Türkei angeführt werden: Das zarte Pflänzchen der Demokratie bekomme auf diese Weise einen sicheren Halt, ein Rückfall in eine Militärdiktatur werde im Verband der EU unmöglich sein, und auch die reale Lage der Menschenrechte werde sich auf diesem Wege weiter verbessern. Insgesamt freilich dürften die Gegner eines türkischen EU-Beitritts das Übergewicht gehabt haben. Und auch wenn sie nicht immer die besseren Argumente hatten, so fanden sie doch bei der Bevölkerung den größeren Anklang. ${ }^{1}$ Ein deutsches Referendum über den EU-Beitritt der Türkei hätte, wenn es im Dezember 2004 durchgeführt worden wäre, wohl zu einem klaren Nein geführt. Ob die Referenden, die demnächst in einigen europäischen Staaten stattfinden werden, $\mathrm{zu}$ einem anderen Ergebnis führen, bleibt abzuwarten.

Die Argumentationslage ändert sich freilich, wenn man die Frage des europäischen Wollens der türkischen EU-Mitgliedschaft durch die einer europäischen Angewiesenheit auf die Türkei ergänzt, wenn es also nicht nur darum geht, ob die Europäer den türkischen Beitritt mit Blick auf die damit verbundenen sozioökonomischen, kulturell-religiösen und politisch-verfassungsrechtlichen Herausforderungen wollen, sondern ob sie nicht vielmehr die Einbindung der Türkei als vollberechtigter Partner in die EU aus geopolitischen Gründen anstreben müssen, weil sie sonst riskieren würden, dass sich an der Südostflanke der EU in absehbarer Zukunft ein Krisenherd entwickelt, der ohne die Türkei nicht erfolgreich zu bearbeiten ist. Das geopolitische Argument hebt also wesentlich auf die Sicherheit Europas und die Stabilität seiner Peripherie ab. Dabei geht es davon aus, dass sich die Europäer auf Dauer nicht aus den Konflikten des Nahen und Mittleren Ostens heraushalten können, sondern im Gegenteil aus wohlverstandenem Eigeninteresse in diesen Konflikten eine konstruktive Rolle spielen müssen. Dies wird aber nur möglich sein, wenn die Türkei fest in die Europä- 
ische Union eingebunden ist und es der muslimischen Welt infolgedessen unmöglich ist, Europa als einen ihr kulturellreligiös fremden Akteur zurückzuweisen. ${ }^{2}$

Das europäische Gesamtinteresse an der politischen Stabilität des Nahen und Mittleren Ostens beruht auf drei Teilinteressen: erstens der Vermeidung oder zumindest doch Eingrenzung von Kriegen, welche zwangsläufig auch die Europäer betreffen werden - entweder weil sie nach Europa übergreifen oder weil die Europäer bei friedensstiftender Intervention immer tiefer in diese Kriege hineingezogen würden. Zweitens der Vermeidung bzw. Unterbindung von Flüchtlingsströmen nach Europa, die $\mathrm{zu}$ einem notorischen Begleiter von Kriegen im Zeitalter der Globalisierung geworden sind und bei einem größeren Krieg in der Region Europa zwangsläufig in Mitleidenschaft ziehen würden. Die Flüchtlingsbewegungen, mit denen sich Europa (und insbesondere Deutschland) während der jugoslawischen Zerfallskriege konfrontiert sah, wären dann nur ein kleiner Vorgeschmack auf das in diesem Fall zu Erwartende gewesen. Drittens geht es um die Sicherheit und Zuverlässigkeit der europäischen Energieversorgung, die nicht nur ein ökonomisches, sondern auch ein sicherheitspolitisches Problem darstellt. In dieser Frage sollte Europa weder von den konkurrierenden Interessen der USA noch von den Launen arabischer Potentaten abhängig sein, bzw. es sollte realisieren, dass es sich solche Abhängigkeiten nicht länger leisten kann. Diese Abhängigkeit mag in der Zeit des Ost-West-Konflikts verkraftbar gewesen sein, als die angenommene oder tatsächliche kommunistische Bedrohung die USA, Europa und die arabische Welt in eine Zwangssolidarität hineindrängte. Auch das hat sich mit dem Ende des Ost-West-Konflikts verändert.

Diejenigen, die in der zurückliegenden Türkei-Debatte die Beitrittsfrage als eine allein des europäischen Wollens traktiert haben, haben die seit den 90er Jahren grundlegend veränderten weltpolitischen Konstellationen nicht in Rechnung gestellt und sind statt dessen davon ausgegangen, das im Schatten des amerikanischen Schutzes entstandene und aufgewachsene Europa befinde sich auch weiterhin in dieser komfortablen Position. Das ist aus vielerlei Gründen jedoch nicht mehr der Fall. Drei davon seien hier besonders genannt: $D a$ ist erstens das veränderte Verhältnis der USA zu Europa, das zunehmend als si- 
cherheitspolitischer Kostgänger und ökonomischer Konkurrent wahrgenommen wird. Die Zeiten, in denen (West-)Europa und die USA ganz selbstverständlich eine Interessen- und Wertegemeinschaft darstellten, sind vorbei. Was geblieben ist, sind gemeinsame Werte, während die Interessen oft divergieren. Organisatorisch hat dies in der Osterweiterung der Nato seinen Niederschlag gefunden, bei der die Aufnahme neuer Mitglieder aus dem postsowjetischen Raum nur einen Aspekt darstellte, während der andere in der Abstreifung jener Selbstfesselungen bestand, die sich die USA in den alten Nato-Strukturen mit guten Gründen auferlegt hatten. Im Vorfeld des jüngsten Golfkrieges ist deutlich geworden, dass die USA die fortgesetzte sicherheitspolitische Kostgängerei der Europäer durch politische Gefolgschaft und finanzielle Unterstützung beglichen wissen wollen (vgl. Münkler 2003: 139ff.). Robert Kagan hat dies in der Formel zusammengefasst, »dass die USA >das Essen zubereiten « und die Europäer >das Geschirr abwaschen« (Kagan 2003: 28). Dieser Preis für die sicherheitspolitische Abhängigkeit Europas von den USA dürfte auf Dauer zu hoch sein. Die Einbindung der Türkei in die EU ist eine zentrale Voraussetzung für eine selbständige Sicherheitspolitik der Europäer.

Zum Erfordernis einer eigenständigen europäischen Sicherheitspolitik hat auch die Vergrößerung der EU in den letzten Jahren beigetragen. So folgte auf die Süderweiterung die Norderweiterung und schließlich die Osterweiterung der EU, in deren Gefolge das ursprünglich nur wirtschaftlich integrierte Europa der Sechs zu einer politischen Größe geworden ist, die sich einen weltpolitischen Platz suchen muss - ob sie dies nun will oder nicht. Die Zeiten, in denen sich die Europäer politisch unsichtbar machen konnten und in den Konstellationen des den Kontinent in zwei Hälften spaltenden Ost-West-Gegensatzes verschwanden, sind endgültig vorbei, auch wenn diejenigen, die die Türkei-Debatte als einen des reinen Wollens der Europäer geführt haben, dies entweder noch nicht gemerkt haben oder aber nicht wahrhaben wollen. Um es zuzuspitzen: Die Europäische Union muss im 21. Jahrhundert eine weltpolitisch bedeutsame Rolle spielen, oder sie wird im Verlauf der ersten beiden Jahrzehnte dieses Jahrhunderts scheitern, das heißt: wieder in die Bestandteile zerfallen, aus denen sie gebildet worden ist. 
Tatsächlich haben die Europäer das Glück gehabt, sich in aller Ruhe auf diese Herausforderung vorbereiten zu können, insofern der Ost-West-Konflikt eine Verlangsamung, wenn nicht Stillstellung der weltpolitischen Abläufe darstellte. Ob die Europäer diese Zeit wirklich genutzt haben, ist freilich eine andere Frage. Jedenfalls hat sich während des Ost-West-Konflikts in den politischen Klassen einiger europäischer Länder die Vorstellung herausgebildet, man habe für Entscheidungsprozesse welcher Art auch immer unendlich viel Zeit zur Verfügung und könne sich dementsprechend bei der Entschlussfassung verhalten. Dass diese Konstellationen nicht mehr vorhanden waren, haben die Europäer erstmals während der jugoslawischen Zerfallskriege erfahren müssen, als sie zu spät reagierten, um die Massaker und Vertreibungen zu verhindern, und schließlich auf die Amerikaner angewiesen waren, um dem Morden ein Ende zu machen. Diejenigen, die das türkische Beitrittsersuchen zur EU als eine Frage verstanden haben, bei der es wesentlich um kulturell-religiöse Probleme geht, haben diese Verknappung der Zeitressource nicht hinreichend wahrgenommen.

Es sind Entwicklungen auf Seiten der USA, Veränderungen bei den Europäern und schließlich eine allgemeine Akzelerierung der Weltpolitik nach dem Ende des Kalten Krieges, die eine Bearbeitung des türkischen Beitrittsersuchens allein aus der Binnenperspektive der Europäer als kurzsichtig und letzten Endes verhängnisvoll erscheinen lassen. Wahrscheinlich kann man sagen, dass dies die spezifische Sicht jener zwei Generationen darstellt, für die das geeinte Europa die politische Antwort auf die den Kontinent verwüstenden Kriege während der ersten Hälfte des 20. Jahrhunderts war. Das waren in der Tat die Antriebskräfte, aus denen der europäische Einigungsprozess erwachsen ist und die ihn auch lange Zeit getragen und vorangetrieben haben. Will man es knapp auf den Punkt bringen, so diente der Prozess der wirtschaftlichen Verflechtung über die nationalstaatlichen Grenzen hinweg, der am Anfang der europäischen Vereinigung stand und nicht erst mit der Gründung der EWG, sondern bereits mit den Montanverträgen begann, der Lösung eines europäischen Binnenproblems: der Bändigung Deutschlands, das seit der Bismarck'schen Reichsgründung aufgrund seiner wirtschaftlichen Macht, seiner Be- 
völkerungszahl und seiner militärischen Stärke der potentielle Hegemon Europas war.

Durch die Teilung Deutschlands im Gefolge des Zweiten Weltkriegs hatte das Problem zwar einiges an Virulenz verloren, doch stellte auch die alte Bundesrepublik das wirtschaftlich wie demographisch bei weitem stärkste Land der EWG wie der EG dar. Das hat sich mit der Vereinigung der beiden deutschen Staaten nochmals verstärkt. Es kommt nicht von ungefähr, dass parallel zur deutschen Vereinigung auch der europäische Integrationsprozess erheblich an Dynamik gewonnen hat - vom Schengen-Abkommen bis zur Euroeinführung und parallel dazu von der Stärkung des Parlaments bis zum Entwurf einer europäischen Verfassung. Deutschland ist durch seine Einbindung in das verfasste Europa aus einem politischen Paria, der es nach dem Ende des Zweiten Weltkriegs war, in einen gleichberechtigten Mitgliedsstaat Europas zurückverwandelt worden, und dieser Doppelprozess, die Bändigung wie die Wiedereingliederung Deutschlands, hat lange die Fortschritte der europäischen Integration getragen und stabilisiert. Aber aus der Lösung des Binnenproblems ist mit der Zeit ein Außenproblem erwachsen: Das geeinte Europa wurde zum Erfolgsmodell, und immer mehr Staaten suchten sich diesem Modell anzuschließen. Was als eine Gemeinschaft der Sechs begonnen hat, ist inzwischen zu einem Verband aus fünfundzwanzig Mitgliedsstaaten geworden, und es ist nicht absehbar, dass es damit sein Bewenden haben wird. Die Sorge über diese Entwicklung, die überaus berechtigt ist, hat sich zuletzt mit dem Beitrittswunsch der Türkei verbunden, und nicht zuletzt im Gefolge dieser Verbindung hat die Türkei-Debatte eine Dynamik erlangt, die wenige Monate zuvor noch unverstellbar gewesen wäre.

\section{II}

Europa ist ein Kontinent mit unklaren geographischen Grenzen, ${ }^{3}$ und selbst dort, wo die geographischen Verhältnisse eher klar sind und eindeutige Demarkationen nahe legen, werden die geographischen Grenzen von kulturellen und politischen Verbindungen überlagert. Europa ist ein Kontinent der unscharfen Grenzen, und das gilt vor allem für die östlichen und 
südlichen Grenzen. Eher unproblematisch ist die europäische Nordgrenze: Der Norden Skandinaviens markiert eine Grenze, deren Bedeutung nicht in Frage steht und hinter der es keine weiteren Beitrittskandidaten gibt. Um einiges problematischer ist dagegen die europäische Westgrenze, auch wenn sie geographisch klar und unfraglich zu sein scheint. Erst jüngst hat der britische Historiker Garton Ash darauf hingewiesen, dass Großbritannien, das geographisch zweifellos zu Europa gehöre, sich sprachlich sehr viel stärker den USA verbunden fühle (vgl. Garton Ash 2004: 28ff.). Die Regierung Blair hat diese Ambivalenz dadurch handhabbar zu machen versucht, dass sie Großbritannien eine Brückenfunktion zwischen Europa und den USA attestierte. Dementsprechend ist sehr bald auch von einer Brückenfunktion der Türkei gesprochen worden, die das zentrale Verbindungsglied zwischen Europa und der islamischen Welt darstellen könne. Wie tragfähig auch immer solche Brücken sein mögen - sie zeigen an, dass hier, aus welchen Gründen auch immer, das Interesse eher an Grenzüberschreitung als an Grenzziehung besteht und dass es Länder gibt, die sich klaren Grenzziehungen entziehen. Im Westen ist dies mit Großbritannien, zumindest bei dessen konservativem Teil, ganz eindeutig der Fall.

Noch sehr viel undeutlicher ist die Ostgrenze Europas. Paul Valery hat von Europa als Vorgebirge Asiens gesprochen, und im Verlaufe ihrer Geschichte haben die Europäer immer wieder mit großer Besorgnis auf ihre Ostgrenze geschaut, an der es in unregelmäßigen Abständen zu massiven Invasionen aus der innerasiatischen Steppe gekommen ist. In geschichtlichen Zeiten beginnt dies bei der Völkerwanderung, die schließlich das Römische Reich im Westen zertrümmerte, und reicht bis zu den verschiedenen russischen Reichsbildungen, in deren Gefolge die europäische Ostgrenze in Bewegung kam. Dabei standen den Vorstößen aus der asiatischen Steppe nun europäische Versuche gegenüber, den eigenen Einflussbereich nach Osten hin auszudehnen und auf diese Weise die europäische Ostgrenze vorzuschieben. Gerade den russischen Reichsbildungen kam dabei eine entscheidende Bedeutung zu. Die Frage der europäischen Ostgrenze, die geographisch kaum zu beantworten ist, ist demgemäß eine wesentlich politische Frage; ihre Beantwortung ist davon abhängig, als was Russland jeweils wahrgenommen 
worden ist: als eine eher europäische oder eine eher asiatische Macht. ${ }^{4}$ Hatten die antiken Geographen die Ostgrenze Europas auf den Don gelegt, so haben die Geographen des 18. Jahrhunderts in Reaktion auf die Reformen Peters des Großen die Ostgrenze Europas bis zum Uralgebirge und zur Wolga vorverlegt, wodurch Russland zu einem europäischen Staat wurde. Das Beispiel zeigt, dass auch geographische Grenzziehungen politisch-kulturell imprägniert sein können.

Geographisch ist die europäische Südgrenze durch das Mittelmeer markiert, jenseits dessen Afrika beginnt. Wer sich auf diese Grenzziehung als eine für die Europäische Union verbindliche Markierung beruft, übersieht, dass in der Antike das Mittelmeer keine Grenze, sondern einen Verbindungsraum darstellte und dass es erst der arabische Vorstoß des 7./8. Jahrhunderts war, der Europa aus dem mittelmeerischen Raum heraus- und in den Nordwesten zurückdrängte. ${ }^{5}$ Aber diese politisch-kulturelle Zurückdrängung Europas war nur von begrenzter Dauer, gelang es den europäischen Handelsmächten doch seit dem 11./12. Jahrhundert, die Araber zurückzuwerfen und in der Zeit der Kreuzfahrerstaaten sogar im östlichen Mittelmeer wieder Fuß zu fassen. Das Mittelmeer blieb ein zwischen Europäern und Türken, Ägyptern sowie Nordafrikanern umstrittener Raum. So waren im Zeitalter des Kolonialismus viele europäische Mächte damit beschäftigt, die gegenüberliegende Küste zu gewinnen und dort Kolonien zu errichten. Die europäische Kontrolle über die afrikanische Nordküste endete mit dem Zusammenbruch der Kolonialherrschaft im Verlauf der 50er Jahre, aber entgegen der Vorstellung, damit sei Europa wieder in seine natürlichen Grenzen zurückgekehrt, geht das Wechselspiel von Vorstoß und Rückzug hier durchaus weiter: Der ökonomischen Durchdringung des nordafrikanischen Raums von Seiten der Europäer stehen in wachsendem Maße Flüchtlingsströme gegenüber, die von Nordafrika nach Europa gelangen.

Der heikelste Bereich der europäischen Grenzen liegt aber im Südosten, wo sich die drei Kontinente Europa, Asien und Afrika überlappen: In einem weiteren Sinn handelt es sich dabei um den unteren Balkan, Kleinasien sowie den Nahen und Mittleren Osten, die in unterschiedlicher Intensität während der letzten Jahrzehnte ein Krisen- und Konfliktgebiet darstellen, 
das mit dem nach 1945 friedlich gewordenen Europa scharf kontrastiert. In der Terminologie Robert Coopers könnte man sagen, dass hier moderne sowie postmoderne und prämoderne Formen von Staatlichkeit aufeinander stoßen (vgl. Cooper 2004). Die starre Fixierung auf die geographische Grenze am Bosporus, wie sie in vielen Debattenbeiträgen angemahnt wurde, verfehlt die intensiven Verbindungen, die Europa klassisch in diesen Raum hinein hatte. Athen und Jerusalem markieren dabei die Orte, aus denen sich die europäische Identität herleitet. Wer darauf Wert legt, Europa als christlich zu bezeichnen, wer womöglich gar von Europa als christlichem Abendland spricht (vgl. Faber 1979), sollte nicht übersehen, dass die Entstehung des Christentums von der Jerusalemer Jesusgemeinde bis zu einem Großteil der Aufenthalte und Briefe des Apostels Paulus ein nahöstlich-kleinasiatischer Vorgang gewesen ist. Die emphatischen Vertreter eines christlichen Europa haben in der Debatte über die kulturellen und politischen Grenzen Europas die Ursprünge ihrer Religion zu einem außereuropäischen Vorgang gemacht. Aber das politisch Entscheidende an der südöstlichen Flanke Europas ist die bis weit nach Europa hineinreichende Instabilität dieser Region, die den Raum des ehemaligen Jugoslawien umfasst und sich einerseits bis zum Schwarzen Meer, andererseits in den Nahen Osten hinein ausbreitet. Spätestens mit dem EU-Beitritt Bulgariens und Rumäniens im Jahre 2007 wird die EU bis weit in diese Zone der politischen Instabilität und wirtschaftlichen Rückständigkeit hineinreichen.

Der Blick in die Geschichte dieses Raums am Überlappungsbereich dreier Kontinente zeigt obendrein, dass er eine Brutstätte für ausgreifende Reichsbildungen, aber auch für Konflikte und Kriege darstellt, die bereits in der Antike ideologisiert wurden, indem sie als ein Zusammenstoß von Ost und West, Despotie und Freiheit dargestellt wurden. Später stellten dann das Byzantinische und anschließend das Osmanische Reich Großmachtbildungen in diesem Raum dar, die sich fast immer in einer Konkurrentenrolle zu Westeuropa begriffen. Und als seit Beginn des 19. Jahrhunderts das Osmanische Reich in eine Periode lange währender Agonie eintrat, waren die west- und mitteleuropäischen Staaten darum bemüht, durch Militärinterventionen die in diesen Raum hinein expandierende russische Macht zu blockieren und vom Mittelmeer fernzuhal- 
ten. Im Krimkrieg haben Frankreich und Großbritannien diese Rolle gespielt, von der Jahrhundertwende bis zum Ende des Ersten Weltkriegs ist sie von Deutschland übernommen worden. In der Zeit des Kalten Krieges schließlich war neben der Bundesrepublik Deutschland die Türkei der geopolitisch wichtigste Nato-Verbündete - was die USA im Unterschied zu vielen Europäern immer gewusst haben.

Der Blick auf die geographischen und kulturellen Grenzen Europas zeigt also, dass die EU ihren weiteren Ausbau weder an geographisch noch kulturell eindeutigen Grenzen orientieren kann. Europa hat weder klare Grenzen noch eine fraglose Identität. Selbst der Rekurs auf das Christentum bleibt unzulänglich, ist für dieses doch die Spaltung in die lateinische und die orthodoxe Christenheit zentral, was nicht nur bedeutsam war für die Trennung von geistlicher und weltlicher Macht, die in der lateinischen Christenheit mit dem Ausgang des Investiturstreits vollzogen war, während die östliche Christenheit weder in Konstantinopel noch in Moskau eine ähnliche Entwicklung vollzogen hat. ${ }^{6}$ Aber selbst wenn man daraus die Konsequenz zieht und die europäische Identität auf die lateinische Christenheit, also das Abendland, beschränkt, so bliebe doch das Problem der konfessionellen Spaltung in Katholizismus und Protestantismus, die nicht nur in politisch-kultureller Hinsicht erhebliche Spuren hinterlassen hat. Mindestens ebenso bedeutsam wie die christliche Grundierung der europäischen Kultur ist nämlich die Neutralisierung der konfessionellen Gegensätze im politischen Ordnungsmodell des Territorialstaats, der sich von einer wesentlich religiösen Fundierung seiner Ordnungsansprüche befreit und dadurch säkularisiert hat. ${ }^{7}$

\section{III}

Lange Zeit ist in der Politikwissenschaft auf den Unterschied zwischen den beiden wichtigsten Organisationsformen des Politischen kein großer Wert gelegt worden: der Differenz zwischen Staat und Imperium (vgl. Münkler 2004, 2005). Man ging im Allgemeinen davon aus, dass Imperien so etwas wie große Staaten seien und sie ansonsten keine weiteren Unterschiede aufwiesen. Tatsächlich unterscheiden sich Staaten und Impe- 
rien jedoch in der Ordnung ihrer Grenzen, so dass die Art der Grenzziehung gleichsam zum Lackmustest für die Frage werden kann, ob wir es mit einem Staat oder einem Imperium zu tun haben. Insbesondere der Nationalstaat, der sich in Europa im Verlauf des 18. und 19. Jahrhunderts durchgesetzt hat, konstituiert sich durch eine Strategie systematischer Grenzbündelung. Nationalstaatliche Grenzen sind nicht nur politische und wirtschaftliche, sondern auch sprachliche und kulturelle Grenzen. Die Grenzen des Nationalstaats sind überdeterminiert, und sein politisches Projekt ist die Durchsetzung dieser Grenzbündelung, notfalls auch mit Gewalt. Um die Frage des Grenzverlaufs sind nicht wenige Kriege geführt worden.

Im Gefolge dieser Grenzbündelung hat mit dem europäischen Nationalstaat ein ungemein handlungsfähiger Akteur die politische Bühne betreten, und diese Handlungsfähigkeit ist ihm nicht zuletzt aus der durch die Grenzbündelung entstandenen Homogenisierung im Innern erwachsen. Vor allem hinsichtlich der inneren Solidarität hat der Nationalstaat alle mit ihm konkurrierenden politischen Ordnungen übertroffen, wobei diese Solidarität sowohl in der Form des Sozial- und Wohlfahrtsstaats als auch in der Mobilisierung der Bevölkerung für die Führung von Kriegen ausmünzbar war. An diesen Mobilisierungsdefiziten sind die alten Reiche bzw. Imperien in der Konfrontation mit dem Nationalstaat gescheitert. Am Ende des Ersten Weltkriegs waren die drei großen Reiche, die bis dahin den mittel- und osteuropäischen Bereich sowie den Raum vom Balkan bis in den Mittleren Osten beherrscht hatten, von der politischen Landkarte verschwunden: Die Donaumonarchie ist gänzlich zerfallen, das Osmanische Reich hat sich auf seinem alten Kerngebiet als Türkei reorganisiert, und das zarische Russland ist in verkleinerter Gestalt und mit radikal verändertem Selbstverständnis als Union der Sozialistischen Sowjetrepubliken wiedergekehrt. In den postimperialen Räumen Mitteleuropas kam es anschließend vom Baltikum bis zum Balkan zur Bildung von Nationalstaaten, die nach dem westeuropäischen Vorbild nun eine Grenzbündelung betrieben, die entweder auf massive ethnische Vertreibungen oder eine Politik der Diskriminierung nationaler Minderheiten hinauslief (vgl. Diner 1999). Eine demokratische Organisation dieser im postimperialen Raum entstandenen Nationalstaaten scheiterte und wurde 
durch eine Melange aus Partei- und Militärdiktaturen abgelöst. Die Politik nationalstaatlicher Grenzbündelung hat in Mitteleuropa zunächst zu erhöhter Instabilität geführt. Den neoimperialen Entwürfen der Diktatoren Hitler und Stalin für diesen Raum, die in den Geheimabkommen vom August 1939 festgeschrieben wurden, erwuchs eine Durchsetzungschance nicht zuletzt aus dieser Instabilität.

Nach dem Zweiten Weltkrieg wurde, freilich begrenzt auf Westeuropa, mit der Entwicklung der EWG eine andere Lösung gesucht: Zwar wurde das nationalstaatliche Ordnungsmodell im Prinzip beibehalten, aber durch die systematische Entflechtung von politischen und wirtschaftlichen Grenzen in seiner Konfliktdynamik und Konfliktintensität deutlich abgeschwächt. Die Grenzentflechtung und damit verbunden die Auflösung scharf ausgebildeter politisch-kultureller Identitäten galt als der Königsweg zur Überwindung des europäischen Problems gesteigerter Belligerenz. Europa beschritt in den 60er und 70er Jahren einen »dritten Weg" zwischen Nationalstaat und Imperium, insofern es Elemente von beidem in einer originellen Weise miteinander vermischte. Aber das Modell des Nationalstaates saß offenbar zu fest in den Köpfen der politischen Klassen Europas, so dass sich der Prozess der europäischen Vereinigung seit Ende der 70er Jahre wieder auf eine Bündelung der unterschiedlichen Grenztypen an den europäischen Außengrenzen zubewegte. Das Modell der Grenzdiversifikation wurde zunehmend durch eine neuerliche Grenzbündelung in den Entwürfen der Finalität Europas abgelöst. Die Folge dessen sind inzwischen scharfe und harte Brüche an den europäischen Außengrenzen, die mittlerweile zu Exklusionsgrenzen geworden sind. Im Ergebnis erwachsen regelmäßig an den neuen EUAußengrenzen weitere Beitrittswünsche, in deren Gefolge dann Beitrittsrunde auf Beitrittsrunde wellenförmig aufeinander folgen. Es ist, wenn man es zuspitzen will, die Politik der Grenzbündelung von Seiten der Europäischen Union, die den permanenten Prozess der EU-Ausdehnung in Gang gesetzt hat und die mittelfristig zu einer Überlastung der Steuerungs- und Integrationsfunktion der EU führen dürfte.

Eine Alternative hierzu ist das Modell der imperialen Ordnung, das auf einer Diversifikation der verschiedenen Grenzlinien besteht. Imperien stellen sich, was Integration und Homo- 
genität anbetrifft, als Ordnungen der um ein Zentrum gelegten Ellipsen und Kreise dar. Imperien bestehen aus einem Kern, Zentralbereichen, die durch die inneren Ringe markiert werden, den Randbereichen der äußeren Ringe und der Peripherie. Die Folge dessen ist, dass Imperien keine harten Brüche an ihren Außengrenzen kennen, sondern eher fließende Übergänge, was sie als flexible Ordnung charakterisiert. Ein an dieser imperialen Ordnung orientiertes Expansionsmodell der Europäischen Union haben sich die Politiker und ihre Berater jedoch nicht zu denken, geschweige denn davon zu sprechen getraut. Dafür war die Erinnerung an die Epoche des außereuropäischen Kolonialismus und der als imperialistisch wahrgenommenen Kriege innerhalb Europas noch zu frisch. Und doch hätten aus dieser Form von Grenzziehung und Integration genau die Anregungen gewonnen werden können, die den Prozess der Neuordnung Europas deutlich flexibler gestaltet hätten, weil sie nicht auf die Alternative von Vollmitgliedschaft oder Assoziation beschränkt geblieben wären.

Als einige aus der CDU-Spitze dann mit dem Vorschlag einer "privilegierten Partnerschaft « für die Türkei aufkamen, was im Prinzip eine Zwischenform von Assoziation und Vollmitgliedschaft war, machten sie den verheerenden Fehler, diesen Status allein auf die Türkei zu beschränken. Richtig wäre gewesen, dieses Modell gestufter Integration beispielsweise auch auf die Slowakei, Rumänien und Bulgarien anzuwenden und es als Perspektive für Osteuropa und Nordafrika zu entwickeln. Unter diesen Umständen wäre ein solches Angebot an die Türkei nicht auf eine bloße Brüskierung hinausgelaufen, die von den Türken als Zuschlagen der europäischen Tür empfunden werden musste. Obendrein hätte die Diskussion über die allmähliche Abflachung der äußeren Ränder der EU unter keinen Umständen mit kulturalistisch-religiösen Begründungen aufgefüttert werden dürfen. Vor allem aber hätte die Abflachung der äußeren Ränder mit einer Stärkung des Zentrums verbunden werden müssen, und die alte Metapher von der Achse ParisBonn/Berlin hätte ein sehr viel realeres Gewicht erlangen müssen. Die Grenzdiversifikation, die im Falle des SchengenAbkommens oder des Euro-Raums ja durchaus funktioniert, hätte auch bei der Verteilung der politischen Gewichte ins Spiel gebracht werden müssen. Das hätte obendrein den Vorteil ge- 
habt, dass sich London dann hätte entscheiden müssen, ob es in Europa die erste Geige spielt oder im Verhältnis zu den USA den Platzanweiser im Zuschauerraum abgibt.

\section{IV}

Der seit einigen Jahren auf dem Aus- und Umbau Europas lastende Zeitdruck ist nicht zuletzt daraus erwachsen, dass es den »Westen" als einen durch geteilte Werte und gemeinsame Interessen zusammengehaltenen politisch-kulturellen Raum nicht mehr gibt. Es ist bezeichnend, dass in letzter Zeit der Westen als Wertegemeinschaft, aber nicht mehr als Interessengemeinschaft apostrophiert wird. Gleichzeitig wird er durch die Hinzunahme einer Reihe ostasiatischer Staaten weiter ausgedehnt. Objektiv liegt diese Entwicklung im Interesse der USA, insofern sie dem Hegemon der westlichen Welt ein Reservoir potentieller Partner für einzelne Unternehmungen zur Verfügung stellt, aus denen der nach seinem Belieben coalitions of able and willing zusammenstellen kann. Diese Entwicklung, die kurzzeitig im Vorfeld des Irakkrieges zu heftigen Debatten über das Verhältnis zwischen Europa und den USA geführt hat, kann langfristig nicht im Interesse der Europäer liegen. Aktuell verlieren sie gegenüber den USA an politischem Gewicht und Einfluss.

Dem steht gleichzeitig die Tatsache gegenüber, dass Europa heute geopolitisch mehr ist als ein bloßer Anhang des amerikanischen Sicherheits- und Schutzschildes, der es objektiv in der Zeit des Ost-West-Konflikts war. ${ }^{8}$ Das Ende der Teilung des Kontinents und der Zusammenbruch der Sowjetunion als Weltmacht hat Europa zu einem potentiell selbständigen Akteur der Weltpolitik aufrücken lassen. Diese Position richtet sich nicht zwangsläufig gegen die USA, aber sie verschafft die Möglichkeit, dass sich die Europäer nicht länger zwingend im Nachtrab der USA bewegen. Gerade aus dieser Nachtrabposition hat in der Vergangenheit der rechte wie linke Antiamerikanismus in Deutschland seine Kraft bezogen. Eine stärkere Selbständigkeit der Europäer gegenüber den USA ist auch darum vonnöten, weil für die USA der atlantische Raum in Zukunft nicht länger prioritär sein wird und er bereits jetzt gegenüber dem pazifischen Raum einen merklichen Bedeutungsverlust erlitten 
hat. Europa wird in Zukunft stärker auf sich selbst gestellt sein, und in dieser Situation wird alles darauf ankommen, dass es diesen Herausforderungen gewachsen ist. Die Einbindung der Türkei in eine außen- und sicherheitspolitisch handlungsfähige EU wäre eine zentrale Voraussetzung dafür.

Der Wiederaufstieg Europas nach dem Ende des Ost-WestKonflikts ist nicht zuletzt der Entstehung großer postimperialer Räume an seinem östlichen Rand geschuldet, in die hinein es sich im Verlauf der 90er Jahre ausgedehnt hat und die mit der jüngsten Beitrittsrunde Teil der EU geworden sind. So konnte die in postimperialen Räumen ansonsten immer wieder zu beobachtende Krisenentwicklung vermieden werden: Der Raum zwischen Lettland und Ungarn zeichnet sich durch eine in jeder Hinsicht bemerkenswerte Stabilität aus, und diese Stabilität dürfte nicht zuletzt aus der Perspektive des EU-Beitritts für die dortigen Länder erwachsen sein. Ganz anders ist dagegen die Entwicklung auf dem Balkan und im Kaukasus verlaufen, wo der Zusammenbruch Jugoslawiens und der Sowjetunion eine politisch fragmentierte und wirtschaftlich ruinierte Landschaft mit starken kulturell-religiösen Gegensätzen hinterlassen hat. Nicht weniger prekär ist die Situation im Nahen und Mittleren Osten, dem postimperialen Raum des früheren Osmanischen Reichs, der mehrere Jahrzehnte von England und Frankreich als Mandatsmächten des Genfer Völkerbundes verwaltet worden ist, bis er dann zwischen der Sowjetunion und den USA in Einflusszonen parzelliert wurde. Auch hier hat der Zusammenbruch der Sowjetunion weit reichende Folgen gezeitigt, die einerseits eine Chance zur Lösung lange verschleppter Probleme darstellen, andererseits aber auch eine erhöhte Konfliktintensität mit allen Gefahren und Risiken nach sich ziehen. Dieser Entwicklung können die Europäer nicht teilnahmslos gegenüberstehen.

Die Gegner eines EU-Beitritts der Türkei haben zuletzt argumentiert, gerade wegen der unabsehbaren und wohl auch unbeherrschbaren Risiken dieses Raumes sollten sich die Europäer von ihm so weit wie möglich fernhalten. Genau dies war gemeint, wenn darauf hingewiesen wurde, dass die EU nach einem Beitritt der Türkei eine unmittelbare Grenze mit Syrien, dem Irak und dem Iran sowie den Kaukasusstaaten Georgien und Armenien haben werde. Dahinter stand offenbar die Vor- 
stellung, wenn man sich nur klein und möglichst unsichtbar mache, würden die weltpolitischen Unwetter schon an einem vorbeiziehen. Das Problem ist freilich, dass Europa infolge seiner Erweiterungsrunden längst zu groß geworden ist, als dass diese Strategie des Wegduckens noch funktionieren könnte. Europa wird so oder so eine direkte Grenze mit den genannten Krisengebieten haben; die Frage ist nur, wo diese Grenze verläuft: durch den Balkan oder am Euphrat. Je besser es der EU gelingt, die Türkei politisch an ihre Standards heranzuführen und sie zugleich wirtschaftlich zu stabilisieren, desto höher ist die Wahrscheinlichkeit, dass diese Grenze am Euphrat und nicht durch den Balkan verläuft. Vor allem daran wird deutlich, dass das türkische Beitrittsersuchen nicht eine allein nach dem innereuropäischen Wollen oder Nichtwollen zu behandelnde Frage ist, sondern dass darin eine Reihe von Faktoren eine Rolle spielt, die eher auf eine Angewiesenheit Europas von der Türkei hinauslaufen.

Die Türkei wird nur dann als ein Puffer zwischen Europa und den genannten Krisengebieten des Kaukasus sowie des Nahen und Mittleren Ostens wirken können, wenn sie bei Europa ist. Ist das nicht der Fall, wird sie nach einiger Zeit zum Bestandteil des Krisengebiets werden. Ursache dafür ist der Umstand, dass die Türkei im Augenblick drei politische Optionen hat, zwischen denen sie sich definitiv entscheiden muss. Es ist dies erstens die europäische Option, für die gegenwärtig die überwiegende Mehrheit der politischen und wirtschaftlichen Eliten eintritt. ${ }^{9}$ Daneben gibt es zweitens die großtürkische Option, also die politische Einflussnahme auf die Turkvölker Mittelasiens, mit der die türkische Politik zu Beginn der 90er Jahre kurzzeitig geliebäugelt hat. Auch wenn kaum wahrscheinlich ist, dass diese Politik erfolgreich sein, d.h. zur Bildung eines großtürkischen Reichs in Mittelasien führen würde, so ist doch absehbar, dass sie einen weiteren Konfliktfaktor in dieser ohnehin labilen Region darstellen würde. Eine solche Entwicklung kann nicht im Interesse der Europäer liegen, zumal sie auf eine innere Destabilisierung der Türkei hinauslaufen würde. Das gilt im übrigen nicht weniger für die dritte Option, die so genannte islamische Karte, bei der die Türkei versuchen würde, im Zeichen der gemeinsamen Religion auf den arabischen Raum Einfluss zu nehmen und damit wieder in die Rolle eintreten wür- 
de, die sie als imperiale Macht über viele Jahrhunderte im arabischen Raum gespielt hat. Auch bei dieser Option ist unwahrscheinlich, dass die Türkei, wenn sie darauf setzen würde, einen längerfristigen und nachhaltigen Erfolg haben würde. Wahrscheinlich ist vielmehr, dass damit die Großregion um einen weiteren Stör- und Krisenfaktor reicher wäre. Es gibt gute Gründe, warum die türkischen Eliten auf die europäische Option setzen, aber es wäre seitens der Europäer überaus unvernünftig anzunehmen, dass die Türkei, wenn ihr die europäische Option durch Beitrittsverweigerung genommen würde, vernünftigerweise auf das Spiel mit den beiden anderen Optionen verzichten würde. Die dadurch ausgelösten Krisen und wahrscheinlich auch Kriege in der Region dürften die Europäer in summa teurer zu stehen kommen als die jetzt projektierten Kosten des EU-Beitritts der Türkei.

\section{Anmerkungen}

1 Die unterschiedlichen Positionen hat Claus Leggewie in einem von ihm herausgegebenen Band zusammengestellt (vgl. Leggewie 2004).

2 Die von Samuel Huntington angestellten Überlegungen zu einer nach dem Ende des politisch-ideologisch geprägten Ost-WestKonflikts wesentlich kulturell-religiös determinierte Konfliktstruktur der Weltpolitik spielt natürlich auch in der muslimischen Welt als Bedrohungsszenario eine erhebliche Rolle (vgl. Huntington 1996).

3 Dazu ausführlicher Münkler (1991: 524ff.).

4 Zur Frage der europäischen oder asiatischen Identität Russlands vgl. Orlando Figes (2003: 380ff.).

5 Dazu ausführlich Rémi Brague (1993) sowie Krzysztof Pomian (1992: 14ff.).

6 Von mindestens ebensolcher Bedeutung wie diese politisch-kulturelle Spaltung ist die unterschiedliche Entwicklung des Christusbildes in der lateinischen und der griechisch-russischen Christenheit: der Leidensmann im einen, der Pantokrator im andern Fall; vgl. hierzu die Beiträge von Rémi Brague (1996) und Dan Diner (1996) in Otto Kallscheuer (1996); zur politischen Bedeutung des Investiturstreits vgl. Ernst-Wolfgang Böckenförde (1967). 
7 Die Entstehung des Staates aus der Epoche der Konfessionskriege ist das zentrale Thema der Schule Carl Schmitts; vgl. hierzu zusammenfassend Roman Schnur (1962).

8 Mehr oder minder deutlich in diese Richtung weisende Überlegungen finden sich bei Peter Sloterdijk (1994) und Joscha Schmierer (1996).

9 Eine differenzierte, auch statistisch untermauerte Argumentation, die die Perspektive einer schrittweisen Anverwandlung der Türkei an Europa aufmacht, findet sich bei Jens Alber (2004).

\section{Literatur}

Alber, Jens (2004): Gehört die Türkei zu Europa? - Ein Sozialporträt der Türkei im Lichte vergleichender Daten der Umfrageforschung, in: Leviathan 4/2004, S. 464-494.

Bahr, Egon (2004): Die Türkei vor Europa. Schicksalsfrage der EU, in: Blätter für deutsche und internationale Politik 12/2004, S. 1458ff.

Böckenförde, Ernst-Wolfgang (1967): Die Entstehung des Staates als Vorgang der Säkularisation, in: Säkularisation und Utopie. Ernst Forsthoff zum 65. Geburtstag, Stuttgart, S. 75-94.

Brague, Rémi (1993): Europa. Eine exzentrische Identität, Frankfurt/New York.

Brague, Rémi (1996): Orient und Okzident. Modelle >römischer Christenheit, in: Otto Kallscheuer (Hg.): Das Europa der Religionen. Ein Kontinent zwischen Säkularisierung und Fundamentalismus, Frankfurt a.M., S. 45-67.

Cooper, Robert (2004): The Breaking of Nations. Order and Chaos in the Twenty-First Century, London.

Diner, Dan (1996): Zweierlei Osten. Europa zwischen Westen, Byzanz und Islam. In: Otto Kallscheuer (Hg.): Das Europa der Religionen, Ein Kontinent zwischen Säkularisierung und Fundamentalismus, Frankfurt a.M., S. 97-116.

Diner, Dan (1999): Das Jahrhundert verstehen. Eine universalhistorische Deutung, München.

Faber, Richard (1979): Abendland. Ein politischer Kampfbegriff, Hildesheim.

Figes, Orlando (2003): Nataschas Tanz. Eine Kulturgeschichte Russlands, Berlin. 
Garton Ash, Timothy (2004): Freie Welt. Europa, Amerika und die Chancen der Krise, München.

Huntington, Samuel P. (1996): Kampf der Kulturen. Die Neugestaltung der Weltpolitik im 21. Jahrhundert, München/Wien.

Kagan, Robert (2004): Macht und Ohnmacht. Amerika und Europa in der neuen Weltordnung, Berlin.

Kallscheuer, Otto (Hg.) (1996): Das Europa der Religionen. Ein Kontinent zwischen Säkularisierung und Fundamentalismus, Frankfurt.

Leggewie, Claus (Hg.) (2004): Die Türkei und Europa. Die Positionen, Frankfurt a.M.

Münkler, Herfried (1991): Europa als politische Idee. Ideengeschichtliche Facetten des Europabegriffs und deren aktuelle Bedeutung, in: Leviathan 4/1991, S. 521-541.

Münkler, Herfried (2003): Der neue Golfkrieg, Reinbek bei Hamburg.

Münkler, Herfried (2004): Staatengemeinschaft oder Imperium. Alternative Ordnungsmodelle bei der Gestaltung von >Weltinnenpolitikı, in: Merkur 2/2004, S. 93-105.

Münkler, Herfried (2005): Imperien. Die Logik der Weltherrschaft vom antiken Rom bis zu den USA, Berlin.

Pomian, Krzysztof (1992): Europa und seine Nationen, Berlin.

Schnur, Roman (1962): Die französischen Juristen im konfessionellen Bürgerkrieg des 16. Jahrhunderts. Ein Beitrag zur Entstehungsgeschichte des modernen Staates, Berlin.

Schmierer, Joscha (1996): Mein Name sei Europa. Einigung ohne Mythos und Utopie, Frankfurt a.M.

Sloterdijk, Peter (1994): Falls Europa erwacht. Gedanken zum Programm einer Weltmacht am Ende des Zeitalters ihrer politischen Absence, Frankfurt a.M. 


\section{Der türkisch-armenische Konflikt und die}

Europafähigkeit der Türkei

OTTO LUCHTERHANDT

\section{Einleitung}

Der türkisch-armenische Konflikt scheint ein Randproblem in der Diskussion um die »Europafähigkeit«, d.h. der EU-Beitrittsund Mitgliedschaftsfähigkeit der Türkei zu sein. Worum geht es bei dem Konflikt? Es gibt eine ganze Reihe von Konfliktthemen und Konfliktbereichen. Ich sehe mindestens vier: ${ }^{1}$

Erstens die Behandlung des Völkermords an den Armeniern im Osmanischen Reich während des Ersten Weltkrieges (1915); zweitens die Lage der Armenier als religiöse, christliche Minderheit in der heutigen Türkei; drittens die Lage der Armenier als ethnische/nationale Minderheit in der heutigen Türkei und viertens das Verhältnis der Republik Türkei zur Republik Armenien insbesondere im Zusammenhang mit der ungelösten Karabach-Frage und der Blockade der armenisch-türkischen Grenze durch die Türkei.

Zwar werden alle diese Themen teils direkt, teils indirekt, teils in allgemeinerer Form, teils speziell in dem jüngsten Fortschrittsbericht der EU-Kommission (SEK/2004/1201)2 zum Grad der Annäherung der Türkei an die »Kopenhagener« EUBeitrittskriterien berührt, aber obwohl für alle vier Konfliktfelder der Bericht mehr oder weniger negativ für die Türkei aus- 
fällt, hat dies die EU-Kommission nicht davon abgehalten, der Union zu empfehlen, nun Beitrittsverhandlungen mit der Türkei aufzunehmen.

Gewiss wäre es verkehrt, daraus den Schluss ziehen zu wollen, das Verhältnis der Türkei zu den besagten Konfliktbereichen mit den Armeniern sei für die Klärung ihrer Europafähigkeit nebensächlich oder gar irrelevant. Denn im Kern geht es bei dem armenisch-türkischen Konfliktverhältnis letztlich immer um die eine Frage: Wie ernst meint es die Türkei mit jenen Werten, welche für die politische Ordnung und die Rechtskultur in Europa unverzichtbar, schlechthin wesentlich sind: Achtung der Menschenwürde, insbesondere die Achtung der Würde derjenigen Menschen, die nationalen, ethnischen, sprachlichen, religiösen, kulturellen Minderheiten angehören, Diskriminierungsverbot, Toleranz gegenüber Andersdenkenden, rechtsstaatlicher Umgang mit Angehörigen solcher Gruppen sowie Freiräume und Schutz zugunsten von Minderheiten.

Die aufgelisteten Konfliktfelder im Verhältnis zwischen der Türkei und den Armeniern können im vorliegenden Rahmen nur ausschnittweise und auch insofern nur fragmentarisch behandelt werden. Beschränken werde ich mich auf zwei meiner Auffassung nach besonders wichtige, signifikante Konfliktfelder, nämlich erstens die Völkermord-Frage und zweitens die Lage der Armenier als religiöse Minderheit in der Türkei.

\section{Die Auseinandersetzung um den Völkermord an den Armeniern 1915}

Die türkische Position zu dieser Frage, ihre Behandlung durch die türkische Regierung ist bis auf den heutigen Tag ein einziger Skandal, und es ist bedrückend, wie wenig gerade die deutsche politische Öffentlichkeit sich dessen bewusst ist. Man stelle sich einmal vor, die Bundesrepublik Deutschland, die Bundesregierung hätte sich seit Gründung der Bundesrepublik, seit der Ära Adenauer, gegenüber dem Völkermord an den Juden in Europa während des Zweiten Weltkrieges so verhalten, wie dies die türkische Republik seit ihrer Gründung 1923/24 gegenüber dem im Osmanischen Reich unter der Herrschaft der Jungtürken begangenen Völkermord an den Armeniern tut. In 
der öffentlichen Diskussion hört man, zumindest in Deutschland, nicht selten die Meinung, die Vernichtung der Armenier während des Ersten und die der Juden während des Zweiten Weltkrieges seien nicht vergleichbar. Abgesehen davon, dass die These schon in sich widersprüchlich ist (weil sie nämlich bestenfalls! - das Ergebnis eines bereits angestellten Vergleiches ist), ist sie unrichtig, weil das eine wie das andere Geschehen die Merkmale des Völkermords erfüllt und weil sich eine derartige Meinung willkürlich über die Ergebnisse der vergleichenden Genozidforschung hinwegsetzt (vgl. Benz 2004; Kieser/ Schaller 2002). Für die offizielle türkische Position ist festzuhalten:

Erstens: die Bagatellisierung, Verfälschung und Leugnung der historischen Tatsachen, die aus heutiger Sicht juristisch, d.h. vom Standpunkt des Völkerrechts und des Völkerstrafrechts als Völkermord einzustufen und zu bewerten sind; zweitens: die Unterdrückung sowohl der geschichtswissenschaftlichen Untersuchung der damaligen Vorgänge im Osmanischen Reich als auch der Bewertung der Vorgänge in der Türkei; ${ }^{3}$ drittens: der anhaltende Kurs der türkischen Regierung, mit diplomatischem und politischem Druck unter Einschluss einer aggressiven Mobilisierung der türkischen Landsleute in EU-Ländern (vgl. Armenisch-Apostolische Kirchengemeinde zu Berlin 1988) zu verhindern, dass Institutionen fremder Staaten und der internationalen Öffentlichkeit die damalige Vernichtung, Ermordung und Vertreibung ${ }^{4}$ als Völkermord verurteilen und viertens: der Versuch, die eigene, offizielle türkische Sprachregelung zum Völkermord politisch-propagandistisch weltweit durchzusetzen.

Was Letzteres anbelangt, sei als Beispiel Deutschland herausgegriffen, namentlich die Homepage der türkischen Botschaft in Berlin: Sie verbreitet die These, dass kein Völkermord vorgelegen habe, sondern eine Umsiedlung, und dass die Armenier an ihrem Schicksal selbst Schuld gewesen seien (vgl. Türkische Botschaft in Berlin 2004):

»Die Zwangsumsiedlung der Armenier im Jahr 1915 war keine Maßnahme gegen einen fiktiven Aufstand, sondern die notwendig gewordene Abwehr des armenischen Aufstandes und die Kollaboration der Armenier mit den feindlichen (russischen - Anm. d. Ü.) Armeen. Sie war unter den damals herrschenden Kriegsumständen nicht zu vermei- 
den [...]. Wie oben bereits angemerkt, war die Umsiedlung der Armenier im Jahr 1915 nicht als vorbeugende Maßnahme gegen einen möglichen Aufstand gedacht und durchgeführt. Dies ist sehr wichtig. Die Zwangsumsiedlung von 1915 war vielmehr eine unvermeidbare Reaktion gegen den tatsächlich begonnenen Aufstand seitens der Armenier und deren Kollaboration mit den feindlichen Armeen mitten im Krieg" (Türkische Botschaft in Berlin 2004)

Hätte sich die Bundesrepublik Deutschland zum Holocaust unter dem Nationalsozialismus auch nur ansatzweise so verhalten wie die türkische Republik zum Völkermord an den Armeniern unter dem Regime der Jungtürken während des Ersten Weltkrieges mit ihrer nationalistisch-rassistischen Ideologie, dann hätte sie sich von der westlichen, liberal-demokratisch orientierten europäischen Ordnung der Nachkriegszeit selbst ausgeschlossen und wäre internationaler Ächtung anheim gefallen.

Man hört immer wieder von Verteidigern der türkischen Position und Politikern, welche sich mit dem VölkermordVorwurf beschäftigen (müssen), man solle die Auseinandersetzung darüber den Historikern überlassen. Im ersten Moment klingt dies durchaus vernünftig, vielleicht sogar überzeugend. Tatsächlich aber handelt es sich um ein durchsichtiges politisches Manöver, denn diese - je nachdem - Mahnung oder Forderung wird zu dem Zweck ausgesprochen, den Eindruck zu vermitteln a) die historische Untersuchung sei noch gar nicht geleistet worden und b) die Beschäftigung mit dem Völkermord-Vorwurf sei keine Sache der Politik.

Beide Thesen dienen offenkundig dem Ziel, die politische Auseinandersetzung mit dem Problem hier und heute zu vermeiden, sie von sich zu schieben, sie zu verhindern, sich im heutigen politischen Geschäft nicht von den »Leichen im Keller der Vergangenheit« stören zu lassen. Ich möchte dazu nur zwei kurze Anmerkungen machen:

Die erste These ist falsch, denn die historische Arbeit ist bereits hinreichend geleistet worden, jedenfalls so qualifiziert, ${ }^{5}$ dass die Bewertung des Materials unter völkerrechtlichen bzw. strafrechtlichen Gesichtspunkten längst einwandfrei möglich ist. Dies aber ist nicht mehr Sache des Historikers, sondern naturgemäß - die des Juristen. ${ }^{6}$ 
Zweitens beweist gerade der Umgang mit dem VölkermordThema in der aktuellen Publizistik und in der internationalen politischen Diskussion, dass es nicht nur um einen weit zurückliegenden historischen Gegenstand geht, sondern um eine hochbrisante politische Frage mit mannigfachen Verästelungen in der Gegenwart.

Nun kann man in juristischer Hinsicht durchaus darüber streiten, ob die Völkermord-Konvention von 1948, die bekanntlich erstmals den Völkermord als Delikts- bzw. Straftatbestand definiert hat (Art. II), auf den Völkermord an den Armeniern während des Ersten Weltkrieges angewendet werden kann. Dies ist unter Völkerrechtlern und unter Strafrechtlern durchaus umstritten. In jüngster Zeit hat der renommierte amerikanische Völkerrechtler Alfred de Zayas den Versuch unternommen, die Geltung der durch die Konvention von 1948 ausgesprochenen Ächtung des Völkermords bereits für die Zeit des Ersten Weltkrieges nachzuweisen (vgl. Zayas 2004). Zu einem gegenteiligen Ergebnis ist das Internationale Strafrechtstribunal in dieser Frage gekommen. Ich persönlich habe die Frage nicht näher untersucht, bin aber etwas skeptisch in Bezug auf die Tragfähigkeit der von de Zayas vorgetragenen Argumentation. Unabhängig davon möchte ich aber mit Nachdruck zumindest auf die moralische Verpflichtung hinweisen, sich mit den Ereignissen von 1915 auch und gerade aus der Sicht der AntiVölkermordkonvention von 1948 zu beschäftigen. Die Konvention ruft selbst dazu geradezu auf. In ihrer Präambel heißt es nämlich:

»In Anerkennung der Tatsache, dass der Völkermord [sic!] der Menschheit in allen Zeiten der Geschichte [sic!] große Verluste zugefügt hat, und in der Überzeugung, dass zur Befreiung der Menschheit von einer solch verabscheuungswürdigen Geißel internationale Zusammenarbeit erforderlich ist $[\ldots] . \ll$

Die Anti-Völkermordkonvention wendet also sich selbst auf die, auf alle der Konvention vorausgegangenen Epochen der Menschheitsgeschichte an. Die Türkei ist der Anti-Völkermordkonvention am 31. Juli 1950 beigetreten. Sie verletzt mit ihrem Verhalten in der Frage des Völkermords an den Armeniern eklatant diese Bestimmung der Präambel; sie verfehlt mit ihrem 
verstockten Verhalten in der armenischen Völkermord-Frage vollkommen den »Geist« der Konvention.

Der Gipfel des Zynismus und der Bösartigkeit in der türkischen Behandlung der Völkermord-Frage ist aber die Tatsache, dass die in der Türkei lebenden Menschen, insbesondere aber die Angehörigen der armenischen Minderheit, mit strafrechtlicher Verfolgung rechnen mussten und strafrechtlich verfolgt wurden, wenn sie als Überlebende den an ihren Vorfahren begangenen Völkermord beim Namen nannten, und in dieser Gefahr befinden sie sich noch immer, weil auch das neue türkische Strafgesetzbuch vom September 2004 einen Straftatbestand vorsieht, der entsprechend instrumentalisiert werden kann (vgl. Art. 305 StGB n. F.). Man ziehe die Parallele zum Holocaust, um die ganze Ungeheuerlichkeit dieser Einstellung der türkischen Regierung zu dem Problemkomplex Völkermord ermessen zu können.

Wie sehr diese Einstellung unter der Regierung Erdoğan vorherrschend ist, wurde noch in anderer Hinsicht im April 2003 deutlich. Der Erziehungsminister der Türkei, Hüseyin Çelik, ordnete per Runderlass einen Aufsatzwettbewerb an allen Schulen des Landes zu dem Thema "Die Haltlosigkeit der Behauptungen vom Genozid an den Armeniern" an. Begleitet wurde die Kampagne von Vorträgen und Lehrerschulungen durch ministerielle Propagandisten, die selbstverständlich mit dem Anspruch auf Wissenschaftlichkeit und historische Wahrheit auftraten. Erfreulich ist immerhin, dass solche Aktionen heute in der Türkei nicht mehr widerspruchslos hingenommen werden, sondern dass sich im liberalen Spektrum der Gesellschaft bzw. der Publizistik Kritik an solchen politischen Aktionen regt. ${ }^{7}$

"Solange die Türkei die Armenier nicht um Verzeihung gebeten hat, ist für mich eine Mitgliedschaft in der Europäischen Union ausgeschlossen «, sagte der bekannte französische Historiker Jacques Le Goff in einem Interview mit der Wochenzeitung DIE ZEIT (vgl. Le Goff 2000). Leider, so muss man befürchten, wird es für eine solche prinzipielle, moralische Haltung, orientiert an den grundlegenden Werten der europäischen Kultur, keine Mehrheit im Entscheidungsprozess der EUAufnahme der Türkei geben, und peinlicherweise ist es gerade 
der Türkei-Kurs der Bundesrepublik Deutschland, der einen in dieser Frage eher pessimistisch stimmt.

\section{Die Lage der Armenier als religiöse Minderheit in der Türkei}

Betrachtet man mit den Augen eines Bundesdeutschen und insbesondere eines bundesdeutschen Juristen die Verhältnisse in der Türkei auf dem Gebiet von Religionsfreiheit und Religionsgemeinschaften, dann wird man sehr rasch nicht ohne Verwunderung und Erstaunen eine ganze Reihe wesentlicher, ja einschneidender Unterschiede gegenüber auf diesem Gebiet in Europa Gewohntem feststellen. Ich will zwei besonders wichtige Punkte hervorheben:

Art. 24 der türkischen Verfassung von $1982^{8}$ garantiert Religionsfreiheit nur in individueller Hinsicht, d.h. Gewissensfreiheit, Freiheit religiöser Anschauung und Überzeugung, Freiheit von religiösen Feiern, Zeremonien, Gottesdiensten; - in korporativer, institutioneller Hinsicht ist Religionsfreiheit nicht garantiert. Mehr als das: die Verfassung schweigt sich über Religion in organisierter, institutioneller Form, über Religionsgemeinschaften und Kirchen vollkommen aus. ${ }^{9}$

Die Einsilbigkeit der türkischen Verfassung in diesem Punkt ist kein Zufall; sie setzt sich in der weiteren Rechtsordnung unterhalb der Verfassung, in Gesetzen, Verordnungen usw. mehr oder weniger klar fort. So gibt es keine Gesetze über die Gründung, die innere Ordnung, die Struktur, den Status (Rechte und Pflichten) von religiösen oder weltanschaulichen Organisationen, und zwar weder für die elementare untere Ebene der lokalen Gemeinden noch für überregionale oder gar zentrale, auf republikanischer Ebene organisierte religiöse Gemeinschaften. ${ }^{10}$ Mehr als das: Das auf der Grundlage von Art. 33 Abs. 4 der Verfassung formell noch immer geltende Vereinsgesetz von 1983 verbietet es, Vereine zu gründen, die sich auf das Merkmal der Religion oder Konfession stützen. Ergänzend verbietet das Gesetz ausdrücklich »Vereine, die religiöse, konfessionelle Unterschiede in der Türkischen Republik propagieren oder entsprechende Minderheiten schaffen «. ${ }^{11}$ 
Der einzige Rechtsakt in der Türkischen Republik,12 welcher dezidiert die Religionsgemeinschaften betrifft, ist die am 24 . Januar 2003 erlassene Ausführungsverordnung über die Stiftungen nichtmuslimischer Gemeinden in Ausführung zu Art. 1 des Stiftungsgesetzes der Türkei vom 5. Juni 1935.13

Nun könnte man vielleicht meinen: Wenn es keine staatlichen, keine gesetzlichen Vorschriften gibt, vielmehr nur eine Verfassungs- bzw. Grundrechtsbestimmung, die wie eine Generalklausel Freiheit religiöser Anschauungen und Gottesdienste verkündet, dann gibt es auch keine bürokratischen Hindernisse aufgrund kleinlicher Vorschriftenregulierung. Dem ist jedoch nicht so. Die große Freiheit nach dem Prinzip >Was nicht verboten ist, ist erlaubt<, beherrscht die türkische Rechts- und Verwaltungsordnung traditionell nicht. ${ }^{14}$ Vielmehr ist die Staatsverfassung und Rechtsordnung in Bezug speziell auf Religionen und Konfessionen ausgesprochen restriktiv und repressiv. Hintergrund dieser Tatsache ist der radikale Bruch der Türkischen Republik mit dem islamischen Charakter des Osmanischen Reiches unter Kemal Pascha und die förmliche Proklamation des »Laizismus" als eines der Grundprinzipien der türkischen Verfassung. ${ }^{15}$ Nach der ständigen Rechtsprechung des türkischen Verfassungsgerichts bedeutet das LaizismusPrinzip nicht nur und nicht lediglich die Trennung von Staatsangelegenheiten und Religionsangelegenheiten, sondern: »In der laizistischen Ordnung wird die Religion von der Politisierung befreit, als Führungsinstrument verdrängt und ihr der richtige und ehrenvolle Platz im Gewissen der Bürger zugewiesen $[\ldots] \ll .16$

Augenscheinlich knüpft das Verfassungsgericht mit dieser radikalen Deutung an die Laizismus-Bestimmung in Abs. 6 der Verfassungspräambel an, wonach »heilige religiöse Gefühle [...] auf keine Weise mit den Angelegenheiten und der Politik des Staates vermischt werden« dürften.

Mit seiner Interpretation des Laizismus-Prinzips erweckt das Verfassungsgericht allerdings den Eindruck, als sei das Prinzip nach türkischem Verfassungs- und Rechtsverständnis eine Garantie von Freiheit, auch und gerade von Religionsfreiheit als Menschenrecht. Das aber ist tatsächlich nicht der Fall. Vielmehr ist das Laizismus-Prinzip ein ideologisches Konzept geworden, das massive Einschränkungen der Religionsfreiheit, 
starke, ja krasse Ungleichbehandlung von Religionen und Konfessionen, Ausübung von Zwang in religiösen Angelegenheiten und eine schleichende, administrative Erdrosselung insbesondere nichtmuslimischer Religionsgemeinschaften rechtfertigt und sie zugleich propagandistisch verschleiert. ${ }^{17}$ Mit dem historischen, politischen Vorbild des türkischen Laizismus, nämlich der französischen laïcité besteht daher letztlich keine Gemeinsamkeit, weil dem französischen Prinzip der laïcité nicht die für das türkische Laizismus-Prinzip typischen freiheits- und gleichheitsfeindlichen Wirkungen anhaften.

Die freiheits- und gleichheitsfeindliche Stoßrichtung und tatsächliche Wirkung des Laizismus-Prinzips resultiert daraus, dass integraler Bestandteil des türkischen Nationalismus - als einem weiteren wichtigen Verfassungsprinzip der Islam ist (vgl. Rumpf 1996: 100ff.) - (und zwar in seiner sunnitischen Ausprägung) und dass die Staatsverwaltung nicht nur de facto, sondern auch de jure und institutionell die Konfession des sunnitischen Islam fördert, ihn privilegiert, andere islamische Richtungen diskriminiert oder gar verfolgt und nichtmuslimische Religionen bzw. Konfessionen administrativ behindert und unterdrückt. ${ }^{18}$

Sichtbarstes institutionelles Zeichen der Verschmelzung von Laizismus, türkischem Nationalismus und sunnitischem Islam ist das Präsidium für Religionsangelegenheiten (diyanet Işleri başkan-ligi) (vgl. Spuler-Stegemann 1996: 240ff.; Rumpf 1996: 111f.).

Es ist als ein Organ der Exekutive ausdrücklich in der Verfassung geregelt (Art. 136 mit der Maßgabe eines speziellen Gesetzes), untersteht unmittelbar dem Ministerpräsidenten und ist eine Art staatliche Religionsbehörde. Entgegen dem Anschein, der von ihrer Bezeichnung ausgeht, ist die Behörde in religiöskonfessioneller Hinsicht aber nicht neutral. Sie steht nicht in Distanz zu und über den Religionsgemeinschaften und Konfessionen, sondern das Präsidium für Angelegenheiten der Religion ist eine oberste Verwaltungsbehörde des sunnitischen Islam in der Türkei und versteht sich zugleich als Zentrum für eine Reform und Modernisierung des Islam - jedenfalls unter dem jetzigen, seit Mai 2003 amtierenden Chef der Behörde, dem islamischen Theologen Ali Bardakoglu (vgl. Hermann 2004). ${ }^{19}$ 
Nicht einmal für die Aleviten verfügt die Behörde über eine eigene Unterabteilung.

Ihr offizielles Mandat gemäß Art. 136 der Verfassung, nämlich »dem Laizismus sowie der nationalen Solidarität und Integration « zu dienen, erfüllt die Behörde also - erstaunlicherweise - durch die Förderung und Durchsetzung eines bestimmten, von ihr vertretenen Islamverständnisses. Laizismus im türkischen Sinne bedeutet demnach die enge, exklusive, genuine und konfessionelle Verbindung von Staat und Religion im Sinne erstens einer Lenkung der Religion durch den Staat und zweitens der Identifizierung des Staates mit einer bestimmten religiösen Richtung bzw. Konfession. Wir haben demnach eine eigenartige Variante von "Staatskirchentum« vor uns, wenn man das Phänomen in die klassischen Formen des Staat-Kirche-Verhältnisses in der westlichen, abendländischen Welt einordnen wollte. ${ }^{20}$

Der Name »Präsidium für Religionsangelegenheiten« vermittelt nicht die geringste Vorstellung, und zwar weder von dem institutionellen Gewicht noch von der prinzipiellen staatsund religionspolitischen Bedeutung dieser Behörde. Denn das Präsidium verfügt über ca. 100.000 Planstellen bzw. Mitarbeiter, zu denen auch und gerade die Imame der (sunnitischen) Moscheegemeinden gehören. Sie werden von dem Präsidium ernannt und aus dem Etat der Behörde bezahlt. Kraft dieser Umstände ist die Religionsbehörde das viertgrößte Ministerium in der Regierung der Türkei - nach den Ressorts der Verteidigung, des Inneren und der Staatssicherheit (vgl. Seufert 2004: 24). Das starke, förmliche, staatskirchlichen Verhältnissen sich annähernde Engagement des türkischen Staates in Religionsangelegenheiten wird durch die Regelung des Religionsunterrichts auf der Grundlage von Art. 24 Abs. 3 der Verfassung von 1982 unterstrichen. ${ }^{21}$

Der staatliche Religionsunterricht war als Pflichtfach nach dem Militärputsch von 1980 eingeführt worden, um den zahllosen privaten Koranschulen (»Imam-Hatib-Schulen«) im Lande entgegenzuwirken (vgl. Seufert 2004). Die Art und Weise, wie die Regelung gehandhabt wurde und wird, spricht freilich der Religionsfreiheit Hohn, denn erstens nimmt das Fach »Religion und Ethik « Partei ausschließlich für den sunnitischen Islam, der in den Unterrichtsmaterialien in engster Verbindung mit der 
Ideologie des türkischen Nationalismus im Grunde wie eine staatliche civil religion vermittelt wird; zweitens werden die Inhalte des Unterrichts allein vom Staat gestaltet und verantwortet, und drittens kommen die Angehörigen nichtsunnitischer islamischer Konfessionen, namentlich die Schiiten und Aleviten, von vornherein nicht in den Genuss der Befreiung von diesem Unterricht. Bis 1990 war der Unterricht sogar ausnahmslos für alle Schülerinnen und Schüler, d.h. auch für diejenigen aus christlichen und jüdischen Familien, verbindlich. Erst seither besteht für sie die Möglichkeit, sich vom Unterricht befreien zu lassen. Wie allerdings die Ausnahme in der Praxis gehandhabt wird, entzieht sich aus Mangel an einschlägigem empirischem Material der Beurteilung. Nach allem, was über die Qualität der Verwaltung und der staatlichen Institutionen in der Türkei bekannt ist, ist insofern Skepsis angebracht.

Das Ausmaß der Verletzung der Religionsfreiheit minderjähriger Kinder und des religiösen Erziehungsrechts der Eltern kann man daran ablesen, dass der Anteil der Aleviten, d.h. der größten nichtsunnitischen Konfessionsgemeinschaft in der Türkei, ca. 12 Millionen Menschen umfasst. ${ }^{22}$

Verglichen damit ist die Gesamtzahl der Christen aller Konfessionen in der Türkei inzwischen verschwindend gering. Absolut verlässliche Zahlen gibt es anscheinend nicht. Die Evangelische Kirche in Deutschland (EKD) spricht von 150.000 Menschen (2001) (vgl. Duncker 2003); Otmar Oehring nimmt nur eine Zahl von 100.000, d.h. von ca. 1,5 Prozent der Gesamtbevölkerung an (vgl. Oehring 2002). Unter den christlichen Konfessionen besitzt die Armenische Apostolische Kirche mit max. 60.000 Menschen (davon ca. 95 Prozent im Raum Istanbul) den größten Anteil. Die einst nach Hunderttausenden zählenden griechisch-orthodoxen Christen unter der Jurisdiktion des Ökumenischen Patriarchen sind in der Türkei auf maximal 2000 Menschen zusammengeschrumpft.

Die Zahlen sind erschütternd: Welche Zerstörung christlichen Gemeindelebens, welches Ausmaß an Entchristlichung hat Kleinasien, eine der Kernregionen des christlichen Orients, im 20. Jahrhundert erlebt! Dabei könnte und sollte man meinen, der Prozess der Unterdrückung, Verdrängung und Vertreibung der Christen aus der Türkei sei wenigstens in der zweiten Hälfte des 20. Jahrhunderts zum Stillstand gekommen und insofern 
eine Entspannung der Lage eingetreten. Schließlich war die Türkei schon unmittelbar nach ihrer Gründung (Mai 1949) in den Europarat aufgenommen worden, hatte sich damit der Geltung der Europäischen Menschenrechtskonvention (EMRK) unterworfen, und schließlich war die Türkei ab 1964 assoziiertes Mitglied der Europäischen Wirtschaftsgemeinschaft (EWG). Leider hat die Integration der Türkei in die wichtigsten europäischen Organisationen, d.h. in jene Institutionen, welche wie keine anderen die Grundwerte der europäischen Zivilisation repräsentieren und namentlich Art. 9 EMRK, ${ }^{23}$ keine Schutzwirkung zugunsten der religiösen, insbesondere christlichen Minderheiten in der Türkei entfaltet (vgl. Luchterhandt 2003: 62ff.). Im Gegenteil und schlimmer noch: Der sich im Zeichen des Kemalismus mit dem sunnitischen Islam identifizierende türkische Staat, seine Bürokratie, hat das Werk der schrittweisen Verdrängung, Auszehrung und langsamen Zerstörung der christlichen Gemeindestrukturen gerade unter der Ägide des Europarats und der EWG/EG-Assoziation des Landes systematisch weiter betrieben. Die freiheitsfeindliche Ideologie des »Laizismus" sowie, anders gesagt, die Christenfeindlichkeit und die Armenierphobie der türkischen Gesellschaft verweisen auf die Hauptgründe der Entwicklung und der so entstandenen heutigen Lage.

Der Befund ist aber noch nicht die ganze Wahrheit. Die Türkei hat ihre Politik der Erdrosselung, Auszehrung und Verdrängung der christlichen Konfessionen auf ihrem Territorium nämlich nicht nur im Widerspruch zum Geist des Europarats und des Art. 9 EMRK betrieben, sondern mit diesem Kurs offen und völlig sanktionslos Jahrzehnte hindurch jene völkerrechtlichen Verpflichtungen verletzt, die sie im Friedensvertrag vom 24. Juli 1923 in Lausanne in Bezug auf den Schutz der »nichtmuslimischen Minderheiten « (»non Muslim minorities«), also zugunsten der christlichen Minderheiten, feierlich unterzeichnet und übernommen hat. Ja, bis zum heutigen Tage, bereits angekommen im »Vorzimmer« der Europäischen Union, ignoriert die Türkei diese Verpflichtungen. Dies geschieht, obwohl sie die Gültigkeit des Vertrages von Lausanne anerkennt und insbesondere auch, dass sich jedenfalls die armenischen und die griechischen Christen auf die Schutzbestimmungen der Art. 3744 berufen können. ${ }^{24}$ 
Um welche Vertragspflichten handelt es sich? Sie lassen sich in den folgenden fünf Punkten zusammenfassen:

1. Umfassendes Verbot der Diskriminierung nichtmuslimischer türkischer Bürger, ihre völlige Gleichberechtigung namentlich (auch) auf dem Gebiet der Reisefreiheit bzw. Ausreisefreiheit, aber auch in Bezug auf den Zugang zu allen öffentlichen Ämtern; 2. Türkische Staatsangehörige nichtmuslimischer Minderheiten sind berechtigt,

»auf eigene Kosten wohltätige, religiöse und soziale Einrichtungen, Schulen aller Art und andere Bildungs- und Erziehungseinrichtungen $\mathrm{zu}$ errichten, $\mathrm{zu}$ verwalten und $\mathrm{zu}$ kontrollieren, dort ihre eigene Sprache zu gebrauchen und ihre Religion frei auszuüben« (Art. 40);

3. Einrichtung von muttersprachlichem Unterricht für Angehörige der nichtmuslimischen Minderheiten in den öffentlichen bzw. staatlichen Schulen; 4. Verpflichtung des Staates, die Bildungs-, Religions- und Sozialeinrichtungen nichtmuslimischer Minderheiten in den Verwaltungsbezirken finanziell $\mathrm{zu}$ fördern, in denen die Minderheiten einen »beachtlichen Anteil« der Bevölkerung bilden; 5. Verpflichtung der türkischen Regierung, »den Kirchen, Synagogen, Friedhöfen und anderen religiösen Institutionen der nichtmuslimischen Minderheiten vollen Schutz « zu garantieren. Allen in der Türkei bestehenden religiösen Stiftungen und religiösen und gemeinnützigen Institutionen wird der Fortbestand aller Einrichtungen und Genehmigungen " garantiert. Damit ist nicht nur der Fortbestand des Status quo zum Zeitpunkt des Friedensschlusses von Lausanne, also 1923, gemeint, denn: »Die türkische Regierung wird hinsichtlich der Schaffung neuer religiöser und gemeinnütziger Institutionen keine der Hilfen verweigern, die anderen privaten Institutionen dieser Art garantiert werden.«

Die auffälligste Verletzung des Vertrages von Lausanne besteht bereits darin, dass die Türkei im klaren Widerspruch zu der abstrakten Umschreibung der Minderheiten (»nichtmuslimischen«) im Vertragstext die Gültigkeit des Vertrages nur zugunsten einiger weniger religiöser Minderheiten anerkennt, nämlich der Armenier, Griechen, Bulgaren und Juden (vgl. Oehring 2002: 6; 21ff.). ${ }^{25}$ Aber selbst den offiziell anerkannten Minderheiten werden ganz wesentliche, ja nahezu alle Garan- 
tien entweder vorenthalten oder aber sie werden nur sehr unvollkommen und eingeschränkt erfüllt. ${ }^{26}$ Das sei am Beispiel der Armenier für einige Schlüsselbereiche des religiösen Lebens dargestellt, nämlich 1. für den Rechtsstatus der Apostolischen Kirche und ihrer Gliederungen; 2. das Eigentumsrecht der kirchlichen Gliederungen und 3. das kirchliche Schulwesen.

\section{III.1 Der Rechtsstatus der Apostolischen Kirche und ihrer Gliederungen.}

\section{Die Ebene der Kirchenleitung: Das Patriarchat27}

Wie bereits bemerkt, findet sich im staatlichen Recht kein einziges Gesetz, das die korporativ, d.h. nach Kirchenrecht autonom organisierten christlichen Religionsgemeinschaften mit Wirkung (auch) für den Geltungsraum der staatlichen allgemeinen Rechtsordnung anerkennt. ${ }^{28}$ Weder das Patriarchat noch die Gemeinden der Armenischen Apostolischen Kirche (und ebenso wenig die anderen Religionsgemeinschaften) können sich auf einen derartigen Rechtsakt beziehen (vgl. Luchterhandt 2003: 44ff.). Allerdings können sich Patriarchat und Gemeinden auf Art. 42 des Vertrages von Lausanne berufen. Sie tun es im Prinzip auch, aber der Staat hüllt sich dazu in Schweigen und lässt auf diese Weise den Rechtsstatus der kirchlichen Organisation insgesamt wie den ihrer einzelnen Gliederungen in der Schwebe. Dies ist ein unerträglicher, für die Kirche unzumutbarer Zustand. Es ist ein Hohn auf die Menschenrechte im Allgemeinen und die Religionsfreiheit im Besonderen, die - wie jeder weiß und durch die gesamte Menschheitsgeschichte bestätigt findet - auf die Ausübung in einer organisierten Gemeinschaft, in institutioneller Form angewiesen ist.

Da der Rechtsstatus des Patriarchats unklar ist, das Patriarchat nicht förmlich als juristische Person anerkannt ist, ist es als solches auch nicht eigentumsfähig, befinden sich also die Liegenschaften des Patriarchats, seine Gebäude usw. in einem rechtlich ungeklärten Zustand. Die Unklarheit hängt wie ein Damoklesschwert über der Kirche, denn sie ist als solche rechtlich nicht dagegen geschützt, sollte der Staat eines Tages auf die Idee kommen, nach ihrem Eigentumsrecht zu fragen. 


\section{III.2 Das Eigentumsrecht der Gemeinden; die Gemeindestiftungen ${ }^{29}$}

Wenngleich auch die Gemeinden als solche, für den Staat rechtlich nicht existent sind, besteht doch immerhin eine gewisse Klarheit hinsichtlich der Eigentumsverhältnisse an ihrem Vermögen. Auf der Grundlage des Stiftungsgesetzes vom 5. Juni 1935 mussten die kirchlichen Gemeinden ihr Vermögen in der Form und auf der Grundlage von Stiftungen verwalten. Das Stiftungsvermögen, das durch Erbschaften, Vermächtnisse wohlhabender Gemeindemitglieder vermehrt wurde, war die entscheidende materielle, finanzielle Grundlage für die Gemeindearbeit, von Baumaßnahmen angefangen bis hin zu karitativen Tätigkeiten der Bezahlung des Personals usw. Allerdings waren die Gemeinden bei der Wahl des zur Verwaltung berufenen "Stiftungsrates « nicht völlig frei, da Geistliche nicht in den Rat hinein gewählt werden durften. Die Stiftung unterlag und unterliegt der strengen staatlichen Kontrolle durch die "Generaldirektion für das Stiftungswesen", einer weiteren Behörde des Staates zur Durchführung seiner repressiven Religionspolitik. Ist ein Stiftungsrat aus irgendeinem Grunde nicht handlungsfähig, kann die Generaldirektion einen staatlichen Treuhänder einsetzen. Nach zehn Jahren der staatlichen Treuhandverwaltung geht das Stiftungsvermögen in das Eigentum des türkischen Staates über, was auch geschah und weiter geschieht. Zwar erwarben die (christlichen) Stiftungen in den folgenden Jahrzehnten weiteres Vermögen durch Erbschaften, Schenkungen, Kauf usw., aber in der Regel wurde das Stiftungsvermögensregister von 1936 nicht auf den jeweiligen Stand gebracht, zumal darüber keine besondere Vorschrift existierte. 1974 erklärte das Oberste Zivilgericht auf Klage des staatlichen Schatzamtes sämtlichen Eigentumserwerb seit 1936 wegen fehlender Eintragung in das Register für rechtswidrig, eine Entscheidung, die im Jahre 2001 - lediglich für die nichtmuslimischen Stiftungen - gerichtlich bestätigt wurde. Während für die muslimischen Stiftungen keine Konsequenzen gezogen wurden, wurden nach jener Wendung der Rechtsprechung bzw. der staatlichen Rechtsauffassung zahlreiche Enteignungen von Gemeindevermögen christlicher (weniger jüdischer) Vermögensobjekte vorgenommen und die von den Stiftungen an- 
geblich rechtsfehlerhaft erworbenen Immobilien dem staatlichen Schatzamt (Fiskus) zu Eigentum übertragen. Betroffen davon waren in den vergangenen 30 Jahren ca. 40 Objekte allein von armenischen Gemeinden. ${ }^{30}$

Die Gefahr, dass der Stiftungsrat handlungsunfähig wird, stieg in der Vergangenheit dadurch, dass die Gemeindemitglieder in dem betreffenden Stiftungsbezirk ihren Wohnsitz haben mussten. Im Laufe der Jahre ergaben sich nämlich räumliche Diskrepanzen zwischen der Lage der Immobilien der Gemeindestiftungen, die meist in den Kerngebieten Istanbuls gelegen waren, und den Wohnungen der Gemeinde- bzw. Stiftungsratsmitglieder. Durch Änderungen des Stiftungsrechts 2002 und im Januar 2003 und insbesondere durch die nun erstmals erlassene Ausführungsverordnung zum Stiftungsgesetz von 1935 wurde die Möglichkeit eröffnet, dass Gemeindestiftungen in den Genuss von Immobilien kommen, die wegen der repressiven, unberechenbaren staatlichen Behandlung der nichtmuslimischen Stiftungen (seit der Gerichtsentscheidung von 1974) Privatpersonen übertragen worden waren. Im Anhang zu ihrer Verordnung von 2003 führte die Regierung 160 nichtmuslimische Gemeindestiftungen namentlich auf. ${ }^{31}$ Von den im November 2003 erstmals zur Eintragung angemeldeten 1.532 Immobilien konnten bis zum Sommer 2004 nur knapp 20 Prozent eingetragen werden. Die für die Registrierung zunächst auf sechs Monate beschränkte Frist wurde inzwischen (Juli 2003) bis zum 19. Januar 2005 verlängert. Der schleppende Fortgang der »Legalisierung « der betreffenden Immobilien als Stiftungseigentum zeigt deutlich die Halbherzigkeit und Unwilligkeit der Behörden zu einer durchgreifenden Liberalisierung ihrer Religionspolitik, zumindest gegenüber den nichtmuslimischen Gemeinschaften.

Das Genehmigungsverfahren ist ausgesprochen restriktivbürokratisch. Zunächst (2002/2003) wurde neben einem Durchlaufen des Instanzenzuges der staatlichen Stiftungsbehörde (Bezirksverwaltung; Generaldirektion) eine Entscheidung des Ministerrats der Türkei in jedem Einzelfall verlangt. Inzwischen genügt die Entscheidung der Generaldirektion, die nach Rücksprache mit interessierten Ministerien und sonstigen Zentralbehörden, namentlich dem Außenministerium und dem Staatssicherheitsdienst, getroffen wird. Einen Anspruch auf Genehmigung bei Vorliegen bestimmter gesetzlich aufgeführter Krite- 
rien des Eigentumserwerbs sieht die Verordnung nicht vor: Die staatlichen Behörden entscheiden nach ihrem freien (religionspolitischen) Ermessen. Hier öffnet sich ein eklatanter Widerspruch zu einem zentralen Prinzip rechtsstaatlicher Verwaltung, nämlich des Ausschlusses willkürlicher, mangels fehlender Kriterien unüberprüfbarer Entscheidungen.

Ausgesprochen schikanös war die bis 1999 geltende Vorschrift, wonach Renovierungsmaßnahmen an Immobilien der Gemeindestiftungen in Höhe von umgerechnet 12.000 Euro der Genehmigung durch die Generaldirektion und das türkische Außenministerium bedurften. Inzwischen ist diese Verfahrensvorschrift bzw. der Genehmigungsvorbehalt zugunsten der Generaldirektion zwar entfallen, doch scheint er zugunsten des Außenministeriums fortzubestehen.

Im Zusammenhang mit der Verwaltung des Gemeindestiftungsvermögens gibt es zahlreiche weitere ungeklärte, daher von den Behörden mehr oder weniger willkürlich gehandhabte Fragen, namentlich der Besteuerung, der Übertragung von Einnahmenüberschüssen auf andere Gemeindestiftungen, der zulässigen Größe von Stiftungsbezirken usw.

\section{III.3 Das kirchliche Schulwesen}

\section{Allgemeinbildende Schulen}

Eine reale - positive - Auswirkung des Vertrages von Lausanne ist im Prinzip die Existenz eines armenischen Schulwesens, das räumlich auf den Großraum Istanbul beschränkt ist (vgl. Kuymçuyan 2002: 17; zum Schulwesen auch Oehring 2002: 29ff.). Die Probleme sind mannigfaltig, wobei die Schwierigkeiten teilweise typisch für das Schulwesen von unter DiasporaVerhältnissen lebenden Minderheiten sind, wie sie strukturell mehr oder weniger in allen Ländern auftreten. Allerdings werden solche strukturellen Schwierigkeiten durch die feindliche Einstellung der staatlichen Behörden gegenüber den nichtmuslimischen Religionsgemeinschaften erheblich verschärft. 1972 existierten noch 32 Schulen der armenischen Minderheit (Grundschulen und Gymnasien) mit 7.366 Schülern. Bis zum Jahr 2000 war ihre Zahl auf 18 Schulen mit 3.786 Schülern abgesunken. Insbesondere die Schülerzahlen der Grundschulen ge- 
hen kontinuierlich zurück - von 2.518 im Jahre 1990 auf 1.640 im Jahre 2000. Es besteht kein Zweifel, dass der anhaltende staatliche, politische Druck auf die Gemeinde, die minderheitenfeindliche restriktive Religionspolitik des Staates die Verhältnisse negativ beeinflusst. Denn unter den obwaltenden Umständen wird es den Schulen bzw. Gemeinden von vornherein schwer gemacht, für qualifizierte Lehrmaterialien und insbesondere moderne, laufend auf den neuesten Stand gebrachte Schulbücher zu sorgen. Je schwächer und dünner die personelle Grundlage der christlichen Gemeinden ist, desto schwieriger ist es für sie, mit diesem Problem fertig zu werden, zumal die staatliche Schulaufsicht die vorhandenen Schwierigkeiten noch künstlich verschärft. Infolgedessen sind die Schulen der armenischen Minderheit, die Minderheitenschulen insgesamt, immer weniger in der Lage, mit den staatlichen Schulen zu konkurrieren, weswegen viele Eltern, die es sich leisten können, ihre Kinder auf teure Privatschulen in Istanbul und im christlichen Ausland schicken.

Ausgesprochen pervers ist die gemäß dem staatlichen Schulgesetz Nr. 625 seit 1965/1966 für »besondere Schulen" geltende Bestimmung (Art. 25), dass die staatliche Schulaufsichtsbehörde den Minderheitenschulen einen stellvertretenden türkisch-muslimischen Schulleiter zuweist, der Dienstvorgesetzter sämtlicher Lehrpersonen ist, während der armenische Direktor nur Vorgesetzter des armenischen Lehrpersonals ist.

\section{Geistliche Lehranstalten}

1970/71 musste das Armenische Patriarchat seine einzige Theologische Hochschule Tbrevank schließen, eine wenig bekannte Tatsache, jedenfalls im Vergleich zu der zur selben Zeit geschlossenen Theologischen Schule Chalki des Ökumenischen Patriarchats auf der Insel Heybeliada (vgl. Gstrein 2004: 19; Kantian 2004; Oehring 2004). Seither kann nichtmuslimischer geistlicher Nachwuchs nicht mehr in wissenschaftlich qualifizierter Form in der Türkei selbst herangebildet werden, ein offenkundig unhaltbarer Zustand, der einzig und allein auf die christentumsfeindliche Haltung des Staates zurückgeführt werden kann. Die Kritik daran von Seiten der EU ist bislang wirkungslos geblieben (vgl. SEK/2004/1201: 45). Ermutigt durch 
das Interesse der Türkei, in die Europäische Union als Mitglied aufgenommen zu werden, und die Kritik von Seiten der EU an der Beschränkung der Religionsfreiheit in der Türkei haben die Leitungen der Armenischen Apostolischen, der GriechischOrthodoxen, der Katholischen und der Syrisch-Orthodoxen Kirchen am 23. September 2002 in einem gemeinsamen Offenen Brief »Zur Frage der religiösen Bedürfnisse von christlichen und nichtislamischen Minderheiten in der Türkei« an den Menschenrechtsausschuss des türkischen Parlaments geschickt und darin folgende Forderung erhoben:

»die gesetzlichen Voraussetzungen dafür zu schaffen, die zur Unterrichtung und zur Ausbildung der Kirchendiener nötig sind und die für die Erfüllung der religiösen Bedürfnisse der Christen einerseits und insgesamt für die Existenz des Christentums in unserem Land unverzichtbar sind « (zit. nach Oehring 2004: S. 39f.).

Der Brief ist unbeantwortet geblieben.

\section{III.4 Staatlich zentral gesteuerte minderheitenfeindliche Religionspolitik - der Minderheitenausschuss ${ }^{32}$}

Es ist schon lange mit Händen zu greifen: Die türkische Regierung betreibt - über den Wechsel der innenpolitischen Machtverhältnisse und Parteiungen hinweg - eine systematische, nachhaltige feindliche Politik gegenüber den nichtmuslimischen religiösen, vor allem aber gegenüber den christlichen Minderheiten. Seit Februar 2004 hat diese Politik auch einen bestimmten Namen: es ist der »Provisorische Minderheitenausschuss", der nach dem Militärputsch von 1961 beim Innenministerium 1962 durch einen Geheimerlass der Regierung gegründet wurde. Mitglieder des Ausschusses waren Vertreter des Innenministeriums, des Außenministeriums, des Nationalen Sicherheitsrates, des Generalstabs und des Geheimdienstes MIT. Das Mandat des Ausschusses bestand insbesondere darin, alle "gegen die nationale Sicherheit gerichteten Aktivitäten der Minderheiten zu beobachten«. Der Ausschuss beschränkte sich jedoch nicht auf Beobachtung, sondern er traf in den von ihm für zweckmäßig oder notwendig erachteten Fällen auch Entscheidungen, und diese konnten von den Betroffenen nicht ange- 
fochten werden. ${ }^{33} \mathrm{Im}$ Februar 2004 ist der Ausschuss durch die »Kommission zur Auswertung der Probleme der Minderheiten « ersetzt worden und weist teilweise eine andere Zusammensetzung auf: Vertreten sind nun das Innenministerium, das Außenministerium, das Erziehungsministerium und die Generaldirektion für das Stiftungswesen. Zwar scheint die neue $\mathrm{Zu}$ sammensetzung darauf hinzudeuten, dass die religiösen und zumal die christlichen Minderheiten nicht mehr von vornherein als tendenziell staatsfeindlich, illoyal, also als Sicherheitsrisiko verdächtigt und eingestuft werden, aber die Existenz des Gremiums als solche und der bisherige Kurs der Institutionen, die darin Sitz und Stimme haben, spricht dafür, dass die restriktive, kleinlich bürokratisch-reglementierende Einstellung des Staates Türkei gegenüber den nichtislamischen Minderheiten mit (noch mehr) Kosmetik fortgesetzt werden wird.

Es ist absehbar, dass die christlichen Kirchen in der Türkei auf ganz wenige, vereinzelte Einrichtungen in Istanbul zusammengeschrumpft sein werden, wenn die Türkei (spätestens) 2015 als Vollmitglied in die Europäische Union aufgenommen sein wird. Dann wird man die Verpflichtungen von Lausanne erfüllen, aber es wird kaum noch Christen, christliche Gemeinden in dem Land geben, die in den Genuss einer dann vielleicht liberaleren Haltung des türkischen Staates kommen könnten.

\section{Schlussbemerkung}

In Bezug auf die Frage, ob bzw. inwieweit die Türkei ein Rechtsstaat und insgesamt - schon heute - europafähig ist, werfen die hier ausschnittsweise für die Minderheit der Armenier in der Türkei beschriebenen Verhältnisse kein gutes Licht. Obwohl unter beträchtlichem politischen und publizistischen Druck aus Teilen der EU-Öffentlichkeit stehend, hat der EUKandidat Türkei es bislang vermieden und erfolgreich vermeiden können, auf dem Gebiet der Religionsfreiheit und der Minderheitenrechte substantielle Verbesserungen einzuführen. $\mathrm{Zu}$ mehr als Kosmetik und freundlichen Absichtserklärungen war und ist sie vorläufig sichtlich nicht bereit. Die Tatsache, dass die EU und ihre Mitgliedsstaaten darauf nicht mit der Verhängung von Nachteilen reagiert haben, kann als Beleg dafür gewertet 
werden, dass ihr Engagement für die Garantie der Religionsfreiheit im Allgemeinen und für die Freiheit der religiösen Minderheiten im sunnitisch-islamischen türkischen Nationalstaat schwach ist und dass die Verhältnisse auf diesem Gebiet offensichtlich kein Hindernis für die Aufnahme von Verhandlungen über den Beitritt des Landes zur EU sind. Der Säkularisierungsprozess hat die politischen Eliten in den EU-Mitgliedsstaaten, ihre führenden Repräsentanten in dieser Generation sichtlich in einem Ausmaß erfasst und geprägt, dass sie mehrheitlich nicht einmal mehr zu einer angemessenen Verteidigung des Menschenrechts der Religions- und Weltanschauungsfreiheit fähig und imstande sind.

\section{Anmerkungen}

1 Ein weiteres, zu Unrecht fast völlig im Schatten der öffentlichen Aufmerksamkeit befindliches Konfliktfeld ist das Schicksal der Stätten und Güter armenischer Kultur auf dem Territorium der Türkei insbesondere in Zentral- und Ostanatolien. Von einzelnen Ausnahmen abgesehen, lässt der türkische Staat seit Jahrzehnten die (meist) sakralen Bauwerke der armenischen Vergangenheit verfallen, unternimmt nichts oder nur Unzureichendes gegen ihre Zerstörung und leistet damit dem Untergang dieses religionsund kulturgeschichtlich bedeutenden Erbes Vorschub. Nach dem physischen Genozid an den Armeniern im Osmanischen Reich bedeutet die Vernichtung ihres kulturellen Erbes in den historischen armenischen Siedlungsgebieten die endgültige Austilgung armenischer Präsenz in Anatolien. Wie sich das mit der Mitgliedschaft der Türkei in der UNESCO vereinbaren lässt, ist ebenso ein Rätsel wie der Umstand, dass sich gegen diese Zustände international kein wirksamer, nachhaltiger Widerstand formiert hat, bislang formieren konnte, obwohl die Zustände seit Jahrzehnten sehr wohl bekannt und immer wieder durchaus vernehmlich beklagt worden sind und beklagt werden.

2 Insbesondere die Seiten 19, 44-46, 56, 171 zur Religionsfreiheit; die Seiten 19f., 30f.; 38f., 49, 56, 172 zur Lage der Minderheiten, die Seiten 158ff. zum Verhältnis der Türkei zur Armenischen Republik und zur Lage im Südkaukasus. 
3 Ein lebendiges Zeugnis dieser türkischen »Geschichtspolitik« ist das Schicksal des Historikers Taner Akçam. Wegen seiner der staatlich sanktionierten, abweichenden Meinung in der Genozidfrage konnte er es jahrelang nicht wagen, in seine Heimat zurückzukehren, weil er sich seines Lebens in der Türkei nicht sicher sein konnte (vgl. Akçam 1996).

4 Es handelt sich um eine ganze Reihe von Parlamentsresolutionen aus den letzten 20 Jahren, darunter auch der Parlamentarischen Versammlung des Europarates und des EU-Parlaments.

5 Damit ist die Feststellung der Geschehnisse, die Erforschung der Unterdrückung und Vernichtung unter Einschluss der Frage gemeint, wer die Hauptverantwortung dafür im Osmanischen Reich und in der Übergangszeit zur Republik Türkei trägt (vgl. Kieser/Schaller 2002: 29f.) und Akçam (1996): Das Werk hat eine umfangreiche Bibliographie, insbesondere der für die Thematik besonders wichtigen Werke W. Dadrians (S. 406-429). Immer noch unverzichtbar ist das Werk von Lepsius (1919).

6 Vom juristischen Standpunkt aus hat sich der Verfasser mit dem Geschehen auseinander gesetzt, d.h. die Frage geprüft, ob die Vorgänge der Jahre 1915 ff. den Tatbestand des Völkermords im Sinne des Art. II der Anti-Völkermordkonvention vom 9. Dezember 1948 erfüllen (vgl. Luchterhandt 2003: 19ff.). Umfassend zum Phänomen des Völkermords, auch des Falles der Armenier Schabas (2003).

7 Hervorgetreten ist hier insbesondere die Zeitschrift »Radikal Iki«. Vgl. die Ausgabe vom 18. Mai 2003.

8 Zugrunde gelegt ist die geltende Fassung vom Mai 2004, zit. nach der Übersetzung bei Rumpf (1996), aktualisiert für Mai 2004 im Internet.

9 Dies konstatiert - lakonisch - auch der jüngste Fortschrittsbericht der EU-Kommission (vgl. SEK/2004/1201: 44).

10 Zur Religionsfreiheit in der Türkei existiert bis heute - auch dies angesichts der Bedeutung der Thematik für das deutsch-türkische Verhältnis ein nur schwer zu begreifender Umstand - keine Monographie. Die folgenden Berichte erfüllen diese Lücke zwar nicht, sind aber, soweit ersichtlich, bislang die einzige, umfassendere Behandlung des Themas im deutschsprachigen Raum und daher unverzichtbar für die Beurteilung der Problematik (vgl. Oehring 2002, 2004; Goltz 2003). 
11 Allerdings wurde ein neues Vereinsgesetz im Juli 2004 vom Parlament verabschiedet, konnte wegen des Präsidentenvetos aber nicht in Kraft treten. Wie berichtet wird, sind in dem neuen Gesetz einige der bisherigen Beschränkungen entfallen. Einschränkende Vorbehalte der Vereinsfreiheit sieht das Gesetz freilich auch weiterhin vor, und hier wird man sowohl die Ausführungsbestimmungen als auch und gerade die Verwaltungspraxis abwarten müssen, ob bzw. inwieweit sich in Bezug auf religiöse oder konfessionelle Gemeinschaften tatsächlich etwas ändern wird.

12 Zum aktuellen Stand der Dinge: vgl. (SEK/2004/1201: 41f.).

13 Der Text ist abgedruckt bei Oehring (2004: 66-69); zur früheren Ausführungsverordnung von 2002 vgl. die Dokumentation der Homepage der Türkischen Botschaft Berlin: Archiv 2002. Ausführlich zu dem Stiftungsrecht weiter unten.

14 Eine umfassende wissenschaftlich-kritische Darstellung des Verwaltungsrechts und der Verwaltungswirklichkeit in der Türkei ist ein weiteres bis heute uneingelöstes Desiderat im deutschsprachigen Raum.

15 Das Laizismusprinzip wurde 1937 mit Verfassungsrang ausgestattet. Heute ist es ausdrücklich berücksichtigt in der Präambel, in Art. 2, Art. 14 Abs. 1, Art. 136 der Verfassung von 1982. Zum Laizismus ausführlich Seufert (2004: 24); ausführlich, wenngleich ziemlich verschwommen bei Rumpf (1999); vgl. auch in historischer Dimension Wedel (1991); ferner: Dressler (1999).

16 So das Verfassungsgericht in seinem »Kopftuch-Urteil« vom 7. März 1989, abgedruckt in Europäische Grundrechte Zeitschrift 1990, S. 146ff. (mit der Kommentierung von Christian Rumpf), siehe auch Rumpf (1999: 178ff.).

17 Im Prinzip erkennt auch Rumpf die freiheits- und speziell religionsfreiheitsfeindliche Konzeption des Laizismus-Prinzips in der türkischen Verfassungsordnung, aber kritisch-systematisch mit der gebotenen Klarheit wird dies von ihm (und leider auch nicht von anderen prominenten »Turkologen «) herausgearbeitet.

18 Ursula Spuler-Stegemann sagt es von der umgekehrten, 'positiven 'Seite her mit folgenden Worten: „Gemäß Art. 10 der Verfassung von 1982 haben alle Staatsbürger unbeschadet ihrer Religionszugehörigkeit gleiche Rechte; Privilegien einzelner Gruppen oder Klassen sind ausdrücklich ausgeschlossen. Dennoch beschränkt sich die staatliche Religionsförderung auf den sunniti- 
schen Islam, der somit faktisch in die Rolle einer Staatsreligion hineingewachsen ist « (Spuler-Stegemann 1996: 239).

19 Im Ministerrat mit religiösen Fragen ist auch im Rang eines Staatsministers befasst der Theologe Mehmet Aydin (vgl. Aydin 2004; Hermann 2004).

20 Zutreffend Spuler-Stegemann in dem oben gebrachten Zitat (vgl. Spuler-Stegemann 1996).

21 Art. 24 Abs. 3 lautet: »Die Religions- und Sittenerziehung und Sittenlehre wird unter der Aufsicht und Kontrolle des Staates durchgeführt. Religiöse Kultur- und Sittenlehre gehören in den Primar- und Sekundarschulanstalten zu den Pflichtfächern. Darüber hinaus ist religiöse Erziehung und Lehre vom eigenen Wunsch der Bürger, bei Minderjährigen vom Verlangen der gesetzlichen Vertreter abhängig“ (zit. nach Rumpf 1996: 323). Völlig in die Irre führt die Übersetzung des Schlusssatzes in Abs. 3 bei Spuler-Stegemann (1996: 239): »[...] im Falle der Minoritäten auf Antrag ihres Repräsentanten [...].«

22 Nach mittleren Schätzungen handelt es sich um ca. 20 Prozent der heute ca. 68 Millionen Einwohner des Landes. Siehe dazu Oehring (2002: 11ff.); zum Aleviten-Problem in jüngerer Zeit siehe Steinbach (1996: 376f.).

23 »Gedanken-, Gewissens- und Religionsfreiheit. (1) Jede Person hat das Recht auf Gedanken-, Gewissens- und Religionsfreiheit; dieses Recht umfasst die Freiheit, seine Religion oder Weltanschauung zu wechseln, und die Freiheit, seine Religion oder Weltanschauung einzeln oder gemeinsam mit anderen öffentlich oder privat durch Gottesdienst, Unterricht oder Praktizieren von Bräuchen und Riten zu bekennen. (2) Die Freiheit, seine Religion oder Weltanschauung zu bekennen, darf nur Einschränkungen unterworfen werden, die gesetzlich vorgesehen und in einer demokratischen Gesellschaft notwendig sind für die öffentliche Sicherheit, zum Schutz der öffentlichen Ordnung, Gesundheit oder Moral oder zum Schutz der Rechte und Freiheiten anderer.«

24 Text der Artikel bei Oehring (2002: 42).

25 Offenkundig orientiert sich der türkische Staat an dem im Osmanischen Reich geltenden Millet-System, d.h. der ausdrücklichen und privilegierten Anerkennung bestimmter »Glaubensnationen«, ohne jedoch die vom Millet-System immerhin begrenzt vermittelten Entfaltungsmöglichkeiten zu gewähren. Die Behandlung und Interpretation der minderheitenrechtlichen Bestim- 
mungen des Vertrages von Lausanne in - begrenzter - Anlehnung an das Millet-System widerspricht aber nicht nur dem Wortlaut des Vertrages selbst, sondern ist ganz und gar inkonsequent, weil die Republik Türkei sich im Zeichen des »Kemalismus« gerade von dem religionspolitischen System des Osmanischen Reiches definitiv getrennt hat.

26 Christian Rumpf kommt zu der erstaunlichen Feststellung, »im Großen und Ganzen [seien] die Minderheitenvorschriften des Lausanner Vertrages durch den Gesetzgeber beachtet worden« (Rumpf 1993: 186).

27 Dazu Oehring (2004: 49ff.).

28 Dazu weist zutreffend Pfr. Gerhard Duncker mit der gebotenen Deutlichkeit hin: »Hingegen gibt es keine Religionsfreiheit für die Kirchen als verfasste Gemeinschaften oder Gemeinden. Sie besitzen keine Rechtspersönlichkeit und sind damit nicht rechtsfähig « (Duncker 2003: 79). Dieselbe Feststellung trifft der Regelmäßige Bericht der Europäischen-Kommission für 2004 (SEK/2004/1201: 45).

29 Zum Folgenden Oehring (2002: 26ff.; 2004: 10-23; 57ff.); Kantian (2004: 16ff.).

$30 \mathrm{Zu}$ dem Ganzen ausführlich Uyar (2001: 22f.).

31 Es handelt sich um die Gemeindestiftungen von Armeniern, Griechen, Georgiern, Syrern, Chaldäern und Juden. 1946 hatten noch 208 Stiftungen, davon 167 in Istanbul, existiert. Auch daran lässt sich der vom türkischen Staat administrativ, gleichsam lautlos gesteuerte Prozess zur Beseitigung der christlichen Minderheiten in Zahlen ablesen (vgl. Oehring 2004: 16f.).

32 Dazu Kantian (2004: 16) und Duncker (2003: 80).

33 Bekannt geworden ist der Ausschuss anscheinend durch einen Bericht in der Zeitung »Radikal« vom 23. Februar 2004.

\section{Literatur}

Akçam, Taner (1996): Armenien und der Völkermord. Die Istanbuler Prozesse und die türkische Nationalbewegung, Hamburg.

Armenisch-Apostolische Kirchengemeinde zu Berlin/Armenische Kolonie zu Berlin (Hg.) (1988): Armenische Frage - türkisch behandelt. Dokumentation einer antiarmenischen Hetzkampagne in 
Berlin-West sowie über die vom Europa-Parlament verabschiedete Resolution zur Armenischen Frage, Bremen.

Aydin, Mehmet (2004): >Der Islam ist moderat $<$. Fragen an den türkischen Religionsminister, in: Frankfurter Allgemeine Zeitung vom 3. April 2004.

Benz, Wolfgang (2004): Der Völkermord an den Armeniern, in: Armenisch-Deutsche Korrespondenz 123/124 (2004), S. 11-13.

Christian Rumpf (1993): Minderheiten in der Türkei und die Frage nach ihrem rechtlichen Schutz, in: Zeitschrift für Türkeistudien 2/1993, S. 173-209.

Dressler, Markus (1999): Die civil religion der Türkei, Würzburg.

Duncker, Gerhard (2003): Die Situation der christlichen Minderheit in der Türkei, in: Kirchenamt der EKD, August 2003, S. 79-83.

Goltz, Joachim (2003): Die Religionsfreiheit in der Türkei, in: Orient Jg. 2003.

Gstrein, Heinz (2004): Chalki: Zwischen Hoffen und Bangen, in: Glaube in der 2. Welt (G2W) 2004.

Hermann, Rainer (2004): Ali Bardakoglu. Modern, in: Frankfurter Allgemeine Zeitung vom 1. März 2004.

Kantian, Raffi (2004): Die EU-Kandidatin Türkei, in: ArmenischDeutsche Korrespondenz 123/124 (2004), S. 15-18.

Kieser, Hans-Lukas/Schaller, Dominik (Hg.) (2002): Der Völkermord an den Armeniern und die Shoah. The Armenian Genocide and the Shoah, Zürich.

Kuymçuyan, Sylvia (2002): Die armenischen Schulen in Istanbul, in: Armenisch-Deutsche Korrespondenz, 115/2002, S. 17.

Le Goff, Jacques (2000): Die Grenzen Europas. >Wir müssen eine gemeinsame Kultur schaffen : Der Historiker Jacques Le Goff über die Aufnahme der Türkei, die neue Einwanderung und Brüssels Mangel an weltlicher Liturgie, in: Die Zeit 50/2000.

Lepsius, Johannes (1919): Deutschland und Armenien 1914 - 1918. Sammlung diplomatischer Aktenstücke, Potsdam.

Luchterhandt, Otto (2003): Der türkisch-armenische Konflikt, die Deutschen und Europa, Hamburg.

Oehring, Otmar (2002): Zur Lage der Menschenrechte in der Türkei Laizismus = Religionsfreiheit? Aachen.

Oehring, Otmar (2004): Die Lage der Menschenrechte - Die Türkei auf dem Wege nach Europa - Religionsfreiheit? Aachen.

Rumpf, Christian (1996): Das türkische Verfassungssystem, Wiesbaden (aktualisiert im Internet im Mai 2004). 
Rumpf, Christian (1999): Laizismus, Fundamentalismus und Religionsfreiheit in der Türkei in Verfassung, Recht und Praxis, in: Verfassung und Recht in Übersee, 32. Jg., S. 164-190.

Schabas, William A. (2003): Genozid im Völkerrecht, Hamburg.

SEK/2004/1201: Kommission der Europäischen Gemeinschaften: 2004. Regelmäßiger Bericht über die Fortschritte der Türkei auf dem Wege zum Beitritt, Brüssel vom 6.10.2004.

Seufert, Günter (2004): Laizismus in der Türkei - Trennung von Staat und Religion, in: Südosteuropa-Mitteilungen 1/2004, S. 17-29.

Spuler-Stegemann, Ursula (1996): Der Islam in ausgewählten Staaten, Türkei, in: Werner Ende/Udo Steinbach (Hg.): Der Islam in der Gegenwart, München, S. 232-246.

Steinbach, Udo (1996): Die Türkei im 20. Jahrhundert. Schwieriger Partner Europas, Bergisch-Gladbach.

Türkische Botschaft in Berlin (2004): Die armenischen Behauptungen. Die Wahrheit hinter den Völkermordbehauptungen. Online unter: http://www.tcberlinbe.de/de/aussenpolitik/armenien/ar2202012.htm

Uyar, Ilyas (2001): Die schleichende Enteignung, in: ArmenischDeutsche Korrespondenz 114/2001, S. 22 f.

Wedel, Heide (1991): Der türkische Weg zwischen Laizismus und Islam, Opladen.

Zayas, Alfred de (2004): Memorandum on the Genocide against the Armenians 1915 - 1923 and the Application of the 1948 Genocide Convention. Online unter http://www.armenian.ch/ asa/Docs/ dezayas_report.pdf. 



\title{
Im Irrgarten der Argumente
}

\author{
MARTIN WINTER
}

Es bedarf keiner prophetischen Gaben um $\mathrm{zu}$ ahnen, dass der Streit um den Beitritt der Türkei zur Europäischen Union in den kommenden Verhandlungsjahren nicht abebben wird. Wer hofft, dass der Gipfelbeschluss der EU vom 17. Dezember 2004 über den Beginn der Gespräche im Oktober 2005 mittelfristig beruhigend wirkt, der dürfte enttäuscht werden. Denn mit diesem Beschluss betritt die EU politisches Neuland. Hinter der Fassade einer normalen Erweiterung nach dem hergebrachten Schema verbirgt sich eine sich selber noch nicht ganz sichere, aber doch unverkennbar hegemoniale Intention. Indem sie der Türkei die Tür öffnet, stellt die EU sich zugleich jene Frage, der sie bislang ausgewichen ist. Der nämlich, wohin sie eigentlich will. Wie gestaltet sie ihre Finalität? Wo liegen ihre Grenzen? Und wo und wie soll, will oder muss sie ihre Nachbarschaft im eigenen Interesse beeinflussen? Weil sie ahnen, dass es um mehr als nur um eine Erweiterung geht, sondern um den Wandel von einer sich selbst genügenden und nach innen gerichteten Union zu einer nach außen machtpolitisch aggressiv auftretenden, brennt der europäischen Öffentlichkeit, Politikern und Parteien plötzlich unter den Nägeln, was aus dem Blickwinkel mancher Regierungen im Prinzip schon entschieden schien.

Doch weder die verstrichenen vier Jahrzehnte, in denen die Türkei immer und immer wieder von europäischen und amerikanischen Politikern zu einem europäischen Land erklärt worden war, noch die Tatsache, dass die Türkei die zweitgrößte 
Armee in der Nato stellt, hat die Aufwallungen dämpfen können. Was den Europäern da jetzt am Horizont dämmert, das beunruhigt sie. Wie tief das reicht, zeigt die Tatsache, dass die althergebrachten Argumente für die Türkei - erstens ist sie europäisch und zweitens haben wir es ihr versprochen - den entstandenen Aufruhr nicht dämpfen können.

Kein Wunder: Der Fall Türkei liegt anders als alle bisherigen Erweiterungen. So war die gewaltige Ausdehnung der EU im Mai 2004 um zehn Länder aus Ost- und Südosteuropa zwar zuweilen in Form und Tempo umstritten, nie aber in ihrer grundsätzlichen Vernunft. Zugunsten der Balten, Polen, Ungarn oder Tschechen wirkte der Gründungsgedanke der Union fort, Europa zu vereinen, um dauerhaften Frieden auf dem Kontinent zu schaffen. In dieses Raster passt die Türkei nicht und noch herrscht Not an Argumenten, die die Menschen in der EU überzeugen und nicht nur die Strategen in den Ministerien und in den Kanzleien. So stürzt die Konkretisierung der Beitrittsperspektive für die Türkei die EU in eine innere wie äußere Zerreißprobe, an deren Ende eine neue Großmacht, aber auch der Ruin Europas stehen kann. Der Kampf um die richtigen Argumente und die richtige Politik beherrscht nun die EU, und die Positionen lagen wohl noch nie so weit auseinander. Sie spannen sich vom deutschen Außenminister Joschka Fischer, der einen Beitritt der Türkei in einem Interview mit der BBC im Oktober 2004 zum »D-Day im Krieg gegen den Terror" hochstilisiert bis zu den düsteren Prophezeiungen, die die französische Politikwissenschaftlerin und Diplomatin Sylvie Goulard in ihrem Buch "Le Grand Turc et la République de Venise" niedergeschrieben hat. Sie befürchtet, dass eine Aufnahme der Türkei zu einer fatalen Entkräftung der eh schon schwer gestressten Europäischen Union führt, die dadurch »auf ewig ins Vorzimmer der Welt abgeschoben « würde. Das Bemerkenswerte dabei ist nicht so sehr, wie unüberbrückbar weit diese Positionen auseinander liegen, sondern dass es sie überhaupt gibt. Ihr streckenweise emotionaler Austausch zeigt, dass die Türkeifrage für die Europäer ganz und gar noch nicht gelöst ist. Das Mantra der protürkischen Erweiterungsprotagonisten von dem Versprechen, das gegeben und dem Kandidatenstatus, der doch längst beschlossen worden sei, kollidiert mit der Wirklichkeit Europas. Eine Umfrage des Ifop-Institutes ergab im Herbst 
2004, dass 55 Prozent der Deutschen und 67 Prozent der Franzosen gegen eine Aufnahme der Türkei sind.

Solch massiver Widerstand aus der Öffentlichkeit und auch aus seinem eigenen politischen Lager hat den französischen Staatspräsidenten Jacques Chirac gezwungen, den möglichen Beitritt der Türkei einer Volksabstimmung zu unterwerfen. Der österreichische Bundeskanzler Wolfgang Schüssel verkündete nach Abschluss des Gipfels die gleiche Absicht. Diese beiden sind nur die ersten, die diesen Schritt gehen müssen, um sich gegen das Risiko des eigenen Scheiterns an der Türkeifrage abzusichern. Auch in anderen Regierungen wie etwa in der dänischen sind die Bedenken groß und die Neigungen zu Referenden wachsen. Die Türkei ist zum öffentlichen Problem Europas geworden. Ihre Aufnahme lässt sich nicht wie in anderen Fällen auf der technischen Ebene von Beamten und auf der politischen von den Staats- und Regierungschefs verhandeln. Wer die Türkei aufnehmen will, der muss die Europäer davon überzeugen, dass das erstens Sinn macht und dass es die Europäische Union zweitens nicht in unkalkulierbare Risiken stürzt. Über vierzig Jahre sind vergangen, seit die Türkei eine Beitrittsperspektive zur europäischen Gemeinschaft bekam. Manches ist auf beiden Seiten in der verflossenen Zeit dazu gesagt worden an Begründungen, an Ansprüchen und an großen politischen Entwürfen. Wie wir heute sehen, hat kaum etwas davon verfangen, was auch daran liegen mag, dass das Aneinanderrücken von EU und Türkei auf beiden Seiten von Anbeginn an von Heuchelei geprägt war. Doch auch die Argumente der Gegenwart verwirren mehr, als dass sie Vertrauen schaffen. In einer erstaunlichen Fehleinschätzung von Stimmungen und Risiken hatte der EUGipfel im Dezember 1999 in Helsinki mit der Verleihung der Eigenschaft eines Beitrittskandidaten an die Türkei einen Schlusspunkt unter die Frage setzen wollen, ob die Türkei zu Europa gehört. Doch in Helsinki wurde nicht abgeschlossen, sondern im Gegenteil eröffnet. Seitdem der türkische Premierminister Recep Tayyip Erdoğan auf der Basis von Helsinki Ernst macht mit der praktischen Anpassung an den acquis communautaire hat die EU ein Problem. Sie ist an den Grenzen ihrer hergebrachten Methode angekommen, Schrittchen für Schrittchen Fakten zu schaffen, die irgendwann unumkehrbar und darum von den Bürgern akzeptiert werden. Mit der Türkei geht 
das nicht mehr, denn ihre Aufnahme wäre für die EU ein Vorstoß in eine neue Dimension mit einigen Chancen und vielen Risiken, der ohne einen breiten Konsens der Bürger schiefgehen muss. Diesen Konsens aber kann die EU nur aufbauen, wenn sie sich in der causa Türkei ehrlich macht. Dafür ist es notwendig, sich die europäisch-türkische Geschichte der Annäherung nüchtern zu vergegenwärtigen und sie nicht zu idealisieren.

\section{3: Die Mutter aller Versprechen}

Bei der feierlichen Unterzeichnung des Assoziationsabkommens mit der Türkei sagte Walter Hallstein am 12.September 1963 in Ankara jenen Satz, der wieder Wellen in Europa schlägt: "La Turqie fait partie de l'Europe" (Archiv der EU-Kommission). Das Bemerkenswerte an dieser Aussage des damaligen Präsidenten der Brüsseler Kommission ist weniger ihr Inhalt, als die Tatsache, dass er gesagt wurde und wann er gesagt wurde. Weil dieser Satz nicht selbstverständlich war, musste er gesagt werden. Weder in der historischen Sicht Europas noch im Empfinden seiner Bürger war die Türkei ein Teil Europas. Und schon gar nicht des europäischen Einigungswerkes. Denn auch wenn die Osmanen immer wieder einmal versucht hatten, eine europäische Macht zu werden und es zweimal sogar bis vor Wien geschafft und sich in den 30-jährigen Krieg einzumischen versucht hatten, und auch wenn sie Teile des Balkans über Generationen besetzt gehalten hatten und von den europäischen Mächten mit einem wachsamen, oft kalkulierenden Auge betrachtet wurden, so waren sie doch nie Teilnehmer jenes sich seit dem 17. Jahrhundert verschärfenden Spieles um Größe, Reichtum und Einfluss unter den europäischen Staaten. Eines Spieles, das immer wieder in Kriege abglitt und den Kontinent mit dem Ersten und dem Zweiten Weltkrieg an den Rand der Selbstvernichtung brachte. Nachdem die Europäer die blutigen Jahrhunderte leid waren, wagten sie sich an den einzig übrig geblieben Weg zu dauerhaftem Frieden: den Zusammenschluss. Dieses Einigungswerk, das mit der hohen Behörde für Kohle und Stahl begann, um zwei wichtige Kriegsgründe zwischen Deutschland und Frankreich aus dem Weg zu räumen, wurde gewiss durch das Heraufziehen des Kalten Krieges be- 
fördert. Aber es war, wie in Jean Monnets »Mémoires « nachzulesen ist, $\mathrm{zu}$ allererst die einzig vernünftige und einzig verbliebene Chance, ein friedliches Europa zu gestalten. An die Türkei hat damals niemand gedacht. Die war aus europäischer Sicht geografisch Kleinasien und aus politischer alles Mögliche, aber gewiss nicht Bestandteil des europäischen Problems. Was also trieb die Europäer dann, die Türkei zum »Teil Europas« zu erklären?

Der Schlüssel zur Antwort liegt im Datum der Hallsteinschen Rede. Zwei Jahre zuvor war in Berlin die Mauer gebaut worden. Die militärischen Blöcke lagen sich in tiefem Misstrauen gegenüber und bereiteten nukleare Vernichtungsstrategien vor. Und am Horizont wetterleuchtete schon die Kuba-Krise, die am 22. Oktober 1963 dann mit voller Wucht ausbrechen und die Welt an den Rand eines weiteren Waffenganges stoßen sollte. Seit Mitte der 50er Jahre war die geostrategische Bedeutung der Türkei für die USA und für ihre europäischen Nato-Partner kontinuierlich gestiegen: als Aufmarschgebiet, als Bollwerk, als Riegel zum Schutz der Ölquellen der arabischen Welt. Mit dem Fortschritt der Raketentechnik kam für Ankara eine neue Bedeutung hinzu. Die Türkei wurde zum unverzichtbaren Glied in der gigantischen Kette aus Raketenvorwarnstationen, die die USA rund um die Sowjetunion legten. Die Türkei entwickelte sich zur Südostflanke der Nato. Das war für das Land nicht immer eine leichte Last, und so lag es nahe, die ein wenig zu mildern. Etwa durch einen privilegierten Zugang zum europäischen Markt, der später dann in eine Zollunion mündete. Hallsteins Reise nach Ankara diente allein dem Zweck, diesen Prozess in Gang zu setzen. Wie weit er eigener Überzeugung und wie weit er dem Drängen Washingtons zu danken ist, wird mit Präzision kaum anzugeben sein. Das spielt aber auch keine Rolle, denn der geschichtliche Kontext lässt keinen Zweifel, dass am Anfang der Beziehung zwischen der heutigen EU und der Türkei nicht der Wunsch nach der friedlichen Vereinigung des zerrissenen Kontinentes stand, sondern ein nüchternes geostrategisches Interesse des Westens, dem ein türkisches Interesse an einer Einbindung in den Westen und am Zugang zu den europäischen Märkten entsprach. Es ist eine Ironie der Geschichte, dass nun, 41 Jahre später, wiederum geostrategische Überle- 
gungen bemüht werden, um die Türkei endgültig in die EU zu heben - allerdings geostrategische Entwürfe ganz anderer Art.

\section{Geburt einer Legende}

Auch wenn es schon lange her ist, lohnt es sich, noch ein wenig bei jenem Septembertag zu verweilen. Denn er gibt Aufschluss darüber, dass nicht nur die Türkei die Gunst der Stunde zu nutzen wusste, sondern dass auch die Europäer keine Skrupel hatten, das Geschäft ideologisch zu verbrämen. Wahrscheinlich dachten sie insgeheim, dass sie am Ende ihre Schecks nicht würden einlösen müssen. Wie weit Betrug und Selbstbetrug gingen, zeigt sich nirgends schöner, als in der Begründung, die Hallstein seiner Erklärung nachschob, die Türkei sei ein Teil Europas. Die Türkei qualifiziere sich nicht nur aus geografischen und historischen Gründen, sondern vor allem als ein Produkt der »machtvollen Persönlichkeit Atatürks«, dessen Politik »einer radikalen, europaorientierten Reform« dem Staat ihren Stempel aufgedrückt habe. Genau dieser kemalistische Staat aber war auch schon damals nicht mit den Prinzipien des sich vereinigenden Europas kompatibel, selbst als es wie 1963 die politische Union noch nicht gab. Autoritäre Strukturen, die Vormachtstellung des Militärs, die Unterdrückung von ethnischen und religiösen Minderheiten und der eklatante Mangel an Rechtstaatlichkeit und Menschenrechten machten die Türkei 1963 untauglich für den Beitritt zur Brüsseler Unternehmung. Aber es ging 1963 eben nicht um eine Prüfung in der Sache, sondern nur um eine passable Begründung für diesen ungewöhnlichen Schritt. Das Argument, Atatürk habe mit seiner Politik die Türkei nach Westen ausgerichtet, reichte dann auch für den Rest des Kalten Krieges. Brüssel kümmerte sich nicht weiter und Ankara auch nicht. Die Türkei unternahm in den Jahren nach Hallsteins Auftritt keine nennenswerten Anstrengungen, ihre politischen, rechtlichen und gesellschaftlichen Strukturen so $\mathrm{zu}$ reformieren, dass sie auf die europäischen Standards passen. So war der erste Beitrittsantrag Ankaras 1987 auf den Sand der Illusion gebaut, dass einem die Mitgliedschaft nach einer gewissen Zeit von selber zufiele. 
Entweder bewegte sich in der Türkei nichts, weil Ankara nicht von Brüssel gedrängt wurde oder weil es unter der gegebenen Konstellation des Kalten Krieges eine automatische Aufnahme erwartete. Doch nichts lag weiter von der Wirklichkeit als das. Denn so wenig die Türken den Vertrag von 1963 als Verpflichtung begriffen hatten, sich den Werten der Europäer anzunähern, so wenig sahen sie darin mehr als ein politisches Lippenbekenntnis und eine ökonomisch langfristig durchaus vorteilhafte Kooperation. Wie mutwillig das Atatürk-Argument von den Europäern an den Haaren herbeigezogen worden war, offenbarte sich in den 90er Jahren, als Ankara auf der Suche nach einem Platz in der neuen Weltordnung ernsthaft an die Tür der EU klopfte. Kaum ging es zur Sache, da entdeckten die Europäer, dass die kemalistischen Strukturen das entscheidende Hindernis für die Türkei sind. Was 1963 noch zur Begründung der Europatauglichkeit der Türkei angeführt wurde, diente nun dazu, sie erst einmal vor der Tür zu halten. Mit der Formulierung der »Kopenhagener Kriterien« setzte die EU dann einen Rahmen, - nicht allein für die Türkei, aber doch mit einem starken Blick auf sie - in den sich jeder Interessierte eingepasst haben muss, bevor er um Beitrittsgespräche bitten kann. Diese Kriterien verlangen der Türkei den Abriss des kemalistischen Staates ab. Ein Unterfangen, an das sich Premier Erdoğan macht, was ihm als einem, der aus der politischen islamischen Bewegung stammt und deswegen immer ein Gegner des kemalistischen Staates war, nicht allzu schwer fallen dürfte.

Selbst wenn die Argumentekombination aus »Ihr habt ein Versprechen gegeben « und »Die Türkei ist seit Atatürk westlich orientiert « historisch und sachlich kaum zu halten ist, so spielt sie doch auch heute immer noch eine Rolle, aus der sogar noch eine ausschlaggebende werden kann. Auf der Seite der EU greifen protürkische Politiker gerne auf sie zurück, um Gegenargumenten, die sich aus der Gegenwart speisen, den Boden zu entziehen. In Ankara nutzen Erdoğan, sein einflussreicher Außenminister Abdullah Gül und die Oppositionsparteien das Argument des Versprechens regelmäßig als letzte Rückfallposition. Und schon ist daraus ein neues Argument gewachsen: das vom Wort halten. Aber welches Wort eigentlich? Wie gesehen gründete sich Hallsteins Erklärung nicht auf prinzipielle historische, philosophische und kulturelle Überlegungen, sondern 
war Ausfluss einer strategischen Notlage des Westens. Nun könnte man natürlich sagen, dass jeder die Suppe auslöffeln muss, die er sich einbrockt und dass man die Türken nun nicht für die Hintergedanken der Europäer zahlen lassen dürfe. Doch Ankara ist nicht das Opfer von europäischen Geschäftemachern, sondern es hat gewusst, um was es geht und es hat für sich dabei ein Maximum herausverhandelt. So lange der Kalte Krieg herrschte und die Türkei für die USA und für die Nato eine wichtige strategische Rolle spielte, ging auch alles glatt. Doch mit dem Zusammenbruch der Sowjetunion verlor die Türkei, weil sich die strategischen Koordinaten über Nacht verschoben.

\section{Die Scheinalternative}

Damit geriet die Türkei in eine politische Klemme. In der Welt der Blöcke hatte sie einen festen und einflussreichen Platz an der Seite der USA und Israels. Jetzt aber verschob sich alles bis zur Unkenntlichkeit und in der Unübersichtlichkeit der sich langsam herausbildenden neuen Weltordnung wurde Ankara nur eines klar: Weil es die alte Rolle nicht mehr spielen konnte, würde es sich eine neue suchen müssen. Dass der Blick dabei schnell auf die EU fiel, zu der man ja eine Eintrittskarte in der Tasche zu haben glaubte, war kein Zufall. Die Westorientierung des kemalistischen Staates spielte hier ebenso eine Rolle wie der Blick ins eigene Hinterland, der ganz und gar nichts Gutes verhieß: im Norden die Länder des Kaukasus, die sich selbstständig gemacht hatten und von denen einige auf großen Vorräten an Öl und Gas sitzen, im Osten der große Iran, an dem sich nach der Schwächung des Irak durch den Golfkrieg 1991 unübersehbare Anzeichen hegemonialer Gelüste zeigten, und im Süden und Südwesten die arabische Welt, die kaum vergessen haben dürfte, wie eng Ankara politisch und militärisch mit Israel zusammenarbeitet. Wollte die Türkei nicht auf sich allein gestellt werden und damit schleichend an Einfluss verlieren, war die europäische Karte die beste, die sie spielen konnte. Auch die wechselnden Regierungen vor Erdoğan haben Druck auf Brüssel gemacht, sehr oft mit Hilfe der USA, die für die Türkei dringend eine neue Unterkunft suchten und früher als 
die Europäer eine neue strategische Bedeutung in der Türkei erkannten. Nicht als Brücke zum Islam sondern als ein Land, durch das man das kaspische Öl sicher in den Westen schaffen kann. Der wirtschaftlichere und ökologisch sicherere Weg hätte durch den Iran geführt, was Washington aus nahe liegenden Gründen vermeiden wollte.

Beim zunehmend hartnäckigen Anklopfen an die europäische Tür stellte sich jedoch sehr schnell heraus, dass die Europäer überhaupt nicht darauf vorbereitet waren, die Türken aber auch nicht. Noch bis in die jüngste Vergangenheit pflegte der quer durch Europa respektierte, ehemalige außenpolitische Sprecher der CDU/CSU-Fraktion im Bundestag, Karl Lamers, zu klagen, dass die Türkei offensichtlich glaube, dass die EU ihr beitreten wolle und nicht umgekehrt. Es begann sich nun $\mathrm{zu}$ rächen, dass Hallsteins Wort von 1963 auf türkischer Seite als Garantie für eine spätere Mitgliedschaft genommen wurde. Dass man die Eintrittsbedingungen in die EU nicht frei verhandeln kann und dass es sich bei Erweiterungen weniger um Aufnahmen, sondern de facto um die Übernahme neuer Länder handelt, dämmerte in Ankara erst dem zum Rechtskonservativen mutierten Islamisten Erdoğan. Aber auch der hat immer noch große Probleme, die innere Logik der europäischen Einigung zu begreifen. Als ihm auf dem Gipfel am 17. Dezember 2004 klar gemacht wurde, dass eine Eröffnung der Beitrittsgespräche nicht möglich sein werde, bevor die Türkei zumindest symbolisch die Republik Zypern anerkennt, die ja Mitglied der EU ist, da beschimpfte Erdoğan die Europäer, ihnen seien 600.000 Griechen wohl wichtiger als 70 Millionen Türken. Dass die EU nicht mit einem Land über den Beitritt verhandeln kann, das ein Mitgliedsland der EU nicht anerkennt, war dem türkischen Premier unverständlich.

Es liegt auf der Hand, warum das so ist. Erdoğan und die türkischen Eliten sind nicht genuin am europäischen Einigungswerk interessiert, sondern einerseits an der wirtschaftlichen Macht der EU und andererseits daran, über die EU eine weltpolitische Rolle spielen zu können. Was Erdoğan von seinen Vorgängern unterscheidet, die den Beitritt allein mit dem Verweis auf die strategische Bedeutung ihres Landes erzwingen wollten, ist die Erkenntnis, dass der Weg in die EU allein über die Erfüllung des acquis communautaire führt. Allerdings blieb 
Erdoğan auch gar keine andere Wahl. Denn ein politischer Trick, mit dem Ankara die EU in den 90er Jahren einer Aufnahme gewogen machen wollte, hatte nicht verfangen. Spürend, dass die sich zur politischen Union mausernde EU nur wenig Neigung zeigte, ihr Versprechen von 1963 zu erfüllen, streute Ankara mit Hilfe der USA das Gerücht, eine von der EU zurückgewiesene oder schlecht behandelte Türkei könne sich zur kleinasiatischen Regionalmacht entwickeln. Eine Drohung, hinter der durchaus ernst gemeinte, großtürkische Träume standen, die gleichwohl nichts mit der Wirklichkeit zu tun hatte, wie sich schnell zeigte. Das Interesse der ehemaligen Sowjetstaaten im Kaukasus an einer türkischen Führungsrolle lag bei Null. Und im Nahen und Mittleren Osten wurde und wird die Türkei mit traditionellem Misstrauen betrachtet. Der Versuch, den türkischen Blick wieder zurück in den Osten zu drehen, wäre im Übrigen spätestens am Iran gescheitert, der selber auf dem Weg zum regionalen Hegemon ist. Der Versuch Ankaras, sich eine strategische Alternative zum Westen aufzubauen, brach so schnell in sich zusammen, dass sich heute kaum noch jemand an ihn erinnert. In der zweiten Hälfte der 90er Jahre klopfte Ankara darum wieder heftig an die Tür der EU. Aber es bedurfte erst dramatischer und unerwarteter Ereignisse, um der Türkei zum ersten Mal seit über 40 Jahren eine echte Chance auf einen Beitritt zu geben.

\section{Der Einbruch des Terrors und die Entdeckung neuer Argumente}

Der 11. September 2001 veränderte den strategischen Blick der großen Länder der EU auf den Lauf der Welt. Das war nicht immer der gleiche Blick und abgesehen vom Krieg gegen das Talibanregime in Afghanistan strebten die europäischen Länder in gegensätzliche Richtungen. Eine gemeinsame europäische Antwort auf die Herausforderung durch den islamistischen Terrorismus wurde dadurch verhindert. Großbritannien, Polen und andere Länder, die sich der von den USA geschaffenen "Koalition der Willigen " anschlossen, setzten auf die neue amerikanische Sicherheitsstrategie, die das Recht der Weltmacht propagiert, überall auf der Welt ihre Interessen mit Waffenge- 
walt durchzusetzen oder Demokratie und Freiheit notfalls mit dem Schwert zu verbreiten. Die Politik des zeitlich und räumlich unbegrenzten »Krieges gegen den Terrorismus « spaltete Europa. Eine Spaltung, die von Washington mit betrieben wurde. Auf der anderen Seite des Grabens, der sich in der Hitze der politischen Wortgefechte über den Irakkrieg immer mehr erweiterte, standen vor allem Deutschland und Frankreich. Beide misstrauten dem »Krieg" gegen den Terrorismus. Beide fürchteten, dass er nur als Instrument für einen neuen amerikanischen Hegemonismus missbraucht werde. Beide hielten den Irak-Krieg für einen Fehler, nicht nur weil er falsch begründet war, sondern weil er die Flamme des Radikalismus in der arabischen Welt anfachen würde.

Was die Lager in der EU aber wirklich und tief reichend unterschied, war der jeweilige Blick auf die zukünftige Rolle Europas in der Welt. Während diejenigen Länder, die der amerikanische Verteidigungsminister Donald Rumsfeld als das "neue Europa « zu loben pflegte, sich reflexartig wie im Kalten Krieg unter den Schirm der USA flüchteten, begannen in Berlin und Paris die ersten Gedankenspiele darüber, dass die EU eine eigenständige außen- und sicherheitspolitische Konzeption brauche, um mit den neuen Herausforderungen fertig zu werden. Diplomaten und Politiker nahmen den Nahen und Mittleren Osten und die Probleme der islamischen Welt stärker wahr als zuvor. Die Anschläge in New York und Washington und später in Madrid führten ihnen vor Augen, dass sich in ihrer unmittelbaren Nachbarschaft etwas zusammengebraut hatte, das sowohl die wirtschaftlichen als auch die sicherheitspolitischen Interessen der Europäischen Union unmittelbar gefährdete. Während die USA trotz der internationalen Mobilität der Terroristen zwischen sich und den Krisenregionen der Welt immer noch den Atlantik und den Pazifik liegen haben, schwelen die Brandherde direkt vor der Haustüre der Europäer. Der Dissens über den Irakkrieg hat die Europäer zwar lange Zeit dabei behindert, eine gemeinsame Antwort auf diese Herausforderung zu finden. Aber in dem Maße, in dem sich Ernüchterung über den Feldzug im Zweistromland breit macht und in dem viele Länder erkennen, dass auch die Mittel der Weltmacht, die militärischen wie die politischen, begrenzt sind, nähert sich die EU in der ihr eigenen, schwankenden Vorwärtsbewegung einer 
politischen Antwort auf die Herausforderungen. In der 2003 diskutierten und verabschiedeten europäischen Sicherheitsstrategie findet sich schon das Konzept einer EU, die ein weites Netz von Verträgen um sich wirft. Im Verfassungskonvent wurde debattiert, welche Instrumente sich die Europäer zulegen können, um ihre Nachbarn an sich zu binden. Und die EUKommission entwickelt die neue Nachbarschaftspolitik. So unterschiedlich die Formen und Ebenen der Absicherung der europäischen Regionalinteressen auch sein mögen, ein Gedanke liegt allen zugrunde: Europa muss sich einen Cordon von Freunden schaffen, der von Russland über den Kaukasus, den Nahen und Mittleren Osten und Nordafrika bis nach Gibraltar reicht. Dabei war allen Beteiligten mehr oder minder klar, dass die Beitrittsmethode dafür kein geeignetes Instrument ist. Lag nach dem Ende des Kalten Krieges der Export von europäischem Frieden und Wohlstand durch den Import der meisten Länder des ehemaligen Ostblocks in die Union auf der Hand, so ist das mit den vielen Ländern, um die es jetzt geht, de facto unmöglich. So wurde etwa Marokko schon mehrfach bedeutet, dass sein Interesse an einer Mitgliedschaft nirgendwo hin führt. Die Instrumente, an denen in Brüssel gebastelt werden, sind nun andere. Sie reichen von ganz normalen Assoziations- und Partnerschaftsabkommen über strategische Partnerschaften mit Schlüsselländern bis hin zur Reaktivierung des BarcelonaProzesses, der den gesamten mediterranen Raum umfasst.

Die Logik spräche dafür, der Türkei in diesem Raster der Nachbarschaftspolitik eine herausragende Stellung zu geben. Ökonomisch ist Ankara über eine Zollunion bereits fest mit der EU verbunden. Zur Europäischen Sicherheits- und Verteidigungspolitik hat sie über die »Berlin-Plus-Regelung « der Nato Zugang. Eine weitere strukturelle Einbindung in die Union, etwa beim Kampf gegen Drogen- und Menschenhandel, wäre problemlos möglich. Das alles ginge, ohne von der Türkei gegenwärtig möglicherweise noch unverträgliche Souveränitätsverzichte zu fordern, wie sie nun einmal mit der EU-Mitgliedschaft einhergehen, und ohne die Union einer Aufnahmebelastung auszusetzen, die sie nicht durchhalten kann. Doch diese Logik einer Alternative zum Beitritt, die in der von den deutschen Christdemokraten, der französischen UMP und der österreichischen ÖVP vertretenen Idee einer privilegierten oder stra- 
tegischen Partnerschaft ihren Niederschlag fand, hatte de facto nie eine ernsthafte Chance. Zum einen nämlich wollte sich die Türkei auf keinen Fall die Gunst der Stunde entgehen lassen und weniger bekommen, als es glaubte, erreichen zu können. Zum anderen fand Ankara in Berlin einen mächtigen Verbündeten, der nach und nach auch den französischen Staatspräsidenten ins Erweiterungsboot bekam, in dem der englische Premierminister bereits an den Rudern saß. Auch Rom und Madrid waren eingestiegen und so gab es am Ende zu wenig Gewicht und zu wenig Mut, den Zug zum Beitritt auf ein anderes Gleis zu schieben.

Eine wesentliche Rolle spielte dabei, dass vor allem Berlin nach dem 11. September 2001 ein neues Argumentationsmuster für den Beitritt der Türkei aufbaute, das von dieser sofort begierig übernommen wurde und seine Kritiker als Leute darstellt, die die Dimensionen der historischen Herausforderungen nicht zu begreifen scheinen. Diese Beitrittsstrategie stützt sich auf drei Argumente:

Erstens: Die Beitrittsperspektive bringt die Demokratisierung und die Modernisierung der Türkei voran. Zweitens: Die Türkei wird für die EU zur Einflussbrücke in den Nahen und Mittleren Osten. Drittens: Eine Aufnahme der Türkei ist ein Signal an die islamische Welt, dass die EU keinen Kampf der Kulturen betreibt.

Alle drei Argumente ziehen ihre Kraft aus der Gegenwart und aus einer vermuteten Zukunft. Deshalb sollte man sich genau ansehen, wie tragfähig sie sind.

\section{Demokratie und Moderne}

Die These, dass die Perspektive einer Mitgliedschaft in der EU die Demokratisierung und die Modernisierung der türkischen Gesellschaft befördert, hat einiges für sich. Der Zwang etwa zu rechtsstaatlichen Verfahren oder zur Respektierung der Rechte von Minderheiten kann ernorme Auswirkungen haben. In Deutschland benutzen dieses Argument darum vor allem die Grünen und viele Sozialdemokraten. In der Türkei wird es von der Demokratiebewegung, von Menschenrechtsgruppen aber auch von bislang unterdrückten Minderheiten wie den Kurden 
genutzt. Erdoğan rechtfertigt sogar seine gesamte Politik mit der These der Demokratisierung und Modernisierung. Jeder einzelne Reformschritt wird in Ankara damit begründet, dass man damit dem Ziel der Aufnahme in die EU ein Stück näher kommt. Darin steckt aber zugleich die Schwäche des Argumentes. Die EU kann zwar einen Zug zur Demokratisierung unterstützen und verstärken. Aber sie kann ihn nicht ersetzen. Eine Türkei, die sich nicht aus eigener Kraft auf den demokratischen Weg bringen kann, die wird es auch nicht mit der Fixierung auf die EU können. Die romantischen Vorstellungen vor allem der deutschen Linken vom demokratischen Auf- und Durchbruch in der Türkei speisen sich aus einem Missverständnis. Der kemalistische Staat mag ein autoritärer sein, aber er war und ist kein diktatorischer Deckel auf einer vom Verlangen nach westlicher Demokratie brodelnden Gesellschaft. Die Verfechter der Demokratisierungsthese übersehen mit einer erstaunlichen Leichtfertigkeit die sozioökonomischen Verhältnisse in der Türkei. Wer über Istanbul und Ankara hinausschaut, ahnt, dass die türkische Gesellschaft noch lange brauchen wird, die in der EU gültigen Werte und Regeln auch in der Praxis zu leben. Für ambitionierte Politiker in Ankara mögen zehn bis fünfzehn Jahre Verhandlungszeit zu lang sein. Für eine Änderung der Gesellschaft aber, die sie europakompatibel machen würde, ist sie bei weitem zu kurz. Jenen, die auf das Problem hinwiesen, dass die Übernahme europäischer Gesetzesnormen noch keine nachhaltige Veränderung der gesellschaftlichen Praxis mit sich bringe, pflegte der frühere Erweiterungskommissar Günter Verheugen entgegenzuhalten, dass die Türkei, die der EU beitrete, eine ganz andere sei, als die wir heute kennen. Auch Joschka Fischer bedient sich gerne dieses Argumentes ohne allerdings erläutern zu können, wie die europäische Perspektive in zehn Jahren schaffen soll, was selbst den Zwangsmodernisierern Atatürks in großen Teilen der Türkei in Jahrzehnten nicht gelang. Das Problem der Verfechter der These von der Demokratisierung und Modernisierung liegt darin, dass sie die fortschrittlichen Städte Istanbul und Ankara mit ihren Unternehmen, ihren Intellektuellen und ihrer Kultur für das Ganze nehmen und wie selbstverständlich davon ausgehen, dass der Rest des Landes automatisch folgen wird. Dass das europäische Gesellschafts- und Rechtsmodell in den ländlichen und vor allem 
in den östlichen Gebieten der Türkei mit jahrhundertealten gesellschaftlichen, kulturellen und religiösen Traditionen kollidiert, wird unterschätzt. Dass die sozioökonomischen Systeme Europas und der Türkei schon seit Jahrhunderten auf verschiedenen Grundfesten stehen und sich nicht einfach miteinander verschmelzen lassen, wird wenn überhaupt nur am Rande diskutiert.

\section{Brücke Türkei}

Die strategische Idee, dass die Europäische Union mit der Türkei einen direkten Einfluss auf die Krisenregionen im Kaukasus und im Mittleren Osten bekommt, ist auf den ersten Blick faszinierend. Die Türkei als ein Land zwischen Orient und Okzident, zwischen Islam und gefestigter westlicher Orientierung scheint den Nach-9/11-Strategen in Berlin, Paris und London ein idealer Mittler. Die Türkei grenzt im Norden an die öl- und gasreichen Kaukasusländer, im Osten an Iran und Irak und im Süden an Syrien. Ein zweiter Blick lässt aber Zweifel aufkommen, ob eine EU-Mitgliedschaft der Türkei tatsächlich den gewünschten Effekt haben wird. So macht man sich in der EU bewusst oder unbewusst kaum Gedanken darüber, wie eine Aufnahme der Türkei in der Region wahrgenommen wird, die man beeinflussen will. Der Historiker Heinrich August Winkler glaubt, dass ein EU-Mitglied Türkei dort nicht als Brücke verstanden würde, sondern als "Brückenkopf des Westens « (Der Spiegel, 51/2004), also als eine potentielle Bedrohung. Für diese Annahme spricht, dass Länder, die einerseits gewohnt sind, in Gebietsgewinnen zu denken und die andererseits über Jahrhunderte selber mal Opfer und mal Täter bei Landnahme und Kolonialisierung waren, sich fragen werden, welche Absichten die EU wirklich treiben, wenn sie ihre Grenzen bis nach Kleinasien hinein ausdehnt. Und das auch noch mit der Hilfe eines Landes, dem nicht nur in der unmittelbaren Nachbarschaft, sondern bis weit nach Nordafrika misstraut wird. Womit wir zum zweiten Grund für Zweifel an der Brückenthese kommen. Eine Brücke braucht auf beiden Ufern ein festes Fundament. Das kann Ankara nicht vorweisen. Im Gegenteil, die Türkei hat aus historischen und aktuell politischen Gründen, im besten 
Falle nur wenig, im schlimmsten Falle das falsche Gewicht in Damaskus, Teheran, Kairo oder Rabat. Die jahrhundertelange Oberherrschaft des Osmanischen Reiches ist in diesen Ländern nicht vergessen. Nicht vergessen ist auch, dass die Türkei sich nach dem Zweiten Weltkrieg mit dem Beitritt zur Nato fest in die militärischen Strukturen des Westens eingegliedert hat, dass sie ein fast bedingungsloser Alliierter der Vereinigten Staaten von Amerika ist und dass sie enge und freundschaftliche Beziehungen $\mathrm{zu}$ Israel pflegt, die bis in die militärische $\mathrm{Zu}$ sammenarbeit hineinreicht. Warum also sollten die Länder der Region der Türkei eine bedeutende Rolle zugestehen? Eine Europäische Union, in deren außen- und sicherheitspolitischer Kursbestimmung die land- und volkreiche Türkei eine ausschlaggebende Rolle spielt, könnte es der EU in diesen Ländern sogar noch schwerer machen, als sie es heute schon hat.

\section{Eine Geste an den Islam}

Das erstaunlichste Argument für einen Beitritt der Türkei ist das religiöse. Auch das ist ein Kind der Terrorangriffe auf New York und Washington. Mit der Aufnahme der Türkei zeige Europa, dass es auch ein islamisch geprägtes Land vertrage. Zugleich sei dies ein zweifaches Signal an andere islamische Länder, dass die EU sich nämlich nicht aus religiösen Gründen abschotte und dass Islam und Demokratie durchaus zusammengehen. Dies ungefähr ist der generelle Tenor der TürkeiFraktion in der EU, den der deutsche Bundeskanzler Gerhard Schröder am Rande des Beitrittsgipfels noch um die Gewissheit verfeinerte, damit verhindere die EU den von Samuel Huntington prognostizierten Zusammenstoß der Kulturen. Nun ist es schwierig, auf dem Gebiet von Glauben und Hoffen festen argumentativen Grund zu finden. Doch einige Dinge fallen ins Auge. So ist die Türkei zwar ein islamisches Land, aber als eines, in dem Staat und Religion seit acht Jahrzehnten mit eiserner Hand auseinander gehalten werden, sitzt es kaum mitten in der Gemeinschaft der islamischen Staaten. Dass diese Türkei einen ideologischen Einfluss auf den radikalen Islam nehmen könnte, ist pure Phantasie. Selbst um auf gemäßigte Islamisten einwirken zu können, müsste die Türkei islamischer werden, 
als sie heute ist. Das mag Erdoğan durchaus zupass kommen, aber die Frage ist doch sehr, ob sich die EU das wirklich wünschen soll. Auch wenn Europa sehr stark durch das Christentum geprägt wurde, so ist die Europäische Union doch keine Christen-Veranstaltung. Dass Ankara im Anlauf auf die Beitrittsverhandlungen Kritiker bezichtigte, sie wollten keine Muslime in ihrem Christenklub haben, war eine taktische Methode, die Skeptiker in der Union in die Defensive zu bringen. Ein durchaus legitimes Mittel für die Türkei. Warum sich allerdings Politiker wie Schröder oder Fischer darauf eingelassen haben, ist schwer nachvollziehbar. Indem sie die Bedeutung der Türkei als ein islamisches Land als politischen Vorteil herausstreichen, betonen sie zugleich einen christlichen Charakter der EU, den diese nicht hat. Und das letzte, was die EU brauchen kann, ist eine Rechristianisierung durch die politische Hintertür und sei es auch nur im Kontext des Wunsches, den Zusammenstoß der Kulturen zu vermeiden. Und noch eines verwundert: Indem sich die Europäer auf das religiöse Argument einlassen, macht sie sich selber blind für die vielfältigen und regional sehr unterschiedlichen sozioökonomischen und politischen Bedingungen, die radikale Islamisten $\mathrm{zu}$ ihren Gunsten ausbeuten. Und dass sich die Türkei, die sich über Jahrzehnte rühmte, Staat und Islam erfolgreich voneinander getrennt zu haben, nun als Leuchtturm in der islamischen Welt zu präsentieren sucht, sollte in europäischen Quartieren zumindest nachdenklich machen.

\section{Das Spiel der Strategen}

Wer die Geschichte der Argumente für einen Beitritt der Türkei auf dem Hintergrund des jeweiligen politischen und historischen Kontextes Revue passieren lässt, dem wird zweierlei auffallen: Zum einen ist die Aussage Hallsteins von der Türkei als einem Teil Europas nie prinzipiell aus dem europäischen Vereinigungsprojekt heraus begründet worden. Zum anderen ist die Geschichte der Annäherung der Türkei an die EU eine Abfolge strategischer Überlegungen auf beiden Seiten, die immer eine Mischung aus kurzfristiger Erfordernis und langfristigen Wünschen waren. 
Dabei sind die jeweiligen Interessen nicht immer mit denen der anderen Seite deckungsgleich. Aber immer lässt sich die Türkeifrage auf einen strategischen Kern reduzieren. Der gegenwärtige stellt sich so dar: Die Türkei sucht dringend nach einer machtpolitischen Anbindung. Mit dem Ende des Kalten Krieges und der Neuordnung der Hinterlassenschaft der Sowjetunion hat das Land am Bosporus erheblich an strategischer Bedeutung verloren und findet sich zugleich in der Lage wieder, keine regionale Führungsmacht werden zu können. Eine Türkei, die Einfluss auf die Welt haben und nicht in regionaler Mittelmäßigkeit versinken will, kann dies unter den gegebenen Bedingungen nur über eine Mitgliedschaft in der EU schaffen, die, ob sie es will oder nicht, auf dem Weg zur Weltmacht ist. Als ein Land, das dann das bevölkerungsreichste in der EU wäre, könnte die Türkei die politische Linie der Union entscheidend prägen und damit die eigene weltpolitische Bedeutung erhöhen. Ginge es alleine um die ökonomischen Möglichkeiten, die Europa bietet oder die wohlgefüllten Töpfe der Regionalförderung, um den Anschluss an die westliche Wirtschaftskraft zu bekommen, dann könnte sich die Türkei auch auf Sonderbeziehungen einlassen. Doch es geht Ankara um Teilhabe an der politischen Union und das heißt vor allem an der Außen- und Sicherheitspolitik der Europäer.

Auf deren Seite liegt das strategische Interesse der EU darin, mit der Türkei einen Einfluss in der islamischen Welt und im Krisenbogen rund um das Mittelmeer zu bekommen. Dass die Türkei dafür nicht gerade der ideale Partner ist, wurde schon dargelegt. Bei der Fixierung auf das Islamproblem wird im Übrigen übersehen, dass das beste Signal an die Länder der arabischen Welt und an den Iran ein fairer Umgang mit ihnen ist. Mit anständigen Assoziierungsabkommen, die ihnen auch wirtschaftlich eine vernünftige Chance auf dem europäischen Markt bieten, die ihnen beim Aufbau von Produktionen, von Bildung und von öffentlicher Verwaltung helfen, kann mehr gegen Radikalismus im Gewande des Islam erreicht werden, als durch die angebliche Signalwirkung der Aufnahme eines islamischen Landes, dessen Glaubwürdigkeit bei den Betroffenen in Zweifel steht. Die europäischen strategischen Argumente bringen zwei weitere Probleme mit sich. Zum einen sind sie nicht türkeispezifisch. Mit ihnen könnte genauso gut die Aufnahme aller Mit- 
telmeeranrainer begründet werden. Zum anderen kann kaum damit gerechnet werden, dass die Bedrohung durch den radikalen Islamismus eine dauerhafte ist. Die Lebenserfahrung spricht dafür, dass die Gründe für die Strategie früher oder später wegfallen.

Und damit geraten wir in den innersten Kern des EUTürkei-Problems: Alle offiziellen Begründungen für die Aufnahme der Türkei entstammen aktuellen Lagen, die sich ändern können. Ein Beitritt aber ist eine Entscheidung für die Dauer. Das türkische Interesse ist dabei klar und nachvollziehbar. Das europäische ist es weniger. Zumal die Türkei für die EU ökonomisch, kulturell und gesellschaftlich auf mehrere Jahrzehnte hinaus zu einer enormen Belastung werden wird. Stehen hinter alledem also noch ganz andere Überlegungen? Bei einigen zumindest. So ergeht sich etwa der deutsche Außenminister durchaus in Andeutungen über einen Zusammenhang zwischen der Aufnahme der Türkei und den Weltmachtambitionen der EU. Anders gesagt, mit einer Erweiterung nach Kleinasien soll Europa an Masse, Größe und damit an Einfluss gewinnen. Abgesehen davon, dass solch eine Überlegung ein erstaunlicher Rückfall in ein antiquiertes Denken in Landmassen wäre, hat August Winkler durchaus Recht, wenn er sagt, dass sich Größe nicht automatisch in Stärke umsetzt (Der Spiegel, 51/2004).

\section{Gesucht: Ehrlichkeit}

Die Europäische Union braucht jetzt trotz des Gipfelbeschlusses mehr als nur technische Verhandlungen darüber, wie die Türkei ihre Strukturen den europäischen anzupassen hat. Sie braucht, will sie sich nicht gefährlich weit von ihren Bürgern entfernen, eine kritische Debatte mit sich selber, was sie machtpolitisch will und ob die Aufnahme der Türkei das dafür richtige Mittel ist. Um das zu beurteilen, muss sie sich auch ehrlich Rechenschaft darüber ablegen, ob sie diese Erweiterung überhaupt verkraften kann. Sylvie Goulard steht mit ihren Befürchtungen, dass ein Beitritt der Türkei die EU politisch blockieren und handlungsunfähig machen wird, nicht alleine da. In der Tat ist die EU schon heute ein schwerfälliges Gebilde, das sich nicht selten gefährlich nahe am Rande der Immobilität bewegt. 
Bislang hat zwar die gefürchtete Blockade von Entscheidungen durch die Aufnahme von zehn Ländern im Mai 2004 noch nicht stattgefunden, aber das ist wohl der Tatsache geschuldet, dass neue Mitglieder in der ersten Zeit meist vorsichtig auftreten. Die gegenwärtigen Strukturen der EU passen aber vorne und hinten nicht mehr für eine Gemeinschaft aus 25 Ländern. Wenn im Jahre 2007 Rumänien und Bulgarien dazustoßen und danach Kroatien, dann besteht die Gefahr, dass sie kollabieren. Sollte die europäische Verfassung alle Volksabstimmungen überstehen und wie geplant in Kraft treten, dann kann ein Desaster vermieden werden. Doch selbst mit der Verfassung bleibt die Frage, ob der Beitritt der Türkei letztlich nicht die politische Union schwächt. Denn das Interesse der Türkei liegt nicht in der europäischen Integration, sondern in der eigenen machtpolitischen Positionierung. Im Zweifel wird Ankara außen- und sicherheitspolitisch nach nationalen und nicht nach europäischen Interessen entscheiden. Nachdem es nicht einmal der EU der 15 gelungen war, eine gemeinsame Antwort auf die amerikanische Sicherheitspolitik zu finden und die Gemeinschaft sich über den Irakkrieg bitter verzankte, gibt es keinen vernünftigen Grund anzunehmen, dass das nach der jetzigen und den zukünftigen Erweiterungen besser werden könnte. Wobei die Türkei eine Sonderrolle spielt, weil sie wie Großbritannien im Krisenfalle die Nato und deren Führungsmacht USA allen europäischen Bemühungen um eine gemeinsame Außen- und Sicherheitspolitik vorziehen wird.

Die Risiken eines Beitrittes der Türkei sind also nicht gering. Darüber kann selbst die angepeilte Verhandlungsdauer von zehn bis fünfzehn Jahren nicht hinwegtäuschen. Diese Zeit mag ausreichen, die rechtlichen Standards der EU in die türkischen Gesetzbücher zu übernehmen. Aber zu glauben, dass sich die türkische Gesellschaft, die türkische Selbstwahrnehmung und die auf nationale Größe fixierte türkische Politik so nachhaltig ändern, dass sie mit der EU kompatibel sind, ist doch etwas leichtfertig. Was auf der europäischen Ebene fehlt, ist zweierlei. Zum einen eine ehrliche und überzeugende Begründung, die die Bürger nachvollziehen und hinter die sie sich stellen können. Eine so schwierige Operation wie die Aufnahme eines nichteuropäischen Landes in die Europäische Union und dann noch eines so großen kann die EU auseinander reißen, wenn es 
über die Köpfe der Völker hinweg geschieht. Zum anderen muss die Union überzeugende Vorkehrungen treffen, die ihre Funktionsfähigkeit nicht nur steigert, sondern die Integration vertieft. Nur wenn wieder ein politischer Zusammenhang zwischen Erweiterung und Vertiefung hergestellt wird, kann die Europäische Union die anstehenden Operationen überleben. Das heißt in der Konsequenz aber auch, dass die EU die Verhandlungen stoppen muss, wenn die Verfassung scheitert. Dann wird sich zeigen, was die Regierungen wirklich wollen und ob sie den Zusammenhang zwischen Funktionsfähigkeit und Stärke begreifen. Immerhin hat der Gipfel in seinem Beschluss am 17. Dezember 2004 daran erinnert, dass die Fähigkeit der Union, neue Mitglieder aufzunehmen und sich zugleich »die Dynamik der europäischen Integration zu erhalten« einen »wichtigen Gesichtspunkt« darstellt. Bei der Erweiterung nach Osten ist dieser weitgehend vernachlässigt worden. Im Falle der Türkei könnte eine Missachtung der Aufnahmefähigkeit der EU in einer politischen Katastrophe enden. Anstatt außenpolitisch an Gewicht, Einfluss und Handlungsfähigkeit zu gewinnen, könnte die EU auf das Stadium einer Freihandelszone zurückgeworfen werden, in der sich ein paar Inseln der politischen Integration verlieren. 

Zwei Kommentare

zum Kommissionsbericht 



\title{
Konditionierte Demokratisierung
}

\author{
Claus LeGGEWIE/SABRINA GIESENDORF
}

Die arabisch-islamische Welt ist die Region, in der sich liberale Demokratie im Weltmaßstab bisher am wenigsten verbreiten und etablieren konnte. So wurde der Krieg gegen den Irak unter anderem damit begründet, der Sturz der Diktatur Saddam Husseins werde einen »Dominoeffekt « der Demokratisierung im Nahen Osten auslösen. Dem von dort ausgehenden Terrorismus sollten auf diese Weise die Grundlagen entzogen werden. Trotz der relativ erfolgreichen Wahl im Januar 2005 könnte die Demokratisierung des Irak scheitern. Der Feldzug hätte dann die bei den Vorreiternationen der westlichen Demokratie bei den arabischen Massen und ihren Meinungsführern eher an Ansehen gekostet. Weiter bleibt der »islamische Gürtel« von Marokko bis Indonesien die Problemzone für Freiheit und Demokratie. Eine Ausnahme - im doppelten Sinne - gibt es allerdings: die Türkei. Sie steht am Rande der arabisch-islamischen Welt, und die Demokratisierung hat dort seit den 90er Jahren erhebliche, vermutlich nachhaltige Fortschritte gemacht. $\mathrm{Zu}$ verdanken ist dies der inneren Modernisierung der türkischen Gesellschaft, aber auch dem Druck, den die Europäische Union und einzelne ihrer Mitgliedsländer auf das semi-autoritäre Regime in Ankara ausgeübt haben. Neben den USA ist damit auch Europa ein wichtiger Stifter und Überbringer von freedom $\mathcal{E}$ democracy in der derzeit »heißesten « Konfliktregion der Welt.

Der im Zusammenhang mit diesem Engagement stehende mögliche EU-Beitritt der Türkei soll hier nicht auf kulturelle 
und normative Grundlagen oder auf die sozioökonomischen Voraussetzungen und Folgen hin befragt werden, was die Debatte bisher dominiert (Leggewie 2004). Vielmehr soll er als Experiment der Implementation demokratischer und rechtsstaatlicher Strukturen von außen betrachtet werden.

»Die Türkei wäre ein wichtiges Modell eines Landes mit einer mehrheitlich moslemischen Bevölkerung, das sich zu grundlegenden Werten wie Freiheit, Demokratie, Rechtsstaatlichkeit und Achtung der Menschenrechte und Grundfreiheiten bekennt«,

heißt es in der "Empfehlung der Europäischen Kommission zu den Fortschritten der Türkei auf dem Weg zum Beitritt« vom 6. Oktober 2004 (KOM/2004/656: [5] 194). ' Diese Empfehlung soll im Folgenden zusammengefasst und kommentiert werden, woran Schlussfolgerungen zur Implementationsproblematik geknüpft werden (Giesendorf 2004). Unsere Hypothese ist, dass sich die Europäische Union erfolgreich als Agentur von außen induzierter Demokratisierung betätigen konnte und die dabei angewandten Machtmittel für einen friedlichen und endogen gestützten Prozess andernorts exemplarisch sein könnten.

\section{Implementationsforschung: Entstehung und Anwendung}

Implementation ist der "politik- und verwaltungswissenschaftliche Terminus für den Prozess der inhaltlichen Umsetzung von Gesetzen, Verordnungen etc. in konkrete Maßnahmen und materielle Leistungen und deren [...] Aufrechterhaltung " (Schubert 2002: 336). Implementationsforschung kam in den Vereinigten Staaten in einer Phase der Reformpolitik auf (Pressman/Wildawsky 1973), für die charakteristisch war, dass gegebene Zustände zunehmend als unerwünscht empfunden wurden und durch Staatsintervention Abhilfe geschaffen werden sollte. $\mathrm{Zu}$ diesem $\mathrm{Zweck}$ wurden neue Politikprogramme ent-

\footnotetext{
* Die »Empfehlung der Europäischen Kommission zu den Fortschritten der Türkei auf dem Weg zum Beitritt« ist im vorliegenden Sammelband als Anhang ab Seite 189 abgedruckt, auf den sich auch die Seitenzahlen beziehen. Die Seitenzahl in eckigen Klammern kennzeichnet die Stelle im Original.
} 
wickelt, (z.B. das amerikanische War-on-Poverty Programm), die zur Veränderung der unerwünschten Zustände beitragen sollten, dabei jedoch auf vielfältige Schwierigkeiten stießen. Zunächst galt die Annahme, die Formulierung eines politischen (Reform-) Programms, sein Vollzug und die erwarteten Wirkungen bildeten eine Einheit; die nähere Untersuchung der einzelnen Phasen schien aus dieser Perspektive heraus überflüssig (Bussmann 1997). Man nutzte black-box Evaluationen, um herauszufinden, ob das Programm als Ganzes den erwünschten Erfolg hatte oder nicht, im Fall eines Misserfolges ging man davon aus, es müsse ein Programmfehler vorgelegen haben, der bereits in der Konzeption des Programms angelegt war. Mit der späteren Entdeckung, dass die Programmkonzeption korrekt sein kann, die Wirkungen aber nicht den Erwartungen entsprechen, setzte sich die Erkenntnis durch, dass es auf dem Weg von der Programmkonzeption bis zur Evaluation mindestens eine weitere Fehlerquelle geben muss: die Umsetzungsphase. Das heißt: Auch während der Umsetzung des Programms können, unabhängig von der Programmformulierung, Probleme auftreten, die $\mathrm{zu}$ unerwünschten Ergebnissen führen (Knoepfel/Kissling-Näf/Bussmann 1997).

Diesen für den nationalen Kontext entwickelten Forschungsansatz übertragen wir auf die supranationale Ebene, um herauszufinden, wie ein vorwiegend nicht einem Staat entspringender Veränderungswunsch - hier der Wunsch der Union zur Stärkung der türkischen Demokratie - in einem DrittStaat wie der Türkei umgesetzt wird. Zu diesem Zweck müssen wir eine weitere Implementationsstufe einführen und einen weiteren, übergeordneten Akteur identifizieren: die Europäische Union. Mit der Einführung der supranationalen Dimension wird der Implementationsprozess vielschichtiger und komplizierter als im nationalen Kontext, vor allem, da die Union weit davon entfernt ist, ein einheitlich handelnder Akteur zu sein und als dieser aufzutreten. Für die theoretische Abstraktion wird jedoch im Folgenden die Union als ebensolcher verstanden.

Die Union und alle weiteren Akteure im Prozess der Implementation verfolgen zunächst unterschiedliche Ziele - die EU (neben der Markterweiterung) vorrangig die Demokratisierung, die Türkei vorrangig den Beitritt. Erst nach einiger Zeit hat die 
Türkei das Demokratisierungsziel und die Umsetzung der Kopenhagener Kriterien als ihr ureigenes Ziel anerkannt und internalisiert, wozu eine Vielzahl von Nicht-RegierungsOrganisationen und entsprechende Bestrebungen der Zivilgesellschaft beitrugen. Wurden die Kopenhagener Kriterien zunächst als »Mechanismen der demokratischen Einmischung " (Rumford 2003: 388) und Eingriff in die nationalstaatliche Politik abgelehnt, verfolgen Union und Türkei mit der Demokratisierung heute offiziell dasselbe Ziel. Für die Türkei ist die Umsetzung der Kopenhagener Kriterien ein Etappenziel auf dem Weg zur Vollmitgliedschaft in der Europäischen Union.

Um ihre Ziele gegenüber der Türkei durchzusetzen, bedient sich die Union seit den 90er Jahren der Strategie der demokratischen Konditionierung, konkretisiert in der Beitrittspartnerschaft. Die türkische Regierung benutzt die Strategie der Regulierung, um ihre innerstaatlichen Ziele durchzusetzen. Dabei zeigt sich, dass jede Strategie suboptimal wirkt, wenn die Zielgesellschaft die Ziele nicht unterstützt oder wenigstens akzeptiert. Die Ineffizienz wird umso größer, je weniger Akzeptanz der Reformen vor allem unter den wichtigsten Akteuren vorhanden ist. Als nachhaltigste Grundlage jeder Umsetzung von Reformen ist daher Überzeugung anzusehen. Wenn die Reformen auf Überzeugung beruhen, stoßen sie auf geringere Widerstände, ihre Umsetzung erfolgt auf freiwilliger Basis und ist effektiver. Die Umsetzung wird im Falle der Unterstützung durch die Zielregierung bzw. -gesellschaft zudem wesentlich effizienter, da der Kontrollaufwand umso geringer wird, je mehr die Maßnahmen akzeptiert werden.

\section{EU-Monitoring: Über Kopenhagen hinaus}

Implementationsfortschritte beziehungsweise Umsetzungsprobleme werden durch das Instrument des Monitoring ermittelt. Zuständig ist in unserem Fall die Generaldirektion Erweiterung der EU-Kommission, deren verantwortlicher Kommissar in der kritischen Periode der EU-Osterweiterung und der Türkei-Verhandlungen Günter Verheugen war (Ende 2004 folgte der Finne Olli Rehn). Die Generaldirektion Erweiterung setzt sich aus verschiedenen Direktoraten zusammen, darunter die Direktorate 
$B$, die für die Koordination der Verhandlungen und Beitrittsvorbereitungen von Bulgarien, Rumänien und der Türkei zuständig sind. Der für die Türkei zuständige Referatsleiter ist weiterhin Martin Harvey. In seiner Arbeitsgruppe wurden und werden die jährlichen Fortschrittsberichte für die Türkei erstellt, wobei die Kommission auf die Unterstützung von nationalen und lokalen Behörden angewiesen ist, die den größten Teil der Recherchen vor Ort erledigen. Eine weitere wichtige Agentur ist die Vertretung der Europäischen Kommission in der Türkei (seit 1987, vormalig Presse- und Informationsbüro der Europäischen Kommission). Sie hat diplomatischen Status und wirkt als Bindeglied zwischen den türkischen Autoritäten und Brüssel; sie dient der Informationsermittlung und als Kanal für Informationsverbreitung bzw. -austausch. Die Vertretung sorgt dafür, dass die Union stets über neue wirtschaftliche und politische Entwicklungen der Türkei unterrichtet ist, in umgekehrter Richtung sorgt sie für die Verbreitung von Informationen über die Europäische Union im Land, beispielsweise durch die Publikation von newsletters, die Organisation von Seminaren oder die Übersetzung wichtiger Dokumente.

Das Monitoring vor Ort geschieht in ständigem Kontakt mit türkischen Behörden, aber auch mit Nicht-Regierungs-Organisationen (NRO) und Informanten in der Türkei (z.B. Journalisten). Eine Rolle spielen die monatlichen Treffen der Delegation mit Vertretern der Botschaften der EU-Mitgliedsstaaten, bei denen ein relativ offener Informations- und Meinungsaustausch über die Lage in der Türkei stattfindet. Schließlich bezieht die Europäische Kommission Informationen direkt von internationalen Organisationen, beispielsweise dem Europarat, der OS$\mathrm{ZE}$, internationalen Finanzinstitutionen oder amnesty international. Diese Organisationen betreiben ein eigenes Monitoring im Hinblick auf ihre speziellen Schwerpunkte und leiten die Ergebnisse ihrer Untersuchungen automatisch an die EU-Kommission weiter. Aus all diesen Quellen trägt die Kommission Informationen über die Türkei zusammen und macht sich ein umfassendes Bild über die Umsetzung der von ihr aufgestellten Kriterien beim Beitrittsaspiranten.

Initiiert wurde der Beitrittsprozess bereits durch das Assoziierungsabkommen der damaligen EWG mit der Türkei im Jahr 1963. Seither hat sich allerdings sowohl der Charakter der Eu- 
ropäischen Gemeinschaft - von der lockeren, sechs Länder umfassenden Wirtschaftsgemeinschaft zur politischen Union - sowie der der Türkei - vom autoritär regierten Entwicklungsland zum "post-kemalistischen « Schwellenland - stark verändert. Nachdem ein Beitritt zwischenzeitlich durch innere Rückschritte (Militärregierungen in der Türkei) und äußere Konflikte (vor allem über Zypern mit Griechenland) unmöglich erschien, stellte die Türkei 1987 einen Antrag auf Mitgliedschaft, mit dem sich die Europäische Union auf dem Helsinki-Gipfel 1999 befasste. In Helsinki ging man allgemein davon aus, die Türkei werde die notwendigen Anpassungsreformen in absehbarer Zeit nicht leisten und die Voraussetzungen für einen Beitritt nicht erfüllen können, doch erwies sich - für viele überraschend - , dass das Land durchaus willens und in der Lage war, sich europäischen Standards anzunähern. Die Lage in der Türkei wurde von der Kommission nach den 1993 vom Europäischen Rat in Kopenhagen festgelegten politischen Kriterien bewertet. Auf Grund der erzielten Fortschritte und bestehenden Defizite beschloss der Europäische Rat im Dezember 2002, nach zwei Jahren erneut zu prüfen, ob die Türkei die politischen Kriterien erfüllt habe, was ein unabweisbarer Einstieg in eine Beitrittspartnerschaft gewesen wäre. Doch obwohl die Europäische Kommission im Oktober 2004 eine klare Empfehlung für die Einleitung einer Beitrittspartnerschaft gegeben und der Europäische Rat dieser Empfehlung im Dezember 2004 nicht widersprochen hat, ist in diversen Mitgliedsländern die Debatte um die Frage, $o b$ die Türkei überhaupt Mitglied werden soll, noch nicht verstummt. Sachlogisch hätte die Frage des o $b$ vor der Frage des wann positiv beantwortet werden müssen. Auf der diplomatischen Ebene hieß es auch, ein Beitritt der Türkei sei grundsätzlich möglich und die Türkei könne im Anschluss an einen (langwierigen) Annäherungsprozess Mitglied werden. Die Kommission hat gewürdigt, dass die Türkei über drei Jahre hinweg wesentliche verfassungs- und allgemeinrechtliche Revisionen auf den Weg gebracht hat: zwei große Verfassungsreformen und acht Legislativpakete, neue Zivil- und Strafgesetzbücher und Durchführungsbestimmungen. Sie würdigt auch die interne »Reformüberwachungsgruppe « unter Vorsitz des für Menschenrechte zuständigen Vizepremierministers. 


\section{Die Empfehlung der EU-Kommission vom Oktober 2004}

Die Empfehlung von 2004 fokussiert klar auf die politischen Kriterien, d.h. auf Fortschritte bei Demokratie, Menschenrechten und Rechtsstaatlichkeit. Bevor wir darauf eingehen, fassen wir die Äußerungen der Empfehlung über die wirtschaftlichen Dimensionen des Beitritts in einem Schaubild zusammen. Generell wird der Türkei von der Kommission bestätigt, sie habe »deutliche Fortschritte auf dem Weg zur funktionsfähigen Marktwirtschaft erzielt und vor allem makroökonomische Ungleichgewichte abgebaut« (KOM/2004/656: [16] 207). Im Einzelnen werden Fortschritte und Desiderate wie folgt bewertet:

\begin{tabular}{|c|c|c|}
\hline \multicolumn{3}{|c|}{$\begin{array}{l}\text { Schaubild 1: } \\
\text { Sektorale Fortschritte und Desiderate des Beitrittskandidaten Türkei }\end{array}$} \\
\hline Bereich & Fortschritte & Defizite/Desiderate \\
\hline Gesamtwirtschaft: & + & $\begin{array}{l}\text { Erleichterung ausländischer Direktinvestitio- } \\
\text { nen, Steigerung der Effizienz der Handelsge- } \\
\text { richte }\end{array}$ \\
\hline Inflation & +++ & \\
\hline Finanzsystem, privat & + & $\begin{array}{l}\text { Bankenaufsicht, Privatisierung von Banken } \\
\text { und Unternehmen }\end{array}$ \\
\hline Öffentliche Finanzen & + & Abbau Haushaltsdefizit \\
\hline Harmonisierung & + & Abbau von Diskriminierungen \\
\hline Freier Warenverkehr & ++ & $\begin{array}{l}\text { Öffentliches Auftragswesen, Abbau techni- } \\
\text { scher Handelshindernisse }\end{array}$ \\
\hline Freizügigkeit & - & $\begin{array}{l}\text { Öffnung des Marktzugangs, Schutz personen- } \\
\text { bezogener Daten, Geldwäschegesetz }\end{array}$ \\
\hline $\begin{array}{r}\text { Gesellschaftsrecht, Wett- } \\
\text { bewerbspolitik }\end{array}$ & $-/+$ & $\begin{array}{l}\text { Rechtsangleichung, Abbau staatlicher Beihil- } \\
\text { fen, Umstrukturierung Stahlsektor }\end{array}$ \\
\hline \multicolumn{3}{|l|}{ Nach Sektoren } \\
\hline Landwirtschaft & $-1+$ & Kontrollkapazitäten \\
\hline Verkehrswesen & + & Luft- und Seeverkehr \\
\hline Fiskalpolitik & $+/-$ & Steuerharmonisierung \\
\hline Währungsunion & - & Unabhängigkeit der Zentralbank \\
\hline Statistik & $-1+$ & Statistikgesetz \\
\hline Soziales/Beschäftigung & + & $\begin{array}{l}\text { Gleichstellung der Geschlechter, sozialer } \\
\text { Dialog }\end{array}$ \\
\hline Energiesektor & + & Privatisierung \\
\hline Industriepolitik & ++ & $\begin{array}{l}\text { Umstrukturierung Banken- } \\
\text { und Stahlsektor }\end{array}$ \\
\hline
\end{tabular}




\begin{tabular}{|c|c|c|}
\hline Wissenschaft/Forschung & + & Berufsbildung \\
\hline Telekommunikation & + & Abbau von Wettbewerbsverzerrungen \\
\hline Kultur und AV-Medien & + & $\begin{array}{l}\text { Aufhebung von Restriktionen bei nicht- } \\
\text { türkischen Rundfunk- und Fernsehsendungen }\end{array}$ \\
\hline Regionalpolitik & - & Nutzung strukturpolitischer EU-Instrumente \\
\hline Umwelt & + & Zahlreiche Rechtsvorschriften \\
\hline $\begin{array}{r}\text { Verbraucher-/ } \\
\text { Gesundheitsschutz } \\
\end{array}$ & + & Produkthaftung, Kontrolle \\
\hline Justiz/Inneres & + & $\begin{array}{l}\text { Korruptionsbekämpfung, illegale Einwande- } \\
\text { rung, volle Anwendung der Genfer Flücht- } \\
\text { lingskonvention }\end{array}$ \\
\hline Zollunion & + & Abbau von Sonderregelungen \\
\hline GASP & ++ & $\begin{array}{l}\text { Vollzugsdefizit bei Sanktionen und Restriktio- } \\
\text { nen }\end{array}$ \\
\hline
\end{tabular}

Neben ökonomischen Fortschritten bescheinigt die Kommission der Türkei nach der stufenweisen Rechtsangleichung auch Fortschritte im Blick auf den acquis communitaire (gemeinschaftlicher Besitzstand), wobei angekündigt wird, dass sich dieser im Prozess der Erweiterung auf 27 und mehr Mitglieder selbst weiterentwickeln wird und dabei auch »Herausforderungen und Möglichkeiten" entstehen können, »die mit dem Beitritt der Türkei verbunden wären« (ebd.: [4] 193). Was für die Bewertung des Beitritts in der innenpolitischen Debatte der EULänder sowie für ihr Verhältnis untereinander besonders wichtig ist, das Wirtschaftsgefälle und die daraus ableitbaren Transferzahlungen, wird relativ kurz abgehandelt:

»Die Türkei hätte lange Zeit Anspruch auf erhebliche Unterstützung aus Mitteln des Strukturfonds und des Kohäsionsfonds. Nach den derzeitigen Bestimmungen könnten dann einige Regionen der jetzigen Mitgliedstaaten, die Strukturfondsmittel erhalten, den Anspruch darauf verlieren. [...] Art und Umfang der Transferzahlungen an die Türkei würden von einer Reihe sich verändernder Faktoren abhängen. Zu diesen Faktoren gehören u.a. die Politiken der EU und die Sonderregelungen, die möglicherweise im Rahmen der Verhandlungen mit der Türkei vereinbart werden [...]. Klar ist allerdings, dass nach gegenwärtigem Stand der EU-Politiken der Beitritt der Türkei mit erheblichen Auswirkungen auf den Haushalt verbunden wäre« (ebd.: [5f.] 194, 196). 
Im Blick auf »zusätzliche Migration« zieht die Empfehlung der Kommission

»lange Übergangszeiten und eine unbefristete Schutzklausel in Betracht [...], um ernsthafte Störungen auf dem EU-Arbeitsmarkt zu vermeiden. Die Bevölkerungsdynamik der Türkei könnte allerdings einen Beitrag beim Ausgleich der Alterung der EU-Gesellschaften leisten« (ebd.: [6] 195).

Damit im Zusammenhang steht die Aussage, dass der TürkeiBeitritt »erhebliche Auswirkungen auf die Zuteilung der Sitze im Europäischen Parlament « und dadurch »die Türkei eine gewichtige Stimme im Entscheidungsverfahren« (ebd.: [7] 196) hätte.

In den vergangenen Jahren sind politische Kriterien ins Zentrum des Monitoring und der Implementationspolitik gerückt. Der Grund dafür liegt in der Geopolitik. Die Kommission sieht die Türkei »in der Lage, einen Beitrag zur regionalen und internationalen Stabilität zu leisten", woraus nicht zuletzt

»die Erwartungen an die EU-Politik gegenüber diesen Regionen wachsen. Viel wird davon abhängen, wie die EU selbst an die Aufgabe herangeht, mittelfristig zu einem vollwertigen außenpolitischen Akteur in Regionen zu werden, die wie der Nahe Osten und der Kaukasus traditionell durch Instabilität und Spannungen gekennzeichnet sind « (ebd.: [5] 194).

Ohne es ausdrücklich zu sagen, stellen die Empfehlungen die Demokratisierung der Türkei damit in einen geostrategischen Zusammenhang.

Auch die auf politischem Gebiet in den Empfehlungen festgestellten Fortschritte, Defizite und Desiderate wollen wir schematisch zusammenfassen, gegliedert nach den Hauptschwächen, die der Türkei aus westlicher Sicht angelastet werden. Diese liegen (a) in der Vernachlässigung von Menschenrechten und Minderheitenschutz, (b) in der Kontinuität eines vom Militär dominierten Etatismus, der wiederum Manifestationen des »tiefen Staates « einbezieht, womit die Unterdrückung der Opposition, Korruption und Verbindungen zur organisierten Kriminalität umschrieben werden, sowie (c) in der Diskriminierung von Frauen. Diese drei Aspekte bezeichnen nicht 
nur demokratiepolitisch die stärksten Defizite der kemalistischen Tradition, sondern werden auch von der vergleichenden Werteforschung als die Bereiche ausgemacht, in denen die türkische Bevölkerung die größten Unterschiede zur westlichliberalen Gesellschaft aufweist (vgl. Gerhards 2004).

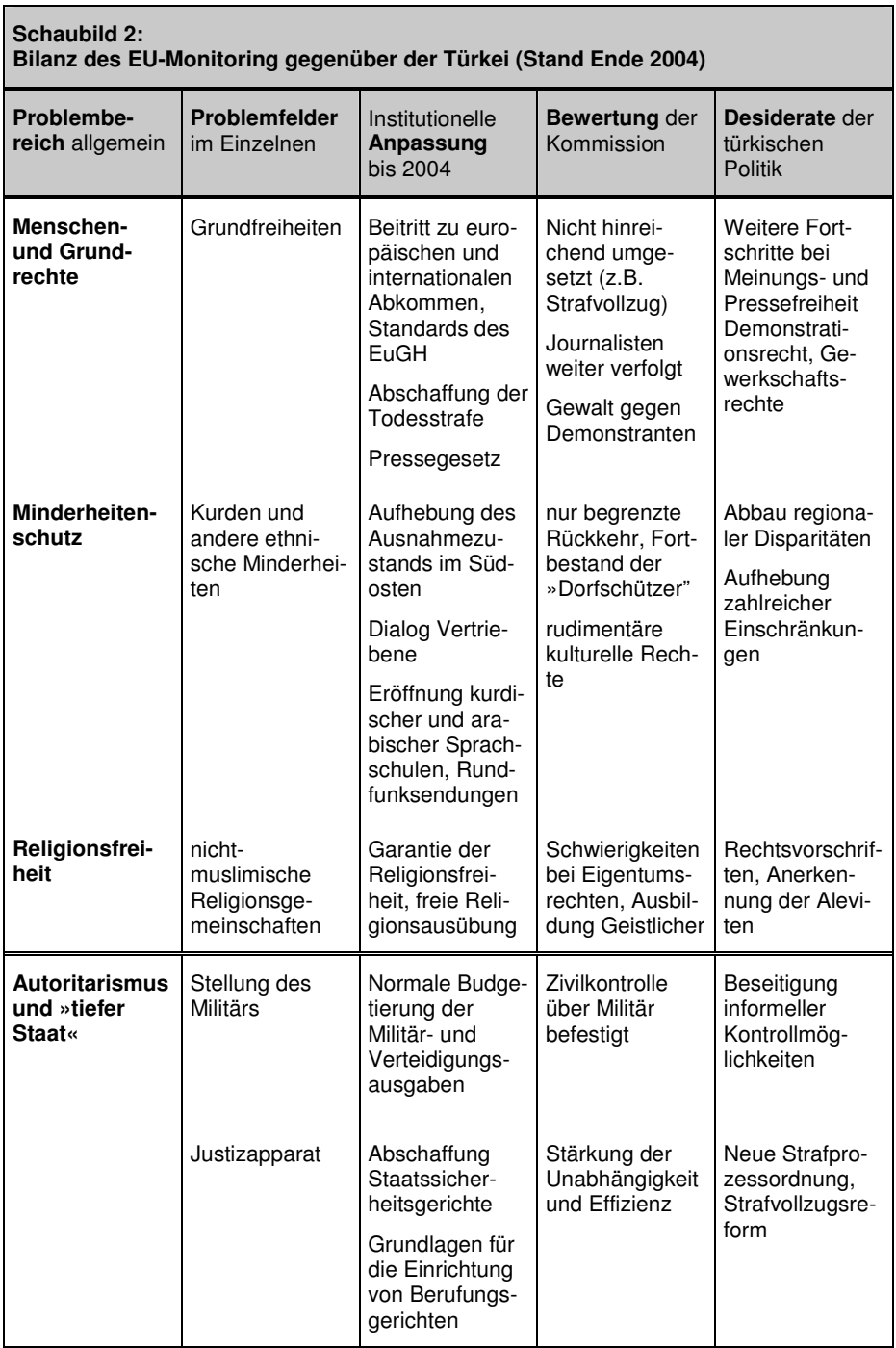




\begin{tabular}{|c|c|c|c|c|}
\hline & $\begin{array}{l}\text { Folter } \\
\text { Korruption } \\
\text { Zivilgesellschaft }\end{array}$ & $\begin{array}{l}\text { „Null- } \\
\text { Toleranz«, } \\
\text { Bestrafung } \\
\text { Schuldiger } \\
\\
\text { Korruptionsbe- } \\
\text { kämpfung } \\
\text { Beitritt zu } \\
\text { GRECO- } \\
\text { Konvention } \\
\text { Vereinsgesetz, } \\
\text { NRO }\end{array}$ & $\begin{array}{l}\text { Nicht mehr } \\
\text { systematisch, } \\
\text { Misshandlungen } \\
\text { kommen weiter } \\
\text { vor } \\
\text { Bleibt in allen } \\
\text { Bereichen d. } \\
\text { Wirtschaft und } \\
\text { d. öfftl. Lebens } \\
\text { ein Problem } \\
\\
\text { Veto Juli } 2004\end{array}$ & $\begin{array}{l}\text { Schärfere Sank- } \\
\text { tionen } \\
\\
\text { Aufhebung }\end{array}$ \\
\hline $\begin{array}{l}\text { Geschlechter- } \\
\text { verhältnis und } \\
\text { Familienpolitik }\end{array}$ & $\begin{array}{l}\text { Frauendiskrimi- } \\
\text { nierung }\end{array}$ & $\begin{array}{l}\text { Gleichheit in } \\
\text { Zivilrecht und } \\
\text { Verfassung } \\
\text { „Ehrenmorde « } \\
\text { stärker } \\
\text { verfolgt, sexuel- } \\
\text { le Gewalt in der } \\
\text { Ehe Straftatbe- } \\
\text { stand } \\
\text { Jungfräulich- } \\
\text { keitstests nur } \\
\text { noch mit ge- } \\
\text { richtlicher An- } \\
\text { ordnung }\end{array}$ & $\begin{array}{l}\text { Lage der Frau- } \\
\text { en immer noch } \\
\text { unbefriedigend }\end{array}$ & $\begin{array}{l}\text { Stärkung der } \\
\text { Frauen im sozi- } \\
\text { alen Leben } \\
\text { Stärkung der } \\
\text { Rechte der } \\
\text { Kinder } \\
\text { Verbot der } \\
\text { Kinderarbeit }\end{array}$ \\
\hline
\end{tabular}

Aus dieser Synopse ergibt sich für die EU-Kommission folgende Gesamtbewertung: Die Türkei sei bei der Gesetzgebung »deutlich vorangekommen «, aber: »Trotz großer Fortschritte bei der Umsetzung der politischen Reformen müssen diese weiter konsolidiert und ausgeweitet werden " (KOM/2004/656: [15] 207). Die Kommission hat für diese »Ja, aber «-Empfehlung Kritik erfahren, sowohl von Seiten türkischer Akteure, die sich eine klarere Empfehlung und eine sofortige Beitrittspartnerschaft gewünscht hätten, als auch von Kritikern innerhalb und außerhalb der Türkei, die sich klarere Worte zu Missständen in allen drei Kerngebieten erhofft hatten. Das Deutsche Orient-Institut kommt zu dem skeptischen Resümee:

»Da die türkische Regierung [...] keine Bereitschaft gezeigt hat, Reformen vorzunehmen, die nicht konkret von der EU gefordert werden, wird das Fehlen wichtiger Forderungen im Bereich der Bekämpfung der Folter, zum Gefängnissystem und in der Frage der Minderheitenrechte 
wahrscheinlich dazu führen, dass hier dringend notwendige Maßnahmen nicht ergriffen werden. Es sollte daher die Chance genutzt werden, in der von der EU-Kommission vorgeschlagenen überarbeiteten Fassung der Beitrittspartnerschaft Nachbesserungen vorzunehmen« (Cremer u.a. 2004: 21f.).

Andere Beobachter kritisieren deutlicher als die EU-Kommission die nach wie vor starke Stellung des Militärs, die halbherzige Öffnung in der Kurdenfrage, die gegenüber der Zivilgesellschaft zögernde Justiz, die mangelnde Respektierung des Folterverbots und die Benachteiligung nicht-muslimischer Religionsgemeinschaften (vgl. Kramer 2004). Die amerikanische Organisation Freedom House hat einen lesenswerten Länderbericht Türkei herausgebracht, der zu den genannten Themen wie auch zum politischen und System weit konkretere Empfehlungen gibt, als es die EU-Kommission für gut befunden hat (vgl. Repucci 2004).

Gleichwohl: Die Perspektiven für Beitrittsverhandlungen entsprechen auch in den Empfehlungen der Kommission nicht gerade dem »virtuous circle«, den sich die Türkei ausgemalt hat. Das kann man an den folgenden acht Punkten deutlich erkennen:

1. Externe Implementation: »Die Türkei hat in ihrem politischen Reformprozess erhebliche Fortschritte gemacht" (KOM/2004/656: [10] 200). Allerdings gibt es nach Auffassung der Kommission weiterhin beträchtlichen Bedarf an Gesetzesänderungen.

2. Interne Implementation: »Die Türkei bemüht sich nachdrücklich um die wirksame Umsetzung dieser Reformen « (ebd.: [10] 201), aber auch dabei bestehen erhebliche Desiderate.

3. Eröffnung von Verhandlungen: Externe und interne Implementation müssen fortgeführt werden. Auf dieser Grundlage »ist die Kommission der Auffassung, dass die Türkei die politischen Kriterien in ausreichendem Maße erfüllt, und empfiehlt die Eröffnung von Beitrittsverhandlungen« (ebd.: [10] 201).

4. Übergangszeit: Für die Übergangszeit empfiehlt die Kommission eine »Drei-Säulen-Strategie«. Die erste Säule besteht in der »Zusammenarbeit zur verstärkten Unterstützung des Reformprozesses in der Türkei, insbesondere im Hinblick auf die 
fortdauernde Erfüllung der politischen Kriterien von Kopenhagen « (ebd.: [10] 201). Die zweite Säule beinhaltet »die spezifischen Bedingungen für die Führung der Beitrittsverhandlungen mit der Türkei« (ebd.: [2f.] 191), und die dritte Säule enthält die Forderung nach einem »wesentlich verstärkte[n] politische[n] und kulturelle[n] Dialog [...], der Menschen aus den EUMitgliedsstaaten und der Türkei zusammen bringen soll« (ebd.: [3] 191).

5. Kein Beitritts-Automatismus: Die Kommission ist davon überzeugt, »dass der Verhandlungsprozess einen unverzichtbaren Beitrag zu weiteren Reformen in der Türkei leisten wird. Dabei liegt es in der Natur der Sache, dass dies ein Prozess mit offenem Ende ist, dessen Ausgang sich nicht im Vorhinein garantieren lässt« (ebd.: [10f.] 202).

6. Aussetzungsdrohung: Bei einem "schwerwiegenden und dauerhaften Verstoß gegen die Grundsätze der Freiheit, Demokratie, Rechtsstaatlichkeit und Achtung der Menschenrechte und Grundfreiheiten $[\ldots]$ " wird die Kommission »die Aussetzung der Verhandlungen empfehlen. Über diese Empfehlung sollte der Rat mit qualifizierter Mehrheit beschließen können« (ebd.: [7] 197).

7. Fortsetzung des Monitoring: Die jährlichen Fortschrittsberichte werden weitergeführt.

8. Ratifizierung: "Das endgültige Ergebnis der Verhandlungen wird vom Europäischen Parlament sowie von allen EUMitgliedstaaten und der Türkei gebilligt werden müssen « (ebd.: [9] 200).

Mehrfach werden die Notwendigkeit einer gründlichen Vorbereitung des Beitrittsprozesses, sein offenes Ende und die Forderung nach der Unumkehrbarkeit des Reformprozesses in der Türkei unterstrichen. Jede Beitrittsgarantie wird vermieden. Auch einen Fahrplan gibt es nicht. Beitrittsdiplomaten und Journalisten sprechen von mindestens zehn bis fünfzehn Jahren bis zu einem eventuellen Beitritt. Die Begründung der Kommission für diese Vorsicht und Zurückhaltung lautet:

»Nur so lässt sich nicht nur Zusammenhalt und Handlungsfähigkeit der Union bewahren, sondern auch vermeiden, dass die Türkei gezwungen wird, Politiken umzusetzen, die möglicherweise dem Entwicklungsstand des Landes nicht entsprechen« (ebd.: [8] 198). 
Irritationen hat in der Türkei verursacht, dass schon für 2005 eine »Überarbeitung der Beitrittspartnerschaft « vorgeschlagen wurde und dann ab Dezember 2005 jedes Jahr »eine allgemeine Beurteilung der Art und Weise stattfinden [wird], wie die politischen Reformen gefestigt und ausgeweitet werden « (ebd.: [7] 197). Beim Monitoring kommen bewährte Erweiterungs-Bewertungen (Twinning, Peer Reviews und TAIEX) ${ }^{1}$ zum Einsatz, wobei die »Heranführungsstrategie « ständig aktualisiert (auf Basis von Phare, ISPA und SAPARD) ${ }^{2}$ und türkeispezifisch angepasst werden soll. Besonderes Augenmerk gilt der Regionalentwicklung des Südostens, für die ein erheblicher Teil der Gemeinschaftshilfe Verwendung finden soll.

\section{Fazit}

Während die Kommission in ihren Empfehlungen konkrete Hinweise auf Reformbedarf vermeidet, will sie zugleich den Eindruck ausschließen, der EU-Beitritt der Türkei sei nunmehr irreversibel. Das hat zum einen innenpolitische Gründe (allerorts gibt es starke parlamentarische Opposition und Meinungsäußerungen gegen einen Beitritt), zum anderen soll es sicherstellen, dass der Reformdruck institutionalisiert und internalisiert wird. Die Notwendigkeit, aber auch das Risiko eines solchen Vorgehens liegen auf der Hand: Einerseits kann die EU keinen Blankoscheck ausstellen, wenn sie Einfluss auf die Innenpolitik eines Landes behalten will, andererseits kann eben diese Dauereinmischung Gefühle verletzten Stolzes und nationalistische Trotzreaktionen hervorrufen und andere Optionen (welche die Türkei ohne Zweifel hat) bestärken. In der Türkei nimmt die Regierung Erdo an einen Teil dieses Risikos auf sich. Bis Anfang 2005 ist ihr die Balancierung der Kräfte gut gelungen.

Kann der Prozess des türkischen EU-Beitritts als gelungenes Beispiel für die Implementation einer europäischen Demokratisierungspolitik betrachtet werden? Der Ausgangspunkt der Implementation ist die Feststellung, dass die Situation in einem Drittstaat unbefriedigend ist und aus Sicht der Union geändert werden sollte. Das primäre Problem im Blick auf die Türkei besteht darin, dass die Union keine direkte Einflussmöglichkeit 
auf diesen souveränen Nichtmitgliedsstaat hat. Eine effektive Einflussnahme ist deswegen nur auf indirektem Weg mit Hilfe der Konditionierung möglich. Diese basiert auf der Überlegung, dass ein Staat eher gewillt ist, exogen vorgegebene Ziele und Forderungen umzusetzen, wenn ihm ein positiver Anreiz geboten wird. Die Voraussetzung für das Funktionieren dieser Strategie ist, dass der Anreiz dem Zielstaat tatsächlich reizvoll und erstrebenswert erscheint.

Der mächtigste Anreiz der EU bestand und besteht darin, der Türkei die Vollmitgliedschaft in der Europäischen Union in Aussicht zu stellen. Die Türkische Republik gilt seit über vierzig Jahren als beitrittswilliger Staat, sie scheint damit ein idealer Kandidat für die Implementation von europäischer Zielsetzung mit Hilfe der Konditionierung zu sein. Mit dem Anreiz der Vollmitgliedschaft konnte die Türkei dazu gebracht werden, die Konditionen der Union zu erfüllen, da die innenpolitischen Kosten dafür nicht unzumutbar hoch waren. Als Beitrittsvoraussetzungen forderte die Union die strikte Beachtung rechtsstaatlicher und demokratischer Prinzipien sowie die Wahrung der Menschenrechte.

Anerkennung und Umsetzung dieser Konditionen waren und sind für die Türkei eine große Herausforderung. Nicht nur Rechtsgrundlagen und Verwaltungssysteme, sondern auch Denkhaltungen und Mentalitäten müssen grundlegend verändert werden. Alles in allem scheint der Prozess erfolgreich zu verlaufen. Das ist beispielsweise daran zu erkennen, dass die Kopenhagener Kriterien, die von der Türkei zunächst als Mittel zum Zweck des EU-Beitritts angesehen wurden, unter der Regierung Erdo an als eigenständig anzustrebende Ziele betrachtet werden. Dieser Prozess der Verinnerlichung der exogen vorgegebenen Kriterien ist ein bedeutsamer Schritt für die Umsetzung der Reformen. Die erfolgreiche Durchführung von Reformen ist davon abhängig, dass die Akteure sie mindestens akzeptieren, besser noch, dass sie ihnen zustimmen und von ihrem Sinn überzeugt sind.

Die von außen angeregten Reformanstrengungen wurden in der Türkei in den letzten Jahren zügig und zielstrebig vorangetrieben, - zumindest auf dem Papier. Die Umsetzung in der Praxis lässt jedoch noch viele Wünsche offen. $\mathrm{Zu}$ dieser Einschätzung kommt das Monitoring der EU und anderer interna- 
tionaler Organisationen. Deswegen beziehen sich die Forderungen an die Türkei in jüngster Zeit hauptsächlich auf die konsequente Umsetzung und Anwendung der Reformmaßnahmen in der Praxis. Das bisher Geleistete, die großen Anstrengungen der Regierung sowie die anhaltend hohe Zustimmung in der türkischen Bevölkerung für den EU-Beitritt lassen vermuten, dass die verlangten Reformen sukzessiv in die Praxis umgesetzt werden können und dieses große Experiment einer supranationalen Implementation der Demokratie erfolgreich ausgehen wird. Entscheidend ist der Zeitfaktor: Während Demokratisierungs- und Integrationsprozesse Jahrzehnte in Anspruch nehmen, sind die Zyklen von Legislaturperioden und Stimmungslagen bekanntlich sehr kurz.

\section{Anmerkungen}

1 Vgl. dazu die Webseiten der EU-Kommission http://europa.eu.int /comm/enlargement/pas/twinning/; http://europa.eu.int/comm/ enlargement/pas/phare/programmes/multi-bene/taiex.htm.

2 Näheres unter http://europa.eu.int/comm/enlargement/pas/phare und http://europa.eu.int/comm/enlargement/pas/ispa.htm sowie http:/ / europa.eu.int/comm/enlargement/pas/sapard.htm.

\section{Literatur}

Bussmann, Werner (1997): Evaluationen in der Schweiz, in: Werner Bussmann/Ulrich Klöti/Peter Knoepfel (Hg.): Einführung in die Politikevaluation, Basel/ Frankfurt a.M., S. 13-35.

Cremer, Jan u.a. (2004): Die Europäische Union und die Türkei. Eine politische Bestandsaufnahme, Hamburg.

Gerhards, Jürgen (2004): Europäische Werte - Passt die Türkei kulturell zur EU? in: Aus Politik und Zeitgeschichte 38/2004, S. 14-20.

Giesendorf, Sabrina (2004): Türkischer EU-Beitritt: Ein gelungenes Beispiel für die Implementation von Politik von außen? Gießen (Diplomarbeit).

Knoepfel, Peter/Kissling-Näf, Ingrid/Bussmann, Werner (1997): Evaluation und Politikanalyse, in: Werner Bussmann/Ulrich Klö- 
ti/Peter Knoepfel (Hg.): Einführung in die Politikevaluation, Basel/Frankfurt a.M., S. 134-146.

KOM/2004/656: Empfehlung der Europäischen Kommission zu den Fortschritten der Türkei auf dem Weg zum Beitritt. Mitteilung der Kommission an den Rat und das Europäische Parlament, Brüssel.

Kramer, Heinz (2004): Die Türkei im Prozess der »Europäisierung«, in: Aus Politik und Zeitgeschichte 33-34/2004, S. 9-17.

Leggewie, Claus (Hg.) (2004): Die Türkei und Europa. Die Positionen, Frankfurt a.M.

Pressman, Jeffrey/ Wildavsky, Aaron (1973): Implementation, Berkeley/CA.

Repucci, Sarah (2004): Countries at the Crossroads 2005: Turkey, Washington D.C.

Rumford, Chris (2003): Resisting Globalization? Turkey-EU-Relations and Human and Political Rights in the Context of Cosmopolitan Democratization, in: International Sociology, 18, 2, S. 379-394.

Schubert, Klaus (2002): Art. Implementation, in: Dieter Nohlen/Rainer-Olaf Schultze (Hg.): Lexikon der Politikwissenschaft, Bd. 1, München, S. 336. 



\title{
Die Botschaft der Diskurse zum EU-Beitritt der Türkei
}

\author{
EMANUEL RICHTER
}

Die öffentliche und fachliche Aufmerksamkeit für den möglichen EU-Beitritt der Türkei ist geradezu überwältigend. Die Debatte wird vor allem im Kreis der Altmitglieder der Europäischen Union in zahlreichen tagespolitischen Medien, in politischen Zentren, in Fachjournalen und Expertenrunden heftig ausgetragen. Dabei ist eine erstaunlich große Beteiligung solcher Politiker und Intellektueller zu verzeichnen, die bislang nie als Kenner der europapolitischen Materie in Erscheinung getreten sind. Zudem vollziehen sich die Türkei-Diskurse in einer scheinbar unauslöschlichen Polarisierung, in der sich leidenschaftliche Gegner und unbeirrbare Verfechter verständnislos gegenüberstehen. Das deutet auf Aufruhr in beiden Lagern. Ein Nerv im kulturellen Selbstverständnis europäischer Gesellschaften scheint getroffen zu sein, der kraftvolle Reize auslöst unter den bisherigen Mitgliedsstaaten noch mehr als beim Aspiranten.

Ist diese Kontroverse das Qualitätsmerkmal für eine intensive Auseinandersetzung mit den Inhalten, um die es bei der Frage nach dem möglichen Beitritt geht? Bei näherer Betrachtung der Argumente drängt sich der Verdacht auf, dass die Diskurse, die man im Lager der Gegner und Befürworter führt, nur teilweise den konkreten Gegenstand des Beitrittsgesuchs zum eigentlichen Thema haben. Hinter allem vordergründigen 
Aussagegehalt der Positionen schimmert eine semantische Ebene durch, die auf einen viel weit greifenderen und grundsätzlicheren Problemhorizont deutet: auf die Grundfrage nach dem Entwicklungsstand und Entwicklungspotential der europäischen Integration. Die hintergründige Botschaft in den ablehnenden wie auch in den befürwortenden Diskursen bezieht sich auf eine Bewertung des gegenwärtigen Zustands und der Dynamik supranationaler Politikgestaltung. Der mögliche TürkeiBeitritt liefert den Anlass zu einem Resümee, das deutlich über die konkreten Fragen der Erweiterung hinausgeht. Ich will im Folgenden versuchen, die kontroversen Diskurse auf diese sublimen Botschaften hin abzutasten und den »Subtext« der aktuellen Debatte zu ermitteln. Im Mittelpunkt steht dabei die »Empfehlung « der Europäischen Kommission zum Beitritt der Türkei, die ich kontrastiv den vielfach artikulierten Ressentiments gegen den EU-Beitritt gegenüberstelle.

Ich beginne mit einer zusammenfassenden Darstellung der Argumente, die in den Diskursen um den Beitritt der Türkei zum Ausdruck kommen. Zunächst gehe ich auf die Positionen im Lager der Gegner ein, bevor ich die befürwortende Empfehlung der Kommission auf ihre Inhalte hin analysiere (I). Es zeichnet sich ein Antagonismus zwischen Vertiefung und Erweiterung ab. In einem zweiten Schritt gebe ich daher einen kursorischen Überblick über das tatsächliche Leistungsvermögen der Europäischen Union im Spannungsbogen von Vertiefung und Erweiterung (II). Abschließend setze ich die Argumente der Gegner wie der Befürworter des Türkei-Beitritts in Beziehung zu dieser Lageschreibung der Europäischen Union. Die kontroversen Argumentationslinien taste ich auf jene Botschaften hin ab, die sie in Hinblick auf die Bewertung der europäischen Integration enthalten (III). Die Argumente beider Lager nehmen gemeinsam einen auffälligen Abstand zum tatsächlichen politischen Leistungsvermögen der Europäischen Union ein. Damit findet eine sublime Botschaft ihren Ausdruck, die ich zu identifizieren versuche: Die einen artikulieren im Grundton der Verbitterung über weitere Belastungen der europäischen Integration ihre Enttäuschung über verloren gegangene Einigungsideale, die anderen blicken zu vertrauensvoll in eine integrationspolitische Zukunft unter Einschluss zahlreicher 
Mitgliedsstaaten, der die Europäische Union gar nicht zu genügen vermag.

Schon lange nicht mehr hatte die europäische Integrationspolitik so leidenschaftliche Debatten um ihre Zielorientierungen zu verzeichnen wie jüngst anlässlich der bevorstehenden Eröffnung von Beitrittsverhandlungen mit der Türkei. Das Scheitern der Europäischen Verteidigungsgemeinschaft, der Weg zur Direktwahl des Europäischen Parlaments, die Einführung des Euro waren einige der wenigen Anlässe, zu denen es in der Vergangenheit eine breite öffentliche Wahrnehmung der EU-Politik und eine hitzige Auseinandersetzung mit integrationspolitischen Themenfeldern gegeben hatte. Dazwischen blieb Europa versunken in wohlwollende Akzeptanz oder entrückte Ignoranz. Selbst die große östliche und südöstliche Erweiterungsrunde vom Mai 2004 auf 25 Mitgliedsstaaten, die für viele schon einen gewöhnungsbedürftigen Innovationsschub darstellte, gab keinen Anlass $\mathrm{zu}$ entsprechend heftigen Kontroversen. Auch das Thema des Beitritts der Türkei selbst, das seit den 60er Jahren immer mal wieder auf der europäischen Tagesordnung stand, war bislang nie Auslöser von Stürmen öffentlicher Stellungnahmen und Interventionen gewesen. Nun aber tobt die Auseinandersetzung. Ein Schwall von Warnungen vor einem EU-Beitritt der Türkei ist zu vernehmen. Es bricht eine Lawine von europapolitischen Stellungnahmen los, die bis in abstrakte Gefilde kulturtheoretischer Positionsbestimmungen hineinführen und vielfach in der Beschwörung des Antagonismus zwischen Christentum und Islam ihren Höhepunkt finden. Diese Vehemenz wird sich nicht ausschließlich mit dem neuen religiösen Fundamentalismus und der Terrorattacke vom 11. September 2001 erklären lassen.

Immer wieder findet sich die Berufung auf europäische Einigungsideale, die bislang allenfalls in den Präambeln der Vertragstexte und ihren zahlreichen Revisionen zu finden sind. Die Kulturgeschichte Europas wird veranschlagt, die nach Ansicht der Beitrittsgegner Christentum und Demokratie, Aufklärung und Laizismus umfasst. Dabei ist die Rede von einem hehren 
Erbe europäischer Identität, das es gegenüber nicht integrierbaren Fremdkulturen zu bewahren gilt. Das Sinnbild der »Türken vor Wien", das auf die Belagerungen im 16. und 17. Jahrhundert anspielt, wird zum unvergänglichen Menetekel einer neuerlichen »Invasion" stilisiert. Die Kulturgeographie wird bemüht, indem man auf vermeintlich klaren Grenzverläufen zwischen Europa und Asien pocht, zwischen dem integrationsfähigen Kontinent und der randständigen Anrainern. Der Zusammenhalt unter kohärenten Nationalgesellschaften wird ins Feld geführt, die nur bedingt kulturfremde Zuwanderung von außen vertragen würden - ungeachtet der supranationalen Grundphilosophie, die doch schon längst so etwas wie die "postnationale" Konstellation ausgerufen hatte. Schließlich kreisen die Diskurse um die scheinbar bedrohte Kohärenz der Europäischen Union in politischer und ökonomischer Hinsicht. In demonstrativer und bislang ungekannter Affirmation des Binnenmarktziels beschwört man die große europäische Wirtschaftskraft und das hohe Industrialisierungsniveau, die es gegen Nivellierungen durch einen strukturschwachen Beitrittskandidaten zu verteidigen gelte. Man sorgt sich um die Finanzstruktur des EU-Haushalts und warnt vor Überlastungen durch einseitige Transferleistungen gegenüber der Türkei. Man nimmt, entgegen der vielfachen Proklamationen eines "starken Europa", Abstand von der Zielvorstellung einer Festigung des weltpolitischen Einflusses der EU und reklamiert eine Art friedenspolitisches Disengagement, das die EU vor der Berührung mit neuen geostrategischen Konfliktlinien in Vorderasien bewahren soll (die Bandbreite entsprechender Positionen ist dokumentiert in Leggewie 2004).

Der Facettenreichtum europäischer Einigungsideale, der im Alltagsgeschäft des europäischen Institutionengefüges längst untergegangen schien, lebt in den ablehnenden Diskursen zum Türkei-Beitritt unvermittelt wieder auf. Die skeptischen Stellungnahmen knüpfen zum Teil an ehrgeizige Integrationsziele an, deren Formulierung sich in fast vergessenen Dokumenten findet, wie der von den europäischen Staats- und Regierungschefs verabschiedeten »Feierlichen Deklaration zur Europäischen Union« vom Juni 1983 oder dem »Entwurf eines Vertrages zur Gründung der Europäischen Union« des Europäischen Parlaments vom Februar 1984 (vgl. Lipgens 1986: 681ff.; 711ff.). 
Manche der gegen den Beitritt reklamierten Argumente greifen sogar noch auf die Zeit vor der Gründungsphase zurück und zeigen sich stellenweise wortgleich zu frühen Europlänen aus der Wende vom 19. zum 20. Jahrhundert, aus der Résistance oder aus der impulsiven Europabewegung der 40er Jahre. Die integrationspolitische Geschichtsmächtigkeit der beitrittsfeindlichen Diskurse wird noch zusätzlich aufgeladen durch den Ton, in dem sie verbreitet wird. Eine ungeahnte Leidenschaftlichkeit erfasst die Auseinandersetzung mit dem Thema. Man legt eine europapolitisch ungeahnte Emphase in die ablehnenden Argumente, man widerlegt mit Verve die Positionen der Befürworter, man bezieht unverzüglich Position zur Gegenposition, und so folgen in rasantem Tempo pointiertes Statement und rüde Replik wechselseitig aufeinander. Bisweilen schlägt Emotionalität um in ungebremste Irrationalität und endet in bornierter Geschichtsblindheit, in vordergründigen kulturellen Ressentiments oder in der Reklamierung abstruser Wertorientierungen.

In völligem Gegensatz dazu steht die »Empfehlung der Europäischen Kommission zu den Fortschritten der Türkei auf dem Weg zum Beitritt«. Schon der umständliche Titel verrät die Absicht nüchterner Abwägung statt plakativer Positionierung. Der Bericht ist als Resümee einer intensiven Prüfung zu verstehen, die mit umfangreicher Datensammlung, Beobachtungen und Gesprächen »vor Ort « einhergegangen ist und von dem erfahrenen »Erweiterungskommissar « Günter Verheugen verantwortet wurde. Es handelt sich nicht um den ersten Bericht seiner Art, sondern nur um ein weiteres Glied in der langen Kette von Berichterstattungen, die seit Jahrzehnten unter der Federführung der Europäischen Union über die Beitrittsfähigkeit der Türkei erstellt und beraten werden. Im Anhang enthält die Empfehlung die Schlussfolgerungen aus dem »Regelmäßigen Bericht«, die in wohltuender Nüchternheit zahlreiche Politikfelder in Hinblick auf die Annäherung der Türkei an Standards der EU abschreiten (KOM/2004/656: [13ff.] 203)*. Die

\footnotetext{
* Die »Empfehlung der Europäischen Kommission zu den Fortschritten der Türkei auf dem Weg zum Beitritt« ist im vorliegenden Sammelband als Anhang ab Seite 189 abgedruckt, auf den sich auch die Seitenzahlen beziehen. Die Seitenzahl in eckigen Klammern kennzeichnet die Stelle im Original.
} 
Empfehlung stellt ihrerseits neue Berichte über die Entwicklung in der Türkei und über den Prozess der türkischen Annäherung an die EU in Aussicht. Die Empfehlung hält sich nicht mit einer erneuten Auflistung der Klischees gegenseitiger Wahrnehmung auf, sondern bietet schon die durchdachte Reaktion darauf an. Es dominiert eine dezente Sachlichkeit. Die weiteren Verhandlungen mit der Türkei sollen auf drei Säulen ruhen, die sich auf die Förderung der Reformen innerhalb der Türkei im Fokus der »Kopenhagener Kriterien« beziehen, auf die prekäre Strategie der Beitrittsverhandlungen, und bemerkenswerter Weise auf die Intensivierung des "politischen und kulturellen Dialogs" zwischen den Menschen in den EU-Staaten und in der Türkei (ebd.: [3] 191; [10] 202). Die Überwindung der gegenwärtig aufgetürmten Barrieren durch hartnäckige Ressentiments auf beiden Seiten avanciert zu einem herausgehobenen Ziel, das unabhängig von den Fortschritten der Beitrittsverhandlungen zu verfolgen bleibt. Die Empfehlung verweist auf die berechtigte Gefahr, dass sich die Türkei angesichts der westeuropäischen Vorbehalte aus ihrer europäischen Einbindung lösen könnte, statt sie zu vertiefen.

Die Empfehlung bezieht sich in Hinblick auf die politische Annäherung der Türkei an die EU auf eine Reihe von bestehenden »europäischen Normen" (ebd.: [3] 191), die von Seiten des Beitrittskandidaten bereits erfüllt werden oder auf die sich die Türkei in deutlich erkennbarer Erfüllungsbereitschaft hinbewegt. Diese "Normen" sind freilich nicht so klar definiert, wie die Verwendung des Begriffs suggeriert. Erste Vorschriften zur Erfüllung politischer und rechtlicher Kriterien für Beitrittskandidaten finden sich schon 1978 in der »Erklärung zur Demokratie« des Europäischen Rats; vielfacher Bezugspunkt aller neueren Beitrittsgesuche sind die so genannten »Kopenhagener Kriterien« von 1993. Dieser Normenkatalog ist freilich begrenzt auf einige plakative Leitbegriffe, an denen sich die Beitrittskandidaten zu orientieren haben: »institutionelle Stabilität als Garantie für demokratische und rechtsstaatliche Ordnung, Wahrung der Menschenrechte sowie Achtung und Schutz von Minderheiten, eine funktionsfähige Marktwirtschaft und die Fähigkeit, dem Wettbewerbsdruck und den Marktkräften innerhalb der Union standzuhalten « (Europäischer Rat 1993: D 264). Welche Schwierigkeiten sich dabei eröffnen, diese allgemeinen Ka- 
tegorien zu operationalisieren, zeigt die Vielfalt der Problemhorizonte, die sich im Versuch ihrer Überprüfung auftun. Die Empfehlung behilft sich durch penible Detailarbeit und listet Punkt für Punkt die bereits geleistete, gerade vollzogene oder noch ausstehende Erfüllung der politischen und rechtlichen Kriterien durch die Türkei auf. Sie leitet daraus die Auffassung $a b$, dass Beitrittsverhandlungen eröffnet werden können (KOM/2004/ 656: [4] 192).

Die Empfehlung ist redlich genug, die Besonderheit des möglichen türkischen Beitritts gegenüber bisherigen Erweiterungsrunden herauszustellen. Als Manifestationen der Besonderheit führt sie die Bevölkerungszahl, die Landesgröße, die geografische Lage und - in einer ihrerseits aussagekräftigen Zurückhaltung hinsichtlich der impliziten Wertungen - das "wirtschaftliche, sicherheitspolitische und militärische Potential« des Landes auf (ebd.: [5] 193). Diese Besonderheiten bleiben aber nicht einseitig nur vom Beitrittskandidaten im Sinne vermehrter Anpassungsbereitschaft abzuarbeiten, sondern erscheinen als ein positives wie negatives Spezifikum, dem sich beide Seiten zu stellen haben. So hebt die Empfehlung unmissverständlich hervor, dass mit dem möglichen Beitritt der Türkei die Erwartung an die EU in Hinblick auf ihr außenpolitisches Engagement in der vorderasiatischen Region beträchtlich wachse. Zugleich weist die Empfehlung nüchtern darauf hin, dass die Türkei auf lange Sicht ein Nehmerland der europäischen Regional- und Strukturpolitik wäre, was die bisherigen Fördersummen und Hilfsmaßnahmen für die gegenwärtigen Nutznießer unweigerlich beträchtlich mindern würde. Die Empfehlung enthält den unausgesprochenen Appell, dem Grundwert der "Solidarität « innerhalb des bestehenden und vor allem des prospektiven Mitgliederkreises einen exponierten Stellenwert zukommen zu lassen. Damit bezieht sie sich mit Nachdruck auf eine Kategorie, die nicht einmal im Verfassungsvertrag einen exponierten Rang einnimmt, denn dort heißt es nur, die Union solle »die Solidarität zwischen den Generationen " sowie »zwischen den Mitgliedstaaten « fördern und zur "Solidarität und gegenseitigen Achtung unter den Völkern« beitragen (CONV 820/03: Art. I/3, Absätze 3 und 4, S. 4).

Die in der öffentlichen Debatte vielfach beschworene »Überfremdung « westeuropäischer Arbeitsmärkte und Gesellschafts- 
strukturen durch die Fremdkultur wird in der Empfehlung geschickt aus ihrer klischeehaften Behandlung gelöst. Die Argumentation kehrt sich um: »Die Bevölkerungsdynamik der Türkei könnte allerdings einen Beitrag beim Ausgleich der Alterung der EU-Gesellschaften leisten", heißt es in der Empfehlung (KOM/2004/656: [6] 195). Das ist die überraschende Umlenkung fremdenfeindlicher Ressentiments in eine arbeitsmarktpolitische Gesamtrechnung. Freilich fußt sie auf einer Ausblendung der Voraussetzungen, auf denen die Akzeptanz der Zugewanderten ruhen muss: Ohne erfolgreiche Integration und gegenseitige Anerkennung kann diese Entschärfung von Xenophobie zur demographischen Komplementärleistung für die eigene Kultur nicht gelingen. Gerade das Fehlen von gegenseitigem Respekt verhindert bisher jegliche nüchterne Abwägung. Die Empfehlung beharrt dennoch auf ihrer positiven Bilanz und führt eine Reihe von Erleichterungen für die politische Interaktion ins Feld, die beiden Seiten durch den Beitritt erlangen würden: Es ließen sich Migrationsströme, Asylfragen, die Bekämpfung von Kriminalität, Terrorismus, Menschenhandel, Drogen- und Waffenschmuggel viel kooperativer und effizienter bewältigen als bislang.

Die Empfehlung vermeidet Schlussfolgerungen, die in emphatischen Beitrittsappellen oder rigorosen Verdikten gegenüber der Annäherung kulminieren. Stattdessen schließt sie mit der Aufforderung, die Beitrittsverhandlungen zu eröffnen und gibt pragmatische »Leitlinien für die Führung von Beitrittsverhandlungen " an die Hand (ebd.: [8f.] 198ff.). Viel Zeit und gegenseitige Akzeptanz wird angemahnt, lange Übergangsfristen werden in Aussicht gestellt. So erweist sich die Empfehlung zumindest vordergründig als ein sachliches Dokument der Bestandsaufnahme, das zahlreiche Problemhorizonte eines Beitritts ohne Beschönigung abschreitet und um eine unvoreingenommene Bilanz bemüht ist. Zahlreiche politische, ökonomische, soziale und kulturelle Schwierigkeiten, Hemmnisse und Strukturprobleme treten zu Tage, für die keine klaren Lösungen absehbar sind und in der Empfehlung auch nicht angeboten werden. Dennoch wirbt die Empfehlung unverdrossen für die Aufnahme der Beitrittsverhandlungen.

Diese ambivalente Bilanz fügt sich zu einer verwirrenden Botschaft: Die Türkei weist eklatante Strukturschwächen auf, 
die Europäische Union wird durch einen Beitritt in vielen Politikfeldern vorerst überfordert sein, aber dennoch spricht nichts gegen die Aufnahme? Der Grundtenor der Empfehlung lautet: Die Europäische Union ist besser als ihr Ruf, sie kann mehr leisten, als viele ihr zutrauen, die Erweiterung bringt mehr politische Kohärenz hervor, als die zahllosen Hemmnisse erahnen lassen. Es ist geradezu bezeichnend, dass die Empfehlung auf einen in sich widersprüchlichen Leitfaden des Europäischen Rats vom Juni 1993 zurückgreift, den sie als allgemeines Glaubensbekenntnis für jegliche Erweiterungsstrategien vorstellt. Es handelt sich um die Beschwörung der "Fähigkeit der Union, neue Mitglieder aufzunehmen, dabei jedoch die Stoßkraft der europäischen Integration $\mathrm{zu}$ erhalten und ihren inneren $\mathrm{Zu}$ sammenhalt und ihre grundlegenden Prinzipien zu wahren « (ebd.: [9] 199). Diese Erwartung bringt die unlösbare Spannung zwischen Vertiefung und Erweiterung ungewollt deutlich zum Ausdruck. Sie verweist unbeabsichtigt auf die Ambivalenzen und Widersprüche zwischen einer Fortentwicklung der EU zur Staatsähnlichkeit und einer Erhöhung ihrer inneren Heterogenität durch den vermehrten Pluralismus unter völlig unterschiedlichen Mitgliedsstaaten. Das darin aufscheinende Problem bezieht sich keineswegs ausschließlich auf den Beitritt der Türkei - es ist vielmehr schon längst im Europa der 25 virulent. Während es die Gegner des Beitritts durch die rückwärtsgewandte Sehnsucht nach ursprünglichen Einigungsidealen in aller Dramatik beschwören, verharmlost es die Empfehlung der Kommission durch die Zuversicht, alles leisten zu können - Erweiterung, vertiefte Integration, Dynamisierung der Supranationalität, Hinnahme starker nationalstaatlicher Einflusssphären, gleichen Nutzen für die Aspiranten wie für den Kreis der Altmitglieder. In beiden Lagern ist die Erwartung an die Europäische Union beängstigend hoch - beängstigend in Hinblick auf die Verkennung des geschrumpften Leistungsvermögens, das sie im Vergleich zur anfänglichen Dynamik supranationaler Institutionenbildung heutzutage besitzt. Das taktische Ausweichen vor einer realistischen Lagebeschreibung in den Diskursen der Gegner wie der Befürworter macht es erforderlich, etwas deutlicher auf die gegenwärtigen Ambivalenzen und auf das somit begrenzte integrative Potential der Europäischen Union einzugehen. 
Die Europäische Union war schon immer eine »Erweiterungsgemeinschaft «, die in ihren Vertragszielen alle europäischen Länder dazu aufforderte, sich ihr anzuschließen. Diese Erweiterung hat sich in der Tat in einem rasanten Tempo vollzogen: von sechs Gründerstaaten vor kaum mehr als fünfzig Jahren zu 25 in der Gegenwart. In den Vertragszielen war zugleich immer die Rede von ökonomischer Angleichung, von einer auf Niveauangleichung gerichteten Strukturpolitik, von technischer Harmonisierung, vom einheitlichen Binnenmarkt und vor allem von einer einheitlichen politischen Struktur, zum Ausdruck gebracht in einer staatsähnlichen Regierungsform. Diese Homogenitätsziele standen von Anfang an im Gegensatz zur Erweiterung, die der Europäischen Union den Umgang mit zunehmender Diversifikation und Pluralismus abfordert. Die Vertiefung hat sich durchaus von der Gründungsphase bis zur Gegenwart auf einem durchaus beachtlichen Niveau eingependelt. Aber in einem Europa der 25 wird unmissverständlich klar: Die Europäische Union kann nicht im Tempo der ersten Jahrzehnte ihres Bestehens weiter homogenisiert werden, sondern diversifiziert sich zunehmend. Die Gewichte verlagern sich von der Einheit auf die Vielfalt (vgl. Beck/Grande 2004; Landfried 2005). Es wächst die Differenz in Europa, die Vertiefung ist der Verlierer gegenüber der Erweiterung.

Es existieren zahllose objektive Faktoren wachsender Differenz im Europa der 25 Mitgliedsstaaten. Die nationalen Bruttosozialprodukte weisen eklatante Diskrepanzen auf, die Verteilungen von Produktionszweigen, Einkommensstrukturen und Beschäftigungsniveau sind höchst disparat. Wirtschaftspolitische Probleme kommen hinzu, die ursächlich gar nichts mit der Erweiterung zu tun haben, sich aber in ihr verstärkt auswirken. Das westeuropäische Modell des Wohlfahrtsstaates ist vorläufig an seine Leistungsgrenzen gestoßen und wird in zahlreichen Nationalstaaten in Richtung auf mehr Eigenbeteiligung zurückgefahren. Das bedeutet eine zunehmende Spreizung von sozialen Statuspositionen und von der Einkommensverteilung innerhalb der Gesellschaften. Die sozialen Schichten bewegen sich voneinander weg, parallel zur wachsenden Differenz im Europa der 25 (vgl. Münch 2001). Eine sich gleichmäßig über 
die rückständigen Gebiete der Europäischen Union erstreckende, homogenisierende Struktur- oder Sozialpolitik wird unmöglich. Europa wird zum Patchwork einer pluralistischen »Mehrebenenpolitik «. Angesichts einer Europäischen Union, die mit Sicherheit um weitere Mitgliedsländer wachsen wird, nimmt die Entfernung von einer staatsähnlichen Finalität weiter zu. Das führt unweigerlich $\mathrm{zu}$ unterschiedlichen Konstellationen des Integrationsfortschritts unter den Mitgliedsstaaten. Der Verfassungsvertrag proklamiert vorausschauend in Art. I-43 eine »abgestufte Integration «: Einige Mitgliedsstaaten können in einem Bereich, in dem es sich nicht um eine ausschließliche Zuständigkeit der EU handelt, selbständig als kleine Gruppe von "Entschlossenen « voranschreiten (CONV 820/03: 35). Die Wahrscheinlichkeit wächst, dass sich die abgestufte Integration, die eigentlich als beispielhaftes Voranschreiten zur Motivierung der zögernden Mitgliedsstaaten konzipiert ist, zur »differenzierten Integration " verfestigt, bei der die unterschiedlichen Integrationsniveaus nicht mehr einander angepasst werden, sondern festgeschrieben bleiben. In der Folge würde sich allmählich ein integrationsfreudiges und gleichzeitig weltpolitisch entscheidungsmächtiges Kerneuropa ausprägen, dem eine weltpolitisch anspruchslose, aber wirtschaftlich aufstrebende Peripherie der Europäischen Union gegenüber steht, die nur in wenigen Politikbereichen das Integrationsniveau der Kerneuropäer erreicht. Damit würde die Gefahr einer innereuropäischen Aufspreizung von Machtpositionen und einer gegeneinander gerichteten Unterschiedlichkeit von Statuspositionen wachsen. Diese Aufsplitterung kommt schon gegenwärtig in den zahlreichen Absprachen unter den machtvollen und großen Mitgliedsstaaten der EU zum Ausdruck. Diese Konstellation wird sich einschränkend in Hinblick auf die weltpolitischen Aktionsfelder der Europäischen Union niederschlagen. Es wird sehr viel schwieriger oder unmöglich, eine harmonisierte AuBenwirtschaftspolitik, Sicherheitspolitik und Verteidigungspolitik zu betreiben. In der "Gemeinsamen Außen- und Sicherheitspolitik " der EU schlägt sich das anhaltende "Spannungsverhältnis zwischen intergouvernementalen und gemeinschaftlichen Zuständigkeiten « hemmend nieder (Weidenfeld 2004: 22). 
Insgesamt rückt die EU von den Visionen der Staatsähnlichkeit ab. Sie hat zwar mittlerweile eine gefestigte institutionelle Gestalt und Entscheidungsstruktur, aber sie erlangt keine Kompensationsfunktion für das nationale oder regionale Wechselspiel zwischen Volkssouveränität und staatlicher Gewaltenteilung. Es wird keinen supranationalen Ersatz für die Nationalstaatlichkeit geben, sondern nur eine Koexistenz von supranationaler Herrschaftsgewalt und nationalstaatlicher Kontrolle, unter striktem Beharren auf solchen Verfahren der Konsensfindung, in die Vetopositionen eingebracht werden können und imstande sind, gegen vitale nationale oder regionale Interessen gerichtete Entscheidungen zu verhindern. Entgegen dem immer mal wieder reklamierten Anspruch der Bundesstaatlichkeit schält sich das Charaktermerkmal eines ausdifferenzierten »Regulationsstaats « heraus: Er erbringt Steuerungsleistungen in vielen Politikfeldern, ist von seiner Identifikations- und Legitimationsstruktur jedoch nicht einem Staat ähnlich, sondern einer administrativen Organisation.

Diese politische Entdynamisierung zeichnet sich keineswegs erst seit der letzten Erweiterungsrunde ab, wird aber von Politikern, europäischen Institutionen und selbst in den bisherigen vertraglichen Zielbestimmungen immer wieder kaschiert. Das Eingeständnis der Unerreichbarkeit einer hochgesteckten, staatsähnlichen Finalität europäischer Integration scheint vor dem Hintergrund der ursprünglichen Ziele, nämlich einer Aufhebung europäischer Nationalstaatlichkeit zum Zwecke der Friedenssicherung in Europa, peinlich und beschämend zu sein. Dabei ist doch die Friedenssicherung vorerst überzeugend gelungen, und selbst die regulative Effizienz hat ein beachtliches Ausmaß erlangt. Paradoxerweise kommt erst mit dem seinerseits als anspruchsvolles Projekt der Integration präsentierten »Verfassungsvertrag « eine behutsamere, nüchternere Formulierung von Zielvorstellungen der Europäischen Union zustande. In seiner Präambel heißt es nun umständlicher:

»In der Gewissheit, dass die Völker Europas, wiewohl stolz auf ihre nationale Identität und Geschichte, entschlossen sind, die alten Trennungen zu überwinden und immer enger vereint ihr Schicksal gemeinsam zu gestalten [...] (CONV 820/03: 1). 
Jedenfalls müsste die Fixierung auf einen auch institutionell klar konturierten Binnenraum eigentlich durch die Akzeptanz von weicheren Grenzziehungen abgelöst werden. Unter diesem Perspektivenwechsel würde die Entscheidung darüber, wer Mitglied wird und wer nicht, ihre existenzielle Bedeutung verlieren. Eine Europäische Union, die vielen Beitrittskandidaten offen steht, würde zum Raum pluralistischer Kooperation statt homogener Integration. Ein solches Rollenverständnis erscheint weder innereuropäisch noch weltpolitisch als gravierende Qualitätseinbuße. Indem sich Europa seiner neuen Vielfalt versichert, diese durch Kooperation den Bürgern zu Bewusstsein bringt und das Ethos der Akzeptanz von Vielfältigkeit innereuropäisch wie weltpolitisch reklamiert, hätte sie ihrerseits ein passables, im globalen Zeitalter durchaus benötigtes Leitbild angenommen. Insofern muss Europa keineswegs die Attitüden eines »Imperiums" annehmen (Münkler 2004: 1463). Die Ausbreitung der eigenen Wertvorstellungen und politischen Funktionen muss nicht im imperialen Gestus des sanften Drucks oder des manifesten Zwangs erfolgen, sondern kann sich als eine Form des beharrlichen Diskurses über politische Ziele, wirtschaftliche Entwicklungen und relevante Wertfragen vollziehen. Erst in einer nicht auf verordnete Anpassung, sondern auf Überzeugung gerichteten Vermittlerrolle würde die Europäische Union das Ideal der kulturellen und politischen Vielfalt in einer pluralisierten Staatenwelt glaubhaft veranschaulichen und authentisch propagieren. Ein solches Rollenverständnis bleibt anschlussfähig an die brisante, wachsende Ausprägung von Kulturvarianz, der man offenkundig nicht effektiv durch imperiale Macht, sondern eher durch die nivellierende Verständigung über die jeweilige Andersartigkeit begegnen kann. Die Europäische Union wäre in einem Zeitalter, das weltweit von kulturellen Antagonismen und Spannungen zwischen imperialen Herrschaftsräumen gezeichnet ist, ein Vermittler zur Förderung regionaler Selbständigkeit, ein Impulsgeber für die wirtschaftspolitische Hilfe zur Selbsthilfe, ein Vorbild für die intensivierte Wahrnehmung und Akzeptanz der Verschiedenartigkeit von Völkern und Kulturen, für den Abbau von Fremdenfeindlichkeit und für die Akzeptanz der Andersartigkeit. 


\section{III}

Setzt man sowohl die vehementen Ressentiments gegen den Beitritt der Türkei wie auch die von unbeirrbarer Zuversicht getragene Bilanz in den Empfehlungen der Kommission mit dem gegenwärtigen Zustand der Europäischen Union in Beziehung, dann drängen sich eindeutige Schlussfolgerungen hinsichtlich des möglichen Beitritts der Türkei auf: Das Land kann langfristig schon deshalb beitreten, weil die beschworene oder unterstellte politische Kohärenz der Europäischen Union gar nicht besteht. Unter diesen Bedingungen ist ein Beitritt harmloser, als beide Seiten aus unterschiedlichen Erwägungen suggerieren.

Die Argumente für und gegen den Beitritt überschätzen demnach die möglichen oder vorhandenen Staatsqualitäten der Europäischen Union. Wo man als Beitrittsgegner vorgibt, eine Lagebeschreibung der EU zu liefern, handelt es sich bei genauerem Hinsehen vielfach um Idealisierungen, die längst verloren gegangene Zielvorstellungen europäischer Integration reklamieren. Die Hürden und Diskrepanzen sind damit geringer, als die öffentlichen Kontroversen vorgeben. Der Beitritt der Türkei würde durchaus in eine Entwicklung passen, deren Homogenisierungspotential viel geringer ist als angenommen. Die Beitrittsempfehlung leidet hingegen unter einer Überschätzung des aktuellen europäischen Integrationspotentials, wenn sie akribisch Wege für die Anschlussfähigkeit der Türkei in zahlreichen europäischen Politikfeldern aufzuzeigen versucht, deren integrationspolitische Signifikanz gering ist. Manche der in der Empfehlung proklamierten Anpassungsprozesse sind durch die Zollunion mit der Türkei schon in die Wege geleitet, andere - wie die Erfüllung der »Kopenhagener Kriterien « - beziehen sich auf universale rechtliche und politische Ideale, die kein Privileg der Europäischen Union darstellen. Wieder andere Integrationsleistungen sind sachlich gar nicht erforderlich (vgl. Kramer 2004: 143). Die EU ist beispielsweise weder besonders gut dafür geeignet noch steht sie unter einem erkennbaren Zwang, nach der türkischen Mitgliedschaft eine führende politische Rolle im vorderasiatischen Raum einzunehmen. Insofern wäre der Beitritt der Türkei nicht zwangsläufig ein folgenreiches Startsignal für ein neues weltpolitisches Selbstverständnis 
der Europäischen Union, sondern lediglich ein Heranrücken an brisante regionalspezifische Perspektiven, ohne den Automatismus einer prägenden politischen Einflussnahme.

Vor dem Hintergrund der beidseitigen Überschätzungen der Europäischen Union lassen sich die sublimen Botschaften in den unterschiedlichen Diskursen präziser bestimmen. Es zeigt sich, dass der mögliche Beitritt des ersten islamisch geprägten Landes seinen Gegnern als Projektionsfläche für strukturelle Enttäuschungen über das mangelnde Entwicklungspotential der Europäischen Union dient. Die bevorstehende Erweiterungsrunde wird zum kaschierten Symbol einer schmerzlichen Selbstspiegelung, die den Verlust staatsähnlicher Finalitätsvisionen vor Augen führt. Die Türkei muss dabei die unbehagliche Rolle der Signalfunktion für die integrationspolitische Ernüchterung übernehmen. Die Berührungsängste, die man gegenüber dem potentiellen Neumitglied zum Ausdruck bringt, gelten eigentlich der Europäischen Union in ihrer manifesten Gestalt: dem Europa des funktionalen Binnenmarkts, der administrativen und technischen Harmonisierung, dem ungebrochenen Einfluss von nationalen Regierungen, Interessenverbänden und Bürokratien, der fehlenden kulturellen Identität, der mangelnden Europabegeisterung in der Bevölkerung, vielleicht auch der schleppenden Demokratisierung. Zum Teil spiegeln sich in dieser Enttäuschung generationenspezifische Empfindungen wider, denn sie wird vornehmlich von jenen Jahrgängen artikuliert, die ihr politisches Bewusstsein in der Phase der Gründungseuphorie und Anfangsdynamik supranationaler Integration ausgeprägt haben. Bei den Befürwortern hingegen dient die Beitrittsvision als vermeintlicher Erfolgsnachweis einer integrationspolitischen Leistungsfähigkeit, die von der Europäischen Union gar nicht erbracht werden kann. Sie verschließen die Augen vor einem begrenzten politischen Steuerungspotential auf der supranationalen Ebene.

Gegner wie Befürworter stellen überhöhte Anforderungen an Europa. Sie entziehen sich der Anerkennung wachsender Differenzierung zwischen lokalen, regionalen, nationalen und supranationalen Entscheidungsebenen, verschärfter ökonomischer Diversifikation, eines untilgbaren kulturellen Pluralismus. Um Selbsttäuschungen zu vermeiden, muss der Subtext der herrschenden Diskurse erkennbar werden. Erstaunlicherweise 
bringt die vorläufig jüngste Dokumentation über den Zustand der europäischen Integration, der Verfassungsvertrag, die gebremste Dynamik der Europäischen Union ungeschminkt zum Ausdruck. Insofern gilt der Verfassungsvertrag zu Recht als eine Richtung weisende Weichenstellung. "Die Strukturentscheidung für die europäische Union der Nationalstaaten ist also durch den Verfassungsvertrag gefallen. Sie wird nicht verändert werden« (Bahr 2004: 1459; vgl. auch Riemer 2003: 43).

Die Debatte über den Beitritt der Türkei ist gleichermaßen eine »Türkeidebatte wie eine EU-Debatte« (Kramer 2004: 14). Hintergründige Botschaften haben den Diskurs über den Beitritt auf eine undurchsichtige Weise instrumentalisiert. Insofern liegt größere Redlichkeit darin, nüchtern die Hemmnisse des Beitritts und penibel die Wege ihrer Überwindung aufzuzeigen, als emphatisch inhaltlich fragwürdige Ressentiments zum Ausdruck zu bringen oder penetrante Einigungseuphorie, die sich gar nicht mit der strukturellen Schlichtheit europäischer Integration zur Deckung bringen lassen. Der integrationspolitische Nachdruck auf beiden Seiten verkennt, dass die Europäische Union nicht mehr abhängig ist von dem Pathos supranationaler Idealisierungen. Die Empfehlungen der Kommission sind daher näher an einer realistischen Lagebeurteilung als die Klagen über die Überforderung der EU durch die Türkei.

Mit dem Diskurs über den möglichen Beitritt der Türkei und weitere bevorstehende Erweiterungsrunden müsste jedenfalls eine unbeschönigte Selbstvergewisserung über die Lage und die Dynamik der Europäischen Union einhergehen. In der gegenwärtigen Verhärtung der Fronten besteht weit reichender Nachholbedarf hinsichtlich einer nüchternen, von hehren Finalitätsvisionen entschlackten Betrachtung der europäischen Integration, die dem Prozess der supranationalen Entdynamisierung Rechnung trägt, statt seine Wirkung zu verdrängen (als Beispiel: Alber 2004). Erst dann wird der Blick auf die Türkei unbefangen werden können und imstande sein, die zu harmonisierenden Politikfelder sachlich zu betrachten - ohne ungerechtfertigte Vorannahmen hinsichtlich der politischen Leistungsfähigkeit der Europäischen Union. 


\section{Literatur}

Alber, Jens (2004): Gehört die Türkei zu Europa? - Ein Sozialportrait der Türkei im Licht vergleichender Daten der Umfrageforschung, in: Leviathan 4/2004, S. 464-494

Bahr, Egon (2004): Schicksalsfrage der EU, in: Blätter für deutsche und internationale Politik 12/2004, S. 1458-1461

Beck, Ulrich/Grande, Edgar (2004): Das kosmopolitische Europa. Gesellschaft und Politik in der Zweiten Moderne, Frankfurt a.M.

CONV 820/03: Entwurf eines Vertrags über eine Verfassung für Europa, dem Europäischen Rat auf seiner Tagung in Thessaloniki am 20. Juni 2003 überreicht.

Europäischer Rat (1993): Schlussfolgerungen der Tagung des Europäischen Rates der Staats- und Regierungschefs in Kopenhagen am 21. und 22. Juni 1993, in: Europa-Archiv, 48/1993., S. D 258-D 276.

KOM/2004/656: Empfehlung der Europäischen Kommission zu den Fortschritten der Türkei auf dem Weg zum Beitritt. Mitteilung der Kommission an den Rat und das Europäische Parlament, Brüssel.

Kramer, Heinz (2004): EU-kompatibel oder nicht? Zur Debatte um die Mitgliedschaft der Türkei in der Europäischen Union, in: Claus Leggewie (Hg.): Die Türkei und Europa. Die Positionen, Frankfurt a.M., S. 141-147.

Landfried, Christine (2005): Das politische Europa. Differenz als Potenzial der Europäischen Union, Baden-Baden.

Leggewie, Claus (2004) (Hg.): Die Türkei und Europa. Die Positionen, Frankfurt a.M.

Lipgens, Walter (1986): 45 Jahre Ringen um die Europäische Verfassung. Dokumente 1939-1984. Von den Schriften der Widerstandsbewegung bis zum Vertragsentwurf des Europäischen Parlaments, Bonn.

Münch, Richard (2001): Offene Räume. Soziale Integration diesseits und jenseits des Nationalstaats, Frankfurt a.M.

Münkler, Herfried (2004): Europas imperiale Herausforderung, in: Blätter für deutsche und internationale Politik 12/2004, S. 14621464.

Riemer, Andrea K. (2003): Die Türkei und die Europäische Union, in: Aus Politik und Zeitgeschichte 10-11/2003, S. 40-46.

Weidenfeld, Werner (2004): Organisation, Institutionalisierung und Fortentwicklung der ESVP, in: Ralph Rotte/Tanja Sprungala (Hg.): 
Probleme und Perspektiven der Europäischen Sicherheits- und Verteidigungspolitik (ESVP), Münster, S. 16-33. 
Anhang:

Empfehlung der Kommission zu den Fortschritten der Türkei auf dem Weg zum Beitritt

KOMMISSION DER EUROPÄISCHEN GEMEINSCHAFTEN, Brüssel, den 6.10.2004, KOM (2004) 656 endgültig 


\section{MITTEILUNG DER KOMMISSION AN DEN RAT UND DAS EUROPÄISCHE PARLAMENT}

\section{Empfehlung der Europäischen Kommission zu den Fortschritten der Türkei auf dem Weg zum Beitritt}

\section{EINLEITUNG}

Die Beziehungen der EU zur Türkei blicken auf eine lange Geschichte zurück. 1963 schlossen die Türkei und die EWG ein Assoziationsabkommen, das eine Beitrittsperspektive enthält. 1995 kam es dann zur Errichtung einer Zollunion, und im Dezember 1999 beschloss der Europäische Rat auf seiner Tagung in Helsinki, die Türkei in den Kreis der Beitrittskandidaten aufzunehmen. Auf seiner Tagung im Dezember 2002 in Kopenhagen hielt der Europäische Rat in seinen Schlussfolgerungen fest, dass »die Europäische Union die Beitrittsverhandlungen mit der Türkei ohne Verzug eröffnen wird, falls der Europäische Rat im Dezember 2004 auf der Grundlage eines Berichts und einer Empfehlung der Kommission entscheidet, dass die Türkei die politischen Kriterien von Kopenhagen erfüllt.« Diese Schlussfolgerungen wurden auf der Tagung des Europäischen Rates im Juni 2004 in Brüssel bestätigt.

Über lange Perioden der europäischen Geschichte hinweg war die Türkei ein wichtiger Faktor der europäischen Politik. Das Land ist Mitglied aller anderen wichtigen europäischen Organisation und leistet seit dem Zweiten Weltkrieg einen wichtigen Beitrag zur Gestaltung der europäischen Politik.

Unter strikter Beachtung des in Kopenhagen im Dezember 2002 erhaltenen Mandates enthält diese Mitteilung die Empfehlung der Kommission bezüglich der Türkei sowie - im Anhang - die Schlussfolgerungen des Regelmäßigen Berichts über die Türkei. Der Regelmäßige Bericht beleuchtet die Fortschritte der Türkei auf dem Weg zum Beitritt in den vergangenen zwölf Monaten. Darin werden auch die Leistungen in Bezug auf die politischen und wirtschaftlichen Kriterien bewertet, die das Land seit dem Helsinki-Beschluss des Europäischen Rates im Jahr 1999 vorzuweisen hat. Die Empfehlung und die Begleitdokumente schaffen eine Grundlage für eine Entscheidung des Europäischen Rates, die für die Zukunft der Europäischen Union von grundlegender politischer Bedeutung ist.

Darüber hinaus haben die Kommissionsdienststellen auch eine Bewertung der Fragen vorbereitet, die mit der Perspektive einer Mitgliedschaft der Türkei verbunden sind. Die Ergebnisse dieser Bewertung werden in der vorliegenden Mitteilung vorgestellt. 
Auf dieser Grundlage wird eine Strategie vorgestellt, die auf drei Säulen beruht. Die erste Säule betrifft die Zusammenarbeit zur verstärkten Unterstützung des Reformprozesses in der Türkei, insbesondere im Hinblick auf die fortdauernde Erfüllung der politischen Kriterien von Kopenhagen. Sie wird sich auf eine überarbeitete Beitrittspartnerschaft stützen, welche Prioritäten vor allem für den Reformprozess festlegen wird, sowie auf eine verbesserte Heranführungsstrategie. Die zweite Säule schlägt die spezifischen Bedingungen für die Führung der Beitrittsverhandlungen mit der Türkei vor. Es werden einige vorläufige Hinweise in Bezug auf die Vorbereitung der Beitrittsverhandlungen für den Fall gegeben, dass der Europäische Rat im Dezember einen entsprechenden Beschluss fassen sollte. Die dritte Säule sieht einen wesentlich verstärkten politischen und kulturellen Dialog vor, der Menschen aus den EU-Mitgliedstaaten und der Türkei zusammenbringen soll. Der Beitritt der Türkei bedürfte einer gründlichen Vorbereitung, um eine reibungslose Integration zu ermöglichen, welche die Errungenschaften von fünfzig Jahren europäischen Einigungsprozesses verstärkt. Dies ist ein Prozess mit offenem Ende, dessen Ausgang sich nicht im Vorhinein garantieren lässt. Ungeachtet des Ausgangs der Verhandlungen oder des anschlie enden Ratifizierungsprozesses müssen die Beziehungen zwischen der EU und der Türkei sicherstellen, dass die Türkei vollständig in europäischen Strukturen verankert bleibt.

\section{BEWERTUNG DER ERFÜLLUNG DER POLITISCHEN KRITERIEN}

Nach Jahrzehnten eher sporadischer Fortschritte ist in der Türkei vor allem seit den Wahlen von 2002 eine erhebliche Annäherung des rechtlichen und institutionellen Rahmens an europäische Standards zu verzeichnen. Wichtigste politische Reformen waren die beiden umfassenden Verfassungsreformen von 2001 und 2004 sowie die acht Gesetzespakete, die zwischen Februar 2002 und Juli 2004 vom türkischen Parlament verabschiedet wurden. Die Beziehungen zwischen Zivilregierung und Militär entwickeln sich zunehmend im Sinne europäischer Normen. Wichtige Änderungen des Justizwesens wurden vorgenommen, darunter die Abschaffung der Staatssicherheitsgerichte. Eine Reform der öffentlichen Verwaltung ist im Gange. Im Hinblick auf die Menschenrechte erkennt die Türkei den Vorrang des Völker- und des Europarechts an. Das Land hat sich weitgehend den einschlägigen internationalen Übereinkommen und gerichtlichen Entscheidungen angepasst, so z.B. in Bezug auf die vollständige Abschaffung der Todesstrafe und die Freilassung von Personen, die wegen friedlicher Meinungsäußerung verurteilt wurden. Auch wenn in der Praxis einige Beschränkungen weiterhin bestehen, wurden die Grundfreiheiten der türkischen Bürger wie die Meinungs- und Versammlungsfreiheit wesentlich erweitert. Die Zivilgesellschaft hat an 
Bedeutung gewonnen. Die kulturellen Rechte der Kurden werden allmählich anerkannt. Der Notstand wurde überall aufgehoben; auch wenn im Südosten des Landes die Lage weiterhin schwierig ist, setzt dort die Normalisierung ein. Im Hinblick auf den verstärkten politischen Dialog leistet die Außenpolitik der Türkei einen positiven Beitrag zur regionalen Stabilität.

Bei ihren politischen Reformen ist die Türkei erheblich vorangekommen, vor allem dank der weit reichenden Verfassungs- und Gesetzesänderungen, die in den letzten Jahren im Einklang mit den Prioritäten der Beitrittspartnerschaft vorgenommen wurden. Allerdings sind weder das Vereinsgesetz, das neue Strafgesetzbuch noch das Gesetz über die zweitinstanzlichen Berufungsgerichte bisher in Kraft getreten. Darüber hinaus warten der Beschluss über die Strafprozessordnung, die Gesetzgebung zur Schaffung einer Kriminalpolizei und das Gesetz über Strafvollzug und Ma regeln noch immer auf ihre Verabschiedung.

Die Türkei unternimmt erhebliche Anstrengungen, um die wirksame Umsetzung dieser Reformen zu gewährleisten. Trotzdem muss die Umsetzung weiter verfestigt und ausgedehnt werden. Dies gilt insbesondere für die »Null-Toleranz-Politik « bei der Bekämpfung von Folter und Misshandlung sowie für die Verstärkung und Durchsetzung der Bestimmungen über Meinungsfreiheit, Religionsfreiheit und Frauen-, Gewerkschafts- und Minderheitenrechte.

In Anbetracht der allgemeinen Fortschritte im Reformprozess und unter der Voraussetzung, dass die Türkei die oben genannten, noch ausstehenden Gesetze in Kraft setzt, ist die Kommission der Auffassung, dass die Türkei die politischen Kriterien in ausreichendem Maß erfüllt, und empfiehlt die Eröffnung von Beitrittsverhandlungen.

Die Unumkehrbarkeit des Reformprozesses, seine Umsetzung, insbesondere im Hinblick auf die Grundfreiheiten, müssen sich über einen längeren Zeitraum bestätigen. Hinzu kommt, dass sich der Besitzstand in Bezug auf die politischen Kriterien ständig weiterentwickelt, vor allem aufgrund der Verfassung für Europa. Die Türkei sollte diese Entwicklung aufmerksam verfolgen.

Die Türkei unterstützt weiterhin aktiv die Bemühungen um eine Klärung des Zypern-Problems; insbesondere stimmte die Türkei der im Friedensplan des UN-Generalsekretärs vorgeschlagenen Lösung zu. Auf seiner Tagung im Juni 2004 ersuchte der Europäische Rat die Türkei, die Verhandlungen über die Anpassung des Abkommens 
von Ankara zur Berücksichtigung des Beitritts der neuen Mitgliedstaaten, die die Kommission im Namen der Gemeinschaft und ihrer 25 Mitgliedstaaten mit der Türkei führt, abzuschließen. Die Kommission erwartet eine positive Antwort der Türkei zu dem Entwurf des Protokolls über die notwendigen Anpassungen, der im Juli 2004 übermittelt wurde. Au erdem sollte beachtet werden, dass jedwede Beitrittsverhandlungen im Rahmen einer Regierungskonferenz stattfinden, welche alle EU-Mitgliedstaaten umfasst.

Der vollständige Wortlaut der Schlussfolgerungen des Regelmäßigen Berichts, in denen auch auf die Fortschritte der Türkei bei der Erfüllung der anderen Beitrittskriterien eingegangen wird, ist dem Anhang Schlussfolgerungen des Regelmäßigen Berichts über die Türkei zu entnehmen.

\section{BeWERTUNG DeR MIT Der PerspeKtive einer Mitgliedschaft DeR TÜRKEI VERBUNDENEN FRAGEN}

Der Beitritt der Türkei stellt sowohl für die Union als auch für die Türkei eine Herausforderung dar. Wird er reibungslos bewältigt, so bietet er beiden Seiten große Möglichkeiten. Wie aus der Bewertung der mit der Perspektive einer Mitgliedschaft der Türkei verbundenen Fragen hervorgeht, werden sich die erforderlichen Vorbereitungen auf den Beitritt bis weit ins nächste Jahrzehnt hinziehen. In dieser Zeit wird sich die EU weiterentwickeln, wobei die Türkei sich noch radikaler verändern dürfte. Auch der gemeinschaftliche Besitzstand wird weiterentwickelt werden, um den Erfordernissen einer EU mit 27 oder mehr Mitgliedern gerecht zu werden. Diese Entwicklung könnte auch die Herausforderungen und Möglichkeiten berücksichtigen, die mit dem Beitritt der Türkei verbunden wären.

Ausgehend vom derzeitigen Stand der EU-Politiken und vom heutigen Kenntnisstand hat die Kommission folgende Fragenkomplexe ermittelt, die in den kommenden Jahren Gegenstand weiterer Überlegungen und Analyse sein müssen:

- Der Beitritt der Türkei würde sich aufgrund der Auswirkungen von Faktoren wie Bevölkerungszahl, der Größe des Landes, seiner geografischen Lage und seinem wirtschaftlichem, sicherheitspolitischen und militärischen Potential von früheren Erweiterungen unterscheiden. Aufgrund dieser Faktoren ist die Türkei in der Lage, einen Beitrag zur regionalen und internationalen Stabilität zu leisten. Die Beitrittsperspektive sollte dazu führen, dass sich die bilateralen Beziehungen zwischen der Türkei und ihren Nachbarn im Einklang mit dem Prinzip der Versöhnung, auf das die Europäische Union ge- 
gründet ist, verbessern. In Anbetracht der bestehenden politischen und wirtschaftlichen Beziehungen der Türkei zu ihren Nachbarn werden auch die Erwartungen an die EU-Politik gegenüber diesen Regionen wachsen. Viel wird davon abhängen, wie die EU selbst an die Aufgabe herangeht, mittelfristig $\mathrm{zu}$ einem vollwertigen außenpolitischen Akteur in Regionen zu werden, die wie der Nahe Osten und der Kaukasus traditionell durch Instabilität und Spannungen gekennzeichnet sind.

- Die Türkei durchläuft zurzeit eine Phase tief greifenden Wandels, in der sich auch die Einstellungen und Haltungen der Menschen rasch verändern. Es liegt im Interesse aller Beteiligten, dass der gegenwärtige Transformationsprozess weitergeht. Die Türkei wäre ein wichtiges Modell eines Landes mit einer mehrheitlich moslemischen Bevölkerung, das sich zu grundlegenden Werten wie Freiheit, Demokratie, Rechtsstaatlichkeit und Achtung der Menschenrechte und Grundfreiheiten bekennt.

- Aufgrund der eher bescheidenen Größe der türkischen Volkswirtschaft und des bereits vor dem Beitritt bestehenden Maßes an wirtschaftlicher Integration wären die wirtschaftlichen Auswirkungen des Beitritts der Türkei positiv, wenn auch relativ begrenzt. Vieles hängt von der künftigen wirtschaftlichen Entwicklung der Türkei ab. Die Eröffnung von Beitrittsverhandlungen dürfte dem Land bei seinen weiteren Bemühungen um makroökonomische Stabilität und Förderung von Investitionen, Wachstum und sozialer Entwicklung Auftrieb geben. Unter diesen Voraussetzungen steht zu erwarten, dass das BIP-Wachstum der Türkei über dem EU-Durchschnitt liegen wird.

- Ähnlich wie bei der jüngsten Erweiterung würde der Beitritt der Türkei, einem Land mit niedrigerem Durchschnittseinkommen, das regionale Wirtschaftsgefälle innerhalb der EU verstärken und damit die Kohäsionspolitik vor eine grö ere Bewährungsprobe stellen. Die Türkei hätte lange Zeit Anspruch auf erhebliche Unterstützung aus Mitteln der Strukturfonds und des Kohäsionsfonds. Nach den derzeitigen Bestimmungen könnten dann einige Regionen der jetzigen Mitgliedstaaten, die Strukturfondsmittel erhalten, den Anspruch darauf verlieren.

- Die Integration der Türkei in den Binnenmarkt wäre mit Vorteilen verbunden. Sie hängt allerdings nicht nur von der Erfüllung der derzeitigen Verpflichtungen im Rahmen der Zollunion $\mathrm{ab}$, sondern auch von der Umsetzung weiterer horizontaler Reformen. Dazu gehören u.a. Verbesserung der Unternehmensführung und -kontrolle (»Corporate Governance«), Stär- 
kung der Regulierungsrahmen, verstärkte Bekämpfung von Korruption sowie wesentliche Verbesserung der Funktionsweise der Justiz.

- Mehr als drei Millionen Türken leben heute in der EU und bilden damit die bei weitem größte Gruppe rechtmäßig hier ansässiger Drittstaatsangehöriger. Die verfügbaren Studien bieten unterschiedliche Schätzungen der zusätzlichen Migration, die nach dem Beitritt der Türkei zu erwarten wäre. Lange Übergangszeiten und eine unbefristete Schutzklausel könnten in Betracht gezogen werden, um ernsthafte Störungen auf dem EU-Arbeitsmarkt zu vermeiden. Die Bevölkerungsdynamik der Türkei könnte allerdings einen Beitrag beim Ausgleich der Alterung der EU-Gesellschaften leisten. In dieser Hinsicht hat die EU ein großes Interesse daran, dass in den kommenden zehn Jahren das türkische Bildungs- und Ausbildungswesen reformiert und durch Investitionen gefördert wird.

- Die Landwirtschaft zählt zu den wichtigsten Wirtschafts- und Sozialsektoren der Türkei und bedürfte daher besonderer Aufmerksamkeit. Die Türkei müsste sich konsequent um die Entwicklung des ländlichen Raums und den Aufbau von Verwaltungskapazitäten bemühen, um dadurch möglichst günstige Voraussetzungen für eine erfolgreiche Beteiligung an der Gemeinsamen Agrarpolitik zu schaffen. Die Türkei bräuchte erhebliche Zeit, um die Wettbewerbsfähigkeit einiger Landwirtschaftssektoren mit dem Ziel zu steigern, wesentliche Einkommensverluste der türkischen Bauern $\mathrm{zu}$ vermeiden. Nach den gegenwärtigen Bestimmungen hätte die Türkei Anspruch auf umfangreiche Unterstützung. Im Veterinärbereich wären erhebliche Anstrengungen erforderlich, um durch Verbesserung der Situation bezüglicher der Tiergesundheit und Verstärkung der veterinärmedizinischen Kontrollen an den östlichen Grenzen ernsthafte Probleme nach dem Beitritt zu vermeiden.

- Der Beitritt der Türkei würde zur Sicherung der Energieversorgungswege für Europa beitragen. Er würde wahrscheinlich eine Weiterentwicklung der EU-Politik zur Bewirtschaftung von Wasserressourcen und der damit verbundenen Infrastruktur erforderlich machen. Die wirksame Umsetzung anderer EU-Politiken in den Bereichen Umwelt, Verkehr, Energie und Verbraucherschutz durch die Türkei würde sich aufgrund deren bisweilen erheblicher grenzüberschreitender Wirkungen auch auf EU-Bürger in anderen Mitgliedstaaten sehr positiv auswirken. 
- Die Verwaltung und Sicherung der neuen langen Außengrenzen der EU würde eine große Herausforderung darstellen und umfangreiche Investitionen erfordern. Eine engere Zusammenarbeit vor und nach dem Beitritt würde die Steuerung von Migrationsströmen, die Behandlung von Asylfragen und die Bekämpfung von organisierter Kriminalität, Terrorismus, Menschenhandel sowie Drogen- und Waffenschmuggel erleichtern.

- Die Auswirkungen des Beitritts der Türkei auf den Haushalt lassen sich erst nach Festlegung der Eckpunkte für die Finanzverhandlungen mit der Türkei im Rahmen der Finanziellen Vorausschau für die Jahre nach 2014 in vollem Umfang bewerten. Art und Umfang der Transferzahlungen an die Türkei würden von einer Reihe sich verändernder Faktoren abhängen. Zu diesen Faktoren gehören u.a. die Politiken der EU und die Sonderregelungen, die möglicherweise im Rahmen der Verhandlungen mit der Türkei vereinbart werden, sowie die zum betreffenden Zeitpunkt geltenden Haushaltsbestimmungen, insbesondere die Obergrenze des Gesamthaushalts. Klar ist allerdings, dass nach gegenwärtigem Stand der EU-Politiken der Beitritt der Türkei mit erheblichen Auswirkungen auf den Haushalt verbunden wäre.

- Was die Organe der EU anbetrifft, so hätte der Beitritt der Türkei - ausgehend von der Verfassung für Europa - erhebliche Auswirkungen auf die Zuteilung der Sitze im Europäischen Parlament an die jetzigen Mitgliedstaaten, insbesondere die großen und mittelgroßen Länder. Im Rat würde sich der Bevölkerungsanteil der Türkei im Abstimmungssystem widerspiegeln - dadurch hätte die Türkei eine gewichtige Stimme im Entscheidungsverfahren. Aufgrund der geplanten Verringerung der Zahl der Kommissionsmitglieder ab 2014 wäre für die Kommission der Beitritt der Türkei mit weniger weit reichenden Auswirkungen verbunden.

\section{VERSTÄRKUNG UND UNTERSTÜTZUNG DES REFORMPROZESSES IN DER TÜRKEI}

Insgesamt muss die Umsetzung der Reformen konsequent fortgeführt werden. Insbesondere sollte auf allen Ebenen des Staates entschlossen gehandelt werden, um die »Null-Toleranz-Politik « bei Folter wirksam durchzusetzen und damit die Folter ein für alle Mal zu beseitigen. Auch die Weiterentwicklung der Zivilgesellschaft ist wichtig. Die Notwendigkeit zur Festigung und Ausweitung der politischen Reformen gilt auch für die Normalisierung der Lage im Südosten des Landes, einschließlich Maßnahmen zur Verbesserung der sozioökonomischen Lage, zur Erleichterung der Rückkehr von Ver- 
triebenen und zur Gewährleistung uneingeschränkter Rechte und Freiheiten für die Kurden. Auch die besonderen Probleme der nichtmoslemischen Religionsgemeinschaften und die Rechte der Gewerkschaften erfordern weitere Maßnahmen.

Zur Gewährleistung der Nachhaltigkeit und Unumkehrbarkeit der politischen Reformen sollte die EU diesen Reformprozess auf der Grundlage einer überarbeiteten Beitrittspartnerschaft, in der die Prioritäten des Reformprozesses festgelegt werden, weiterhin aufmerksam verfolgen. Ausgehend von der Untersuchung im Regelmäßigen Bericht wird die Kommission für das Frühjahr 2005 eine Überarbeitung der Beitrittspartnerschaft vorschlagen. Auf dieser Grundlage wird ab Ende 2005 jedes Jahr eine allgemeine Beurteilung der Art und Weise stattfinden, wie die politischen Reformen gefestigt und ausgeweitet werden. $\mathrm{Zu}$ diesem Zweck wird die Kommission dem Europäischen Rat bis Dezember 2005 einen ersten Bericht vorlegen. Das Tempo der Reformen wird den Fortgang der Verhandlungen bestimmen.

Im Einklang mit dem Vertrag über die Europäische Union und der Verfassung für Europa wird die Kommission bei einem schwerwiegenden und dauerhaften Verstoß gegen die Grundsätze der Freiheit, Demokratie, Rechtsstaatlichkeit und Achtung der Menschenrechte und Grundfreiheiten, auf denen die Union beruht, die Aussetzung der Verhandlungen empfehlen. Über diese Empfehlung sollte der Rat mit qualifizierter Mehrheit beschließen können.

Auch nach der Eröffnung der Beitrittsverhandlungen müssen der verstärkte politische Dialog und das regelmäßige Monitoring fortgesetzt werden. Wie bisher werden sie mit der fachlichen Unterstützung durch die Kommission Hand in Hand gehen. Der Dialog im wirtschaftlichen Bereich wird ebenfalls fortgesetzt werden müssen und zwar mit einem deutlichen Bezug zum gemeinschaftlichen Besitzstand und insbesondere zu den in der EU angewandten Methoden der wirtschaftspolitischen Koordinierung.

Unter Einsatz der in den letzen Jahren entwickelten Instrumente wie Twinning, Peer Reviews und TAIEX sollte die EU die Türkei weiterhin bei der Erreichung der notwendigen rechtlichen und tatsächlichen Konvergenz unterstützen. Die Heranführungsstrategie für die Türkei sollte aktualisiert und auf die Prioritäten der überarbeiteten Beitrittspartnerschaft ausgerichtet werden, die wiederum auf dem Regelmäßigen Bericht und der Bewertung der mit der Perspektive einer Mitgliedschaft der Türkei verbundenen Fragen beruhen wird. Konkrete Initiativen müssen entwickelt werden, um die sozioöko- 
nomische Entwicklung im Südosten des Landes zu fördern. Dazu muss auch ein erheblicher Teil der für die Türkei bestimmten Gemeinschaftshilfe eingesetzt werden.

Bis 2006 wird die finanzielle und technische Unterstützung der EU für die Beitrittsvorbereitungen der Türkei weiterhin im Rahmen des im Dezember 2001 vom Rat gebilligten Heranführungsinstruments erfolgen. Die Kommission hat dem Rat die Schaffung eines neuen Heranführungsinstruments vorgeschlagen, das der Türkei ab 2007 zugute kommen würde und welches auf den bestehenden Instrumenten Phare, ISPA und SAPARD aufbaut. Im Zusammenhang mit der nächsten Finanziellen Vorausschau wird die Kommission eine Aufstockung der Mittelzuweisungen für die Türkei vorschlagen.

\section{LEITLINIEN FÜR DIE FÜHRUNG VON BEITRITTSVERHANDLUNGEN}

Die oben zusammengefasste Bewertung zeigt deutlich, dass sowohl die EU als auch die Türkei viel Zeit benötigen werden, um die Voraussetzungen für eine reibungslose Integration der Türkei in die EU zu schaffen. Nur so lässt sich nicht nur Zusammenhalt und Handlungsfähigkeit der Union bewahren, sondern auch vermeiden, dass die Türkei gezwungen wird, Politiken umzusetzen, die möglicherweise dem Entwicklungsstand des Landes nicht entsprechen.

Die Beitrittsverhandlungen finden im Rahmen einer Regierungskonferenz statt, in der Beschlüsse Einstimmigkeit erfordern. Der Verhandlungsrahmen muss den spezifischen Herausforderungen in Bezug auf einen Beitritt der Türkei Rechnung tragen. Die genauen Eckpunkte werden erst nach dem Beschluss zur Eröffnung von Verhandlungen auf der Grundlage folgender allgemeiner Leitlinien ausgearbeitet werden können.

Unmittelbar nach der offiziellen Eröffnung der Verhandlungen wird die Kommission eine umfassende Untersuchung des Besitzstands (genannt »Screening «) vorbereiten, um dessen Inhalt $\mathrm{zu}$ erläutern und erste Anhaltspunkte dafür zu bekommen, welche Fragen bei den Verhandlungen aufgeworfen werden könnten. Die Verhandlungen werden sich komplex gestalten und einerseits den Schwierigkeiten der Türkei bei der Anwendung des Besitzstands, andererseits der Notwendigkeit von Regelungen zur Erleichterung der harmonischen Integration des Landes in die EU Rechnung tragen müssen. Die Umsetzung der Agrarpolitik und der Kohäsionspolitik in der Türkei bieten dafür zwei Beispiele. Ein drittes Beispiel sind die Bestimmungen über die Freizügigkeit. Vermutlich werden, wie auch bei früheren Erweiterungen, umfangreiche Sonderregelungen und - in einigen Bereichen - lange Übergangszeiten erforderlich sein. Im Falle der 
Freizügigkeit könnten unbefristete Schutzklauseln in Betracht gezogen werden. Die Kommission wird im Laufe der Verhandlungen ihre Analyse verfeinern und erst dann ein konkretes Konzept für jede dieser Fragen vorlegen.

Inhaltlich werden die Verhandlungen in einzelne Verhandlungskapitel unterteilt werden, die jeweils einen bestimmten Politikbereich abdecken. Die Kommission wird dem Rat erst dann die Aufnahme von Verhandlungen zu jedem einzelnen Kapitel empfehlen, wenn sie der Auffassung ist, die Türkei sei ausreichend darauf vorbereitet. In Bezug auf bestimmte Verhandlungskapitel mit einer wirtschaftlichen Dimension sollte das Vorhandensein einer funktionierenden Markwirtschaft Voraussetzung für die Eröffnung der Verhandlungen sein.

Vor der Eröffnung der Verhandlungen zu jedem einzelnen Kapitel müssen Richtgrößen (»Benchmarks«) für dessen vorläufigen Abschluss, gegebenenfalls auch für die Eröffnung der Verhandlungen, festgelegt werden. Diese Richtgrößen könnten sich auf ein ausreichendes $\mathrm{Maß}$ an Rechtsangleichung und eine zufrieden stellende Bilanz bei der Umsetzung beziehen. Darüber hinaus sollten die bestehenden rechtlichen Verpflichtungen aus dem Assoziationsabkommen und der Zollunion - insbesondere diejenigen, die die Verpflichtungen aus dem gemeinsamen Besitzstand widerspiegeln noch vor Eröffnung der Verhandlungen zu den entsprechenden Kapiteln erfüllt werden.

Entscheidend für Fortschritte bei den Verhandlungen wird nicht nur die Annäherung der Türkei an die EU sein. Auch die EU muss sich darauf vorbereiten, denn - wie der Europäische Rat im Juni 1993 feststellte - »die Fähigkeit der Union, neue Mitglieder aufzunehmen, dabei jedoch die Stoßkraft der europäischen Integration zu erhalten und ihren inneren Zusammenhalt und ihre grundlegenden Prinzipien zu wahren, stellt ebenfalls einen sowohl für die Union als auch für die Beitrittskandidaten wichtigen Gesichtspunkt dar«. Aus der bisherigen Analyse eines Beitritts der Türkei ergeben sich keine Anhaltspunkte dafür, dass bei den Politiken im Bereich Binnenmarkt größere Anpassungen erforderlich wären. Die Verhandlungen werden wie immer auf der Grundlage des geltenden Besitzstandes stattfinden. Trotzdem könnte es notwendig werden, noch vor dem Beitritt der Türkei Anpassungen des Besitzstands vorzunehmen. Die EU wird in jedem Fall erst die Finanzielle Vorausschau für die Zeit nach 2014 festlegen müssen, bevor sie sich der finanziellen Auswirkungen bestimmter Verhandlungskapitel annimmt. Es könnten Regelungen erforderlich sein, die den spezifischen Verhältnissen in der Türkei Rechnung tragen. Schließlich wird die EU auch über eine Stärkung 
der Politik in den kritischen Bereichen nachdenken müssen, wie sie in der Bewertung der mit der Perspektive einer Mitgliedschaft der Türkei verbundenen Fragen aufgezeigt werden, wie zum Beispiel die Sicherung der Außengrenzen und die Außenpolitik.

Den erfolgreichen Abschluss des gesamten Beitrittsprozess könnte die Türkei in erster Linie durch die entschlossene Umsetzung weiterer Reformen gewährleisten. Die Verhandlungen und die Aussicht auf den Beitritt dürften zu weiteren politischen, sozialen, kulturellen und wirtschaftlichen Reformen in der Türkei beitragen. Das endgültige Ergebnis der Verhandlungen wird vom Europäischen Parlament sowie von allen EU-Mitgliedstaaten und der Türkei gebilligt werden müssen.

\section{VERSTÄRKUNG DES DIALOGS ZWISCHEN DER EUROPÄISCHEN UNION UND DER TÜRKEI}

Der Dialog zu einigen Aspekten der Beziehungen zwischen der EU und der Türkei muss unbedingt verstärkt werden. Dabei müssen auch mehrere wichtige Fragen, die die EU nicht in erster Linie betreffen, angesprochen werden. Eine Reihe von Foren sollte eingerichtet werden, in denen Menschen aus den EU-Mitgliedstaaten und der Türkei zusammenkommen, um sich freimütig und offen über ihre jeweiligen Sorgen und Wahrnehmungen auszutauschen. $\mathrm{Zu}$ den Themen dieses Dialogs gehören u.a. kulturelle und religiöse Unterschiede, Fragen der Migration sowie Sorgen im Hinblick auf Minderheitenrechte und Terrorismus. Die wichtigste Rolle in diesem Dialog sollte die Zivilgesellschaft spielen, die dabei von der EU unterstützt werden sollte. Die Kommission wird Vorschläge dazu vorlegen, wie dieser Dialog in Zukunft gefördert werden kann.

\section{SCHLUSSFOLGERUNGEN UND EMPFEHLUNGEN}

Die vorstehende Analyse veranlasst die Kommission $\mathrm{zu}$ folgenden Schlussfolgerungen und Empfehlungen:

(1) Die Türkei hat in ihrem politischen Reformprozess erhebliche Fortschritte erzielt, vor allem durch die weit reichenden Verfassungsund Gesetzesänderungen, die in den letzten zwei Jahren entsprechend den Prioritäten der Beitrittspartnerschaft verabschiedet wurden. Allerdings sind weder das Vereinsgesetz, das neue Strafgesetzbuch noch das Gesetz über die zweitinstanzlichen Berufungsgerichte bisher in Kraft getreten. Darüber hinaus warten der Beschluss über die Strafprozessordnung, die Gesetzgebung zur Schaffung einer Kriminalpolizei und das Gesetz über Strafvollzug und Ma regeln noch immer auf ihre Verabschiedung. 
(2) Die Türkei bemüht sich nachdrücklich um die wirksame Umsetzung dieser Reformen. Gesetzgebung und Umsetzungmaßnahmen müssen trotzdem weiter gefestigt und ausgedehnt werden. Dies gilt insbesondere für die »Null- Toleranz-Politik « gegenüber Folter und Misshandlung und für die Umsetzung der Bestimmungen über Meinungs- und Religionsfreiheit, Frauenrechte, ILO-Standards einschließlich Gewerkschaftsrechte sowie Minderheitenrechte.

(3) In Anbetracht der bereits erreichten allgemeinen Fortschritte im Reformprozess und unter der Voraussetzung, dass die in Absatz (1) genannten, noch ausstehenden Gesetze in Kraft treten, ist die Kommission der Auffassung, dass die Türkei die politischen Kriterien in ausreichendem Maß erfüllt, und empfiehlt die Eröffnung von Beitrittsverhandlungen. Die Unumkehrbarkeit des Reformprozesses, seine Umsetzung insbesondere im Hinblick auf die Grundfreiheiten, müssen sich über einen längeren Zeitraum bestätigen.

(4) Es wird vorgeschlagen, eine Strategie zu verfolgen, die auf drei Säulen beruht. Die erste Säule umfasst die Zusammenarbeit zur verstärkten Unterstützung des Reformprozesses in der Türkei, insbesondere in Bezug auf die fortdauernde Erfüllung der politischen Kriterien von Kopenhagen. Zur Gewährleistung der Nachhaltigkeit und Unumkehrbarkeit der politischen Reformen sollte die EU weiterhin den Fortgang dieses Reformprozesses aufmerksam verfolgen. Dies wird auf der Grundlage einer überarbeiteten Beitrittspartnerschaft geschehen, in der die Prioritäten für weitere Reformen festgelegt werden. Jährlich wird ab Ende 2005 eine allgemeine Überprüfung der Fortschritte bei den politischen Reformen vorgenommen werden. $\mathrm{Zu}$ diesem Zweck wird die Kommission dem Europäischen Rat bis Dezember 2005 einen ersten Bericht vorlegen. Das Tempo der Reformen wird den Fortgang der Verhandlungen bestimmen.

(5) Im Einklang mit dem Vertrag über die Europäische Union und der Verfassung für Europa wird die Kommission bei einem schwerwiegenden und dauerhaften Verstoß gegen die Grundsätze der Freiheit, Demokratie, Rechtsstaatlichkeit und Achtung der Menschenrechte und Grundfreiheiten, auf denen die Union beruht, die Aussetzung der Verhandlungen empfehlen. Über diese Empfehlung würde der Rat mit qualifizierter Mehrheit beschließen.

(6) Die zweite Säule betrifft die spezifische Herangehensweise bei den Beitrittsverhandlungen mit der Türkei. Die Beitrittsverhandlungen finden im Rahmen einer Regierungskonferenz, in der Beschlüsse Einstimmigkeit erfordern, und mit voller Beteiligung aller EU-Mitglieder statt. Die Verhandlungen werden sich komplex gestalten. Für 
jedes Verhandlungskapitel sollte der Rat für den vorläufigen Abschluss, und gegebenenfalls die Eröffnung, der Verhandlungen Richtgrö en (»Benchmarks«) festlegen, welche Rechtsangleichung und eine zufrieden stellende Bilanz bei der Umsetzung des Besitzstands mit beinhalten. Bestehende rechtliche Verpflichtungen, die sich an den Besitzstand anlehnen, müssen vor Eröffnung der Verhandlungen zu den entsprechenden Kapiteln erfüllt werden. Lange Übergangszeiten könnten notwendig sein. Zusätzlich könnten in einigen Bereichen wie den Strukturpolitiken und der Landwirtschaft Sonderregelungen erforderlich sein und im Hinblick auf die Freizügigkeit der Arbeitnehmer unbefristete Schutzklauseln in Betracht gezogen werden. Der Beitritt der Türkei wird mit größeren finanziellen und institutionellen Auswirkungen verbunden sein. Die Union wird die Finanzielle Vorausschau für die Zeit nach 2014 festlegen müssen, bevor sie die Verhandlungen beenden kann. Darüber hinaus wird die Kommission während der Verhandlungen die Fähigkeit der Union überwachen, neue Mitglieder aufzunehmen und die Integration zu vertiefen, unter voller Berücksichtigung der Vertragsziele hinsichtlich der gemeinschaftlichen Politiken und der Solidarität.

(7) Die dritte Säule sieht einen wesentlich verstärkten politischen und kulturellen Dialog vor, der Menschen aus der EU und der Türkei zusammenbringt. Die wichtigste Rolle in diesem Dialog, der von der EU unterstützt werden sollte, sollte die Zivilgesellschaft spielen. Die Kommission wird Vorschläge darüber vorlegen, wie ein solcher Dialog gefördert werden kann.

(8) Die Kommission ist davon überzeugt, dass der Verhandlungsprozess einen unverzichtbaren Beitrag zu weiteren Reformen in der Türkei leisten wird. Dabei liegt es in der Natur der Sache, dass dies ein Prozess mit offenem Ende ist, dessen Ausgang sich nicht im Vorhinein garantieren lässt. Ungeachtet des Ausgangs der Verhandlungen oder des anschlie enden Ratifizierungsprozesses müssen die Beziehungen zwischen der EU und der Türkei sicherstellen, dass die Türkei vollständig in europäischen Strukturen verankert bleibt. Der Beitritt der Türkei müsste gründlich vorbereitet werden, um eine reibungslose Integration zu ermöglichen, welche die Errungenschaften von fünfzig Jahren europäischen Einigungsprozesses verstärkt. 


\section{Anhang: \\ Schlussfolgerung des Regelmäßigen Berichts über die Türkei}

Als der Europäische Rat im Dezember 1999 beschloss, die Türkei als Beitrittskandidaten einzustufen, vertrat er die Auffassung, dass die Türkei über die Grundmerkmale eines demokratischen Systems verfügt, zugleich aber ernsthafte Defizite bei den Menschenrechten und beim Minderheitenschutz aufweist. Im Jahr 2002 stellte die Kommission in ihrem Regelmäßigen Bericht fest, dass der Status als Kandidatenland die Türkei ermuntert hat, merkliche Fortschritte bei der Annahme einer Reihe grundlegender, doch nach wie vor begrenzter Reformen zu machen. Zu diesem Zeitpunkt war klar, dass die meisten Maßnahmen noch umgesetzt werden müssen und dass viele andere Fragen, die zur Einhaltung der politischen Kriterien von Kopenhagen erforderlich sind, erst noch angegangen werden müssen. Auf dieser Grundlage beschloss der Europäische Rat im Dezember 2002, Ende 2004 erneut zu prüfen, ob die Türkei die politischen Kriterien von Kopenhagen erfüllt.

Im Zuge einer Reihe verfassungs- und allgemeinrechtlicher Änderungen wurden über drei Jahre hinweg (2001-2004) in Einklang mit den Prioritäten der Beitrittspartnerschaft politische Reformen durchgeführt. Es gab zwei große Verfassungsreformen 2001 und 2004 sowie acht Legislativpakete, die das Parlament zwischen Februar 2002 und Juli 2004 verabschiedet hat. Ferner wurden neue Gesetzbücher verabschiedet, darunter ein Zivilgesetzbuch und ein Strafgesetzbuch. Durchführungsbestimmungen zu diesen Reformen wurden in Form zahlreicher anderer Gesetze, Verordnungen, Dekrete und Rundschreiben erlassen. Vor Ort ergriff die Regierung Maßnahmen, um die Reformen besser umsetzen zu können. Die Reformüberwachungsgruppe, ein Gremium unter Vorsitz des für Menschenrechte zuständigen Vizepremierministers, wurde eingerichtet, um die Reformen breit $\mathrm{zu}$ überwachen und praktische Probleme $\mathrm{zu}$ lösen. Auch vor Ort kam es zu bedeutenden Fortschritten, wenngleich die Umsetzung der Reformen immer noch uneinheitlich verläuft.

Was die Beziehungen zwischen Zivilsphäre und Militär betrifft, so hat die Regierung ihre Kontrolle über das Militär zunehmend behauptet. Im Interesse einer transparenteren Haushaltsführung wurde dem Rechnungshof gestattet, Militär- und Verteidigungsausgaben zu prüfen. Außerbudgetäre Fonds wurden in den allgemeinen Haushalt eingegliedert, so dass eine uneingeschränkte parlamentarische Kontrolle möglich ist. Im August 2004 wurde erstmals ein Zivilist zum Generalsekretär des Nationalen Sicherheitsrats bestellt. Der Prozess der vollständigen Angleichung der Beziehungen zwischen Zivilsphäre und Militär an die Praxis der EU ist im Gange; dennoch üben 
die Streitkräfte in der Türkei nach wie vor über eine Reihe informeller Mechanismen Einfluss aus.

Die Unabhängigkeit und Effizienz der Justiz wurden gestärkt, die Staatssicherheitsgerichte abgeschafft und einige ihrer Zuständigkeiten den neu geschaffenen Gerichten für schwere Straftaten übertragen. Unlängst wurden die Rechtsgrundlagen für die Einrichtung von Berufungsgerichten geschaffen, doch der Entwurf einer neuen Strafprozessordnung und die Gesetzentwürfe bezüglich der Einrichtung der Kriminalpolizei und des Strafvollzugs warten noch auf ihre Verabschiedung.

Seit Januar 2004 ist die Türkei Mitglied in der Gruppe der Staaten gegen Korruption des Europarates (GRECO). Insbesondere im Zuge der Aufstellung ethischer Regeln für Staatsbedienstete wurden einige Korruptionsbekämpfungsmaßnahmen angenommen. Doch bleibt die Korruption trotz dieser rechtlichen Entwicklungen in nahezu allen Bereichen der Wirtschaft und des öffentlichen Lebens ein ernstes Problem.

Was den allgemeinen Rahmen für die Einhaltung der Menschenrechte und die Wahrnehmung der Grundfreiheiten betrifft, so ist die Türkei den wichtigsten internationalen und europäischen Übereinkommen beigetreten und hat das Prinzip des Vorrangs dieser internationalen Menschenrechtsübereinkommen vor dem nationalen Recht in der Verfassung verankert. Seit 2002 bemüht sich die Türkei verstärkt um den Vollzug von Entscheidungen des Europäischen Gerichtshofs für Menschenrechte. Höhere Justizinstanzen wie das Kassationsgericht haben in einigen Entscheidungen die Reformen entsprechend den Standards des Europäischen Gerichtshofs ausgelegt, darunter Fälle im Zusammenhang mit dem Gebrauch der kurdischen Sprache, Folter und Meinungsfreiheit. Einige Verfahren wurden wieder aufgenommen und endeten mit zahlreichen Freisprüchen. Im Fall Leyla Zanas und ihrer ehemaligen Kollegen, die im Juni 2004 aus der Haft entlassen wurden, wird nach einer Entscheidung des Kassationsgerichts ein weiteres Mal verhandelt.

Die Todesstrafe wurde gemäß dem Protokoll Nr. 13 zur Europäischen Menschenrechtskonvention, das die Türkei im Januar 2004 unterzeichnet hat, vollständig abgeschafft. Die verbleibenden Verweise auf die Todesstrafe wurden aus dem geltenden Recht getilgt. Weitere Anstrengungen, darunter auch Bestimmungen im neuen Strafgesetzbuch, wurden unternommen, um stärker gegen Folter und Misshandlung vorzugehen. Die Verfahren für die Untersuchungshaft wurden an europäische Standards angeglichen; aller- 
dings werden Häftlinge von den Vollzugsbeamten nicht immer über ihre Rechte aufgeklärt. Die Behörden verfolgen gegenüber der Folter eine »Null-Toleranz-Politik" und in einer Reihe von Folterfällen wurden die Schuldigen bestraft. Folter findet nicht mehr systematisch statt, doch es treten noch häufig Fälle von Misshandlungen, einschließlich Folter auf und es bedarf weiterer Anstrengungen, um dieses Vorgehen zu unterbinden.

Die Lage in Bezug auf die freie Meinungsäußerung hat sich erheblich verbessert, doch bleiben mehrere Probleme bestehen. Inzwischen beschäftigt man sich mit der Lage von Personen, die wegen friedlicher Meinungsäußerung verurteilt wurden, und mehrere aufgrund der alten Bestimmungen verurteilte Personen wurden freigesprochen oder freigelassen. Verfassungsänderungen und ein neues Pressegesetz haben die Pressefreiheit erhöht. Mit dem neuen Gesetz werden Sanktionen wie die das Verbot von Veröffentlichungen, die Unterbindung des Vertriebs und die Beschlagnahme von Druckmaschinen abgeschafft. In zahlreichen Fällen jedoch werden Journalisten und andere Bürger, die ihre Meinung friedlich äußern, noch rechtlich verfolgt. Das neue Strafgesetzbuch stellt im Hinblick auf die Meinungsfreiheit nur einen beschränkten Fortschritt dar.

Sollte das ursprünglich im Juli 2004 verabschiedete und dann vom Veto des Präsidenten blockierte Vereinsgesetz in Kraft treten, nimmt es dem Staat in erheblichem Maße die Möglichkeit der Einflussnahme auf die Tätigkeit von Vereinigungen und trägt zur Stärkung der Zivilgesellschaft bei. Trotz der Maßnahmen zur Lockerung der Einschränkungen der Demonstrationsfreiheit wird immer noch von der Anwendung unverhältnismäßiger Gewalt gegen Demonstranten berichtet.

Trotz der verfassungsrechtlichen Garantie der Religionsfreiheit und obwohl die freie Religionsausübung weitgehend ungestört verläuft, stoßen nichtmuslimische Religionsgemeinschaften nach wie vor auf Schwierigkeiten im Zusammenhang mit der Rechtpersönlichkeit, den Eigentumsrechten, der Ausbildung der Geistlichen, Schulen und ihrer internen Verwaltung. Mit geeigneten Rechtsvorschriften könnten diese Schwierigkeiten überwunden werden. Die Aleviten sind nach wie vor nicht als muslimische Minderheit anerkannt.

Was die wirtschaftlichen und soziale Rechte betrifft, so wurde der Grundsatz der Geschlechtergleichheit zivil- und verfassungsrechtlich gestärkt. Im Rahmen des neuen Strafgesetzbuchs können Personen, die »Ehrenmorde« verüben, zu lebenslangen Gefängnisstrafen verurteilt werden, Jungfräulichkeitstests ohne gerichtliche Anordnung 
werden untersagt und sexuelle Gewalt in der Ehe wird zum Straftatbestand. Die Lage der Frauen ist immer noch unbefriedigend; Diskriminierungen und Gewalt gegen Frauen und auch "Ehrenmorde" bleiben ein großes Problem. Die Rechte der Kinder wurden gestärkt, Kinderarbeit gibt jedoch weiterhin Anlass zu ernster Sorge. Die Gewerkschaftsrechte stehen nach wie vor nicht in Einklang mit den ILO-Normen.

Was den Minderheitenschutz und die Ausübung der kulturellen Rechte betrifft, so wurde die Verfassung geändert, um das Verbot des Gebrauchs des Kurdischen und anderer Sprachen aufzuheben. Unlängst haben im Südosten der Türkei mehrere kurdische Sprachschulen eröffnet. Rundfunk in Kurdisch und anderen Sprachen und Dialekten ist inzwischen gestattet und es wurden bereits, wenngleich in begrenztem Ausmaß, Sendungen ausgestrahlt. Der Ausdruck der kurdischen Kultur in allen ihren Formen stößt mittlerweile auf mehr Toleranz. Die im Bereich der kulturellen Rechte angenommenen Maßnahmen stellen lediglich einen Beginn dar. Nach wie vor gibt es insbesondere im Bereich des Rundfunks und der Ausbildung in Minderheitensprachen erhebliche Einschränkungen.

Der 15 Jahre in einigen Provinzen im Südosten geltende Ausnahmezustand wurde 2002 vollständig aufgehoben. Bestimmungen, die während des Ausnahmezustands zur Einschränkung der Rechte während der Untersuchungshaft herangezogen wurden, wurden geändert. Die Türkei hat mit vielen internationalen Organisationen und auch mit der Kommission einen Dialog über die Frage der Binnenvertriebenen aufgenommen. Ein Gesetz über den Ausgleich der Verluste aus Terroranschlägen wurde verabschiedet. Obwohl Arbeiten zur Formulierung eines systematischeren Konzepts für die Region im Gange sind, wurde noch keine integrierte Strategie im Hinblick auf den Abbau der regionalen Disparitäten und die Deckung der wirtschaftlichen, sozialen und kulturellen Bedürfnisse der Lokalbevölkerung angenommen. Die Rückkehr der Binnenvertriebenen in den Südosten hielt sich in Grenzen und wurde durch das System der Dorfschützer sowie durch mangelnde materielle Unterstützung behindert. Weitere Maßnahmen sollten gezielt die Empfehlungen des Sonderbeauftragten für Vertriebene des UN-Generalsekretärs aufgreifen.

Zusammenfassend lässt sich feststellen, dass die Türkei auf vielen Gebieten mit weiteren Reformpaketen, Verfassungsänderungen und der Verabschiedung eines neuen Strafgesetzbuchs sowie insbesondere mit den im Vorjahresbericht benannten Prioritäten und der Beitrittspartnerschaft bei der Rechtsetzung deutlich vorangekommen 
ist. Trotz großer Fortschritte bei der Umsetzung der politischen Reformen müssen diese weiter konsolidiert und ausgeweitet werden. Das gilt für die Stärkung und vollständige Umsetzung der Bestimmungen über die Achtung der Grundfreiheiten und den Schutz der Menschenrechte einschließlich der Rechte der Frau, die Gewerkschaftsrechte, Minderheitenrechte und die Probleme der nichtmuslimischen Religionsgemeinschaften. Die zivile Kontrolle über das Militär muss behauptet und der Rechtsvollzug sowie die Justizverfahren müssen dem Tenor der Reformen entsprechend angepasst werden. Die Korruption sollte weiter bekämpft werden. Die »NullToleranz-Politik« gegenüber der Folter sollte durch entschlossene Anstrengungen auf allen Ebenen des türkischen Staates verstärkt werden. Die Normalisierung der Lage im Südosten sollte mit der Rückkehr der Vertriebenen, einer Strategie für die sozioökonomische Entwicklung und der Schaffung der Voraussetzungen für die uneingeschränkte Wahrnehmung der Rechte und Freiheiten der Kurden weiter verfolgt werden.

Der politische Wandel und die Änderungen im Rechtssystem der Türkei in den letzten drei Jahren sind Teil eines längeren Prozesses und es wird einige Zeit dauern, bis sich der Geist der Reformen in der Haltung der Exekutive und der Justizbehörden auf allen Ebenen landesweit widerspiegelt. Um die offenen Herausforderungen anzugehen und die bürokratischen Hürden zu nehmen, bedarf es ungebrochener Entschlossenheit. Die politischen Reformen werden weiterhin genau beobachtet.

Was den verstärkten politischen Dialog betrifft, so haben sich die Beziehungen zu Griechenland positiv entwickelt. Einige bilateraler Abkommen wurden unterzeichnet und mehrere vertrauensbildende Maßnahmen angenommen. Der Prozess der Sondierungsgespräche wurde fortgesetzt. In der Zypernfrage hat die Türkei im letzten Jahr die Bemühungen des UN-Generalsekretärs um eine umfassende Lösung des Zypern-Problems unterstützt und tut das auch weiterhin. Der Europäische Rat ersuchte die Türkei im Juni 2004, mit der Kommission im Namen der Gemeinschaft und ihrer 25 Mitgliedstaaten Verhandlungen über die Anpassung des Ankara-Abkommens zur Berücksichtigung des Beitritts der neuen Mitgliedstaaten aufzunehmen. Die Kommission erwartet eine positive Antwort auf den Entwurf für das Protokoll über die notwendigen Anpassungen, der im Juli 2004 der Türkei übermittelt wurde.

Die Türkei hat weitere deutliche Fortschritte auf dem Weg zu einer funktionsfähigen Marktwirtschaft erzielt und vor allem makroökonomische Ungleichgewichte abgebaut. Die Türkei dürfte auch in der 
Lage sein, dem Wettbewerbsdruck und den Marktkräften innerhalb der Union standzuhalten, sofern sie ihre Stabilisierungspolitik entschlossen fortsetzt und weitere wichtige Strukturreformen in Angriff nimmt.

Wirtschaftliche Stabilität und Vorhersehbarkeit haben sich seit der Wirtschaftskrise von 2001 deutlich verbessert. Die früher hohe Inflation wurde auf einen historischen Tiefststand zurückgeführt, die politische Einflussnahme wurde verringert und der institutionelle und ordnungspolitische Rahmen wurde dem internationalen Standard angenähert. Es hat also ein wichtiger Wandel in Richtung auf eine stabile und auf klaren Vorschriften beruhende Wirtschaft stattgefunden. Die wichtigsten wirtschaftlichen Schwachpunkte wie etwa Ungleichgewichte im Finanzsektor wurden in Angriff genommen. Die Aufsicht über den Finanzsektor wurde verschärft. Dadurch hat sich die Belastbarkeit der türkischen Wirtschaft deutlich verbessert. Wichtige Fortschritte machten auch die Bemühungen um mehr Transparenz und Effizienz in der öffentlichen Verwaltung und den öffentlichen Finanzen. Außerdem wurden wichtige Maßnahmen ergriffen, um den Zufluss ausländischer Direktinvestition zu erleichtern und den Rechtsrahmen für die Privatisierung zu verbessern.

Um die derzeitige positive Dynamik in dauerhaftes Wachstum und Stabilität umzuwandeln, ist es von entscheidender Bedeutung, dass der derzeitige Reformprozess fortgesetzt wird. Die Beibehaltung einer stabilitätsorientierten Wirtschaftspolitik ist dabei ein entscheidender Faktor. Wichtig ist vor allem ein Abbau der Haushaltsungleichgewichte und eine Fortsetzung der Inflationsbekämpfung. Das Wirtschaftsklima würde durch eine Straffung der Verwaltungsverfahren und eine Stärkung der Rechtsstaatlichkeit verbessert. Ganz besonders wichtig ist in diesem Zusammenhang eine Steigerung der Effizienz der Handelsgerichte. Die Aufsicht über den Bankensektor und die aufsichtsrechtlichen Vorschriften sollten weiter an die internationalen Normen angepasst werden. Die Privatisierung der staatlichen Banken und Unternehmen sollte beschleunigt werden. Ausreichende öffentliche und private Investitionen und Verbesserungen im Bildungsbereich sind wichtig, um die Wettbewerbsfähigkeit und das Wachstumspotenzial der Wirtschaft zu erhöhen. Der Zufluss ausländischer Direktinvestitionen muss durch die Beseitigung noch vorhandener Hindernisse angekurbelt werden.

Die Türkei ist bei der Harmonisierung in vielen Bereichen vorangeschritten, bewegt sich jedoch weiterhin bei vielen Kapiteln in einem frühen Stadium. Auf allen Gebieten sind weitere Arbeiten nötig; neue Rechtsvorschriften sollten nicht vom Besitzstand abweichen 
und die Diskriminierung nichttürkischer Dienstleister oder Waren sollte beendet werden. Die Verwaltungskapazität muss gestärkt werden. Darüber hinaus sollte kein Mitgliedstaat von den gegenseitigen Vorteilen, die sich aus der Angleichung an den Besitzstand ergeben, ausgeschlossen werden.

Im Bereich freier Warenverkehr schreitet die Übernahme des Besitzstands ständig voran, ist aber nicht abgeschlossen und in der Durchführung weiterhin uneinheitlich. Bei den horizontalen und Rechtsvorschriften und Verfahren sowie bei sektorspezifischen Rechtsangleichungen und insbesondere beim neuen Konzept wurden beträchtliche Fortschritte vor allem bei der Konformitätsbewertung und der Marktüberwachung erreicht. Das Gesetz über das öffentliche Auftragswesen weist immer noch Unterschiede zum Besitzstand auf. Die Türkei sollte ihre Anstrengungen bei der Abschaffung technischer Handelshindernisse verstärken und die Einhaltung der Verpflichtungen aus dem Assoziationsratsbeschluss 1/95 über die Zollunion verbessern sowie notwendige Maßnahmen zur Durchsetzung des freien Warenverkehrs in nicht harmonisierten Bereichen ergreifen.

Im Bereich Freizügigkeit können keine Fortschritte vermeldet werden und die Rechtsangleichung befindet sich insgesamt noch in einem sehr frühen Stadium. Die Verwaltungskapazität muss noch erheblich erweitert werden. Im Bereich freier Dienstleistungsverkehr wurden Verbesserungen bei den Finanzdienstleistungen - mit Ausnahme von Versicherungen - erzielt, aber bei den nichtfinanziellen Dienstleistungen sind keine Fortschritte $\mathrm{zu}$ verzeichnen. Hier ist der Marktzugang weiterhin eingeschränkt. Bei den freiberuflichen Dienstleistungen sind seit dem letzten Regelmäßigen Bericht keine Fortschritte zu verzeichnen. Die Angleichung an den Besitzstand im Bereich des Schutzes personenbezogener Daten muss noch vollzogen werden. Es ist eine Behörde für den Schutz personenbezogener Daten zu schaffen und die Unabhängigkeit der bestehenden Aufsichtsbehörden im Bereich Finanzdienstleistungen muss sichergestellt werden. Auch die für ausländische Staatsbürger geltenden Beschränkungen sind aufzuheben. Beim freien Kapitalverkehr ist die Angleichung an den Besitzstand begrenzt. Priorität sollte die Annahme des Geldwäschegesetzes sowie die Aufhebung der Beschränkungen für Investitionen ausländischer Staatsbürger genießen. Verbesserungen in diesem Bereich zögen Vereinfachungen für den Zustrom ausländischer Direktinvestitionen nach sich.

Auch beim Gesellschaftsrecht sind nur begrenzte Fortschritte erzielt worden. Es wurden enorme Anstrengungen bei der Bekämpfung der 
Produktpiraterie zum Schutz der Rechte an geistigem und gewerblichem Eigentum unternommen, aber die unzureichende Verwaltungskapazität stellt weiterhin ein Hindernis dar. Im Bereich der Wettbewerbspolitik ist die Angleichung des Kartellrechts beträchtlich, und es sind weitere Fortschritte $z u$ verzeichnen. Im Gegensatz dazu ist allerdings die Rechtsangleichung bei den staatlichen Beihilfen trotz der Aufnahme in die Zollunion äußerst begrenzt. Die Annahme des Gesetzes über staatliche Beihilfen und die Schaffung einer Aufsichtsbehörde für staatliche Beihilfen sind entscheidende Themen. Weitere Anstrengungen sind auch bei der Vorbereitung eines praktikablen Umstrukturierungsprogramms für den Stahlsektor vonnöten.

Im Bereich Landwirtschaft können im Vergleich zum Vorjahresbericht nur wenige Fortschritte vermeldet werden. Auch ist die Rechtsangleichung insgesamt nach wie vor gering. Insbesondere im Veterinärwesen, bei der Pflanzengesundheit und bei den Lebensmitteln sind Fortschritte erreicht worden, aber die Übernahme und die Verwaltungskapazitäten reichen noch nicht aus, um die effektive Umsetzung des Besitzstands zu gewährleisten. Die ländliche Entwicklung, die Ausrottung von Tierseuchen und der Ausbau der Verwaltungen genießen weiterhin Priorität. Im Fischereiwesen wurden nur sehr begrenzte Fortschritte erzielt. Die Bemühungen um das Ressourcenmanagement sowie um die Stärkung der Inspektions- und Kontrollkapazitäten müssen verstärkt werden.

In allen Verkehrsbereichen können einige Fortschritte vermeldet werden, mit Ausnahme des Luftverkehrs. Allerdings ist die Rechtsangleichung insgesamt noch begrenzt und in sämtlichen Bereichen bestehen einige Probleme weiter. Insbesondere im Seeverkehr ist anzumerken, dass die Quote der zurückgehaltenen Schiffe immer noch erheblich über dem EU-Durchschnitt liegt und dass die Türkei weiterhin auf der Schwarzen Liste der Pariser Vereinbarung über Hafenstaatkontrollen verzeichnet wird. Unter zypriotischer Flagge fahrende Schiffe oder Schiffe, die einen zypriotischen Hafen angelaufen haben, wird das Anlegen in türkischen Häfen immer noch verweigert. Die Übernahme des Besitzstands muss parallel zum Beitritt zu internationalen Übereinkommen erfolgen. Das Personal und die Kapazitäten des Verkehrsministeriums müssen erheblich aufgestockt werden.

Im Steuerbereich sind lediglich begrenzte Fortschritte bei der indirekten Besteuerung festzustellen, während bei den direkten Steuern oder bei der Verwaltungszusammenarbeit keine Verbesserungen zu erkennen sind. Das türkische Steuersystem ist insgesamt nur teilweise an den Besitzstand angeglichen, sodass in allen unter dieses Kapitel 
fallenden Bereichen noch erheblicher Handlungsbedarf besteht. In Bezug auf die Mehrwertsteuer, die Steuerbefreiungen und die geltenden Steuersätze ist die Angleichung besonders voranzutreiben. Was die indirekte Besteuerung betrifft, so dürfen Verbrauchsteuern nicht zu einer Benachteiligung eingeführter Erzeugnisse führen. Ferner ist die Verwaltungskapazität auszubauen, insbesondere bei der Eintreibung der Steuern.

Bei der Wirtschafts- und Währungsunion sind im Vergleich zum Vorjahr keine Fortschritte erzielt worden und auch die Rechtsangleichung insgesamt ist gering. Wesentliche Aspekte, die verbessert werden müssen, sind die Unabhängigkeit der Zentralbank und die verbleibenden Möglichkeiten eines bevorrechtigten Zugangs zum Finanzsektor bei der Haushaltsfinanzierung.

Im Bereich der Statistik sind stetige Fortschritte erzielt worden, aber die Angleichung ist noch sehr begrenzt. Daher sind in diesem Bereich noch erhebliche Anstrengungen erforderlich. Priorität sollte hierbei das neue Statistikgesetz genießen.

Auf dem Gebiet Soziales und Beschäftigung sind seit dem Vorjahresbericht vor allem bei der Gesundheit und Sicherheit am Arbeitsplatz Fortschritte erreicht worden. Die problematischsten Bereiche sind weiterhin die Gleichstellung der Geschlechter, das Arbeitsgesetz, die Bekämpfung von Diskriminierungen und der soziale Dialog. Die Durchsetzung und die umfassende Anwendung dieser Rechtsvorschriften stellen noch große Herausforderungen dar.

Die Türkei hat im Kapitel Energie einige Fortschritte zu verzeichnen, während die Rechtsangleichung an den einschlägigen Besitzstand noch begrenzt und vor allem uneinheitlich ist. Für die wirksame Umsetzung des Besitzstands ist der Ausbau der Verwaltungskapazität unerlässlich. Die Umstrukturierung des Sektors, einschließlich der Privatisierung und Beseitigung der Preisverzerrungen, sollte fortgesetzt werden.

Bei der Industriepolitik wurde eine breite Annäherung an die Grundsätze der Industriepolitik der EU vollzogen. Die Türkei hat eine Industriestrategie angenommen, aber die Privatisierung und die Umstrukturierung sind nicht wie geplant vorangekommen Besonderer Bemühungen bedarf die Umstrukturierung des Stahlsektors und der staatlichen Banken. Trotz der Verbesserungen der Rahmengesetzgebung erreichen die ausländischen Direktinvestitionen nur einen niedrigen Stand. Der Zugang von Klein- und Mittelbetrieben zu Finanzierungsquellen hat sich verbessert und die türkische Politik ent- 
spricht weitgehend der Unternehmenspolitik der Gemeinschaft. Es sind jedoch weitere Anstrengungen nötig, um den Zugang der KMU zu Finanzquellen sowie das geschäftliche Umfeld zu verbessern. Insbesondere ist eine wirksamere Bearbeitung von Fällen durch die Handelsgerichte anzustreben. Die in der Türkei übliche Definition von Klein- und Mittelbetrieben stimmt nicht mit den einschlägigen Empfehlungen der Kommission überein.

Einige Fortschritte wurden im Bereich Wissenschaft und Forschung erzielt. Der Rahmen für die Zusammenarbeit wurde geschaffen und die türkischen Vertreter nahmen als Beobachter an den Ausschusssitzungen zur Vorbereitung des 6. Rahmenprogramms teil. Um sich am Rahmenprogramm umfassend und wirksam zu beteiligen, muss die Türkei ihre forschungsbezogene Verwaltungskapazität weiter ausbauen. Auch bei der allgemeinen und beruflichen Bildung konnten einige Fortschritte, insbesondere bei der Einschulung von Mädchen in benachteiligten Regionen, verwirklicht werden. Die Beteiligung der Türkei an den EG-Programmen ist zufrieden stellend, aber die Investitionen liegen noch unter dem EU-Durchschnitt. Die Reform und der Ausbau der Schulungs- und Bildungspolitik und der entsprechenden Institutionen sowie die Rolle des Hohen Rates für das Bildungswesen (YÖK) und die Verknüpfungen von Arbeitsmarkt und allgemeiner und beruflicher Bildung müssen verbessert werden.

Im Telekommunikationssektor sind die Festnetz-Telefondienste im Jahr 2004 vollständig liberalisiert worden und auch der Wettbewerb bei den Internetdiensten hat sich belebt. Insgesamt wurde eine gewisse Angleichung an den Besitzstand vollzogen, aber seit dem Vorjahresbericht sind nur sehr begrenzte Fortschritte erzielt worden. Weitere Anstrengungen müssen unternommen werden, um den Rechtsrahmen zu vervollständigen und die Vorschriften auch wirksam umzusetzen. Dies schließt die Ausstattung der Telekommunikationsbehörde mit entsprechenden Befugnissen ein. Ferner ist bei allen Telekommunikationsdiensten ein vergleichbarer Wettbewerb sicherzustellen.

Obwohl die Rechtsangleichung an den Besitzstand im Kapitel Kultur und audiovisuelle Medien noch begrenzt ist, hat die Türkei einige Fortschritte bei seiner Übernahme erzielt, indem sie die Verordnung über Rundfunk- und Fernsehsendungen in Sprachen und Dialekten, die traditionell von türkischen Bürgern gesprochen werden, verabschiedet hat. Mit der Umsetzung dieser Verordnung ist begonnen worden und inzwischen werden Sendungen in nationalen oder regionalen Kanälen in kurdischer oder anderen Sprachen ausgestrahlt. Die mit dieser Verordnung verknüpften Bedingungen sind jedoch weiterhin 
restriktiv, so dass erhebliche Anstrengungen nötig sind, um eine Angleichung an den Besitzstand zu erreichen.

Der Besitzstand im Bereich der Regionalpolitik wirkt sich auf die Umsetzung der Struktur- und Kohäsionsfonds aus. Hier sind nur sehr wenige Entwicklungen zu verzeichnen und auch die Angleichung an den Besitzstand ist begrenzt. Im Hinblick auf die geeignete Nutzung der strukturpolitischen Instrumente der EU müssen noch erhebliche Anstrengungen unternommen werden. Die erforderlichen Institutionen müssen geschaffen und die Verwaltungskapazitäten ausgebaut werden.

Im Kapitel Umwelt sind einige Fortschritte zu vermelden. So wurde die Verwaltungskapazität ausgebaut. Die Übernahme des Besitzstands im Umweltbereich insgesamt befindet sich noch auf einem niedrigen Stand. Die Verwaltungskapazität muss weiter gestärkt und die Zusammenarbeit der beteiligten Behörden verbessert werden. Die größten Anstrengungen sind bei den horizontalen Rechtsvorschriften sowie in den Bereichen Luft- und Wasserqualität, Abfallwirtschaft, Naturschutz, industriebedingte Umweltverschmutzung und Risikomanagement nötig.

Beim Verbraucher- und Gesundheitsschutz sind die Bemühungen um eine Übernahme des Besitzstands, insbesondere bei der Marktüberwachung fortgesetzt worden. Die Angleichung ist auf den verschiedenen Gebieten des Verbraucherschutzes unterschiedlich weit vorangeschritten und ist bei nicht sicherheitsrelevanten Maßnahmen am größten. Die Anstrengungen für eine wirksame Übernahme und Umsetzung des Besitzstandes bei der Produkthaftung und für höhere Verwaltungskapazitäten müssen fortgesetzt werden.

Die Türkei hat sich weiterhin bemüht, die Rechtsangleichung im Bereich Justiz und Inneres voranzubringen. In so wesentlichen Bereichen wie der Reform des Justizwesens und der Bekämpfung der Korruption sind jedoch weitere Fortschritte nötig. Die Zusammenarbeit aller einschlägigen Behörden auf nationaler Ebene sowie die Kooperation mit der EU muss insbesondere bei der illegalen Einwanderung und dem Menschenschmuggel fortgesetzt werden, auch mittels Verhandlungen über ein Abkommen zur Rückführung von Flüchtlingen. Die geografische Beschränkung der Genfer Flüchtlingskonvention ist aufzuheben und die Zusammenarbeit der einschlägigen Institutionen sollte verbessert werden.

Bei der Übernahme des Besitzstandes der Zollunion sind seit dem letzten Bericht einige Fortschritte erzielt worden: Die Verwaltungs- 
kapazität wurde ausgebaut und die Rechtsangleichung hat mit Ausnahme bestimmter Gebiete insgesamt einen hohen Stand erreicht. Die in Freizonen geltenden nichtzollrechtlichen Vorschriften weichen weiterhin vom Besitzstand ab und müssen entsprechend angeglichen werden. Im Kapitel Außenbeziehungen ist die Angleichung insgesamt schon weit vorangeschritten und im Vergleich zum letzten Jahr sind noch einige Fortschritte erzielt worden. Die Annahme des Allgemeinen Präferenzsystems der EG in weiten Teilen stellt einen wichtigen Fortschritt dar. Einige Abweichungen vom Besitzstand bestehen weiter, einerseits im Hinblick auf Sonderregelungen im Rahmen des APS und andererseits aufgrund schwieriger Verhandlungen mit bestimmten Drittstaaten. Die Türkei wird ermuntert, ihre Bemühungen in diesem Bereich fortzusetzen. Die Gemeinsame Außen- und Sicherheitspolitik ist weitgehend an die EU-Politik angeglichen, wobei in Bezug auf die Nachbarstaaten der Türkei einige Unterschiede bestehen. Die Vollzugsbilanz der Türkei könnte verbessert werden, wenn sie ihre Positionen in internationalen Gremien noch stärker an die der EU annähert und sicherstellt, dass vereinbarte Sanktionen oder Restriktionen auch angewendet werden.

Im Bereich der Finanzkontrolle sind seit dem Vorjahresbericht einige Fortschritte zu vermelden. Hier ist insbesondere die Annahme des Gesetzes über die öffentliche Finanzverwaltung und Finanzkontrolle zu nennen, das zwar erst ab dem Jahr 2008 umfassend angewendet wird, aber dennoch einen bedeutenden Fortschritt darstellt. Die Türkei sollte ihre Verwaltung weiter stärken und die Kapazitäten zum Schutz der finanziellen Interessen der Gemeinschaft weiter ausbauen. Darüber hinaus sind bei den Finanz- und Haushaltsbestimmungen bedeutende Fortschritte bei der Aufstellung und dem Vollzug des Staatshaushalts erreicht worden. Bei der Anwendung der Bestimmungen für Eigenmittel konnten jedoch keine Verbesserungen erzielt werden. Daher sind weitere Anstrengungen nötig, um die Annahme der erforderlichen Rechtsvorschriften und ihre Umsetzung voranzutreiben.

Die Umsetzung der formell an den Besitzstand angeglichenen Rechtsvorschriften ist weiterhin unzureichend. Die Verwaltungskapazität muss in den meisten Bereichen ausgebaut werden, damit die Umsetzung und die wirksame Durchsetzung des Besitzstandes gesichert ist. In einigen Fällen müssen im Rahmen der Umstrukturierung auch neue Strukturen geschaffen werden, z. B. bei den staatlichen Beihilfen und der regionalen Entwicklung. Die geschaffenen Regulierungsbehörden müssen mit den für die Wahrnehmung ihrer Aufgaben erforderlichen Befugnissen ausgestattet werden. Hierzu gehört eine entsprechende Personal- und Ressourcendecke, damit sie ihre 
Beschlüsse auch durchsetzen können. In dieser Hinsicht muss auch ihre Unabhängigkeit geschützt werden. Die gelungene Zusammenarbeit zwischen der Kommission und den türkischen Behörden beispielsweise bei der Konformitätsbewertung sollte auf andere Bereiche ausgedehnt werden. 



\section{Autoren}

Sabrina Giesendorf, Doktorandin der Politikwissenschaft über das Thema »Probleme transnationaler Demokratieimplementation am Beispiel der Türkei« an der Justus-Liebig-Universität Gießen.

Hakki Keskin, Dr. rer. pol., Professor für Politik und Migrationspolitik im Fachbereich Sozialpädagogik an der Hochschule für Angewandte Wissenschaften Hamburg und Bundesvorsitzender der Türkischen Gemeinde in Deutschland.

Helmut König, Dr. phil., Professor für Politische Wissenschaft an der Rheinisch-Westfälischen Technischen Hochschule Aachen.

Claus Leggewie, Dr. disc. pol., Professor für Politikwissenschaft und Direktor des Zentrums für Medien und Interaktivität an der Justus-Liebig-Universität Gießen.

Otto Luchterhandt, Dr. jur., Professor für Öffentliches Recht und Ostrecht am Fachbereich Rechtswissenschaft I der Universität Hamburg und Direktor der Abteilung für Ostrechtsforschung.

Herfried Münkler, Dr. phil., Professor für Theorie der Politik am Institut für Sozialwissenschaften der Humboldt-Universität zu Berlin. 
Emanuel Richter, Dr. phil., Professor für Politische Systeme am Institut für Politische Wissenschaft der Rheinisch-Westfälischen Technischen Hochschule Aachen.

Faruk Şen, Dr. rer. pol., Professor an der Universität DuisburgEssen und Direktor des Zentrums für Türkeistudien.

Manfred Sicking, Dr. phil., Leiter des Fachbereichs Wirtschaftsförderung/Europäische Angelegenheiten der Stadt Aachen und Lehrbeauftragter am Institut für Politische Wissenschaft der Rheinisch-Westfälischen Technischen Hochschule Aachen.

Hans-Ulrich Wehler, Dr. phil., em. Professor für Allgemeine Geschichte an der Universität Bielefeld

Martin Winter, Korrespondent der Frankfurter Rundschau in Brüssel. Zuvor berichtete er aus Washington und aus Bonn. 


\section{Die Neuerscheinungen dieser Reihe:}

Matthias Groß, Holger

Hoffmann-Riem, Wolfgang

Krohn

\section{Realexperimente}

Ökologische Gestaltungsprozesse in der Wissensgesellschaft

Juni 2005, ca. 220 Seiten, kart., ca. $24,80 €$,

ISBN: 3-89942-304-6

Barbara Christophe Metamorphosen des Leviathan in einer post-sozialistischen

\section{Gesellschaft}

Georgiens Provinz zwischen Fassaden der Anarchie und regulativer Allmacht

Mai 2005, ca. 300 Seiten, kart., ca. $26,80 €$,

ISBN: 3-89942-323-2

Peter Fuchs

\section{Konturen der Modernität}

Systemtheoretische Essays II (herausgegeben von

Marie-Christin Fuchs)

Mai 2005, ca. 200 Seiten,

kart., ca. $21,80 €$,

ISBN: 3-89942-335-6
Sabine Brombach, Bettina Wahrig (Hg.)

LebensBilder

Leben und Subjektivität in neueren Ansätzen der Gender Studies

April 2005, ca. 250 Seiten, kart., zahl. z.T. farbige Abb., ca. $26,00 €$,

ISBN: 3-89942-334-8

Hannelore Bublitz

In der Zerstreuung organisiert

Paradoxien und Phantasmen der Massenkultur

April 2005, ca. 150 Seiten,

kart., ca. $14,80 €$,

ISBN: 3-89942-195-7

Gerald Willms

Scientology

Kulturbeobachtungen jenseits der Devianz

März 2005, 428 Seiten,

kart., 29,80 €,

ISBN: 3-89942-330-5

Helmut König, Manfred Sicking (Hg.)

Gehört die Türkei zu Europa? Wegweisungen für ein Europa am Scheideweg

März 2005, 220 Seiten, kart., $22,80 €$, ISBN: 3-89942-328-3

Leseproben und weitere Informationen finden Sie unter: www.transcript-verlag.de 


\section{Die Neuerscheinungen dieser Reihe:}

Michael Guggenheim

Organisierte Umwelt

Umweltdienstleistungsfirmen

zwischen Wissenschaft,

Wirtschaft und

Politik

März 2005, 330 Seiten,

kart., $28,80 €$,

ISBN: 3-89942-296-1

Thomas Kunz

Der Sicherheitsdiskurs

Die Innere Sicherheitspolitik und ihre Kritik

Februar 2005, 422 Seiten,

kart., $29,80 €$,

ISBN: 3-89942-293-7

Jacqueline Holzer

Linguistische Anthropologie

Eine Rekonstruktion

Januar 2005, 322 Seiten,

kart., $29,80 €$,

ISBN: 3-89942-301-1

Uwe Lewitzky

Kunst für alle?

Kunst im öffentlichen Raum

zwischen Partizipation,

Intervention und Neuer

Urbanität

Januar 2005, 138 Seiten,

kart., $14,80 €$,

ISBN: 3-89942-285-6

\author{
Karl H. Hörning, \\ Julia Reuter (Hg.) \\ Doing Culture
}

Neue Positionen zum

Verhältnis von Kultur und

sozialer Praxis

2004, 264 Seiten,

kart., $25,80 €$,

ISBN: 3-89942-243-0

Frankfurter Arbeitskreis für politische Theorie \&

Philosophie (Hg.)

Autonomie und Heteronomie der Politik

Politisches Denken zwischen

Post-Marxismus und

Poststrukturalismus

2004, 206 Seiten,

kart., $24,80 €$,

ISBN: 3-89942-262-7

Johannes Glückler

\section{Reputationsnetze}

Zur Internationalisierung von Unternehmensberatern. Eine relationale Theorie

2004, 306 Seiten,

kart., $29,80 €$,

ISBN: 3-89942-265-1

Jan Kruse

Arbeit und Ambivalenz

Die Professionalisierung

Sozialer und Informatisierter Arbeit

2004, 370 Seiten,

kart., $29,80 €$,

ISBN: 3-89942-230-9

Leseproben und weitere Informationen finden Sie unter: www.transcript-verlag.de 


\section{Die Neuerscheinungen dieser Reihe:}

Dominique Schirmer

Soziologie und

Lebensstilforschung in der

Volksrepublik China

Perspektiven einer

Mikrotheorie gesellschaftlichen

Wandels

2004, 248 Seiten,

kart., 29,00 €,

ISBN: 3-89942-258-9

Peter Fuchs

Theorie als Lehrgedicht

Systemtheoretische Essays I.

hg. von Marie-Christin Fuchs

2004, 212 Seiten,

kart., 23,80 €,

ISBN: 3-89942-200-7

Gabriele Klein (Hg.)

\section{Bewegung}

Sozial- und kulturwissenschaft-

liche Konzepte

2004, 306 Seiten,

kart., $26,80 €$,

ISBN: 3-89942-199-X

Sabine Kampmann,

Alexandra Karentzos,

Thomas Küpper (Hg.)

Gender Studies und

Systemtheorie

Studien zu einem

Theorietransfer

2004, 212 Seiten,

kart., 22,80 €,

ISBN: 3-89942-197-3
Bettina Heintz, Martina Merz,

Christina Schumacher

Wissenschaft, die Grenzen schafft

Geschlechterkonstellationen im disziplinären Vergleich

2004, 320 Seiten,

kart., $26,80 €$,

ISBN: 3-89942-196-5

Gabriele Klocke

Über die Gleichheit vor dem

Wort

Sprachkultur im geschlossenen

Strafvollzug

2004, 350 Seiten,

kart., $26,80 €$,

ISBN: 3-89942-201-5

Barbara Zielke

Kognition und soziale Praxis

Der Soziale Konstruktionismus und die Perspektiven einer postkognitivistischen Psychologie

2004, 376 Seiten,

kart., $29,80 €$,

ISBN: 3-89942-198-1

Sven Lewandowski

\section{Sexualität in den Zeiten}

funktionaler Differenzierung

Eine systemtheoretische

Analyse

2004, 340 Seiten,

kart., $26,80 €$,

ISBN: 3-89942-210-4

Leseproben und weitere Informationen finden Sie unter: www.transcript-verlag.de 